\title{
TECHNICAL FEASIBILITY STUDY OF NET-ZERO ENERGY HOUSE FOR CANADA - CASE STUDY OF TEAM NORTH 2009 US DOE SOLAR DECATHLON COMPETITION
}

\author{
By \\ Toktam Saeid \\ B.Sc. (Bachelor of Science) \\ Azad University, Iran, 2004
}

A thesis

Presented to Ryerson University

\author{
In partial fulfillment of the \\ requirements for the degree of \\ Master of Applied Science \\ in the program of \\ Mechanical Engineering \\ RRAPERTV GF

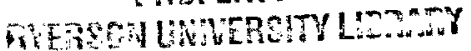

Toronto, Ontario, Canada, 2010

CToktam Saeid, 2010 


\section{Author's Declaration}

I hereby declare that I am the sole author of this thesis.

I authorize Ryerson University to lend this thesis to other institutions or individuals for the purpose of scholarly research.

I further authorize Ryerson University to reproduce this thesis by photocopying or by other means, at the request of other institutions or individuals for the purpose of scholarly research. 


\section{Borrower's Page}

Ryerson University requires the signatures of all persons using or photocopying this thesis.

Please sign below, and give address and date. 


\title{
TECHNICAL FEASIBILITY S'TUDY OF NET-ZERO ENERGY HOUSE FOR CANADA - CASE STUDY OF TEAM NORTH 2009 US DOE SOLAR DECATHLON COMPETITION
}

\author{
Toktam Saeid \\ Masters of Applied Science \\ Department of Mechanical \& Industrial Engineering \\ Ryerson University, Toronto, Ontario, Canada, 2010
}

\begin{abstract}
In October 2009, Team North competed in the US DOE 2009 Solar Decathlon competition. Team North's mission was to design and deliver North House, an energy efficient solarpowered home while training Canada's next generation of leaders in sustainable design.

In North House, the PV system on the roof was the primary energy generation, complimented by a custom PV cladding system on the south, east and west facades. A solar assisted heat pump system, including a three-tank heat transfer and storage system, the horizontally mounted evacuated-tube solar thermal collectors on the roof and a variable capacity heat pump met the hot water and space heating demands. A second variable capacity heat pump was utilized for space cooling. The solar thermal system was studied using TRNSYS simulation. For the initial assessments the simulations were run for Baltimore. Then, the analyses were extended to different cities across Canada. In all scenarios the same house was linked to the system. The minimum annual solar fraction of the different cities was $64 \%$ and it rose up to $81 \%$.
\end{abstract}

Finally the data measured during the competition were analyzed and compared with the data resulting from the simulation. According to competition measures, during the 10 days of competition in Washington DC, the PV system generated $271.6 \mathrm{kWh}$ of electricity and the solar thermal system produced $91.7 \mathrm{kWh}$ while the house consumption was $249.1 \mathrm{kWh}$. As a result, North House was evidently a net-positive house. 


\section{Acknowledgements}

This thesis would have not been possible without the kind support of my supervisor. He led me through this path by his trenchant critiques, probing questions and his remarkable patience. Without his enthusiasm, inspiration and his invaluable guidance, my academic perspective would not be this straightforward. Simply put: Solute Sir!

I would like to extend my deep gratitude to my parents for their constant support and dedication to my education. They deserve the highest praise from the deepest part of my heart, "Love you guys!"

I am also grateful to Dr. Hessam Taherian for his valuable suggestions and constructive criticisms.

I would also like to acknowledge the support and help of the following individuals:

Mr. Humphrey Tse, Ms. Aya Dembo, Mr. Fabio Almeida, Mr. Dahai Zhang and all Team North, Team Ontario/BC, members.

Team North members: Lauren Barhydt, Lyn Bartram, Chris Black, Chris Brandson, Sebastien Brideau, Wade Brown, Kush Bubbar, Brent Crowhurst, Aya Dembo, Muan Demchenko, Chloe Doesburg, Alan Fung, Brittany Hanam, Yin He, Andrea Hunniford, Natalie Jackson, Jennifer Janzen, Ivan Lee, David Lieberman, Bart Lomanowski, Andrew Marston, Donald McKay, Rob Mackenzie, Raqib Omer Mian, Kevin Muise, Lindsey Nette, Bradley Paddock, Matt Peddie, Johnny Rodgers, Toktam Saeid, David Schellingerhoudt, Sonja Storey-Fleming, John Straube, Geoff Thun, Humphrey Tse, Jamie Usas, Kathy Velikov, Allan Wilson, Robert Woodbury, Dahai Zhang, Philip Beesley, Michael Collins, Mark Gorgolewski, Andrew Haydon, Hon Lam, David Marques, Russel Richman, Omar Siddiqui, Kun Chieh Tsai, Ron Wakkary, Andrew White, Alan Wong, Peter Yu. 


\section{Table of Contents}

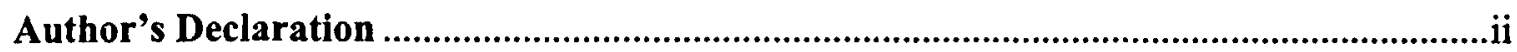

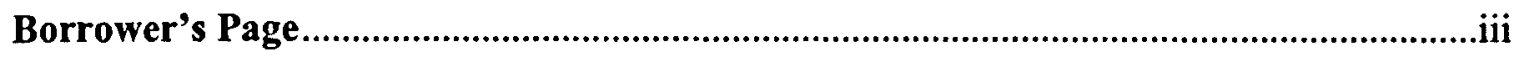

Abstract..............................................................................................................................

Acknowledgements ..............................................................................................................

Table of Contents .......................................................................................................................

List of Tables

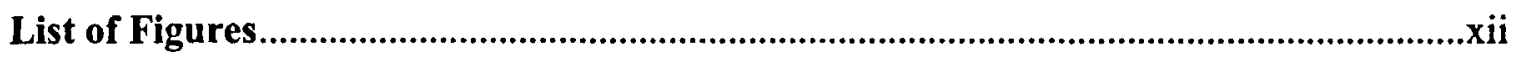

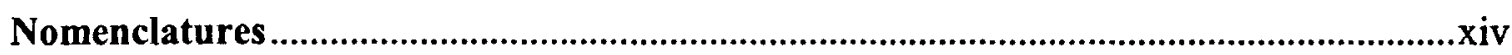

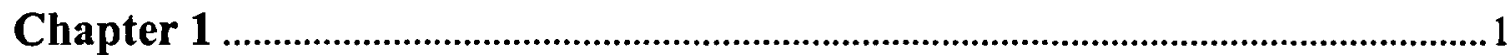

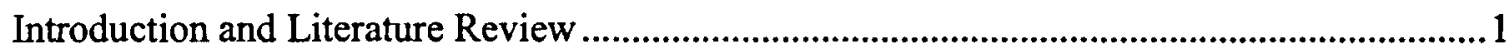

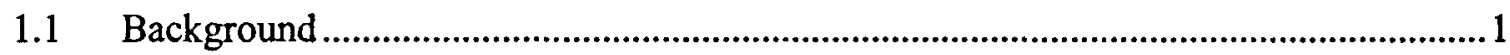

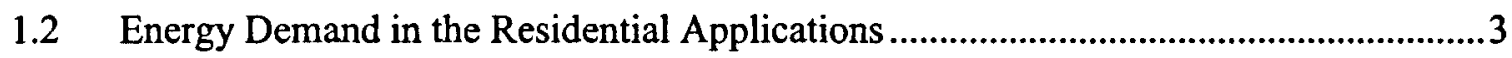

1.2.1 Residential Sector Contribution in Energy Consumption .......................................

1.2.2 The Need for Sustainability ................................................................................

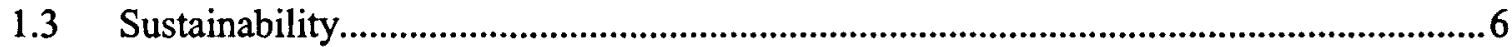

1.3.1 Definition of Sustainable Development ...................................................................6

1.3.2 Renewable Energy ..........................................................................................

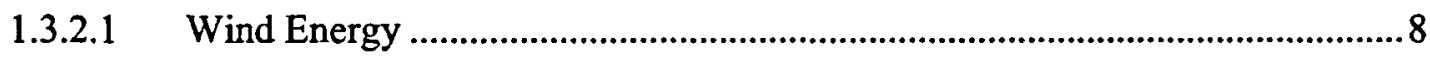

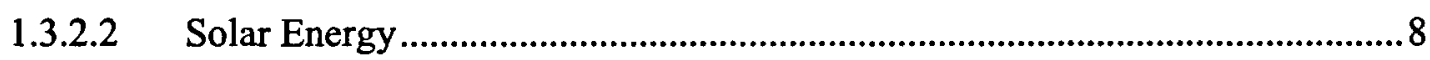

1.4 Introduction to Building Simulation Tool (TRNSYS)................................................12

1.4.1 TRNSYS Evaluation as a Simulation Tool ............................................................12

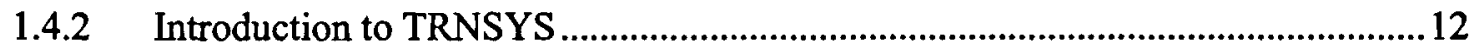

1.5 Introduction to North House and the Solar Decathlon Competition..............................14

1.5.1 Solar Decathlon Competition.....................................................................................14

1.5.1.1 The 2007 Solar Decathlon Participants and their Designs..............................14

1.5.1.2 The US 2009 Solar Decathlon Competition....................................................15

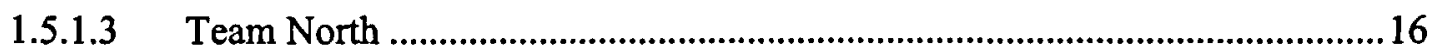

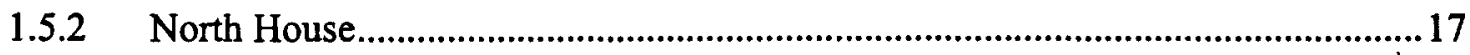

1.5.2.1 A House for Climate Extremes ...................................................................... 18

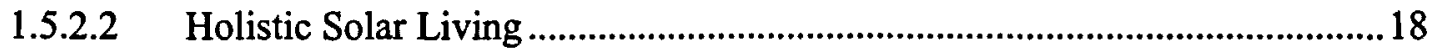

1.5.2.3 DReSS (Distributed Responsive System of Skins) ......................................... 18 
1.5.2.4 Adaptive Living Interface System................................................................... 19

1.5.2.5 Customizable Components......................................................................... 19

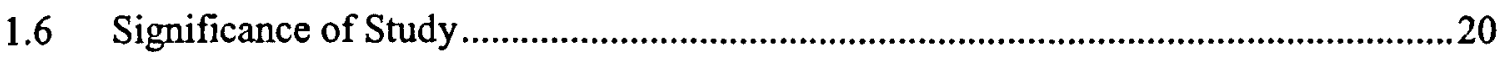

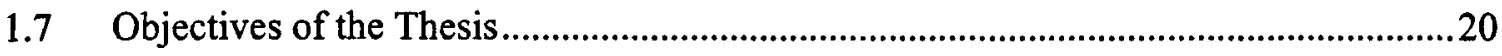

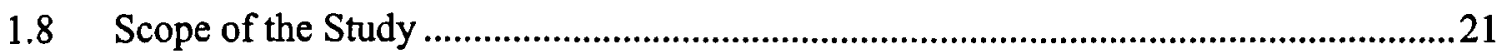

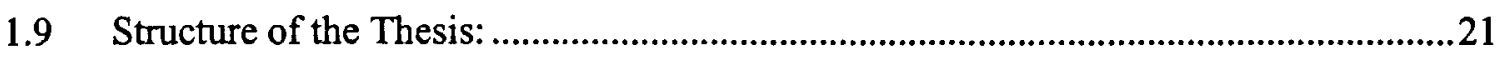

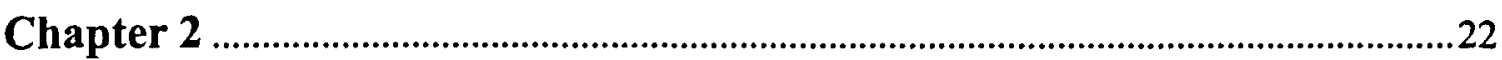

North House Building Simulation ........................................................................................22

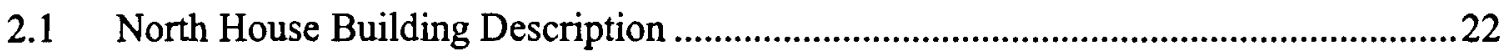

2.1.1 Building Orientation and Form.........................................................................23

2.1.2 Passive and Active Building Envelope...........................................................23

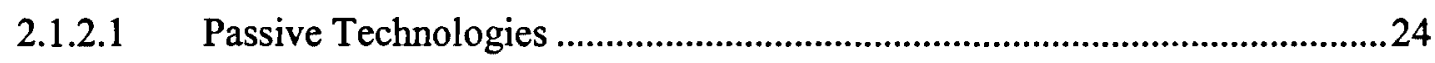

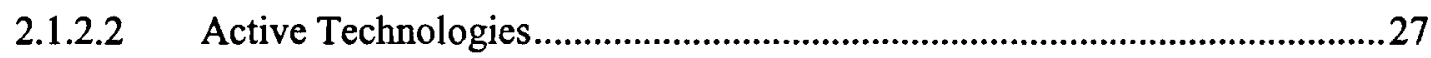

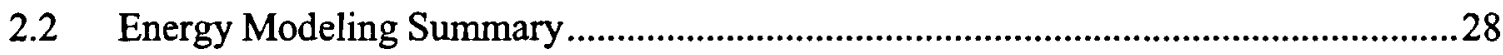

2.2.1 House Energy Balance......................................................................................28

2.2.2 Detailed House Model in TRNSYS.....................................................................29

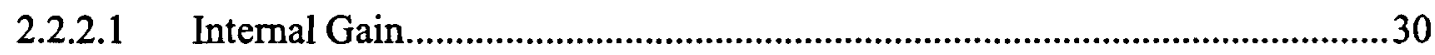

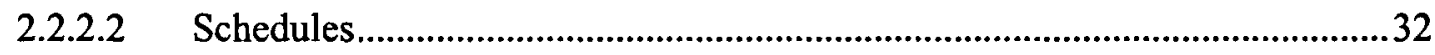

2.2.2.3 Lighting Design ..........................................................................................

2.2.3 Distributed Photovoltaic System ........................................................................

2.2.3.1 Initial Solar Resource Assessment ..............................................................34

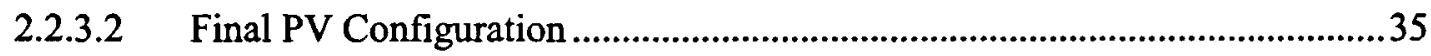

2.2.3.3 Simulation models and results .................................................................36

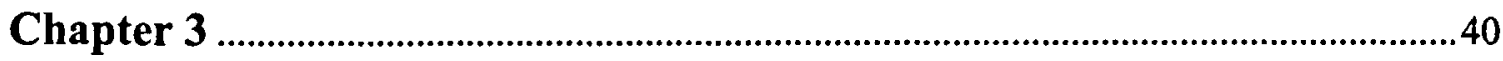

Design Process of the HVAC System....................................................................................40

3.1 Preliminary design of the North House HVAC system .................................................40

3.1.1 Domestic Hot Water System (DHW) ............................................................

3.1.2 Infloor System Layout .................................................................................

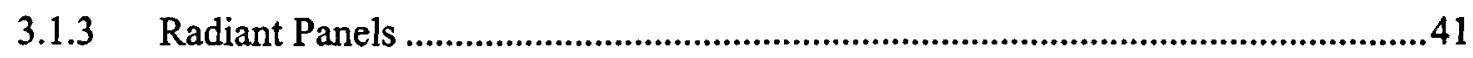

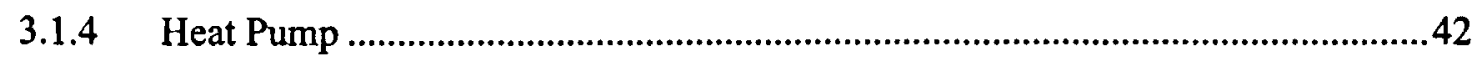

3.1.5 Grey Water Heat Recovery System (GWHR) .....................................................42

3.1.6 Heat Recovery Ventilation System (HRV) …….................................................42

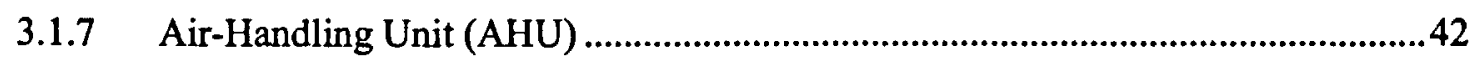

3.1.8 Option 1 System Analysis .............................................................................. 


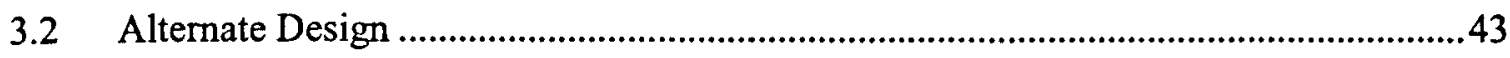

3.2.1 Domestic Hot Water (DHW) Heating ................................................................4

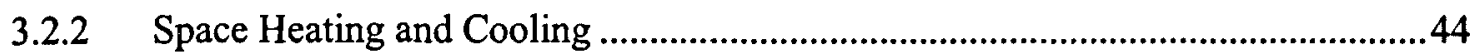

3.2.3 Description of the Mechanical System for Different Scenarios .............................45

3.3 Solar Assisted Space Heating System.......................................................................4

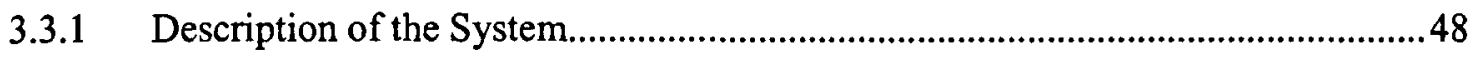

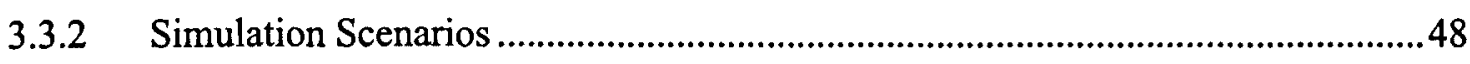

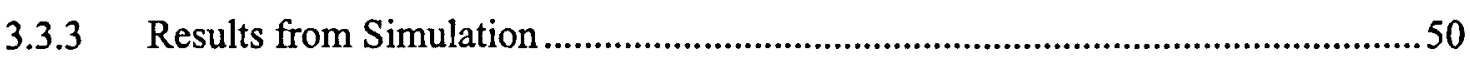

$3.4 \quad$ Heat Dump Capacity of the Small Pond ..................................................................

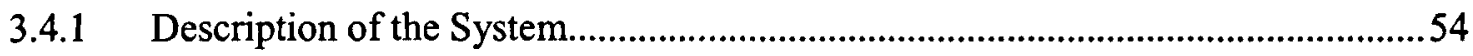

3.4.2 Simulation Scenarios ...................................................................................5

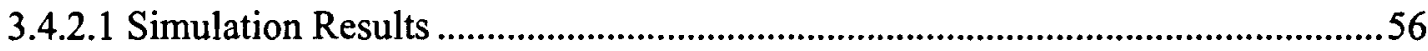

3.5 Utilizing PID Controller for External Shading .........................................................61

3.5.1 Introduction to PID Controller.................................................................................61

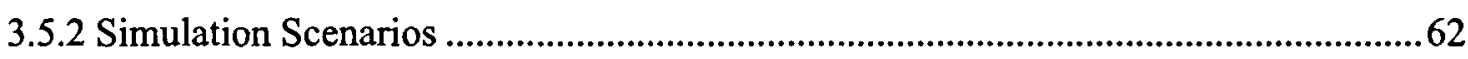

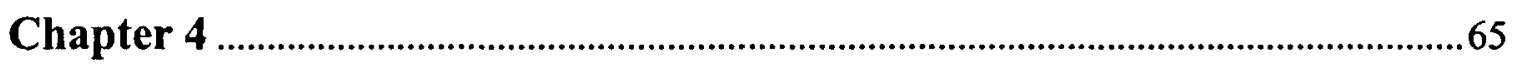

North House Solar Domestic Hot Water and HVAC System....................................................65

4.1 Description of the Overall System............................................................................65

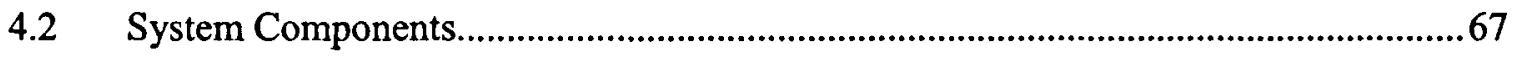

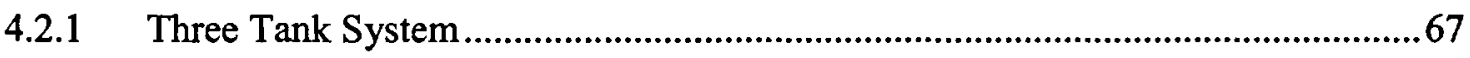

4.2.2 Direct-Flow Solar Thermal Evacuated Tubes ...................................................68

4.2.3 Variable Capacity Heat Pumps...........................................................................68

4.2.3.1 Heat Pump Assisted Solar Thermal .............................................................69

4.2.3.2 Integrated Desuperheater in Solar-Assist Heat Pump .....................................69

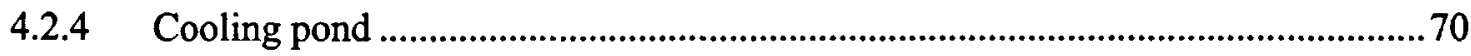

4.3 System Performance in Simulation............................................................................73

4.3.1 Simulation Details .......................................................................................73

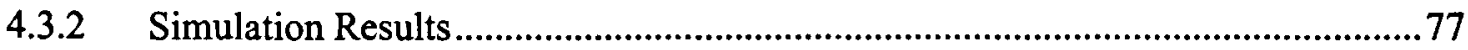

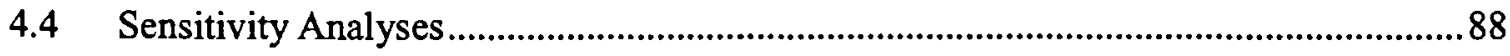

4.5 Competition Measured Data ....................................................................................

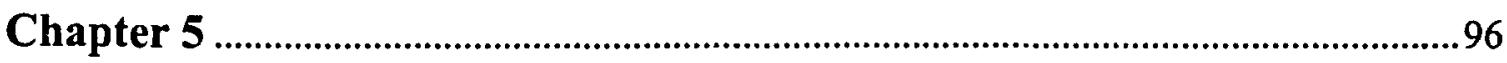

North House Energy Balance (Competition Data vs. Simulation Data)...................................96

5.1 Energy Production .............................................................................................96

5.2 Energy Consumption ............................................................................................98 
5.1.1 Case 1: External shading, Interior Blind, Lighting, Bed, ALIS ...........................100

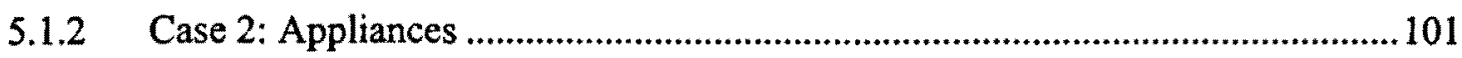

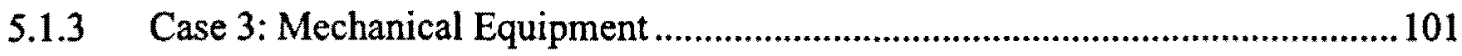

5.3 Score of North House in US DOE 2009 Solar Decathlon ................................................102

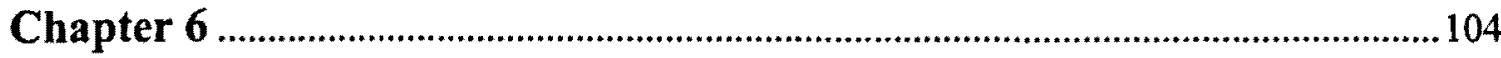

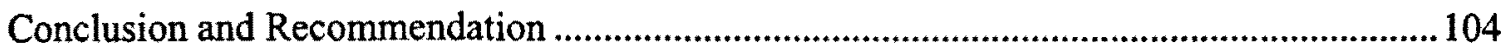

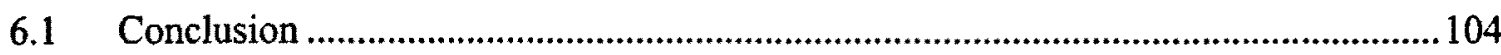

6.2 Recommendations and Future Work ....................................................................106

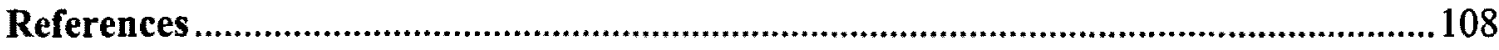

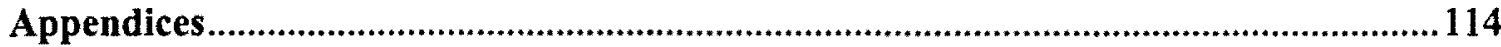

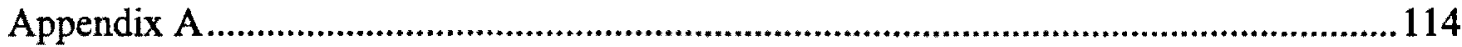

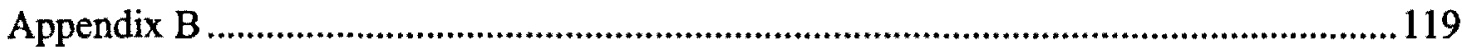

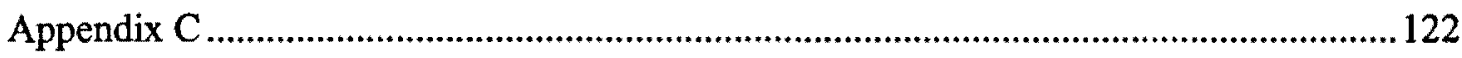

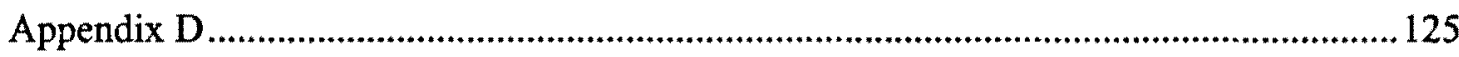




\section{List of Tables}

Table 1: Summary of the North House energy consumptions...................................................28

Table 2: Summary of the North House energy productions .......................................................29

Table 3: Description of the model inputs..............................................................................29

Table 4: North House appliances energy consumption ...........................................................30

Table 5: PV energy production for the first week of October (Baltimore)..............................36

Table 6: Annual PV energy production (Toronto)..................................................................37

Table 7: PV energy production for Toronto when Shuco panels were utilized.........................38

Table 8: Comparison of HP consumption for different tank sizes and flow rates when VTC was utilized (Toronto) ........................................................................................................53

Table 9: Comparison of HP consumption for different tank sizes and flow rates when VTC was utilized (Baltimore)...............................................................................................................53

Table 10: Results from the small pond simulation for the cases with minimum pump

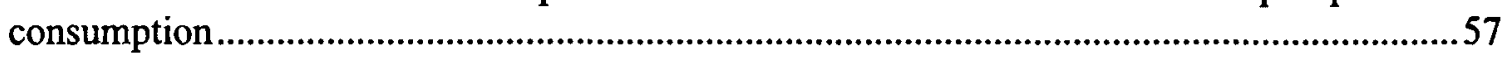

Table 11: Comparison between HP consumption and pump consumption ...............................61

Table 12: Summary of the results for the cooling season .......................................................63

Table 13: Summary of the results for the heating season ........................................................63

Table 14: Summary of the results for the shoulder season .......................................................63

Table 15: The effect of shading on the house temperature and heating/cooling demand.........64

Table 16: List of the features that improved the energy efficiency of the system....................72

Table 17: Domestic hot water draw (DHW) schedule ..............................................................74

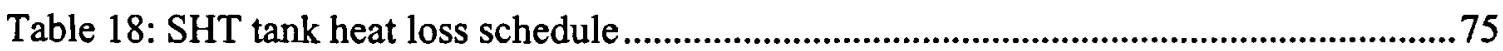

Table 19: Time intervals for heating and cooling seasons........................................................75

Table 20: Space heating and hot water energy requirements ...................................................84

Table 21: Energy balance study of the NH heating energy production/demand for Baltimore

Table 22: Energy balance study of the NH heating energy production/ demand for Toronto. 85 Table 23: Energy balance study of the NH heating energy production/ demand for Vancouver

Table 24: Energy balance study of the NH heating energy production/ demand for Edmonton

Table 25: Energy balance study of the NH heating energy production/ demand for Halifax .87 Table 26: Energy balance study of the NH heating energy production/ demand for Montreal

Table 27: Results from the sensitivity analyses 
Table 28: Results for the solar energy production during the completion and data obtained from simulation...

Table 29: List of minor appliances with their electronic requirement, time of usage and the resultant energy consumption (Fung et al., 2003)................................................................116 


\section{List of Figures}

Figure 1: Canadian secondary energy use (left) and Canadian GHG emission (right) in 20052

Figure 2: Residential energy indicators, 1990 and 2005 (NRCan, 2008)...............................4

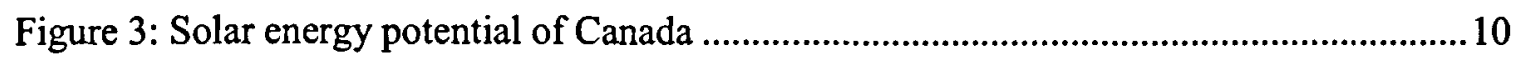

Figure 4: Demonstration of TRNSYS Simulation Studio (left) and TRNBuild (right)

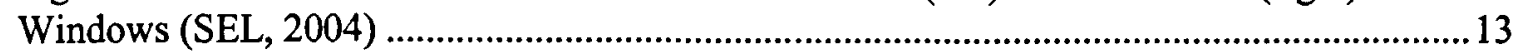

Figure 5: 2009 Solar Decathlon, National Mall, Washington DC.........................................15

Figure 6: Team North with members of Canadian embassy, 2009 Solar Decathlon, National

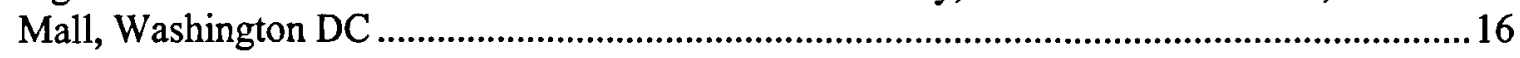

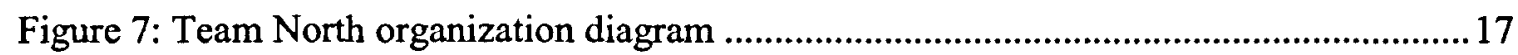

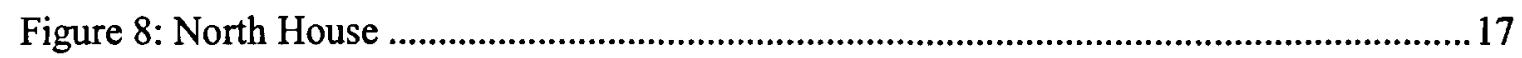

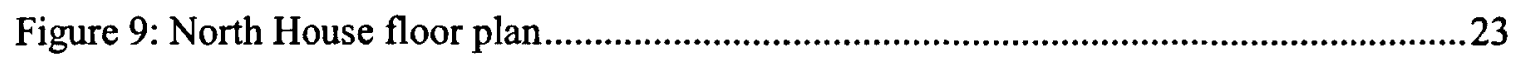

Figure 10: Quad-Layered Insulated Glazing Unit (IGU).......................................................2

Figure 11: Exterior Shading Arrangement.......................................................................26

Figure 12: Repositioning system ......................................................................................35

Figure 13: Annual PV energy production for Toronto ...........................................................38

Figure 14: PV energy production on each facade (Toronto) ………….....................................39

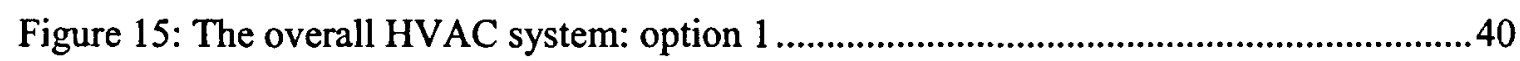

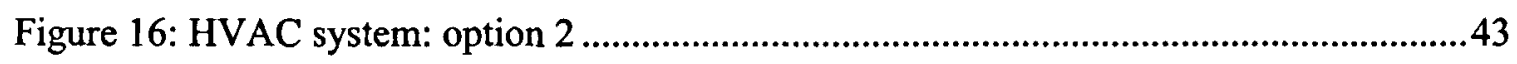

Figure 17: TRNSYS model layout of the proposed system...............................................50

Figure 18: Various tank sizes vs. ASHP consumption for different flow rates (vacuum tube

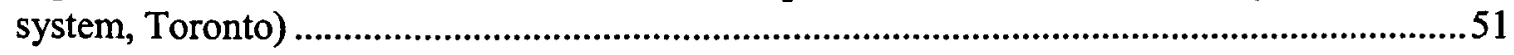

Figure 19: Various tank sizes vs. ASHP consumptions for different flow rates (vacuum tube

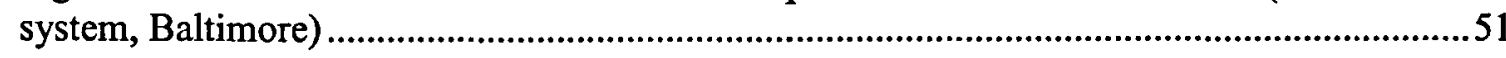

Figure 20: Comparison of the heat pump consumption for different cities when flat plate was

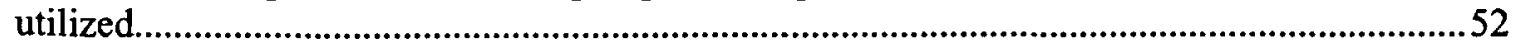

Figure 21: Design layout in TRNSYS simulation studio.........................................................56

Figure 22: \%RH profiles for Toronto and Baltimore......................................................57

Figure 23: Ambient temperature profile for Toronto and Baltimore......................................58

Figure 24: House temperature profile for Toronto .............................................................59

Figure 25: House temperature profile for Baltimore ..............................................................5

Figure 26: HP consumption for the system without pond for Baltimore..................................6

Figure 27: HP consumption for the system without pond for Toronto..................................6

Figure 28: Definition of different time intervals over one year...............................................62

Figure 29: Schematic of the North House HVAC system .................................................66

Figure 30: NH mechanical system schematic including component's details .........................70 
Figure 31: Lay out of the three tank system inside of the denspack.................................... 71

Figure 32: Ventilation system layout inside the densepack ...........................................72

Figure 33: House temperature and heating/ cooling loads in October, Baltimore..................76

Figure 34: House temperature and heating/ cooling loads in April, Baltimore ........................77

Figure 35: HWT temperature and backup electric heater signal during the heating season (Baltimore) .78

Figure 36: HWT temperature and backup electric heater signal during the cooling season (Baltimore) .78

Figure 37: SHT temperature during the heating season (Baltimore) ..................................79

Figure 38: SHT temperature during the cooling season (Baltimore) ...................................80

Figure 39: House temperature during the winter (Heating season, Baltimore) ......................80

Figure 40: HWT temperature and backup electric heater signal during heating season (Toronto)

Figure 41: HWT temperature and backup electric heater signal during cooling season (Toronto) 82

Figure 42: SHT temperature during heating season (Toronto) .......................................... 83

Figure 43: SHT temperature during cooling season (Toronto) ...............................................83

Figure 44: House temperature profile during the cooling season, Halifax ...........................8 88

Figure 45: Response of the heating system to the temperature variations.............................91

Figure 46: Comparison between the exterior \%RH and the house $\%$ RH.............................92

Figure 47: Space heating scenario on Oct 16th from 8:00PM to 12:00AM .........................93

Figure 48: Analysis of the tank temperature and control signal in the PHT and SHT loop

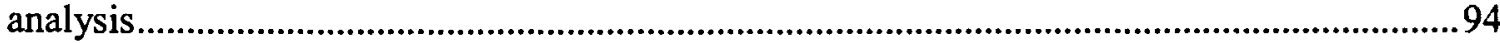

Figure 49: The analysis of the tank temperature in the SHT and HWT loop ......................95

Figure 50: PHT temperature relative to outdoor temperature.........................................95

Figure 51: PV system energy generation during the competition, Washington .....................96

Figure 52: Solar thermal system energy production during the competition, Washington DC

Figure 53: Comparison between Washington DC and Baltimore outside temperature for the ten days of competition 98

Figure 54: North House energy production/consumption during the competition................ 102 Figure 55: Scores of teams participated in the US DOE 2009 Solar Decathlon competition 103 Figure 56: \% solar fraction for different cities across Canada 105 


\section{Nomenclatures}

\begin{tabular}{|c|c|}
\hline ALIS & Adaptive Living Interface \\
\hline AHU & Air Handling Unit \\
\hline ASHP & Air-Source Heat Pump \\
\hline AUST & Average Unheated Surface Temperature \\
\hline AUT & Auxiliary Tank \\
\hline BCMP & Branch Circuit Power Meter \\
\hline BIPV & Building Integrated Photovoltaic \\
\hline $\mathrm{CDD}$ & Cold Degree Day \\
\hline CHAS & Central Home Automated Server \\
\hline COP & Coefficient of Performance \\
\hline CSP & Concentrating Solar Power \\
\hline DHW & Domestic Hot Water \\
\hline $\mathrm{DSC}$ & Digital Scroll Compressor \\
\hline GHG & Green Gas Emission \\
\hline GUI & Graphical User Interface \\
\hline GWHR & Grey Water Heat Recovery system \\
\hline HDD & Heating Degree Day \\
\hline HP & Heat Pump \\
\hline HRV & Heat Recovery Ventilation \\
\hline HVAC & Heating Ventilation Air Conditioning \\
\hline HWT & Hot Water Tank \\
\hline IGU & Insulated Guad-layered Unit \\
\hline MPT & Mean Panel Temperature \\
\hline NZEB & Net-Zero Energy Building \\
\hline PCM & Phase Change Material \\
\hline
\end{tabular}




$\begin{array}{ll}\text { PHT } & \text { Preheat Tank } \\ \text { PV } & \text { Photovoltaic } \\ \text { SEER } & \text { Seasonal Energy Efficiency Ratio } \\ \text { SHGC } & \text { Solar Heat Gain Coefficient } \\ \text { SHT } & \text { Space Heating Tank } \\ \text { VTC } & \text { Vacuum Tube Collector } \\ \text { WWR } & \text { Window to Wall Ratio }\end{array}$




\section{Chapter 1}

\section{Introduction and Literature Review}

\subsection{Background}

Canadians are fortunate to have diverse sources of energy, but only recently have they come to recognize the additional potential in reducing the energy they waste. Making sure the energy supplies go further yields significant benefits for all Canadians.

Energy is required for heat, light, transportation, cooling, and power for equipment. Between 1990 and 2004, the demand in Canada for energy has increased by 23\% (NRCan, 2006 ${ }^{\mathrm{a}}$ ). This increase has mainly been caused by the growth in both population and economic activity. According to studies done by Natural Resources Canada, without significant ongoing improvements in energy efficiency in all end-use sectors, energy use would have increased by $36 \%$, instead of the actual $23 \%$ (NRCan, 2007). Population is forecast to increase by $11 \%$ between 2005 and 2020; therefore, this growth is expected to contribute a $20 \%$ increase in energy use between these years (NRCan, $2006^{\mathrm{b}}$ ).

Generally, there are two types of energy use: primary and secondary. Primary energy refers to the energy required to transform one form of energy to another and also the energy used to bring energy supplies to the consumer (NRCan, 2008). Organizations such as the US Department of Energy (DOE) are concerned with national energy numbers, and are typically interested in primary or source energy. In 2005, the total amount of primary energy consumed by Canadians was estimated at $12369 \mathrm{PJ}^{\mathrm{I}}$ (NRCan, 2008). Globally, buildings use 30 to $40 \%$ of the primary energy (Houvila, 2007). However, this energy is typically generated from biomass in low income countries and it comes mostly from the burning of fossil fuels in middle and high income nations (Houvila, 2007). Secondary energy use is the energy used by final consumers in various sectors of the economy (NRCan, 2008). Secondary energy use encompasses energy required for space heating and cooling in the residential and

\footnotetext{
${ }^{1}$ One petajoule $(\mathrm{PJ})$, which is a million billion $\left(10^{15}\right)$ joules, is equivalent to the energy required by 8900 households (excluding transportation requirements) over one year.
} 
commercial/institutional sectors. Commercially, it comprises energy required to run machinery in the industrial and agricultural sectors. Secondary energy use accounted for $69 \%$ of the primary energy use in 2005 (NRCan, 2008). All subsequent references in this chapter to "energy" should be interpreted as secondary energy.

In 2005, total Canadian GHG emissions ${ }^{\text {II }}$ are estimated to have been 747.5 megatonnes (Mt), $66 \%$ of which resulted from secondary energy use (NRCan, 2008). Within the United States, the building sector accounts for approximately $48 \%$ of annual GHG emissions, with $36 \%$ of the direct energy related GHG emission (Nässén et al., 2007). Figure 1 shows the distribution of secondary energy use and GHG emissions, by sectors in Canada.
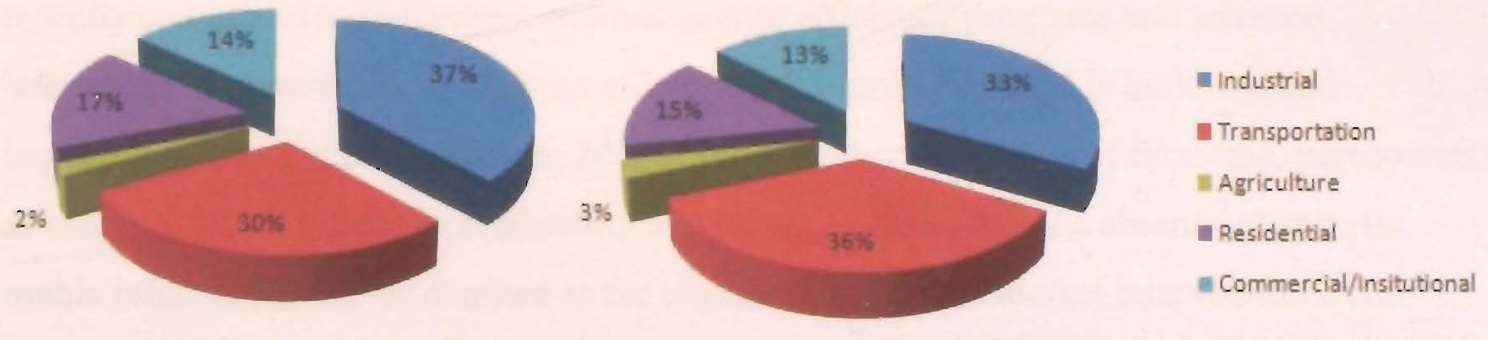

Figure 1: Canadian secondary energy use (left) and Canadian GHG emission (right) in 2005

Energy efficiency refers to how effectively energy is used to provide a certain level of service or output. A number of recent studies have addressed the significant potential for energy efficiency improvements in Canada. Although these studies vary in methodology, they share a common goal which leads to energy efficiency improvements. Some of the studies that support this potential are:

- A 2006 study assessed how consumers would make energy choices. It indicated that energy conservation, efficiency and renewable energy can reduce the growth of the energy demand between $16 \%$ and $56 \%$ by 2025 (MKJA and Marbek Resource Consultant, 2006).

- The National Round Table on the Economy and the Environment released a long-term climate change study in 2006 that examined how technologies could reduce emissions. It suggested that energy efficiency could achieve approximately $40 \%$ of

\footnotetext{
II GHG emissions include carbon dioxide $\left(\mathrm{CO}_{2}\right)$, methane $\left(\mathrm{CH}_{4}\right)$ and nitrous oxide $\left(\mathrm{N}_{2} \mathrm{O}\right)$
} 
their goal of a $60 \%$ reduction in greenhouse gas emissions, more than any other single source (NRTEE, 2006).

- A paper in Ontario covering the residential, commercial/institutional and industrial sectors, 2005 to 2025 , concluded that electricity saving potentials from energy efficiency would be in the $3 \%$ to $13 \%$ range (Ontario Energy Association, 2006).

- A 2002 BC Hydro study focused on technologies that were commercially viable by the year 2005 . It demonstrated that electricity demand could be reduced by $11 \%$ to $15 \%$ per year for the residential, commercial and industrial sectors by 2016 (BC Hydro, 2002)

Energy efficiency is becoming noticeably important to the extent that the G8 ${ }^{\text {III }}$ countries recently committed to implement national energy efficiency programs and advance international cooperation, notably on efficiency standards, sustainable buildings and improvements in industry (NRCan, 2006a). On the other hand, lack of financing, perceptions of risk and lack of access or availability of new technologies and the absence of specific, usable information can be counted as the obstacles of the new market intervention from society's point of view.

\subsection{Energy Demand in the Residential Applications}

\subsubsection{Residential Sector Contribution in Energy Consumption}

Over half of the global population is now living in urban settlements in which three quarters of global resources are consumed (Robinson et al., 2009). Energy derived from fossil fuels is dominant among the resources; therefore, it is important that proposed settlements are designed to minimize their net energy consumption.

The residential sector within the United States consumes approximately $20-25 \%$ of the primary energy, meaning that households account for about $50 \%$ of the $\mathrm{CO}_{2}$ emission within the U.S. building sector (Greening et al., 2001; Abrahamse et al., 2007; Stein and Meier, 2000). In Canada, residential sector contributes approximately 80 megatons of GHGs to the environment yearly (Syed et al., 2008).

\footnotetext{
III The G8 Group consists of the U.S., Britain, France, Germany, Canada, Japan, Italy, Russia
} 
The mix of energy used in the residentiai sector has changed over the period. Specifically, natural gas and electricity have become more dominant than oil. These increases resulted mainly from increased availability of natural gas and lower natural gas prices relative to oil (NRCan, 2008). There are also other factors that affect residential energy demand. Figure 2 shows some of these choices such as, the spacious living space, the aging population that tends to remain in their homes longer and using more devices that consume energy.

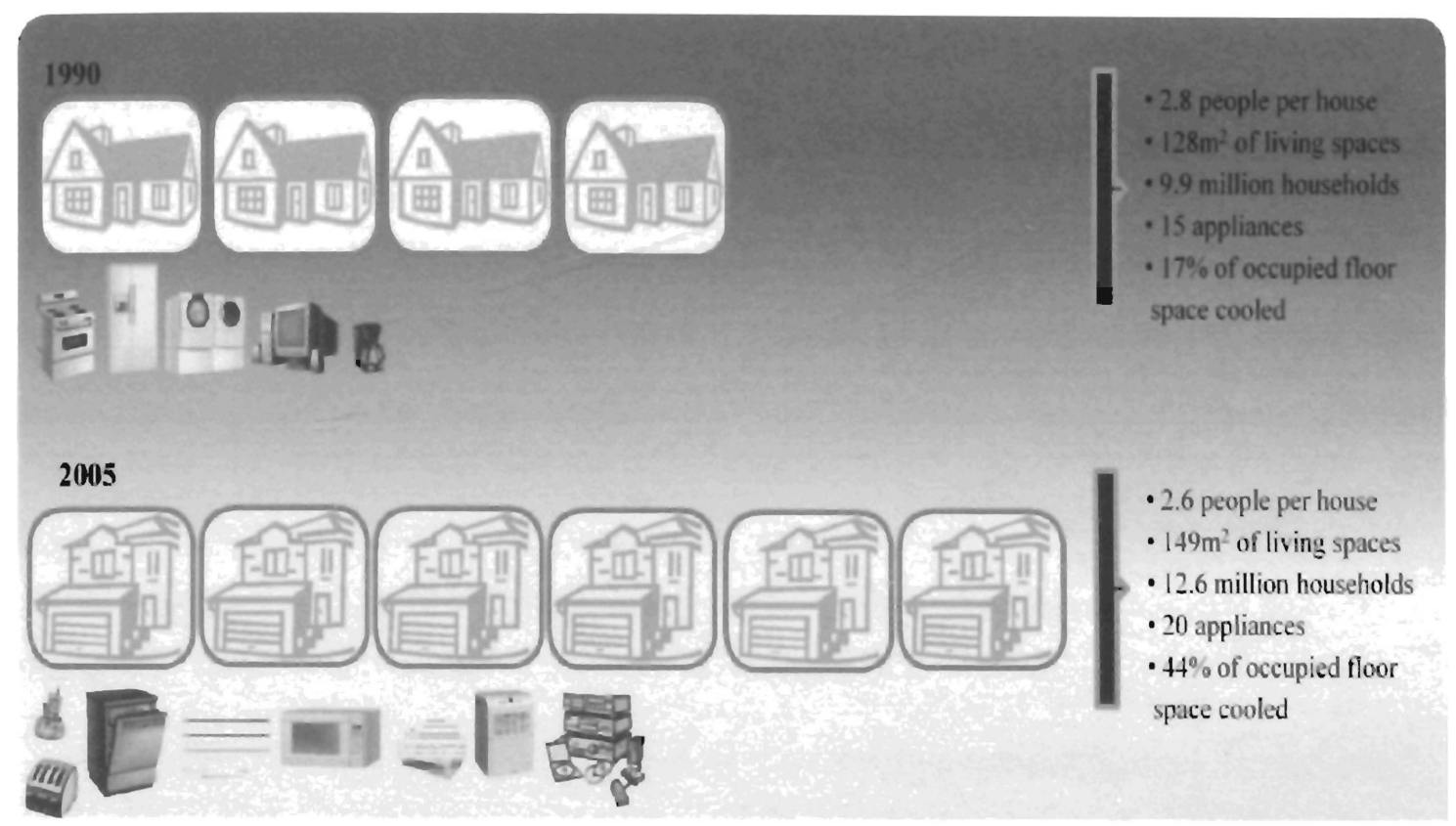

Figurc 2: Residential energy indicators, 1990 and 2005 (NRC'an, 2008)

The average unit energy use of all major household appliances decreased every year.

However, the increased number of minor appliances offsets the benefits of the energy efficiency gains of major appliances (NRCan, 2008). Energy efficiency of existing buildings and houses could be improved by incorporating the new technologies. For example, existing houses could be retrofitted with highly efficient mechanical equipments, windows, doors and lighting. Where feasible, buildings and houses would also use renewable energy technologies, uncorporate on-site, off-site generation and be interconnected with other buildings and houses within the community.

\subsubsection{The Need for Sustainability}

The number of high efficiency new homes in Canada increased in the period from 2002 to 2006. New buildings and houses incorporated the most energy efficient insulation and air tightness systems; windows and doors; new buildings system integration through 
commissioning; lighting and daylighting technologies; heating, ventilation and air conditioning equipment, and high performance metering, monitoring and control systems.

One study done in Warsaw, Poland indicated that the amount of energy use for heating purposes can be characterized by an index for seasonal heating demand. This index described the heat needed to heat $1 \mathrm{~m}^{2}$ of heated area during a standard heating season as $E_{s}\left[\mathrm{kWh} / \mathrm{m}^{2} \mathrm{a}\right]$ (Wojdyga, 2009). Buildings built in the years 1979-88 in Poland were characterized by the value of an index for seasonal demand at a level of $340 \mathrm{kWh} / \mathrm{m}^{2}$ a, in comparison with lowenergy buildings whose demand for heat reaches a level of $30-40 \mathrm{kWh} / \mathrm{m}^{2}$ a, and occasionally $10-15 \mathrm{kWh} / \mathrm{m}^{2} \mathrm{a}$, in the case of passive houses (Wojdyga, 2009).

A net zero-energy building (NZEB) is a residential or commercial building with greatly reduced energy needs through efficiency gains such that the balance of energy needs can be supplied with renewable energy technologies (Torecellin et al., 2006). The NZEB definition emphasizes both demand-side and supply strategies. This can be done by the combination of applicable efficiency measures and renewable energy supply options (Torecellini et al., 2006). There are several options that can be considered in order to achieve this goal, for example,

- Reduce site energy use through low-energy building technologies by daylighting, high-efficiency HVAC equipment, natural ventilation, evaporative cooling, etc;

- Use renewable energy sources available at the site like photovoltaic(PV), solar hot water, low-impact hydro, and wind located on-site;

- Use renewable energy sources available off site to generate energy on site; like biomass, wood pellets, ethanol, or biodiesel that can be imported from off site;

- Purchase off-site renewable energy sources utility-based wind, PV or other "green" purchasing options.

Biofuels such as waste vegetable oil from waste streams and methane from human and animal wastes can also be valuable energy sources. Fuel cells and micro-turbines do not generate energy; rather they typically transform purchased fossil fuels into heat and electricity (Torecellini et al., 2006).

One of the disadvantages with these central resources is that they require infrastructure to move the energy to the building, which is not always available. 
Due to the increase in GHG emissions in recent decades, a concern has risen over the climatic changes across the globe. In order to address such concerns, an international treaty has been set forth, known as the Kyoto Protocol ${ }^{\text {IV }}$ (IPCC, 1997). The mission of this treaty is the stabilization of GHG concentrations in the atmosphere at a certain level. To meet this target, Canada promised to reduce its GHG emissions by utilizing renewable energy technology, thus avoiding expensive investments in large central power stations and in transmission and distribution systems (Syed et al., 2008).

By the year 2030, Canadian communities should meet energy demand through the integration of energy systems, making the best use of local on-site renewable sources interconnected with the public energy distribution systems (NRCan, 2006 ${ }^{\mathrm{a}}$ ). Increasing the energy efficiency levels of regulated equipment, and eliminating the least efficient models through performance-based regulations, could also contribute to overall energy efficiency improvements within the building and housing stock.

\subsection{Sustainability}

\subsubsection{Definition of Sustainable Development}

Sustainable development is defined as "development that meets the need of the present without compromising the ability of future generations to meet their own needs" (Brundtland Commission $\mathrm{v}, 1987$ ). The concept of sustainable development has gained popularity in recent years. It was originally introduced as a microeconomic concept in forestry, meaning a strategy aimed at providing wood continually without denuding the forest (Renn et al., 2009). In recent years, the concept of sustainability has been evolved. It includes economic development, ecological stability and compatibility with social goals and values (Renn et al., 2009). Inviting the public to be part of the decision making process for defining the targets of sustainable development and facilitating the implementation of sustainable policies has been a major objective in most environmental policy circles.

\footnotetext{
${ }^{\mathrm{N}}$ Intergovernmental Panel on Climate Change (IPCC). (1997)

Retrieved November 25, 2008 from http://www.ipcc.ch/about/about.htm.

${ }^{\vee}$ Brundtland Commission. (1987). Our Common Future.
} 
The concept has been widely applied to governmental economic planning. For the Wuhan, China, government, the strategic thinking such as energy saving and sustainability was gradually reflected, as a result of employment of the Ecological Footprint (EF). As a result, the government increased technology investment, actively developed new resources and improved utilization of available resources and productivity (Wu and Liang, 2009).

There is a growing consensus that social and economic sustainability depends on limited natural capital. Therefore, not only is the acceptance of the concept of sustainability and taking the idea into the actions a serious concern, but also developing a concept of sustainability that can accomplish the right balance between preservation and change is a big challenge. Energy and energy efficiency are significantly related to sustainable development (Rosen, 2002). One of the important factors for accomplishing sustainable development is the requirement of energy sources that are fully sustainable. Society needs to utilize the energy resources such that the development results in the minimal negative environmental, health and societal impacts while preserving the life cycle of the resources. Moreover, reduction of environmental impacts can be achieved through increased energy utilization efficiency, for example cogenerating electricity and heat rather that generating them separately (Rosen, 2002).

The term 'sustainable development' is a combination of two words and unites three aspects economic progress, avoiding environmental damages and sustaining a peaceful society - in one vision (Renn et al., 2009). However, whether the combination of ecological stability, economic development and social compatibility can simultaneously be accomplished is still unclear.

\subsubsection{Renewable Energy}

There are various supply renewable energy technologies that are available for zero energy building. Technologies available today include photovoltaic (PV), solar hot water, wind, hydroelectric, and biofuels. All these renewable sources are preferable over conventional energy sources such as coal, oil and natural gas. In Toronto, Canada, it is proposed that 120 megawatts of electricity be generated in the City from renewable energy sources by 2012 and up to a1000 megawatts by 2050 (Toronto's Sustainable Energy Strategy, 2009). 


\subsubsection{Wind Energy}

Among other renewable alternatives, wind has a significant potential, and wind farms have become common all over the world due to its clean and renewable nature .

In 2001, Denmark generated $2000 \mathrm{MW}$ of electricity from more than 7,500 wind turbines (Sahin, 2004) . In 2002, Germany produced $3300 \mathrm{MW}$, while the United Kingdom intended to increase its wind energy capacity to $6000 \mathrm{MW}$ by 2010 (CanWEA, 2003). Canada had a wind-generated electricity capacity of $311 \mathrm{MW}$ resulting in contributing to around $0.5 \%$ of electricity production by the end of 2003 . This trend helped Canada to reach over $1000 \mathrm{MW}$ in 2006, and the Canadian provinces are targeting over $9000 \mathrm{MW}$ wind-generated electricity by the end of $2015^{\mathrm{VI}}$ ( (NRCan, 2007). According to the Canadian Wind Energy Association, Canada has a wind energy potential of $28000 \mathrm{MW}$, which could provide $20 \%$ to $25 \%$ of Canada's electricity demand (CanWEA, 2003).

Micro wind turbines offer an alternative energy source to the countries which are moving towards reducing energy consumption and GHG emission. Hence, they offer a good environmental benefits and cost economics. They are suitable for the residential application due to their small size, reliable power output and their compatible and robust structure (Syed et al., 2008).

\subsubsection{Solar Energy}

Solar energy has earned a considerable worldwide potential among all renewable energy technologies due to its accessibility. Direct solar energy, such as Concentrating Solar Power (CSP) or Photovoltaic (PV), has an enormous potential in the path of sustainability. Currently solar energy technology is available in the form of low temperature heat (non-concentrating collectors), high-temperature heat (CSP) and direct electricity (PV).

Looking at the advantage of the building integration of renewable technologies, more and more countries have set targets for using photovoltaic systems in the building sector. Rooftop installations in Japan (more than 70,000$)$, USA $(1,000,000)$, and Europe $(1,000,000)$ indicate the worldwide increase in attention to Building-Integrated PV (BIPV) systems. The European

\footnotetext{
${ }^{\mathrm{VI}}$ Natural Resources Canada: Wind Energy , 2007 Retrieved from http://www.nrcan.gc.ca/se/etb/cetc/cetc01/htmldocs/Publications/factsheet_wind_energy_e.html.
} 
Commission (EC) had a target of increasing the PV electricity production to $2000 \mathrm{MW}$ by 2010 in comparison to 52 and $200 \mathrm{MW}$ in 1995 and 1999, respectively (Ayoub et al., 2000; Bakos et al., 2003).

A solar thermal power plant in a region with abundant sunshine can reach a continuous production of $30 \mathrm{MW} / \mathrm{km}^{2}$, whereas the maximum yield that can be obtained from biomass is $2 \mathrm{MW} / \mathrm{km}^{2}$, and from wind parks is $1.5 \mathrm{MW} / \mathrm{km}^{2}$ (Voorthuysen, 2009). Each kilowatt of photovoltaic micro power can potentially offset 1.58 tons of $\mathrm{CO}_{2} /$ year when replacing coal use, 1.30 tons of $\mathrm{CO}_{2}$ /year when replacing oil use, and 0.73 tons of $\mathrm{CO}_{2}$ /year when replacing natural gas use (Ayoub et al., 2000). The problem that needs to be addressed with solar systems is that they would deliver a surplus of electricity in the summer and have a deficit in the winter. This seasonal and day-evening variation problem can be effectively resolved if the electrical utility allows net-metering. In net-metering, a system owner receives retail credit for at least a portion of the electricity he/she generates.

In study done in Tunisia and the United Arab Emirates as the operation sites (Lecoufle et al., 2009), the annual electrical output of each of the different options was simulated for the PV and CSP options. Global Irradiation (GHI) and Direct Normal Irradiation (DNI) were considered as the used solar resources for the case of PV and CSP respectively. Considering light slope terrain for both scenarios, more than 2,000 full load hours was achieved by the PV plant using tracking systems. For the CSP technology with storage, the power generation reached more than 3,000 full load hours per year. Although it is known that the performance of PV modules goes down in hot climates, the results are still relatively high (Lecoufle et al., 2009).

If a desert area equal to the size of France is covered with solar panels or solar thermal power plants, both having an efficiency of $15 \%$, the whole current global consumption of oil, coal, gas and uranium can be replaced (Voorthuysen, 2009).

All Canadian capitals compare favorably with the major cities in Germany (Berlin) and Japan (Tokyo), two world-leading countries in terms of PV installed capacity (Pelland et al., 2006). Figure 3 shows the promising solar energy potential of Canada as given in PV maps obtained from NRCan's website. 


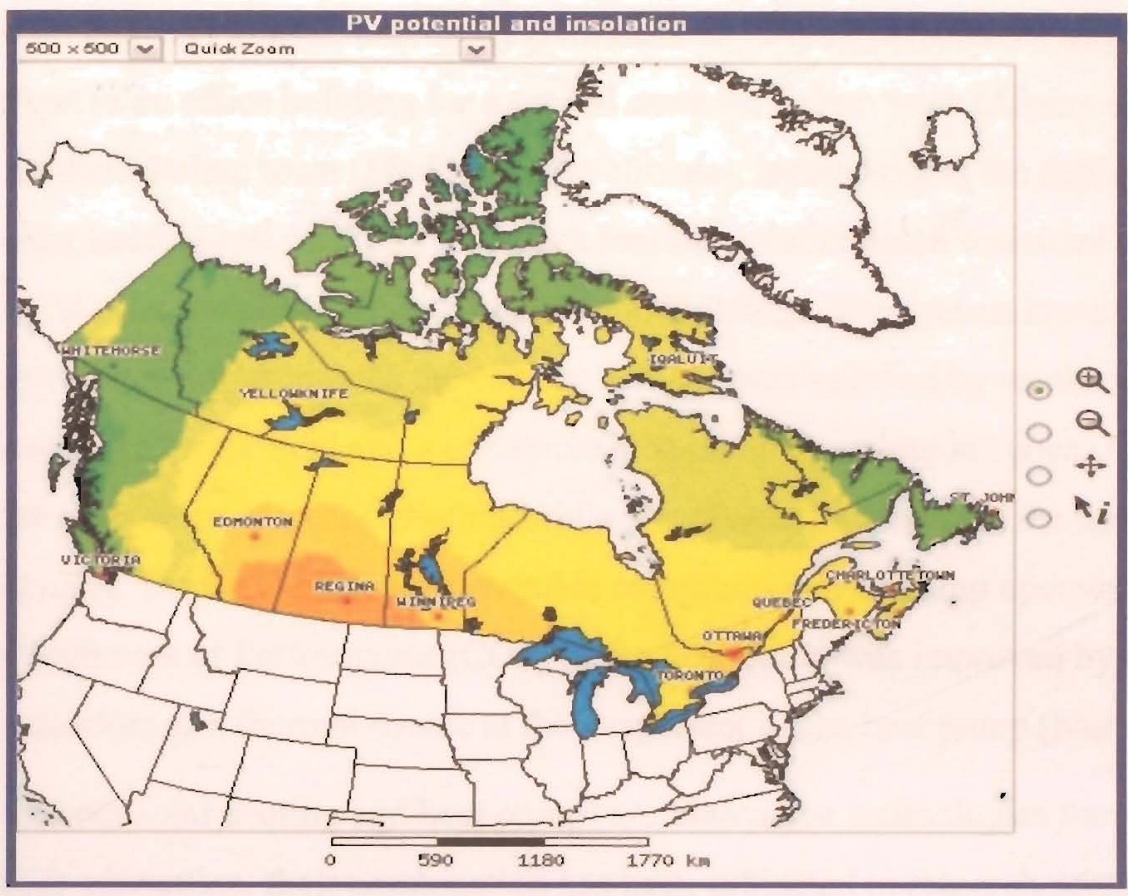

Figure 3: Solar energy potential of Canada ${ }^{\text {III }}$

Considering the fact that the global electricity consumption in 2003 was $1,686 \mathrm{GW}_{\text {average }}$ (Voorthuysen, 2006), if humanity decides to make an approach towards the Solar Age, a widely supported action should be taken. In order to do so, hundreds of thousands of square kilometers of solar fields must be built, complete with power stations, thermal storage tanks and solar fuel factories.

\subsection{Solar Heating System}

Technologies such as solar hot water systems and solar space heating with larger solar collector areas and storage units for enlarged solar fractions have been utilized more than before. However, solar heating systems still suffer from a necessity for an additional heat source, in most cases based on fossil fuels. The problem is caused by the gap between solar radiation availability driven from day/night and summer/winter shift and thermal energy requirement (Trinkl et al., 2009).

Using a combination of conventional and renewable energy such as combined heat and power systems and solar photovoltaic technology can enhance the energy performance of new

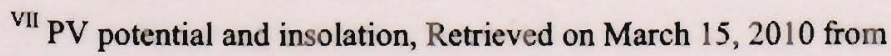

NRCan website at: https://glfc.cfsnet.nfis.org/mapserver/pv/pvmapper.phtml
} 
buildings and houses. One study (Nurzia et al., 2008), presented a solar heating and cooling plant in an office building for a typical northern Italian town (Alpine climate) and a typical southern Italian town (Mediterranean climate), indicated that the deployment of combined solar heating and cooling system is a feasible solution in all countries where high solar irradiation matches high cooling loads in buildings. The system layout was considered as follows: in warm months the cooling demand was satisfied by an absorption chiller driven by a solar collector field and a reversible heat pump operating in series. A hot storage matches the variability of solar radiation, while a cold storage smoothes the non-stationary demand of cooling. During winter, the reversible compression heat pump operates for space heating. The Coefficient of Performance (COP) of the heat pump was improved by utilizing the solar collectors as a thermal source at the evaporator of the heat pump (Nurzia et al., 2008).

As both solar heating and heat pumps are innovative technologies for sustaining ecological heat generation, their combination has been subjected to research continuously. Fundamental research regarding the combination of a heat pump and solar collectors was conducted in a simulation (Freeman and Mitchell, 1979). The development of a solar heat pump system with latent heat storage was another innovation (Comakli et al., 1993). The possibility of water/ice phase change storage into such system for industrial applications led to promising results (Trinkl et al., 2004). The annual simulation results of the solar heating system offered promising prospects for further applications of both the heat pump and the solar thermal system in Central Europe (Trinkl et al., 2009). The proposed solar/heat pump heating system was also found to be more suitable for buildings because of acceptable space demand, as well as the reduction of electric energy demand for the heat pump by managing the source and sink temperatures.

However, for the solar system to be more efficient, some integrated storage with high energy density and high energy capacity is required. Water is a very good medium in the heating applications since a good stratification can be maintain in the storage (Cabezaet al., 2006). By utilizing conventional hot water storage with a $30^{\circ} \mathrm{C}$ temperature difference, it is possible to store approximately $30 \mathrm{kWh}_{\text {thermal }} / \mathrm{m}^{3}$ of storage (Martin and Setterwall, 2009). A similar study indicated that by an appropriate design of thermal energy storage using phase change material technology (PCM) it is possible to triple the capacity to over $90 \mathrm{kWh}$ thermal $/ \mathrm{m}^{3}$ (Martin and Setterwall, 2009). 


\subsection{Introduction to Building Simulation Tool (TRNSYS)}

\subsubsection{TRNSYS Evaluation as a Simulation Tool}

Building energy software tools arose in the 1970s, followed by refinement within the professional realm in the 1980s, and expansion of scope, scale, and diverse user applicability in the 1990s (Mills, 2004 ). Today, the U.S. Department of Energy lists 342 tools on their Web directory (DOE, 2008). Building energy simulation programs ideally model all aspects of a building that influence energy use and thermal and visual comfort for the occupants. Integrated energy performance simulation tools usually model the transient response of the building structure, through transfer functions or a finite difference method.

The simulation packages require standardized codes to insure that a proposed building simulation will meet a minimum performance guideline. A number of standards and guidelines have been developed in an effort to assist end users in choosing an appropriate tool. ANSI/ASHRAE Standard 140 (ASHRAE, 2005) is one of those standards assisting simulators in assessing tool capabilities and helping software developers in verifying their work. A number of studies done in applying ASHRAE Standard 140 to TRNSYS indicated the reliability and validity of the results obtained from TRNSYS simulation. It was identified that there is a great deal of leeway within a given software package to make widely varying assumptions and yet still fall well within the range of acceptability (Bradley et al., 2004)

Given such sensitivities, it might be concluded that it would be difficult to obtain a consistent set of assumptions that would cause a software package to pass the entire ASHRAE test. However, TRNSYS did acceptably pass all the tests using the conformed assumption set defined by the ASHRAE test (McDowell et al., 2004)

\subsubsection{Introduction to TRNSYS}

TRNSYS consists of a suite of programs: The TRNSYS simulation Studio, the simulation engine (TRNDIl.dll) and its executable file (TRNExe.exe), the Building input data visual interface (TRNBuild.exe), and the Editor used to create stand-alone redistributable programs known as TRNSED applications (TRNEdit.exe) (SEL, 2004). A TRNSYS project is typically set up by connecting components graphically in the Simulation Studio. The user can create projects by drag-and-dropping components to the workspace, connecting them together by linking the outputs of one component to the inputs of another component and finally set the 
global simulation parameters. The user can check a component's configuration and the link between two components.

The simulation can be executed once all the necessary components are placed on the assembly panel, the parameters and initial values are defined for each component and the necessary links between components are made and the internal connections from. Once they are completed the results can be viewed and printed using an online plotter. Based on the results, adjustments can be made to the components in the project in the Assembly Panel and more simulations can be run.

All the information required simulating the building is described in a special window called TRNBuild. TRNBuild is the tool used to enter input data for modeling multi-zone buildings. The user can also edit the building description through the simulation studio by selecting "Edit Building" icon. It allows user to specify all the building structure details, as well as everything that is needed to simulate the thermal behavior of the building, such as windows optical properties, heating and cooling schedules, etc.
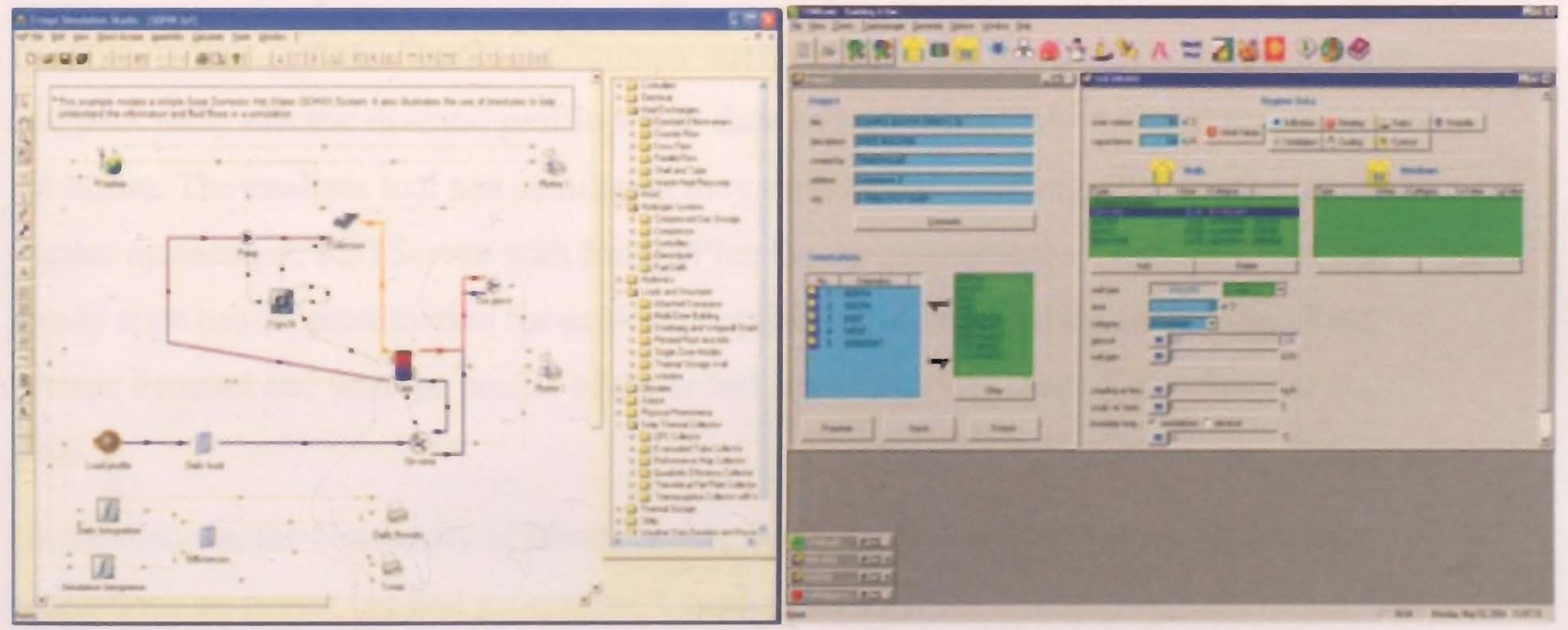

Figure 4: Demonstration of TRNSYS Simulation Studio (left) and TRNBuild (right) Windows (SEL, 2004) When performing building energy simulations, it is important to keep in mind that there are many considerations that can significantly affect the output. Getting results that approach reality is a difficult task, even if various systems, constructions and geometry are accurately accounted for. Occupancy behaviour can throw off any assumed results by $50 \%$ or more. Hence, the intent is to use the software to assess the relative impact on design decisions, before tackling a rigorous simulation aimed at predicting realistic values of annual energy use. 


\subsection{Introduction to North House and the Solar Decathlon Competition}

\subsubsection{Solar Decathlon Competition}

The National Renewable Energy Laboratory (NREL) and the U.S. Department of Energy (DOE) have established the Solar Decathlon as an international competition to increase awareness about solar-powered homes and demonstrate that a well designed house can generate enough electricity to meet the needs of a household.

\subsubsection{The 2007 Solar Decathlon Participants and their Designs}

Twenty student teams from universities in the US, Puerto Rico, Germany, Canada and Spain participated in the third Solar Decathlon held on 2007. The student teams assembled real-life, $800 \mathrm{ft}^{2}$ super-efficient solar homes (Johnson, 2007 ).

Georgia Tech was one of teams that participated in the Solar Decathlon 2007 competition. An estimation of the expected household energy consumption was fundamental for the design of the photovoltaic system. For the preliminary analyses, the team generated a typical average and peak daily electric demand profile which then was translated into the total PV supply for the house. The analysis tool and simulation they used included: EnergyPlus for the thermal system assessment, RETScreen with EnergyPlus for the mechanical system selection, and steady state heat approximation for exploring options to reduce heating and cooling load, electric demand and wattage profile of the actual appliances and loads (Choudhary et al., 2008 ).

ElementHouse, the University of Illinois's entry, utilized EnergyPlus to provide accurate estimations on power use and generation. Coupling EnergyPlus with daylighting simulation performed with Radiance, assisted the team to finalize the building envelope which embraced the passive and low energy ideas to minimize the annual heating and cooling loads (Wang et al., 2009).

The University of Illinois's house was the only entry that featured an all-electric design. No solar thermal collectors were used; space and water heating was accomplished primarily through heat pumps. The house module was sensibly conditioned with autonomous, custom mini-split heat pumps using all radiant and natural convection heat exchange for the interior side (Barnes et al., 2009). 
The Santa Clara University (SCU) team designed a solar house with the goai of being highly sustainable by using streamlined technologies, providing as much power as needed, and by minimizing the energy usage within the building. The energy and thermal loads were modeled using EnergyPlus. The thermal energy design decisions for their house were based largely on a combination of the solar decathlon contest requirements and technologies that were sustainable and commercially available (Elizondo, Lebassi, \& Gonzalez-Cruz, 2009).

The University of Texas house was called the BLOOMHouse. The team developed a prefabricated $6.6 \mathrm{~kW}$ stand-alone solar-powered modular house that could be adapted to a specific site and modified for the needs of a different site within a different climatic zone, and client context. The house was designed to meet the target of $\$ 0.10 / \mathrm{kWh}$ for power in the year 2015, and to introduce the ideas of how to integrate renewable energy technologies into residential buildings (Garrison, 2008).

Current community development programs in the United States and other countries consist primarily of planning and zoning regulations that focus on economic and population growtr: The Pennsylvania State University entry focused on a building-centred community development process. The design and construction of two prototype homes for two different communities were then presented as case studies for the competition (Floras Phelps et al., 2007).

\subsubsection{The US 2009 Solar Decathlon Competition}

In 2009 Solar Decathlon, 20 college and university teams from around the world designed, built and operated their versions of the most attractive, effective, and energy-efficient solarpowered home The 2009 Solar Decathlon competition consisted of 10 contests that centered on the ways in which energy is used in people's daily lives. During the competition the teams received points for their performance in ten contests and opened their homes to the public.
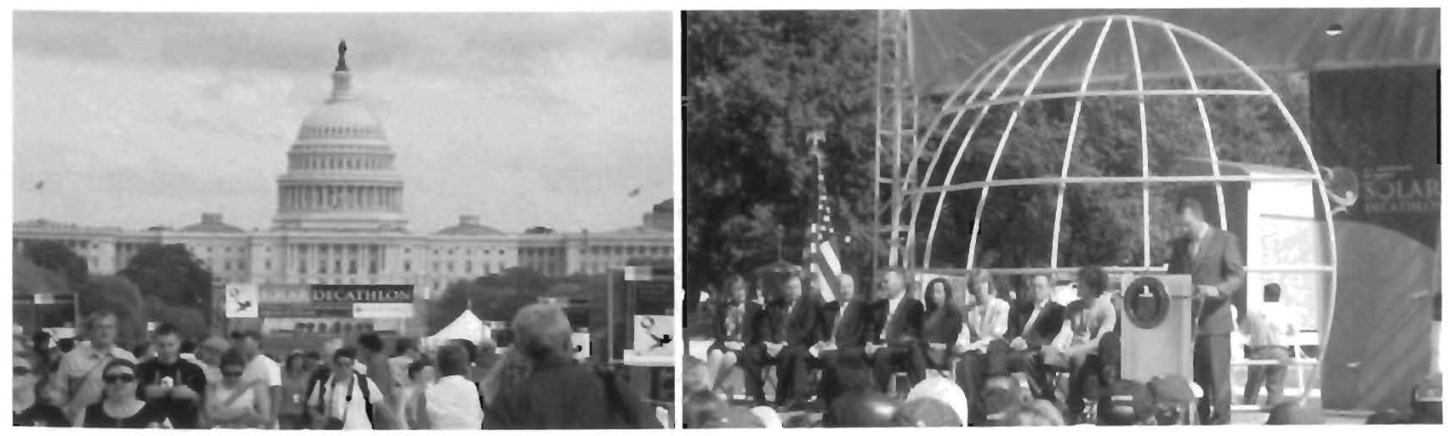

Figure 5: 2009 Solar Decathlon, National Mall, Washington DC 


\subsubsection{Team North}

In October 2009, Team North, a consortium of Ryerson University, University of Waterloo and Simor. Fraser University competed in the 2009 Solar Decathlon. Team North's mission was to design and deliver a home called "North House", a compelling and marketable solarpowered home while training Canada's next generation of leaders in sustainable design. The combination of astive and passive solar design, integrated energy production, customized component, and mobile interactive technologies is a powerful vehicle of advancement in Canadian new housing industry, as weli as improvement in the health and well-being of Canadian residents.

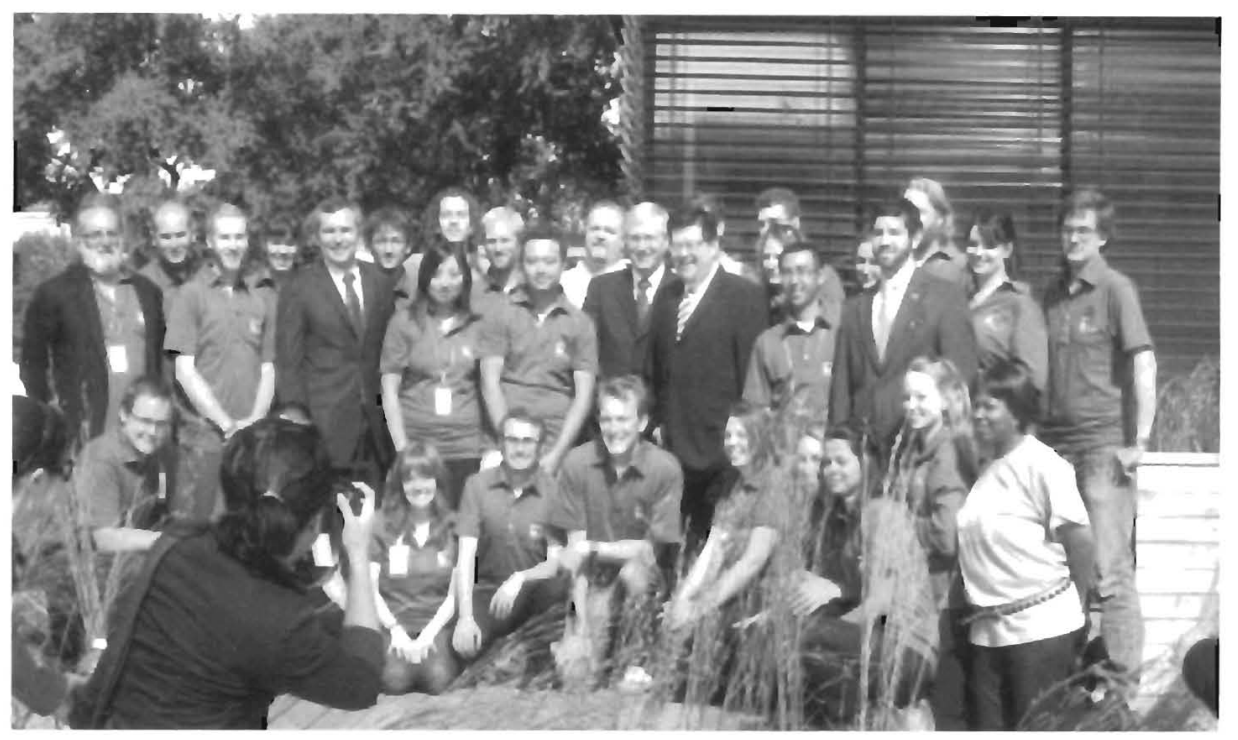

Figure 6: Team North with members of Canadian embassy, 2009 Solar Decathlon, National Mall, Washington DC

\subsection{Team-Based Operative Strategies}

Given the complexity of the task and the number of parallel activities and feedback loops that need to be occurring simultaneously, a typical hierarchical project structure would simply not work. In order to navigate through the intensive activities of design, energy modeling, envelope design, product testing, prototyping, component development, business modeling, life cycle costing, materials acquisition, fundraising, document production, construction, transportation and shipping, installation, balancing, and monitoring that will comprise the project, several layers of organization had been created that were task specific and tried to recognize the synergies between teams ( North House Project Manual, June 2, 2009). The organizational diagram illustrated in Figure 7 shows the operations and interactions within our student-faculty team. 


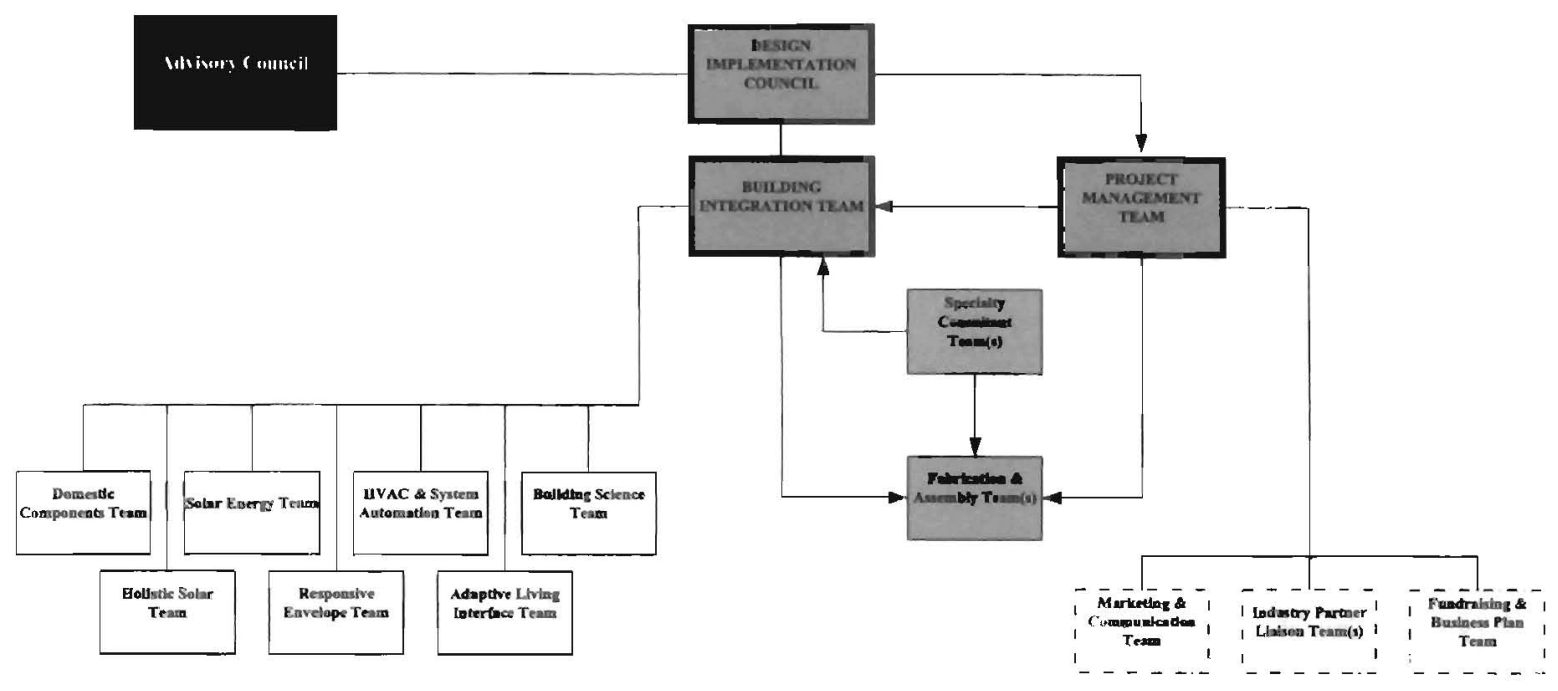

Figure 7: Team North organization diagram

The teams were not divided according to discipline but according to the various activities that need to be undertaken and involved individuals from different disciplines. Representatives from industry partners were invited to join the discussions. Team North considered building manufacturers and suppliers not as contractors but as design collaborators, and encouraged the possibility of the design research to develop new products in collaboration with industry.

\subsubsection{North House}

North House is more than green, developing a new and innovative green housing model that makes sustainable living attractive and rewarding. Energy efficiency is only half of the sustainable living equation. North House goes beyond carbon counting to help support daily living patterns and energy use routines. The design approach is based on three strategies: A House for Climate Extremes, Holistic Solar Living and DReSS (Distributed Responsive System of Skins). Following descriptions are obtained from the North House project manual.
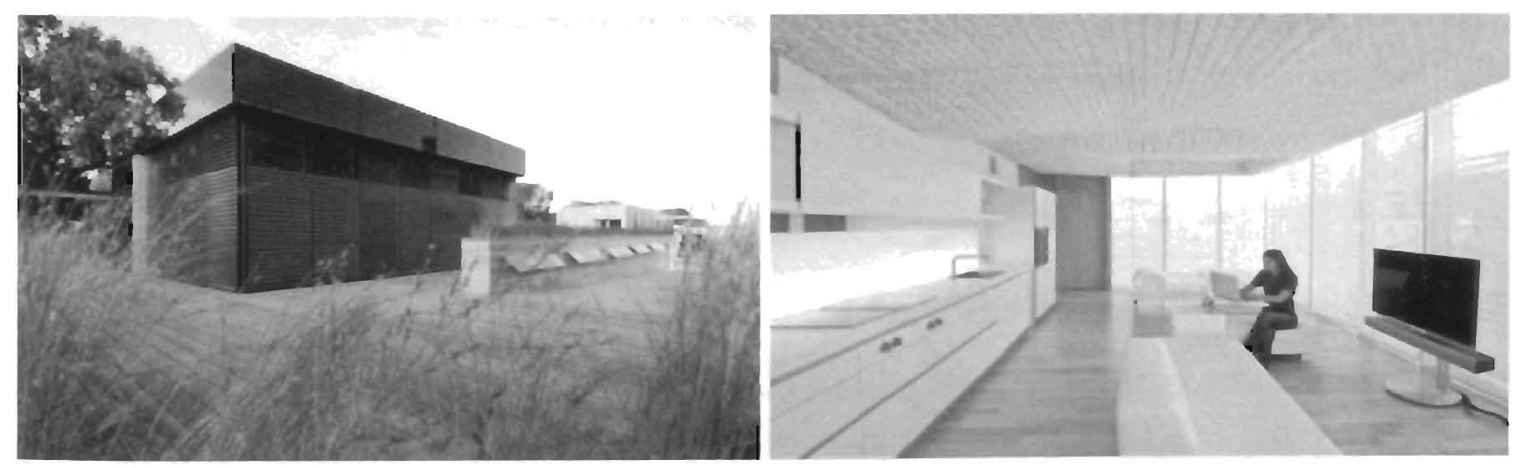

Figure 8: North House 


\subsubsection{A House for Climate Extremes}

North House was designed with a highly insulated, efficient, passively and mechanically conditioned interior that was wrapped by a layered envelope that modulated the house's response to various climates, solar and shading conditions. The footprint of the house was compact and efficient, minimizing envelope surface area and maximizing opportunities for east-west passive ventilation. The interior consisted of a dense pack of service on the north side of the house, opening to a generous and flexible living space. The flexible living space accommodated sleeping, eating and living functions with custom reconfigurable furniture that maximized openness and multi-functionality. This flexible framework allowed North House to be customized for different living needs, to be adapted to multiple regions across the country and to take advantage of new technologies and developments in envelope and solar technologies. The modular design of North House also allowed the building to be easily divided into component modules for fabrication, transportation, assembly and future expansion to accommodate a variety of familial situations.

\subsubsection{Holistic Solar Living}

The team defined Holistic Solar Living as an approach to making and living that incorporates the energy and benefits of the sun in all ways possible. The consideration of daylighting, passive systems, microclimate generation, maintenance, food production, solar phase change materials, and solar responsiveness is essential to this perspective. Strategies deployed included a responsive system of louvers that wrapped the entire house in a luminous array, alternatively shading and allowing panoramic views of the landscape, locating the bed on the east side of the house to witness the sunrise, and having the kitchen, dining and outdoor eating on the west side to enjoy afternoon and sunset light. Holistic Solar Living also includes using the sun's energy to grow vegetable and herbs in the garden and along the south facing windows and drying and canning to preserve food to limit refrigeration.

\subsubsection{DReSS (Distributed Responsive System of Skins)}

The North House was structured and constructed in layers. The exterior layers of the house comprised a 'thick' Responsive Envelope that physically mediated energy production, environmental conditions, and the personal comfort preferences of the occupants. It was composed of flexible layers integrated with PVs to generate solar energy. The layers provided 
passive solar gain when necessary, shading at other times, opened to the exterior when views were desired, and were capable of mitigating extreme climatic shifts by closing down when the house was in conditioned mode or opening up to allow the house to breathe during the temperate seasons. The house incorporated incremental, simple, adaptable, distributed systems throughout to achieve its energy, living, and sustainable goals.

\subsubsection{Adaptive Living Interface System}

The Adaptive Living Interface System (ALIS), developed especially for North House, was comprised of interactive technologies combined with ambient and haptic information cues, which helped the residential occupant both to control the systems of the house, and provide feedback on the operation of the house, in this way supporting behavioural transformation towards energy saving living patterns. The ALIS was moving beyond automated controls to directly address the needs of residential occupants by providing an easy-to-use ubiquitous interface, supporting residential tasks, integrated with the user's lifestyle and providing meaningful performance feedback.

Three types of user interface components comprised the ALIS. First, a standard web-based graphical user interface (GUI) that can be accessed from anywhere with an internet connection was developed. This GUI included traditional application-style tools which provided an overview of building state and performance and which supplied alerts according to user-specified events. Furthermore, the GUI was extended to a set of mobile components for a SmartPhone. A set of small, peripheral, always-on information components were defined. These components provided a continuous overview of the house, delivered appropriate alerts, and served as a quick navigation button into remote controls. Finally, an ambient and subtle information system was explored. It was integrated into the house itself, and it changed its behaviour, as conditions changed, in ambient and non-intrusive ways.

\subsubsection{Customizable Components}

Team North was collaborating with a custom fabricator to optimize shop-built CAD/CAM production techniques and technologies for the North House prototype, to lighten the structure as much as possible in order to facilitate transport, assembly, disassembly and material use. Use of shop-built prefabrication and component assemblies supported efficient transportation, assembly and disassembly on the National Mall in Washington, DC. North 
House was conceived as a prototype of mass-customization, and demonstrated a given range of systems and technologies. Each system, however, had the capacity to be completely removed and replaced with alternative systems - to allow modification, research, and testing long into the future.

\subsection{Significance of Study}

Canada has one of the coldest climates in the world. Most parts of the country go through a long winter season. In addition, there is a prevalence of single-family housing across Canada. As a consequence, total end-use energy consumption in Canada is high. In Canada, $78 \%$ of all residential energy use is for space heating and water heating (NRCan, 2008). In order to avoid utilizing conventional energy sources, renewable energy technologies that are available for zero energy buildings need to be developed. There are various renewable energy technologies. Technologies available today include photovoltaic (PV), solar thermal, wind, hydroelectric, and biofuels. PV systems provide a clean, sustainable, and environmentally friendly source of energy. It has been estimated that if a $30 \mathrm{~m}^{2} \mathrm{PV}$ array were to be installed on the roof of an average Canadian house, it would supply approximately $4000 \mathrm{kWh}$ annually, approximately $45 \%$ of the house electrical consumption (Ayoub et al., 2000). Using NZEB design goals gives us the opportunity of designing more than a low-energy building with an energy savings goal and takes us into the realm of a sustainable energy endpoint. North House is a simple yet innovative solar powered house that produced more energy than it consumed. The solar heating system provided $100 \%$ of the heating and hot water needs even when available solar energy was reduced.

\subsection{Objectives of the Thesis}

The overall objective of this thesis is to investigate the energy performance of North House. In order to do that, the energy balance of the house utilizing new renewable and energy efficient technologies was studied using TRNSYS simulation. Finally the data obtained from the simulation were compared to real time data obtained from ten days of competition to test the performance of the system. To reach these objectives the following case studies were conducted:

1. Different HVAC designs; 
2. Each system, including the solar heating system, cooling pond and exterior shading was modeled in TRNSYS independently to study their performances individually;

3. The final overall design was simulated in TRNSYS and the results were compared to real time data;

4. The system performance was studied for five Canadian cities.

\subsection{Scope of the Study}

This study is limited by a simple control system modeled in TRNSYS. The actual North House HVAC control was a complex control system that needs to be programmed in order to use in TRNSYS. The PCM material was not integrated in the TRNSYS model.

In TRNSYS weather library the closest location to Washington DC is Baltimore. In reality, they are slightly different in terms of the ambient temperature and the solar radiation. Therefore, when comparing the data collected during the competition and the simulation data, this consideration needs to taken into account.

\subsection{Structure of the Thesis:}

The summary of the work carried out to form this thesis is outlined as follows with the contents of the individual chapters:

Chapter 1: Literature review, introduction to North House and the US 2009 Solar Decathlon.

Chapter 2: North House building description including windows, walls, external shading, lighting and control system and introduction to energy modeling of the house.

Chapter 3: Introduction to the different HVAC designs split as option 1 and option 2 (alternate option), Result analysis from modeling the cooling pond, infloor system and PID controller in TRNSYS

Chapter 4: Description of North House HVAC system and TRNSYS model of the system Chapter 5: Sensitivity analysis and comparison of the data with real time data Chapter 6: The general conclusion and discussion 


\section{Chapter 2}

\section{North House Building Simulation}

\subsection{North House Building Description}

The North House engineering design focused on delivering a low-energy and highly efficient net-energy-positive solar building that was capable of adapting to the various climates of Canada. To achieve this, North House optimized the use of the sun by using passive solar design principles to minimize energy consumption, while deploying distributed buildingintegrated photovoltaic and solar-thermal technology to maximize energy production. This was complemented by an integrated smart control system, which sought out the optimal low energy approach to operate the home and still maintain a high degree of occupant comfort.

To achieve this goal, numerous technical challenges were met in the design and construction of North House that, in some cases, defied conventional norms of residential design. Areas of notable technical innovation were as follows ( North House Project Manual, June 2, 2009) ${ }^{\mathrm{vm}}$ :

- Building Orientation and Form

- Passive and Active Building Envelope

- Domestic Hot Water and HVAC System

- Distributed Photovoltaic System

- Integrated Smart Control System

Most of the engineering work had been evaluated through a series of computer models, including overall annual building energy simulations, window heat transfer simulations, PV power production simulations, and HVAC systems integration simulations. These simulations had been made part of the iterative integrated design process intended to optimize and refine all of the components of the house. Results from the simulations gave the team valuable insight regarding the performance of the design, which was considered in conjunction with other design requirements before any decisions were made.

\footnotetext{
${ }^{\mathrm{VII}}$ Note from the author: The information provided in Chapter 2 is obtained from North House Project Manual, submitted to DOE on June 2, 2009. Since this thesis will be using as a future reference, essential information on the house required to be included.
} 


\subsubsection{Building Orientation and Form}

Contrary to most solar homes orientated with a longer façade along the east-west axis to maximize solar exposure to the south, North House took on a compact form. The surface area to internal volume ratio was reduced resulting in less solar exposure. The beneficial trade-off was the reduction of the amount of energy to heat and cool. While this reduced the solar exposure of the home to the south, the reduction in Southern exposure was compensated for by installing a full-height floor-to-ceiling glazing wall system on the South, East, and West façades to maximize solar gain.

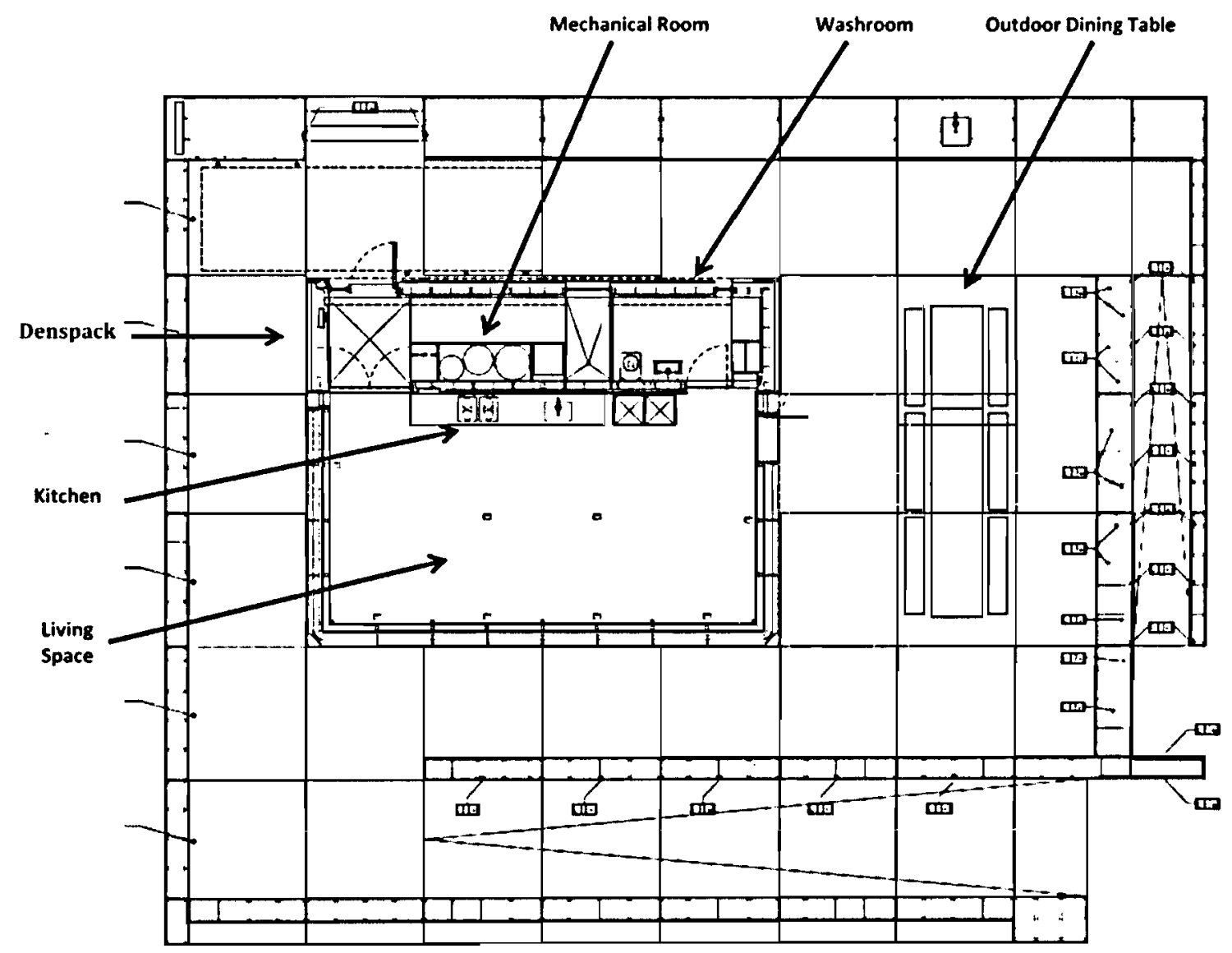

Figure 9: North House floor plan

\subsubsection{Passive and Active Building Envelope}

The building envelope had a significant role in the overall passive solar design strategy of North House by carefully controlling energy and mass flows between the exterior and interior of the house. North House featured both active solar technologies and passive technologies. 


\subsubsection{Passive Technologies}

\subsection{Walls Description}

One of the significant energy loads in a typical Canadian home is space heating. The most effective way to reduce heating load is to have a highly insulated and air-tight building envelope to minimize heat transfer. The opaque walls were constructed out of $2 \times 6$ wood sandwich panels insulated with 5.5" of closed-celled Soy-Lock polyurathane spray foam insulation, with an additional 3.5" of spray foam outboard of the sandwich panel in between the offsetting $2 \times 4$ wood studs. The exterior layer of spray foam minimized thermal bridging from the studs.

Nominal R-values are typically reported, however, they are not representative of the actual heat transfer across the wall, since the short-circuiting thermal bridges from the studs are not accounted for. The wall system had a nominal R-value of R-64, and an actual R-value of R47 with studs. The floor had a little less insulation, with a nominal R-value of R-51 and R-36 with joists, since it did not have any insulation outside of the sandwich panel. This was due to the fact that the permanent installation of the home will have an insulated foundation. The walls in North House were more than three times more insulating than the walls of a typical Canadian home.

\subsection{Phase Change Material (PCM)}

Phase change materials (PCM) embedded underneath the finished floor helped to effectively utilize the solar gains by storing the free heat during the day and releasing it at night. Although PCMs are typically placed above suspended ceilings, PCMs in North House were placed underneath the floor to effectively collect the solar radiation that shines down from the sun through the highly glazed façades. The PCMs consisted of a salt-hydrate solution which changed phase at $24^{\circ} \mathrm{C}$. Due to the large amount of latent heat, the application of PCMs can reduce the conventional thermal mass. PCMs helped stabilize daily temperature fluctuations of the home and reduced peak space heating and cooling loads and allowed for HVAC sizing to be reduced leading to significant savings in HVAC design.

\subsection{Windows Description}

As part of the highly insulated building envelope, North House used some of the most insulating high performance windows available in the industry. A highly glazed façade on the 
east-, west-, and south-face covered the main living space of the home. In total North House had a window-to-wall ratio (WWR) of approximately $70 \%$ yet still was a net-positive home. The façades of North House were constructed with a highly insulated quad-layered krypton filled glazing unit (IGUs) which was able to harness passive solar heat from the sun with its relatively low $\mathrm{U}$-value of $0.474 \mathrm{~W} / \mathrm{m}^{2} \mathrm{~K}(\mathrm{R}-12)$ yet relatively high $\mathrm{SHGC}$ of 0.404 . The quad glazed configuration featured two sheets of glass sandwiching two layers of plastic films which had selective low-e coatings. Placing the low-e coatings in this configuration limited the amount of long-wave thermal radiation transmission from indoors to outdoors while still allowing significant amounts of solar gain through the glazing. Figure 10 illustrates different layers of the quad-layered window unit. Despite specifying a high-performance glazing unit, most of the desired performance may be lost through a poorly designed frame. These IGUs were combined with highly insulated wood mullions and innovative warm-edge spacers to ensure a high level of thermal insulation through the window assembly. The result of the investigation was the production of a high-performance curtain wall system that was approximately four times more insulating than a typical aluminum curtain wall.

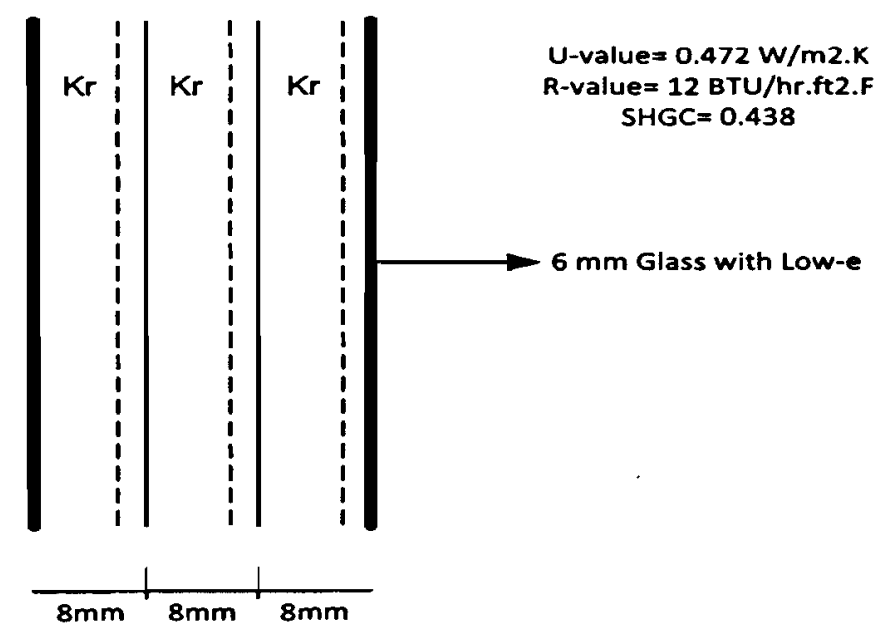

Figure 10: Quad-Layered Insulated Glazing Unit (IGU)

\subsection{Shading (External Blinds)}

One significant problem with buildings with highly glazed façades is overheating due to excessive solar gains. This problem was overcome by the use of dynamic shading through the form of exterior venetian blinds (Figure 11). The exterior venetian blinds were able to block unwanted solar gains which helped to significantly reduce the cooling load of the home. The control of the dynamic shading system was innovatively coupled with the home's 
HVAC control system to maintain a high level of thermal comfort while using minimal energy. The central home automation set the modes of the blinds and automatically determined the angle of the sun from the time of the day.

The exterior venetian blinds had four modes of automated operation: open, gain, block, and closed. Using location, orientation, time of day, and time of year the blind controllers were continuously aware of the location of the sun. Gain and block modes oriented the slats parallel and perpendicular to the sun's rays respectively. Transitions between modes were coordinated based on the interior temperature of the house. When the heating system was activated, the blinds were open, allowing maximum heat gain. When the cooling system was activated, the blinds blocked the direct rays of the sun. In the deadband between heating and cooling temperature set points the blinds attempted to maintain temperature by alternating between block and gain modes. In the event of overheating, the blinds were closed completely. Under low light conditions or high wind the blinds were retracted.

Careful consideration was taken by the design team to avoid unwanted cyclic behaviour of the blinds when the HVAC system was running and to ensure that the PCMs were fully charged before the transition to blocking mode; thus, all systems worked together to provide a high level of thermal comfort while using a minimum amount of energy.

The exterior blinds were not only part of the thermal management system of the home but were also part of the lighting system, since they allowed varying degrees of daylight.

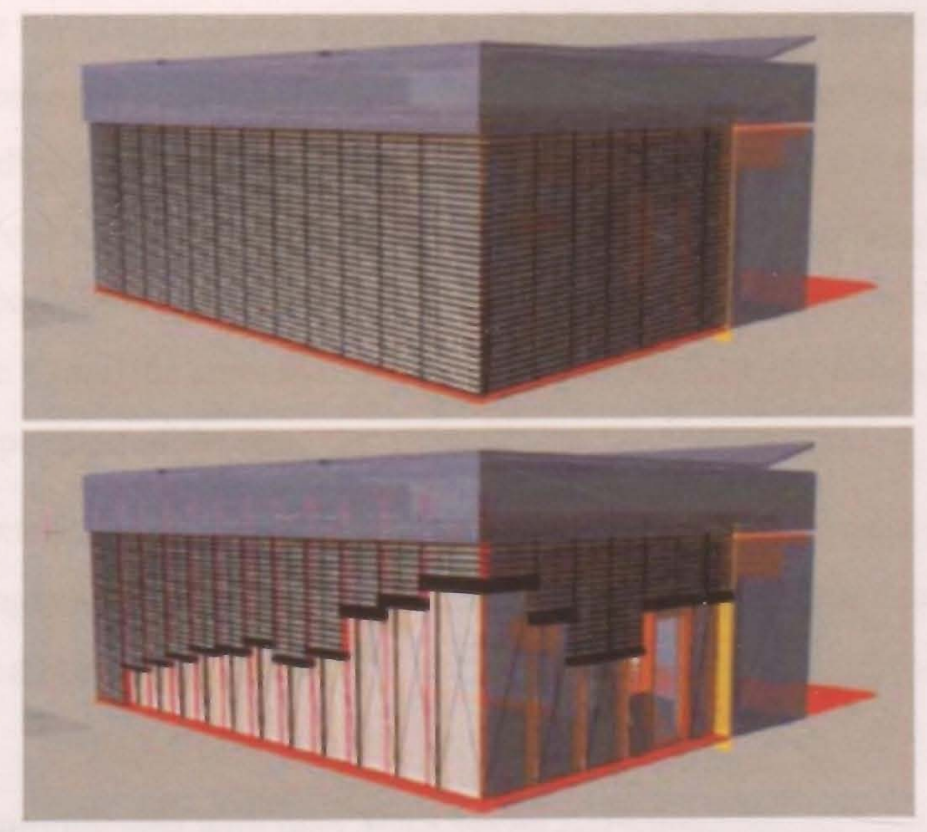

Figure 11: Exterior Shading Arrangement 


\subsubsection{Active Technologies}

\subsection{Solar Thermal and HVAC System}

The mechanical system in North House was designed with the goal of collecting enough solar energy to cover the majority of the domestic hot water and space heating demands throughout the year, while conserving every last watt of electrical power. A comprehensive description and a detailed design are provided in Chapter 4.

\subsection{Distributed Photovoltaic System}

In order to achieve North House's goal of maximizing power production throughout the year, in a variety of climatic conditions, energy production systems are integrated into virtually every surface of the building envelope. Many different PV array configurations were initiated and studied to evaluate the different design configurations. A detailed design analysis is presented in the following sections.

\subsection{Integrated Smart Control System}

The North House integrated controls system offers many opportunities for technical innovation. Because the building's integrated control system has to efficiently manage the operation of multiple subsystems and provide feedback to the user regarding the performance of the house, the control system was being custom designed and built.

At the heart of the integrated control system was the Central Home Automation Server (CHAS), which managed both the Graphic User Interface (GUI) as well as all subsystems of the house. Depending on internal and external conditions, the CHAS was able to make highlevel decisions to enhance the energy performance of the house. For example, the CHAS determined the operation of the external shading system depending on the internal air temperature of the home, the amount of incoming solar radiation, the exterior wind speeds, and the expected position of the sun.

HVAC control, external shade automation, bed actuation, interior and exterior environment, and water consumption monitoring were implemented with the Beckhoff programmable logic controller. Using a human body metaphor, the Beckhoff was considered the spinal cord of North House.

The Beckhoff communicated with the CHAS via an ADS interface over ethernet. 
Coordination by the CHAS was accomplished over this interface by changing space heating, cooling, and hot water set-points. The solar thermal controller was connected to a data logger which allowed for the CHAS to query the amount of solar thermal energy collected allowing daily feedback. Data were also collected via ADS interface in a database for historical analysis for the occupants.

\subsection{Energy Modeling Summary}

Energy and mass flows in buildings are inherently dynamic and complex. Any attempt to capture the interactions between various building elements (such as envelope, energy systems, occupants, appliances, etc.) requires sophisticated modeling techniques. Even when a sophisticated, integrated model is available, the predictions rely heavily on occupant behaviour. From the onset of the North House project, computer simulations were used to assess the performance of the building and its components. The TRNSYS simulation was used to assess the energy performance of the house.

\subsubsection{House Energy Balance}

The total energy balance of the North House was based on the performance analyses of the active and passive energy systems incorporated into its design. Tables 1 and 2 summarize how each house component was modeled.

Table 1: Summary of the North House energy consumptions

\begin{tabular}{|l|l|}
\hline \multicolumn{2}{|c|}{ Consumption } \\
\hline Space Heating & $\begin{array}{l}\text { Annual idealized demand profile was predicted by TRNSYS. } \\
\text { Based on these results, an average demand value was } \\
\text { calculated for each month and applied to the model. }\end{array}$ \\
\hline Space Cooling & Annual idealized demand profile was predicted by TRNSYS. \\
\hline DHW & $\begin{array}{l}\text { The system was modeled in TRNSYS and was coupled to the } \\
\text { solar thermal system. }\end{array}$ \\
\hline Appliances and Plug Loads & $\begin{array}{l}\text { Energy consumption of appliances was based on product } \\
\text { specification, modified where necessary, for expected } \\
\text { occupancy use. Where hot water was used, the values account } \\
\text { for water heating energy but did not reflect the DHW system } \\
\text { conversion efficiency. } \\
\text { Plug loads were based on anticipated usage schedules and } \\
\text { average power draws. }\end{array}$ \\
\hline Lighting & \begin{tabular}{l} 
Lighting consumption was estimated based on the wattage of \\
\hline
\end{tabular}
\end{tabular}


the lighting components and an occupancy schedule.

Table 2: Summary of the North House energy productions

\begin{tabular}{|l|l|}
\hline \multicolumn{2}{|l|}{ Production } \\
\hline PV & $\begin{array}{l}\text { Electrical production was modeled in TRNSYS and NREL's } \\
\text { PVWatts calculator using the selected PV modulus and } \\
\text { representative areas of the east, west, south façade and roof } \\
\text { over one year period for Toronto. } \\
\text { The possible accumulation of snow was neglected. } \\
\text { Inverter efficiencies and losses were neglected. }\end{array}$ \\
\hline Solar Thermal & $\begin{array}{l}\text { This system was modeled in TRNSYS in combination with the } \\
\text { DHW model. The reported value was the useful collected } \\
\text { heat, some of which would be lost in dissipaters when demand } \\
\text { was insufficient to take advantage of the collected heat (Chapter 4). The } \\
\text { solar thermal system was designed to operate with a large } \\
\text { thermal storage system once the house is situated in its } \\
\text { permanent location. }\end{array}$ \\
\hline
\end{tabular}

\subsubsection{Detailed House Model in TRNSYS}

Building energy analysis was performed using TRNSYS. The models focused mainly on predicting annual space heating and cooling energy, beginning with a very simple model and progressively adding building elements representative of the North House design. Emphasis was placed on establishing the relevant model inputs to reduce the house energy demand. The results indicated that the demand for space heating and cooling can be decreased drastically primarily by providing appropriate solar protection and thermal mass. Table 3 summarizes the model inputs. The building geometry and construction were based on the drawing set.

Table 3: Description of the model inputs

\begin{tabular}{|c|c|c|}
\hline \multicolumn{3}{|c|}{ Conditioned space } \\
\hline Floor area & $\mathrm{ft}^{2}$ & 670 \\
\hline Internal ceiling height & $\mathrm{ft}$ & 9.66 \\
\hline Space volume & $\mathrm{ft}^{3} / \mathrm{min}$ & 6472.2 \\
\hline \multicolumn{3}{|c|}{ Set-Points } \\
\hline Air temperature (Annual) & ${ }^{\circ} \mathrm{C}$ & $22-24$ \\
\hline Air relative humidity & $\% \mathrm{RH}$ & $45-55$ \\
\hline \multicolumn{3}{|c|}{ Minimum Ventilation Requirements (ASHRAE 62.2 standards) } \\
\hline Occupants & & 2 \\
\hline Ventilation rate per occupant & $\mathrm{ft}^{3} / \mathrm{min}$ & 7.5 \\
\hline Ventilation rate per sq. $\mathrm{ft}$ & $\mathrm{ft}^{3} / \min$ & 0.01 \\
\hline
\end{tabular}




\begin{tabular}{|c|c|c|}
\hline Total ventilation & $\mathrm{ft}^{3} / \min$ & 21.7 \\
\hline Total ventilation & $\mathrm{ACH}$ & 0.2 \\
\hline Blower test & $\mathrm{ACH}$ at $50 \mathrm{~Pa}$ & $0.6^{1 x}$ \\
\hline Natural infiltration & $\mathrm{ACH}$ & 0.04 \\
\hline Total minimum ventilation & $\mathrm{ACH}$ & 0.24 \\
\hline \multicolumn{3}{|c|}{ Bathroom fan } \\
\hline \multirow[t]{3}{*}{ Exhaust rate } & $\mathrm{I} / \mathrm{s}$ & $25^{x}$ \\
\hline & $\mathrm{ft}^{3} / \min$ & 52.9 \\
\hline & $\mathrm{ACH}$ & 0.49 \\
\hline \multicolumn{3}{|c|}{ Range hood fan } \\
\hline \multirow[t]{3}{*}{ Exhaust rate } & $\mathrm{l} / \mathrm{s}$ & $50^{\mathrm{xI}}$ \\
\hline & $\mathrm{ft}^{3} / \min$ & 105.9 \\
\hline & $\mathrm{ACH}$ & 0.98 \\
\hline \multicolumn{3}{|c|}{ Heat Recovery Ventilation( HRV) } \\
\hline HRV efficiency & $\%$ & 70 \\
\hline
\end{tabular}

\subsubsection{Internal Gain}

Appliances, entertainment system and miscellaneous plug loads were considered as the house internal heat gain. North House appliances were selected to be as energy efficient as possible. Table 4 shows the appliance list with estimated annual and weekly energy use and approximate sensible and latent multipliers. The internal gains were based on double occupancy as well as the predicted use of the appliances selected for the house.

Table 4: North House appliances energy consumption

\begin{tabular}{|l|c|c|}
\hline \multicolumn{3}{|c|}{ Refrigerator } \\
\hline Leibherr HC1060 & $\mathrm{kWh} / \mathrm{y}$ & $297.0^{\mathrm{XII}}$ \\
\hline Energy/year & $\mathrm{kWh} / \mathrm{w}$ & 5.7 \\
\hline Energy/week & & 1.0 \\
\hline Sensible energy multiplier & & 0.0 \\
\hline Latent energy multiplier & \\
\hline \multicolumn{3}{|l|}{ Dishwasher } \\
\hline Gaggenau DF 261760 & \\
\hline
\end{tabular}

${ }^{\mathrm{x}}$ German Passive House target

${ }^{x}$ Suggested by CMHC, Retrieved on May 2009 from: http://www.cmhcschl.gc.ca/en/co/maho/yohoyohe/momo/momo_004.cfm

${ }^{\mathrm{XI}}$ Minimum suggested by CMHC, Retrieved on May 2009 from: http://www.cmhcschl.gc.ca/en/co/maho/yohoyohe/momo/momo_004.cfm

${ }^{\mathrm{xn}}$ Product specification manual 


\begin{tabular}{|c|c|c|}
\hline Energy/year & $\mathrm{kWh} / \mathrm{y}$ & $190.0^{\mathrm{XI11}}$ \\
\hline Energy/week & $\mathrm{kWh} / \mathrm{w}$ & 3.7 \\
\hline Estimated Energy/year for North House & $\mathrm{kWh} / \mathrm{y}$ & 114.0 \\
\hline Estimated Energy/week for North House & $\mathrm{kWh} / \mathrm{w}$ & 2.2 \\
\hline Sensible energy multiplier & & 0.6 \\
\hline Latent energy multiplier & & 0.2 \\
\hline \multicolumn{3}{|l|}{ Oven } \\
\hline \multicolumn{3}{|l|}{ Gaggenau BO 250-611 } \\
\hline Energy/year & $\mathrm{kWh} / \mathrm{y}$ & $166.4^{\mathrm{x} I V}$ \\
\hline Energy/week & $\mathrm{kWh} / \mathrm{w}$ & 3.2 \\
\hline Sensible energy multiplier & & 1.0 \\
\hline Latent energy multiplier & & 0.0 \\
\hline \multicolumn{3}{|l|}{ Cook top } \\
\hline \multicolumn{3}{|l|}{ Gaggenau VI 221} \\
\hline Energy/year & $\mathrm{kWh} / \mathrm{y}$ & $254.8^{\mathrm{XV}}$ \\
\hline Energy/week & $\mathrm{kWh} / \mathrm{w}$ & 4.9 \\
\hline Sensible energy multiplier & & 0.8 \\
\hline Latent energy multiplier & & 0.2 \\
\hline \multicolumn{3}{|l|}{ Cloth Dryer } \\
\hline \multicolumn{3}{|l|}{ Bosch Axxis condensation } \\
\hline Energy/year & $\mathrm{kWh} / \mathrm{y}$ & $419.0^{x 11}$ \\
\hline Energy/week & $k W h / w$ & 8.1 \\
\hline Sensible energy multiplier & & 0.2 \\
\hline Latent energy multiplier & & 0.0 \\
\hline \# of cycle in quoted energy consumption & cycles/year & 416.0 \\
\hline Estimated actual number of cycles(NH)XVII & cycles/year & 208.0 \\
\hline Estimated energy per year(NH) & $\mathrm{kWh} / \mathrm{y}$ & 209.5 \\
\hline Estimated energy per week(NH) & $k W h / w$ & 4.0 \\
\hline \multicolumn{3}{|l|}{ Clothes Washer } \\
\hline Bosch Axxis plus & & \\
\hline
\end{tabular}

\footnotetext{
XII Product specification manual

${ }^{\mathrm{XIV}}$ Estimated usage: 4 hours a week, $0.8 \mathrm{kWh} /$ hour, Retrieved from:

http://www.dgbmt.de/PI_en_Alt/Infodesk_Service/Consumer_Information/Measuring_Energy_Consumption_of _kitchen_ovens.htm

${ }^{\mathrm{xv}}$ Estimated usage: 1 hour/day, $0.7 \mathrm{kWh} / \mathrm{h}$

${ }^{x v I}$ Retrieved from: http://oee.nrcan.gc.ca/Publications/infosource/Pub/appliances/2007/pdf/07-ClothesDryers.pdf

${ }^{\mathrm{x} I I} \mathrm{NH}$ stands for North House
} 


\begin{tabular}{|c|c|c|}
\hline Energy/year & $\mathrm{kWh} / \mathrm{y}$ & $129.0^{x \mathrm{~V} I 11}$ \\
\hline Energy/week & $\mathrm{kWh} / \mathrm{w}$ & 2.5 \\
\hline Sensible energy multiplier & & 0.8 \\
\hline Latent energy multiplier & & 0.0 \\
\hline \# of cycle in quoted energy consumption & cycles/year & 392.0 \\
\hline Estimated actual number of cycles(NH) & cycles/year & 156.0 \\
\hline Estimated energy per year(NH) & $\mathrm{kWh} / \mathrm{y}$ & 51.3 \\
\hline Estimated energy per week(NH) & $k W h / w$ & 1.0 \\
\hline \multicolumn{3}{|c|}{ Flat screen TV } \\
\hline \multicolumn{3}{|l|}{ Samsung LN-R3228W 32" } \\
\hline Energy/year & $\mathrm{kWh} / \mathrm{y}$ & 127.8 \\
\hline Energy/week & $k W h / w$ & 2.5 \\
\hline Sensible energy multiplier & & 1.0 \\
\hline Latent energy multiplier & & 0.0 \\
\hline \multicolumn{3}{|c|}{ Desktop computer } \\
\hline \multicolumn{3}{|c|}{ Assume average draw of $70 \mathrm{~W}$ with LCD display } \\
\hline Energy/year & $\mathrm{kWh} / \mathrm{y}$ & 76.4 \\
\hline Energy/week & $k W h / w$ & 1.5 \\
\hline Sensible energy multiplier & & 1.0 \\
\hline Latent energy multiplier & & 0.0 \\
\hline \multicolumn{3}{|c|}{ Misc. plug loads } \\
\hline \multicolumn{3}{|l|}{ Assume average load of $25 \mathrm{~W}$} \\
\hline Energy/year & $\mathrm{kWh} / \mathrm{y}$ & 281.4 \\
\hline Energy/week & $k W h / w$ & 4.2 \\
\hline
\end{tabular}

The energy consumption of the major appliances utilized in the North House and the SUI House projects are compared to a typical home's appliances assumed by CMHC standards (NRCan, 2005). The results are provided in Tables 1 and 2 in Appendix A. The energy consumption by appliances, excluding the miscellaneous appliances, was reduced by $57 \%$ and $45 \%$ for the case of the North House and the SUI house respectively.

\subsubsection{Schedules}

Internal gain and ventilation schedules were created to approximate the occupancy of the house. Different internal gain schedules were constructed for weekdays and weekends to account for appliance use such as clothes washer, clothes dryer and oven. The ventilation

\footnotetext{
XVw Retrieved from: http://oee.nrcan.gc.ca/Publications/infosource/Pub/appliances/2007/pdf/06_ClothesWashers.pdf
} 
schedule included, in addition to the minimum ventilation requirements, a bathroom exhaust fan and a range hood fan that provided additional ventilation during certain hours in the day.

\subsubsection{Lighting Design}

The general strategy for the artificial lighting of North House was to achieve maximum integration with the architecture so that the lighting fixtures become invisible when not in use. North House as designed so that little or no artificial lighting is required during daylight hours: the ample glass on the three perimeter walls of the living space, combined with the dynamic shading system allowed for ample day-lighting; the window at the shower on the north side provided ambient light in the densepack service zone. Artificial lighting was used to complement daylight when necessary and used a combination of energy efficient fluorescent and LED lighting to maximize amenity, comfort, and appropriate colour rendering and minimize energy use.

The main living space provided a combination of ambient and task lighting. Ambient lighting was provided by a flexible framework of fluorescent lights located behind a custom-designed diffusing soffit, allowing for easy reconfiguration and response to the variable interior arrangements. Specific task lights dropped below the soffit to illuminate work surfaces; the kitchen counter, for example, was illuminated by a combination of pendant LED task lights which hung below the soffit and LED lighting integrated behind translucent Corian panels installed along the length of the counter. A custom sculptural diffuser was suspended from the living room ceiling and masked the presence of an array of remote phosphor LED downlights and sensors and included lenses that provided decorative and ambient effects above the dining area. The remote phosphor technology of the living space fixtures had a fixture efficiency of over 50 lumens per watt compared to compact fluorescent efficacies of 36 lumens per watt. Task lighting in the living area was provided by a work lamp that can be stored in the mobile workstation. For bedtime reading, a portable LED reading lamp could be clipped on to the bed's suspension cables, which also carry a low voltage current.

In the densepack service zone, the majority of the electric lighting was provided by T5 fluorescent tubes concealed in continuous coves within the dropped wood ceiling. In the bathroom, a high-CRI linear fluorescent source was integrated seamlessly into bathroom mirror.

All of the interior lights were controlled with zone controls and user profiles developed 
through the Central Home Automation Server (CHAS).

As a general sustainability strategy, the team tried to minimize the impact of manufacturing by using fewer fixtures, and by buying locally manufactured products. The lighting choices for North House included careful consideration of life cycle costing and safe disposal. For example, all fluorescent sources use mercury. The Philips T5 lamp selection has the lowest rated level of mercury at $1.5 \mathrm{gm}$ and with a 40,000 hour plus lamp life this light source could match the life of the home.

\subsubsection{Distributed Photovoltaic System}

\subsubsection{Initial Solar Resource Assessment}

Many different PV array configurations were studied to evaluate the different design configurations:

1. The first scenario consisted of a horizontal roof covered in photovoltaics and a 5-foot high band at the top of the east, west and south facades.

2. The second case represented a roof covered in photovoltaics but tilted 12 degrees towards the south (maximum tilt to stay within solar envelope) with PV installed on the east and west facades where possible.

3. The third case represented an area, the size of the roof, tracking the sun in two axes.

4. The last scenario was the same as the second case, but for a greater slope of the roof (39 degrees).

According to the analysis conducted by engineering team (North House project Manual, June 2,2009 ), the largest production would be achieved by utilizing the last option. The third case had the second largest PV production followed by the first scenario. The second had the least electricity generation. On the other hand, the third scenario would be difficult to produce due to the size of the roof, and would not fit within the solar envelope. Also, if the two-axis tracking was constrained within the solar envelope, it was found that there would be no gain in electricity generation compared to a static roof with vertical sides. Moreover, third and fourth cases could not be used during competition because of the competition rules and regulations (Appendix D) but were good for comparison purposes.

The concept of a "partial tracking" (repositioning) system as seen in Figure 3 was evaluated. The array in this concept was split in four sections and stayed within the solar envelope at all 
time. In the morning, the two sections on the west side of the house would tilt towards the east. At around midday, the two sections on the north side would tilt towards the south. Finally, in the evening, the two sections on the east side of the house would tilt west. This was an interesting concept but it was proven by design team, to result in almost the exact same power production as a fixed tilted roof at 11.5 degrees.

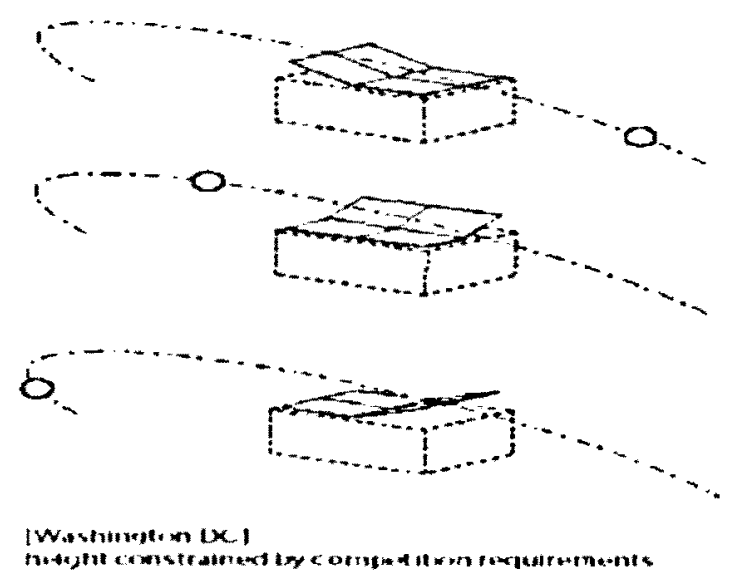

Figure 12: Repositioning system

From the analyses, it was found that the single most important variable for PV energy production is the total PV area. Based on these findings, the following PV layout was chosen.

\subsubsection{Final PV Configuration}

Integrating PVs into every surface on the building resulted in using the surface area on the building as an active energy producer, as well as avoiding some of the complexities of solar tracking which plagued many large PV installations in the past, particularly in cold climates. In addition, the precise orientation of the house and its solar exposure would become less of a problem since PV panels were mounted on a large area on the building at different orientations.

A large array of typical photovoltaic (PV) panels was located on the flat roof. The rest of North House's electrical power production came from building integrated photovoltaic (BIPV) panels located on the south, east, and west façades, which operated when the sun was at a low angle. The combination of both horizontally- and vertically-mounted PV allowed North House to make use of its surface area to collect solar energy without re-orientating itself. 


\subsubsection{Simulation models and results}

The modeling of the photovoltaics was initially done in TRNSYS by the engineering team. All facade PVs were assumed to be Day 4 Energy 36MC panels.

In this configuration, the roof contained 56 panels divided into 4 strings of 14 panels, of which two inverters handled two strings each. The east- and west- facades each contain 13 panels each attached in series. Only one inverter was needed for these two strings as only one side of the house faces the sun at any given time. The south-façade contained 8 panels in series. The model assumed no losses in the lines or the inverters. These losses should be fairly small (between 5-10\%).

As shown in table 5, the total PV output for during the competition (10 days) was estimated to be $197 \mathrm{kWh}$. Table 6 shows the energy production for the competition period. Since Washington, DC weather data is not included in the TRNSYS library, the weather data for Baltimore was used.

Table 5: PV energy production for the first week of October (Baltimore)

\begin{tabular}{|c|c|c|c|c|}
\cline { 2 - 5 } \multicolumn{1}{c|}{} & \multicolumn{4}{c|}{ Energy Production per week (kWh) } \\
\cline { 2 - 5 } & Roof & East-West & South & Total \\
\hline First week of October & 125.9 & 48.7 & 22.8 & 197.4 \\
\hline
\end{tabular}


Table 6: Annual PV energy production (Toronto)

\begin{tabular}{|c|c|c|c|c|c|c|c|c|c|}
\hline \multirow{4}{*}{ Month } & \multicolumn{2}{|c|}{ Roof (8.28kW) } & \multicolumn{2}{c|}{ East (1.83 $\mathrm{kW})$} & \multicolumn{2}{c|}{ West (1.83 kW) } & \multicolumn{2}{c|}{ South (1.18 kW) } & Total \\
\cline { 2 - 8 } & $\begin{array}{c}\text { Peak sun } \\
\text { hours } \\
\left(\mathrm{kW} / \mathrm{m}^{2} / \text { day }\right)\end{array}$ & $\begin{array}{c}\text { AC } \\
\text { energy } \\
(\mathrm{kWh})\end{array}$ & $\begin{array}{c}\text { Peak sun } \\
\text { hours } \\
\left(\mathrm{kW} / \mathrm{m}^{2} / \text { day }\right)\end{array}$ & $\begin{array}{c}\text { AC } \\
\text { energy } \\
(\mathrm{kWh})\end{array}$ & $\begin{array}{c}\text { Peak sun } \\
\text { hours } \\
\left(\mathrm{kW} / \mathrm{m}^{2} / \text { day }\right)\end{array}$ & $\begin{array}{c}\text { AC } \\
\text { energy } \\
(\mathrm{kWh})\end{array}$ & $\begin{array}{c}\text { Peak sun } \\
\text { hours } \\
\left(\mathrm{kW} / \mathrm{m}^{2} / \text { day }\right)\end{array}$ & $\begin{array}{c}\text { AC } \\
\text { energy } \\
(\mathrm{kWh})\end{array}$ & $\begin{array}{c}\text { Energy } \\
(\mathrm{kWh})\end{array}$ \\
\hline January & 1.47 & 262 & 1.1 & 42 & 1.18 & 45 & 2.7 & 79 & 428 \\
February & 2.27 & 395 & 1.58 & 58 & 1.76 & 66 & 3.18 & 84 & 603 \\
March & 3.19 & 627 & 2.13 & 87 & 1.78 & 70 & 2.89 & 79 & 863 \\
April & 4.36 & 811 & 2.54 & 97 & 2.41 & 92 & 2.83 & 70 & 1070 \\
May & 5.6 & 1052 & 3.5 & 141 & 2.69 & 103 & 2.67 & 62 & 1358 \\
June & 6.14 & 1075 & 3.4 & 126 & 3.16 & 115 & 2.55 & 53 & 1369 \\
July & 6.02 & 1062 & 3.42 & 127 & 3.07 & 112 & 2.6 & 54 & 1355 \\
August & 5.15 & 907 & 3.05 & 113 & 2.84 & 105 & 2.96 & 68 & 1193 \\
September & 4.08 & 714 & 2.69 & 98 & 2.34 & 83 & 3.46 & 84 & 979 \\
October & 2.55 & 464 & 1.61 & 60 & 1.64 & 61 & 2.97 & 81 & 666 \\
November & 1.3 & 204 & 0.74 & 20 & 0.81 & 23 & 1.73 & 43 & 290 \\
December & 1.07 & 178 & 0.7 & 22 & 0.69 & 20 & 1.93 & 56 & 276 \\
\hline Ave/month & 3.61 & 646 & 2.21 & 82.7 & 2.03 & 74.8 & 2.7 & 67.8 & 870.8 \\
\hline Total & - & 7752 & - & 993 & - & 897 & - & 813 & 10450 \\
\hline
\end{tabular}

These results were modified based on selection of Schuco PV panels. Solar electric power was generated with four arrays: one on the roof (Day4 panels), and one each on the east, south and west facades (Schuco panels) of the building. Five Xantrex inverters were used to convert the $\mathrm{DC}$ power into grid quality $\mathrm{AC}$ power. The rooftop arrays were the main power producers and the facade arrays allowed for a more even energy production over the course of the day and year. The model was representative of typical output for the city of Toronto, where the house will be permanently located.

Solar power generation from each individual inverter was available via the Xantrex display unit. Total power generation and cumulative energy production were monitored with the power logic branch circuit power meter. The Branch Circuit Power Meter (BCPM) allowed for the measurement of power and energy readings for the grid connection, solar feed, and each breaker circuit in the main electrical panel. The data were collected by the CHAS and logically grouped for feedback to the user and historical analysis.

The entire PV array and BIPV was expected to produce approximately $10,940 \mathrm{kWh}$ annually. All of the power produced by this array was converted into grid quality power by inverters and fed directly into the electrical grid. An estimated $10 \%$ of the energy would be lost in the 
winter if the snow was allowed to accumulate on the roof array. Table 7 shows the data from the simulation, and Figure 13 illustrates the data graphically.

Table 7: PV energy production for Toronto when Shuco panels were utilized

\begin{tabular}{|c|c|c|c|c|c|c|c|c|c|}
\hline \multirow[b]{2}{*}{ Month } & \multicolumn{2}{|c|}{ Roof $(8.28 \mathrm{~kW})$} & \multicolumn{2}{|c|}{ East $(2.21 \mathrm{~kW})$} & \multicolumn{2}{|c|}{ West (2.21 kW) } & \multicolumn{2}{|c|}{ South (1.45 kW) } & \multirow{2}{*}{$\begin{array}{l}\text { Total } \\
\text { energy } \\
\text { (kWh) }\end{array}$} \\
\hline & $\begin{array}{c}\text { Peak sun } \\
\text { hours } \\
\text { (kW/m2/day) }\end{array}$ & $\begin{array}{c}A C \\
\text { energy } \\
(\mathrm{kWh})\end{array}$ & $\begin{array}{c}\text { Peak sun } \\
\text { hours } \\
\text { (kW/m2/day) }\end{array}$ & $\begin{array}{c}A C \\
\text { energy } \\
\text { (kWh) }\end{array}$ & $\begin{array}{c}\text { Peak sun } \\
\text { hours } \\
\text { (kW/m2/day) }\end{array}$ & $\begin{array}{c}\text { AC } \\
\text { Energy } \\
(\mathrm{kWh})\end{array}$ & $\begin{array}{c}\text { Peak sun } \\
\text { hours } \\
\text { (kW/m2/day) }\end{array}$ & $\begin{array}{c}\text { AC } \\
\text { energy } \\
\text { (kWh) }\end{array}$ & \\
\hline January & 1.47 & 262 & 1.1 & 49 & 1.18 & 52 & 2.7 & 98 & 428 \\
\hline February & 2.27 & 395 & 1.58 & 68 & 1.76 & 77 & 3.18 & 103 & 643 \\
\hline March & 3.19 & 627 & 2.13 & 100 & 1.78 & 81 & 2.89 & 98 & 906 \\
\hline April & 4.36 & 811 & 2.54 & 112 & 2.41 & 106 & 2.83 & 86 & 1115 \\
\hline May & 5.6 & 1052 & 3.5 & 164 & 2.69 & 120 & 2.67 & 77 & 1413 \\
\hline June & 6.14 & 1075 & 3.4 & 146 & 3.16 & 133 & 2.55 & 65 & 1419 \\
\hline July & 6.02 & 1062 & 3.42 & 147 & 3.07 & 129 & 2.6 & 67 & 1405 \\
\hline August & 5.15 & 907 & 3.05 & 131 & 2.84 & 121 & 2.96 & 84 & 1243 \\
\hline September & 4.08 & 714 & 2.69 & 114 & 2.34 & 96 & 3.46 & 103 & 1027 \\
\hline October & 2.55 & 464 & 1.61 & 69 & 1.64 & 71 & 2.97 & 100 & 704 \\
\hline November & 1.3 & 204 & 0.74 & 23 & 0.81 & 27 & 1.73 & 54 & 308 \\
\hline December & 1.07 & 178 & 0.7 & 25 & 0.69 & 24 & 1.93 & 69 & 296 \\
\hline Ave/month & 3.61 & 646 & 2.21 & 96 & 2.03 & 86 & 2.7 & 84 & 912 \\
\hline Total & - & 7751 & - & 1148 & - & 1037 & - & 1004 & 10940 \\
\hline
\end{tabular}

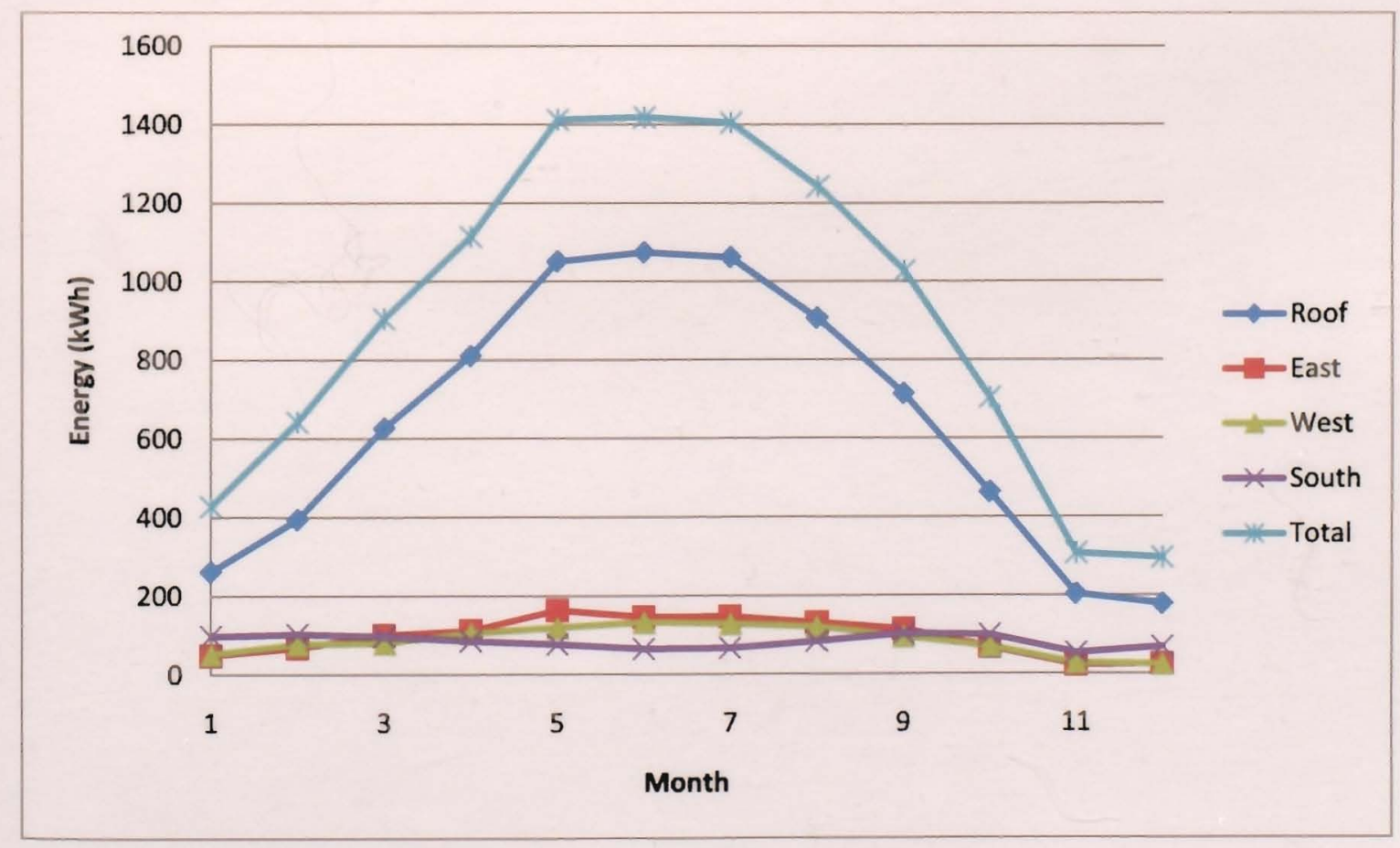

Figure 13: Annual PV energy production for Toronto 
Figure 13 shows the expected useful energy produced by the photovoltaic arrays. Ignoring any losses between the PV array and the grid, and any disruptions in production due to shading or snow cover, all of the electricity generated is considered useful.

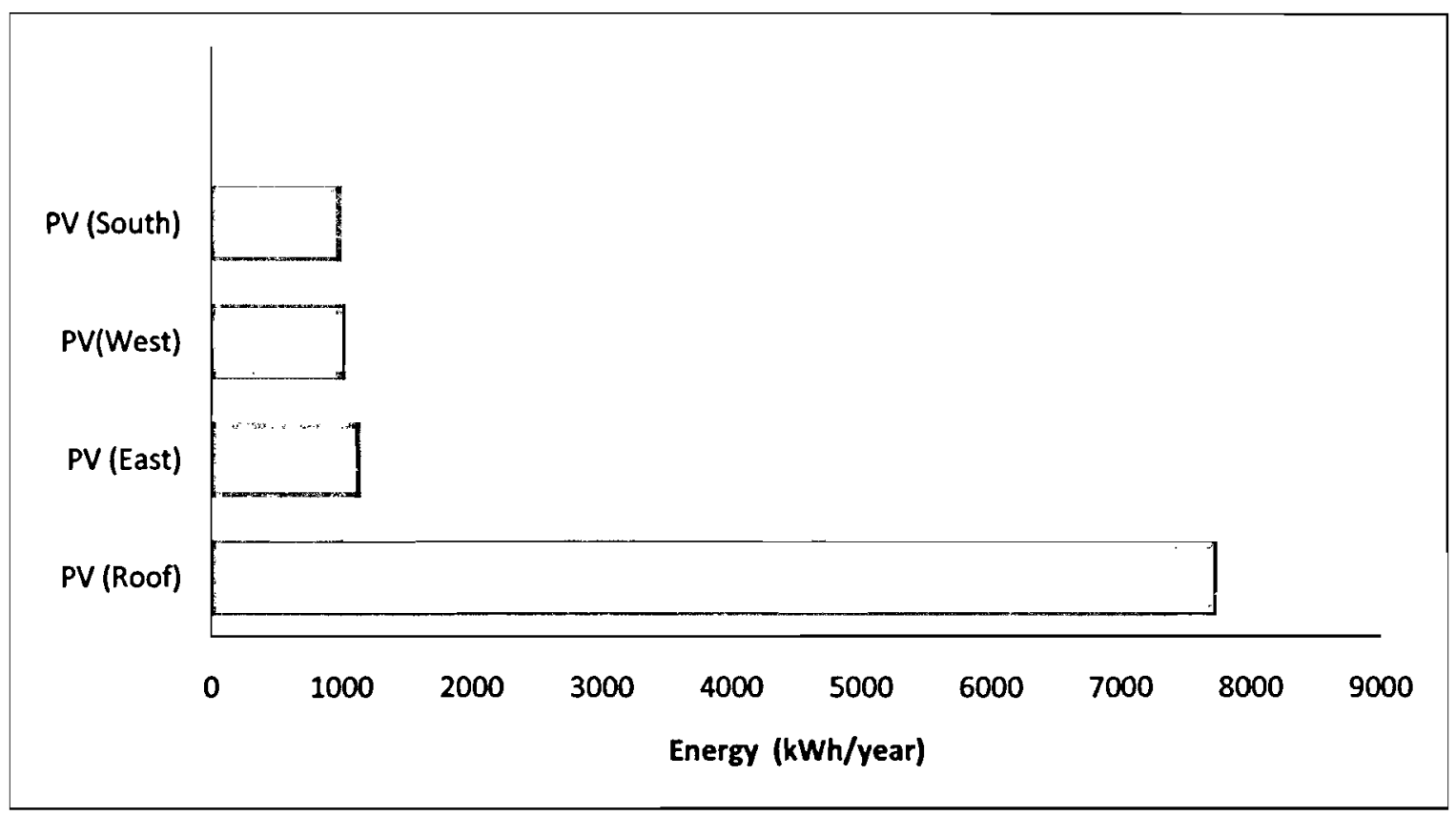

Figure 14: PV energy production on each facade (Toronto)

As illustrated in Figure 14, PV array on the roof acted as the primary electrical producer and produced approximately $71 \%$ of the house's electrical production. 


\section{Chapter 3}

\section{Design Process of the HVAC System}

\subsection{Preliminary design of the North House HVAC system}

The Heating, Ventilation and Air Conditioning (HVAC) is a system where multiple mechanical components are linked together to form an overall system. The system provides desired comfort and an ideal indoor environment. An integrated HVAC system incorporating a heat pump, radiant panels, infloor heating and solar Domestic Hot Water (DHW) was initially designed for the Solar Decathlon house. Figure 15 provides a complete schematic illustrating the interconnection between the various components. A brief description of the system components is also provided in the following section.

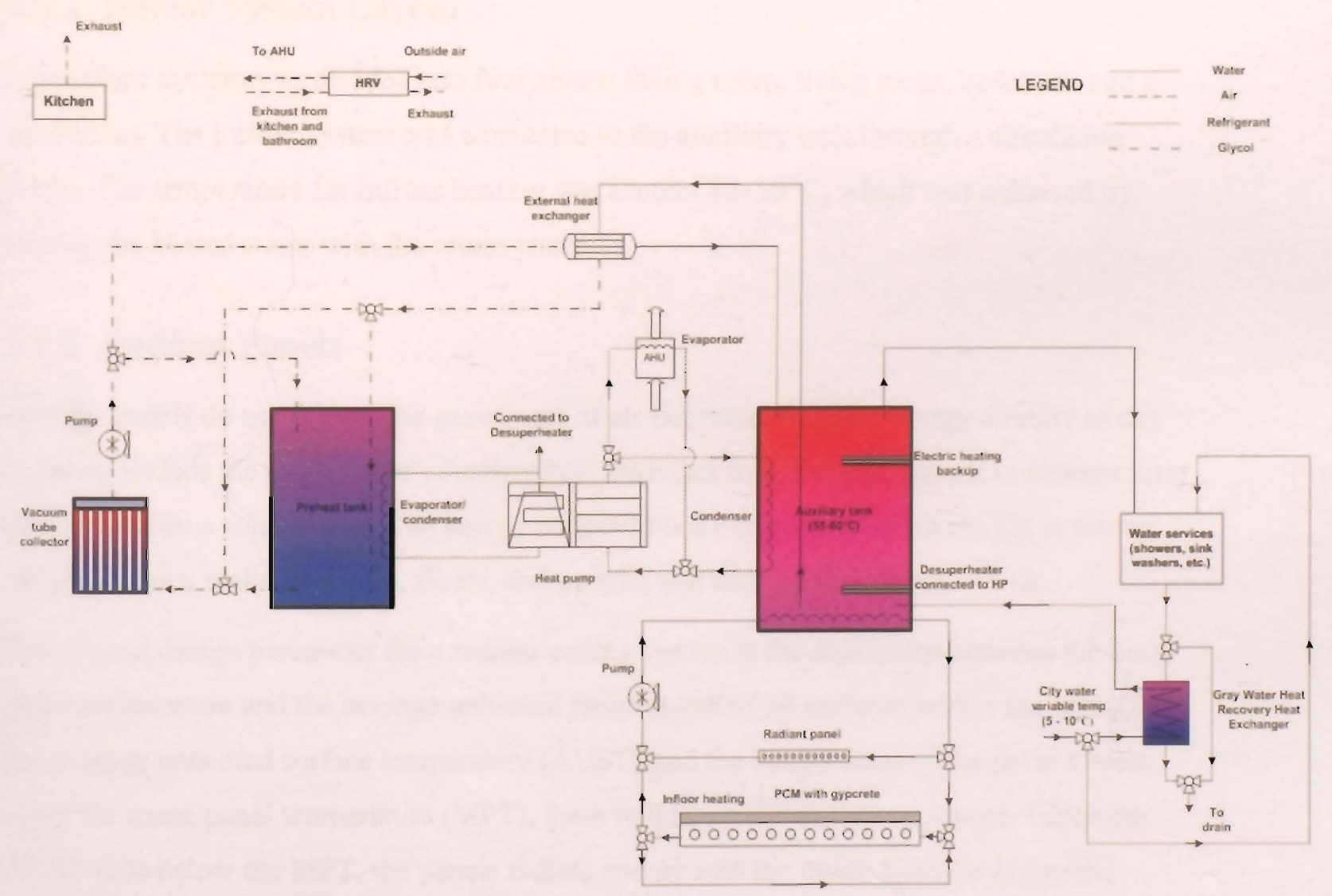

Figure 15: The overall HVAC system: option 1 


\subsubsection{Domestic Hot Water System (DHW)}

The system consisted of vacuum tube solar collectors, a circulation pump, an external heat exchanger, an $800 \mathrm{~L}$ pre-heat tank, and a $300 \mathrm{~L}$ auxiliary tank. The pre-heat tank was directly heated by the solar collector through the glycol loop. The auxiliary tank was utilized for space heating and water heating purposes. It could be charged either by the solar collector using the external heat exchanger when the solar energy was available or by the heat pump when the solar gain was not sufficient. The water temperature in the auxiliary tank (AUT) had to be maintained around $55-60^{\circ} \mathrm{C}$. In case the temperature in AUT dropped below $55^{\circ} \mathrm{C}$, an electric heater located inside the AUT was activated to charge the tank. From the auxiliary tank, the hot water passed through a mixer, where it was mixed with the cold city water for the water services.

The infloor heating loop and radiant panels were also connected to the AUT for space heating purposes.

\subsubsection{Infloor System Layout}

The infloor system was divided into four zones: dining room, living room, bedroom, and a washroom. The infloor system was connected to the auxiliary tank through a circulation pump. The temperature for infloor heating was around $30-35^{\circ} \mathrm{C}$, which was achieved by mixing the heated water with the return water.

\subsubsection{Radiant Panels}

Radiant panels do not rely on the movement of air but rather transfer energy directly to any building surface the panel "sees". Radiant heat, like that from the sun, travels in straight lines until it reaches a solid object. The energy radiated does not initially warm the air, it warms the glass areas, walls, furniture, floors, and people, and they, in turn, warm the air.

The critical design parameter for a radiant ceiling system is the difference between the mean panel temperature and the average unheated temperature of all surfaces within the space. If the average unheated surface temperature (AUST) and the temperature of the air in a room equal the mean panel temperature (MPT), there will be no net energy exchange. When the AUST falls below the MPT, the panels radiate energy into the room. For this design the panels could be heated up to $60^{\circ} \mathrm{C}$. 


\subsubsection{Heat Pump}

A variety of options were considered for the selection of the heat pump for the house. The critical factor in the selection of an appropriate heat pump was the capacity of the unit. Generally, the vast majority of the heat pump systems manufactured is designed to support moderate to large heating/cooling loads typical for a single family home. However, the north house was a small house with a highly insulated building envelope, so the cooling/heating loads were minimal when compared to an average house. This led to the idea of designing and developing a custom-built heat exchanger.

\subsubsection{Grey Water Heat Recovery System (GWHR)}

A grey water heat recovery unit manufactured by GFX was utilized. The grey water heat recovery system used drain water from the house's water services to preheat city water going into the auxiliary tank. One of the complications introduced through the use of GWHR was the configuration of it. Since the system was vertically mounted, height restrictions of the plumbing fixtures in the competition were a critical factor. In order to resolve the problem, a horizontally mounted unit was considered but a reduction in efficiency and plumbing complexities would have been a challenge.

\subsubsection{Heat Recovery Ventilation System (HRV)}

The exhaust air collected from the kitchen and bathroom exchanged the heat with the fresh air through a Heat Recovery Ventilation unit (HRV). Extra exhaust was released from the kitchen exhaust. In addition to the HRV, a basic ERV (Energy Recovery Ventilator) system could have been considered. An ERV system can recover both sensible and latent heat and it may be beneficial in certain applications and climates (e.g. air conditioned house with hot and humid outside air), but the fan power is usually higher than that of HRV and the sensible heat recovery efficiency is generally also lower than that of HRV.

\subsubsection{Air-Handling Unit (AHU)}

The indoor air was circulated through the Air Handling Unit (AHU) and distributed to the living room and bedroom through the diffusers. The AHU was composed of the evaporator, filter and a fan. The fresh air passing through the Heat Recovery Ventilator (HRV) was sent to air handling unit (AHU) and then was delivered to the house. 


\subsubsection{Option 1 System Analysis}

The operation of the system and heating and cooling modes were investigated under a variety of different conditions. In all the heating/cooling scenarios, energy recovered from the exhaust air and the ventilation was achieved from the HRV system. The exhaust was collected from the kitchen and bathroom.

There were several parameters that made the design not suitable for the competition. The system complexity was the major issue. In order to simplify the HVAC system, another system configuration was proposed.

\subsection{Alternate Design}

In the new layout the infloor heating was located in the bathroom and changing room. The radiant panel heating was completely eliminated. Thus, a cooling pond was added in order to meet the house cooling requirement. Figure 16 illustrates the second option.

\section{Overall System}
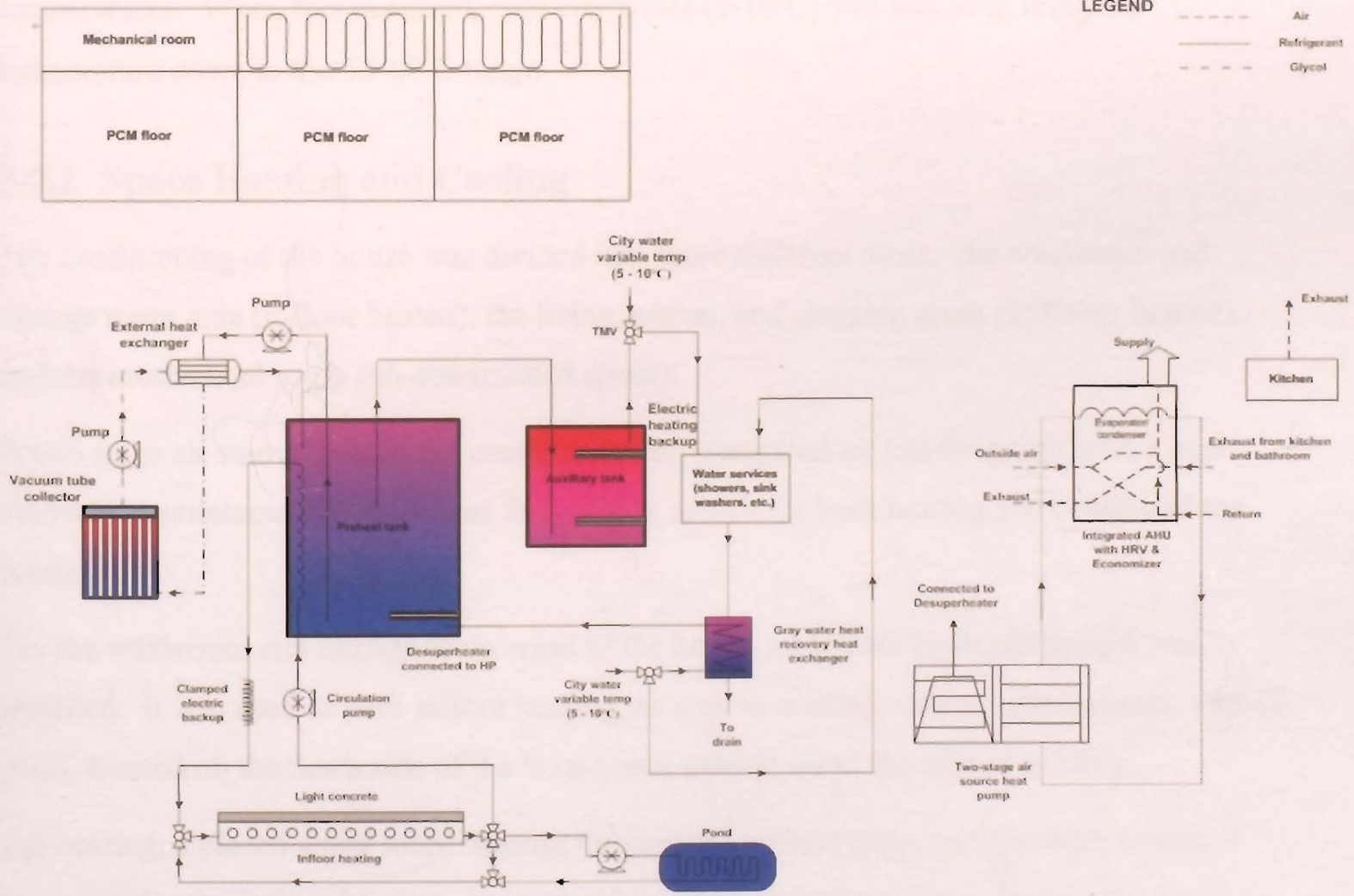

Figure 16: HVAC system: option 2 
In order to break down the description of the overall system, the mechanical systems are discussed in terms of domestic hot water heating, and space heating and cooling.

\subsubsection{Domestic Hot Water (DHW) Heating}

Two tanks were used for DHW heating. A stratified preheat tank was used for space heating as well as DHW heating purposes, and an auxiliary tank was used to provide DHW between $55-60^{\circ} \mathrm{C}$.

Water in the preheat tank was heated in multiple ways: solar thermal collectors, a desuperheater, and grey water heat recovery system. Primarily, an array of solar thermal collector was used to provide heat to preheat tank. A glycol loop was fed through solar thermal collectors and then transferred heat through an external heat exchanger to cooler water drawn from the bottom of the preheat tank. If the solar gain was not available to the thermal collectors, a desuperheater connected to a two stage air-source heat pump was activated to provide additional heat.

During the summer, the hot water coming from the preheat tank might have high temperatures. When this occurred, cold city water $\left(5-10^{\circ} \mathrm{C}\right)$ was mixed to bring the temperature down to the $55-60^{\circ} \mathrm{C}$ range.

\subsubsection{Space Heating and Cooling}

The conditioning of the house was divided into three different areas: the washroom and change room area (infloor heated), the living, eating, and sleeping areas (force-air heated), and the mechanical room (un-conditioned space).

A two stage air source heat pump connected to an integrated air handling unit with a heat recovery ventilator/economizer was the primary source for both heating and cooling of the house.

For the washroom and change room areas of the house, an infloor hydronic system was installed. It was used as both infloor heating, as well as cooling. During the summer, a small pond, located on the north side of the house, was used to assist the infloor cooling.

For heating, a closed water loop, running through the preheat tank, was the main source of hot water for the infloor heating. In cases where the temperature of the closed loop water 
exiting the preheat tank was not sufficient, additional heating was provided by a clamped electric heating element.

Phase change material (PCM) was incorporated in the floor of the living, eating and sleeping area of the house.

\subsubsection{Description of the Mechanical System for Different Scenarios}

Different scenarios were considered in order to meet the house heating and cooling energy demands. A grey water heat recovery unit was utilized to preheat the city water going into the auxiliary tank for all the hot water production scenarios.

\subsubsection{Cooling Scenario A: Sunny Days}

Hot water system:

- Primary hot water heating: solar thermal collectors

- Secondary hot water heating: desuperheater

- Tertiary hot water heating (electric element): auxiliary tank

Space cooling:

- Primary Space Cooling: Two stage air source heat pump connected to integrated air handling unit (AHU) with heat recovery ventilator (HRV)

- Extra Cooling: When possible, the infloor hydronic system circulated water to the small pond. This only occurred when the temperature of the small pond was lower than the temperature of the water in the infloor hydronic system and if the slab temperature was higher than its ideal temperature.

\subsubsection{Cooling Scenario B: Cloudy Days \& Nights}

Hot water system:

- Primary hot water heating: desuperheater

- Secondary hot water heating (electric element): auxiliary tank

Space cooling: 
- Primary space cooling: Two stages air source heat pump connected to integrated AHU with HRV. For nights that required cooling, if the ambient enthalpy and outdoor relative humidity were less than the indoor enthalpy and indoor relative humidity the economizer functioned and bypassed the HRV.

- Extra cooling: The same condition as scenario A

\subsubsection{Heating Scenario C: Sunny Days}

Hot water system:

- Primary hot water heating: solar thermal collectors

- Secondary hot water heating: desuperheater

- Tertiary hot water heating (electric element): auxiliary tank

Space heating:

- Primary Space heating: Two stage air source heat pump connected to integrated air handling unit (AHU) with heat recovery ventilator (HRV). Infloor hydronic heating with a clamped electric back-up heating coil was the heating source for the washroom \& change room floor areas.

\subsubsection{Heating Scenario D: Cloudy Days, Nights \& Early Mornings}

Hot water system:

- Primary hot water heating: desuperheater

- Secondary hot water heating (electric element): auxiliary tank

Space heating:

- Primary space heating: Two stage air source heat pump connected to integrated air handling unit (AHU) with heat recovery ventilator (HRV). Infloor hydronic heating with a clamped electric back-up heating coil was the heat source for the washroom and change room floor areas.

Studies were performed to investigate the impact of different components on the energy balance of the house. The solar assisted space heating system and utilization of a small pond were modeled in TRNSYS separately for cooling and heating seasons. In order to integrate 
the dynamic shading which had a significant impact on energy balance of the house, the proportional controller was considered. Due to the importance of the shading system on the heating and cooling demand, PID controllers were also investigated. For each analysis, the results were presented for the cities of Toronto and Baltimore, which provided the closest available weather data to Washington, D.C. in TRNSYS.

\subsection{Solar Assisted Space Heating System}

Radiant systems are widely used in residential building applications. However, air based systems are still the more popular option in North America. By analyzing the performance of both air based and radiant heating systems involving solar collectors, radiant floor systems were able to use more of the available solar energy to assist in covering space heating demands (Haddad et al., 2007). The incorporation of solar thermal energy in the CIESOL XIX building reduced the energy consumption of the air-conditioning system and resulted in an annual reduction of 13 tons of $\mathrm{CO}_{2}$ emissions (Rosiek and Battlles, 2009). In their proposed study, real data of an existing building were used to demonstrate the benefits of properly matching the passive and active solar techniques. The designed system was able to provide sufficient energy to supply an absorption machine during the summer and sufficient to cover the whole heating demand (Rosiek and Battlles, 2009).

Several comparisons of different solar collector types and their mounting orientations were considered for the solar-assisted space heating system. The two solar collector types that were studied were flat plate collectors and vacuum tube collectors. Sensitivity analyses were conducted to determine the optimal installation of the solar thermal system to maximize the solar thermal capture/utilization so as to reduce the overall space heating energy consumption of the house. The fluctuation of consumption for an electric heating element, as auxiliary heating, was analyzed according to the size of tanks, as well as according to the variation of the flow rate and the position of the auxiliary electrical backup heater in the tanks.

\footnotetext{
${ }^{x I X}$ CIESOL (CENTER DE INVESTIGACION DE LA ENERGIA SOLAR)

Center of Investigation of the Solar Energy, University of Almeria, Spain
} 


\subsubsection{Description of the System}

The mechanical system was described by separating it into three different loops: the energy acquisition loop, the heat exchanger loop, and the domestic hot water loop.

The first loop was the energy absorbing and collecting loop. It was made up of an array of solar collectors of $9 \mathrm{~m}^{2}$ total surface area associated with a heat exchanger and with a preheat tank of $750 \mathrm{~L}$ of storage capacity. The second loop was made up of a heat exchanger inside the preheat tank connected to infloor radiant loops. In order to study the effect of the infloor heating system more precisely, infloor heating was modeled for all the zones in the house, including washroom and change room. Also a one-ton air source heat pump (ASHP) acted as the main back-up heating for this system.

The third loop was used for the production of hot water. It was made up of an auxiliary tank of $300 \mathrm{~L}$ equipped with two auxiliary heaters that could provide $2 \mathrm{~kW}$ of heating each. The temperature was maintained at $55^{\circ} \mathrm{C}$ or above to be able to have the possibility of taking three showers of $15 \mathrm{~min}$ length each, consecutively in the morning, as required by the competition's rule. A waste heat recovery heat exchanger was placed at the drain to recover part of the energy back to the inlet city tap water before going into the hot water tank.

In this study the focus was mainly on the first and second loops, but the third loop was simulated as well to allow the model to be more similar to how this system would perform in the competition.

\subsubsection{Simulation Scenarios}

A comparison between flat plate and vacuum tube collectors, and their orientations (vertical, horizontal and 20 degree tilt angle) was reported as the first part of the study. The study of different types of collector (first part of analysis) was based on preheat tank average temperature. For each case three different collector flow rates were considered, 0.3, 0.5 and $0.81 / \mathrm{s}$. The simulation time step was one minute and the simulation was run over one year (8760hr).

For the second part of the study, the main focus was the performance of the vacuum tubes integrated in the overall system. The installation was optimized to reduce the overall energy consumption which was mainly by the heat pump.

For the vacuum tube collector, the simulations were run for: 
- 550,650 and $750 \mathrm{~L}$ water preheat tank

- $0.1 \mathrm{~L} / \mathrm{s}$ and $0.2 \mathrm{~L} / \mathrm{s}$ flow rate

- With/Without infloor system

The installation was optimized to reduce the overall energy consumption which was mainly by the heat pump. The simulation time step was one minute and the simulation was run over one year. Smaller simulation time steps increased the simulation time significantly while there was no additional information provided. On the other hand, the ASHP module did not produce consistent results when the time step was larger than 2.5 minutes. The selected tilt of 10 degrees was to conform to the competition rules regarding the allowed total height of the structure.

The electricity consumption of the heat pump was analyzed while the size of the tanks was changed, as well as when there was a change in flow rate. Two flow rates of 0.1 and $0.2 \mathrm{~L} / \mathrm{s}$ were used in the simulations. These flow rates were determined based on preliminary test runs to find an optimum flow rate range that minimized the pressure drop while yielding good heat transfer coefficient. Also a flow rate of zero was simulated to allow for a comparison of heat pump consumption in the various cases. The zero flow rate to the infloor loop represented the case that there was no infloor heating. Figure 17 shows the layout and the different components of the simulation model created in TRNSYS. 


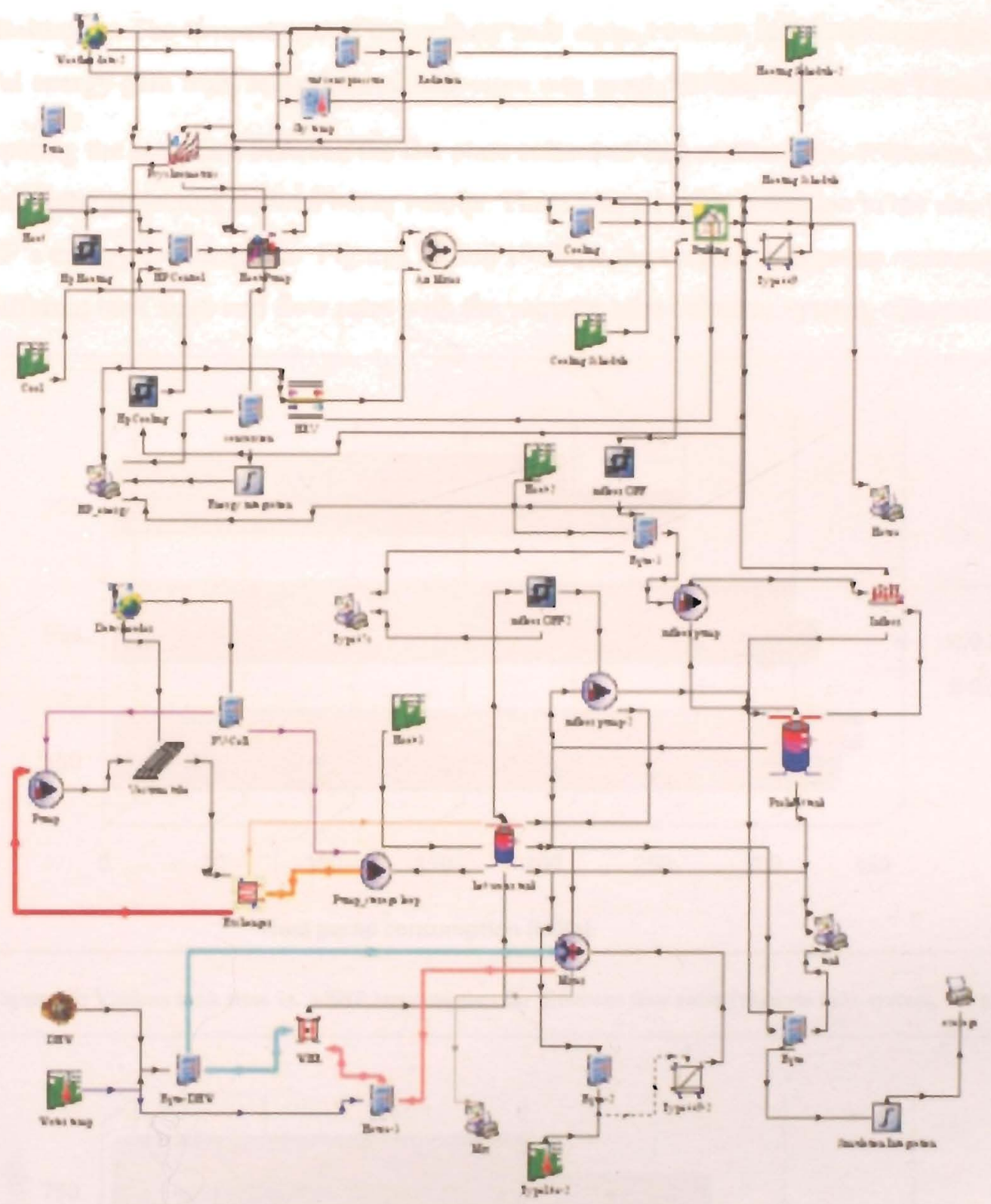

Figure 17: TRNSYS model layout of the proposed system

\subsubsection{Results from Simulation}

The study of different types of collectors, vacuum tube and flat plate, for the city of Toronto, confirmed that utilizing vacuum tubes results in a higher preheat tank temperature leading to a reduction in the heat pump power consumption.

From the analyses of all the scenarios, it was seen that the house temperatures were maintained above the required temperature of $22^{\circ} \mathrm{C}$ for the heating season. This allowed the team to confirm that the annual heating demand was met by all the scenarios for both Toronto 
and Baltimore. The temperature of the preheat tank varies between 20 to $70^{\circ} \mathrm{C}$ over the year. Useful energy gain from solar thermal collectors was around $3700 \mathrm{kWh} /$ year for Toronto.

Comparing the scenarios between the flat plate collectors and vacuum tube collectors, the vacuum tube collectors showed better results. There was a higher reduction in the one-ton ASHP's energy consumption. Figures 18 and 19 show the varying heat pump consumption for different tank sizes and flow rates with the vacuum tube collector system, consecutively.

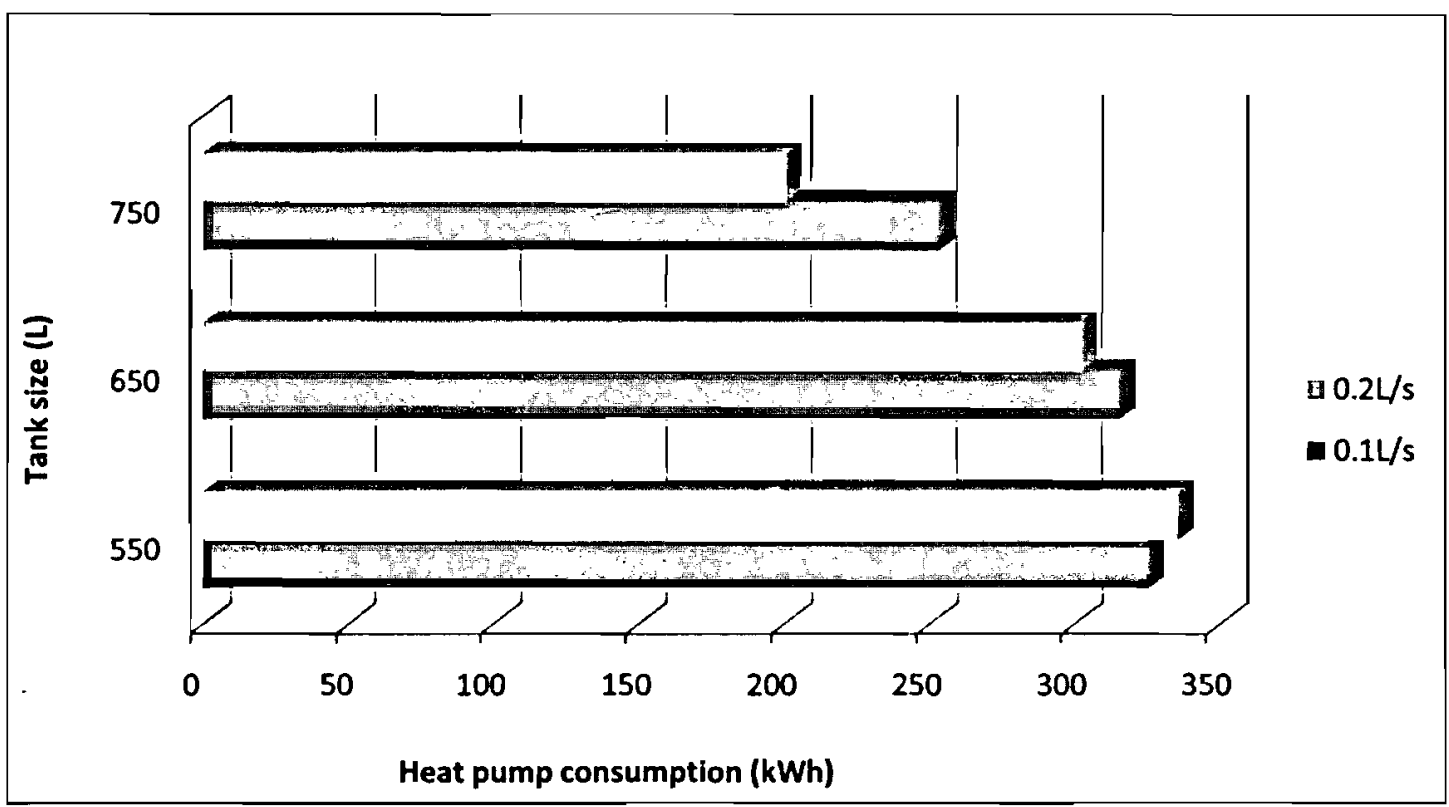

Figure 18: Various tank sizes vs. ASHP consumption for different flow rates (vacuum tube system, Toronto)

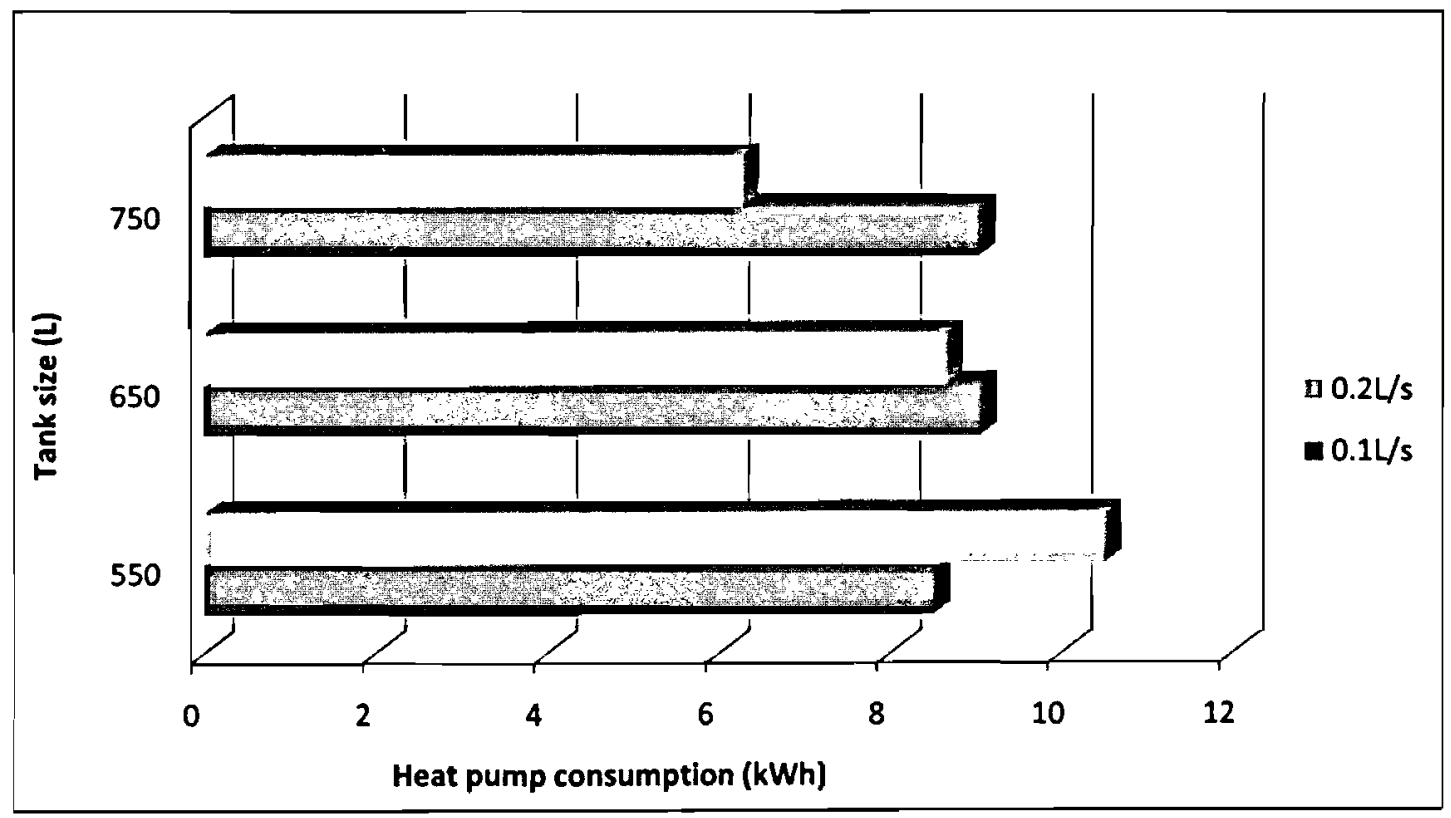

Figure 19: Various tank sizes vs. ASHP consumptions for different flow rates (vacuum tube system, Baltimore) 
From these results, the scenario where the flow rate was at $0.2 \mathrm{~L} / \mathrm{s}$ and the preheat tank size was 750L indicated the lowest energy consumption of the ASHP for both Baltimore and Toronto. It was worth noting that for Baltimore, if the flow rate to the infloor slab was low $(0.1 \mathrm{~L} / \mathrm{s})$, increasing tank size would not decrease consumption, whereas for Toronto, regardless of flow rate, a larger storage tank proved to be better.

Without the infloor heating system, the ASHP consumption increased drastically. The simulations showed that for Baltimore, the infloor heating system was capable of meeting most of the annual heating demand, and in Toronto, the ASHP was required, but consumption of the ASHP was reduced to $8 \%$ of consumption required if only the ASHP was utilized.

Figure 20 indicates that the heat pump consumption increased when vacuum tube system was replaced with the flat plate.

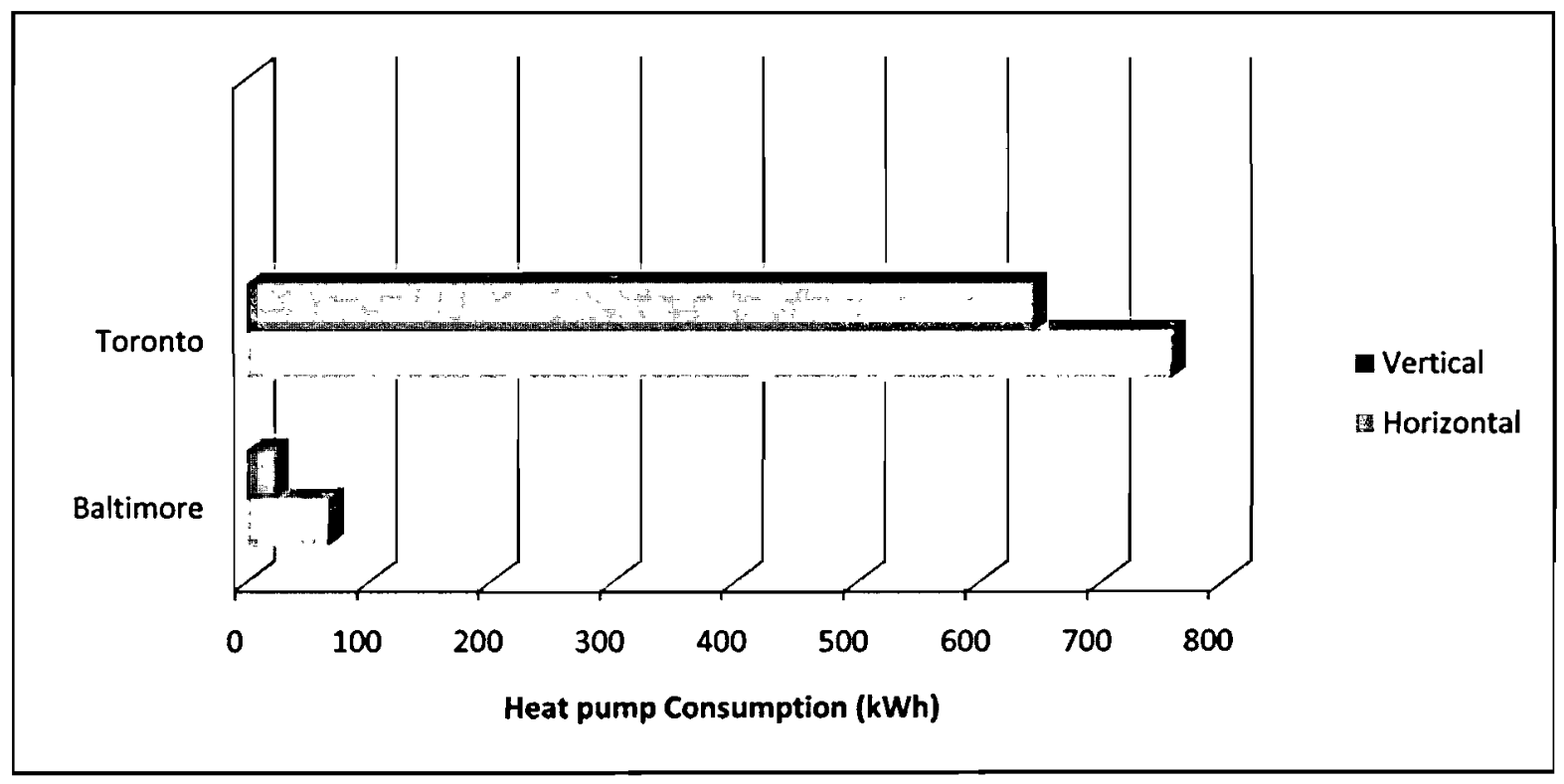

Figure 20: Comparison of the heat pump consumption for different cities when flat plate was utilized

Utilizing Vacuum Tube Collectors (VTC), Tables 8 and 9 show the change in heat pump consumption along with the consumption of the heat pump when the infloor heating was not utilized. 
Table 8: Comparison of HP consumption for different tank sizes and flow rates when VTC was utilized (Toronto)

\begin{tabular}{|c|c|c|c|c|}
\hline \multicolumn{3}{|l|}{ Toronto } & \multirow{2}{*}{$\begin{array}{l}\text { Flow rate into } \\
\text { the infloor loop } \\
(L / s)\end{array}$} & \multirow{2}{*}{$\begin{array}{c}\text { Heat pump } \\
\text { consumption } \\
\text { (kWh) }\end{array}$} \\
\hline Collector & Infloor & $\begin{array}{c}\text { Tank } \\
\text { (ㄴ) }\end{array}$ & & \\
\hline \multirow{7}{*}{$\begin{array}{c}\text { Vacuum tube collector } 9 \mathrm{~m}^{2} \\
\text { Tilt } 10 \text { degree } \\
\text { Orientation: fixed south }\end{array}$} & \multirow{6}{*}{ With } & \multirow{2}{*}{550} & 0.1 & 325.3 \\
\hline & & & 0.2 & 336.0 \\
\hline & & \multirow{2}{*}{650} & 0.1 & 315.8 \\
\hline & & & 0.2 & 302.9 \\
\hline & & \multirow{2}{*}{750} & 0.1 & 253.6 \\
\hline & & & 0.2 & 200.9 \\
\hline & \multicolumn{2}{|c|}{ Without Flow } & - & 2417.6 \\
\hline
\end{tabular}

Table 9: Comparison of HP consumption for different tank sizes and flow rates when VTC was utilized (Baltimore)

\begin{tabular}{|c|c|c|c|c|}
\hline \multicolumn{3}{|l|}{ Baltimore } & \multirow{2}{*}{$\begin{array}{l}\text { Flow rate into } \\
\text { the infloor loop } \\
(\mathrm{L} / \mathrm{s})\end{array}$} & \multirow{2}{*}{$\begin{array}{l}\text { Heat pump } \\
\text { consumption } \\
\text { (kWh) }\end{array}$} \\
\hline Collector & Infloor & $\begin{array}{c}\text { Tank } \\
\text { (L) }\end{array}$ & & \\
\hline \multirow{7}{*}{$\begin{array}{l}\text { Vacuum tube collector } 9 \mathrm{~m}^{2} \\
\qquad \text { Tilt } 10 \text { degree } \\
\text { Orientation: fixed south }\end{array}$} & \multirow{6}{*}{ With } & \multirow{2}{*}{550} & 0.1 & 8.5 \\
\hline & & & 0.2 & 10.5 \\
\hline & & \multirow{2}{*}{650} & 0.1 & 9.1 \\
\hline & & & 0.2 & 8.7 \\
\hline & & \multirow{2}{*}{750} & 0.1 & 9.0 \\
\hline & & & 0.2 & 6.3 \\
\hline & \multicolumn{2}{|c|}{ Without Flow } & - & 1453.0 \\
\hline
\end{tabular}

The calculations demonstrated that with the higher flow rate of $0.2 \mathrm{~L} / \mathrm{s}$, the $750 \mathrm{~L}$ tank was the best choice in terms of heat pump consumption. Although the infloor system met most of the heating demand for Toronto and Baltimore both, the use of a heat pump was still necessary when the weather was at an extreme temperature (cold or hot temperature) or when no solar is available. The heat pump energy consumption for Baltimore was found to be lower than that of Toronto due to the milder climate. 


\subsection{Heat Dump Capacity of the Small Pond}

The cost and energy effectiveness of passive cooling systems are both worth considering by homeowners. These techniques can be utilized in the overall system to reduce, and in some cases eliminate, mechanical air conditioning in areas where cooling is a dominant problem. Early studies for the climate of Shiraz, Iran indicated that utilizing a roof pond can reduce the cooling demand by $79.0 \%$ and $58.1 \%$ for the cases of shaded-pond, and un-shaded pond respectively (Raeissi \& Taheri, 1996). For the climate of Baghdad, Iraq, integrating an evaporative cooling system using a roof pond with the help of a mechanical ventilator for real-life conditions where the ratio of the roof area to exterior walls is reasonably large, the cooling load could be reduced by around $29 \%$ (Kharrufa and Adil, 2008). An alternative study showed that in an actual building the drop in cooling load for a single room is between $28 \%$ and $30 \%$ (Niles, 1976). Studies done in the Delhi climate indicated that the pond in a shade (e.g. by a tree) works better than the shaded-pond (e.g. under the deck) (Spanaki, 2007) (Tang and Etzian, 2004). The reason is that in the first case the pond water exchanges thermal radiation with the sky at night, whereas the shaded pond, which is shaded both in day time and at night, water exchanges heat with the ambient temperature in the shade. The cold sky as a heat sink for radiating bodies was considered as a potential alternative to conventional cooling techniques (Chen et al., 1991). The Cooling Storage Roof (CSR) research agency in Omaha, Nebraska concentrated on maximizing summer radiative and evaporative heat loss from exposed CSR surfaces (Chen et al., 1990). The coupling of the CSR with auxiliary cooling/heating systems could provide additional energy conservation. Combining that with the ground-coupled heat pump could result in load control features in addition to energy conservation advantages (Chen et al., 1990)

\subsubsection{Description of the System}

The analyses were performed assuming the pond orientation to be on the north side of the house. The pond dimensions were defined to be $2.2 \mathrm{~m}$ wide, $0.3 \mathrm{~m}$ deep and a length of $12.3 \mathrm{~m}$ due to the land restriction. The system was described by having one loop made up of an exchanger coil, with the outer diameter of $0.016 \mathrm{~m}$ inside the pond and it was also connected to infloor radiant loops. Sensitivity analyses were conducted to determine the reasonable length of spool, the diameter of the pipe and various flow rates. 


\subsubsection{Simulation Scenarios}

A comparison between various coil diameters and tube lengths were analyzed while different flow rates were taken into consideration. The simulations were run for the cooling season, defined to start from May 1st to October 15th, when the house needed to be cooled down; therefore, the simulation time period was considered to be from $2880 \mathrm{hr}$ to $7032 \mathrm{hr}$. The purpose of the study was to reduce the overall energy consumption by finding the best case. The simulations were done:

- For different coil tube diameters
○ $0.016 \mathrm{~m} \mathrm{OD}, 0.014 \mathrm{~m} \mathrm{ID}$
○ $0.022 \mathrm{~m} \mathrm{OD}, 0.0199 \mathrm{~m} \mathrm{ID}$
○ $0.029 \mathrm{~m} \mathrm{OD}, 0.027 \mathrm{~m} \mathrm{ID}$

- For different tube (spool) lengths
- $5 \mathrm{~m}$
○ $10 \mathrm{~m}$
$\circ 15 \mathrm{~m}$

- For different flow rates
○ $500 \mathrm{~kg} / \mathrm{hr}$
- $1000 \mathrm{~kg} / \mathrm{hr}$
- $2000 \mathrm{~kg} / \mathrm{hr}$
- $2500 \mathrm{~kg} / \mathrm{hr}$

The results for each case were compared with the house with the pond not being integrated in the overall system. The pressure drop in the pipe was calculated per scenario. Furthermore the electricity consumption of the pump located in the pond loop and the heat pump were simulated to allow the comparison of the various cases. Furthermore the electricity consumption of the pump located in the pond loop and the heat pump were simulated to allow the comparison of the various cases. Figure 21 shows the TRNSYS model of the system. 


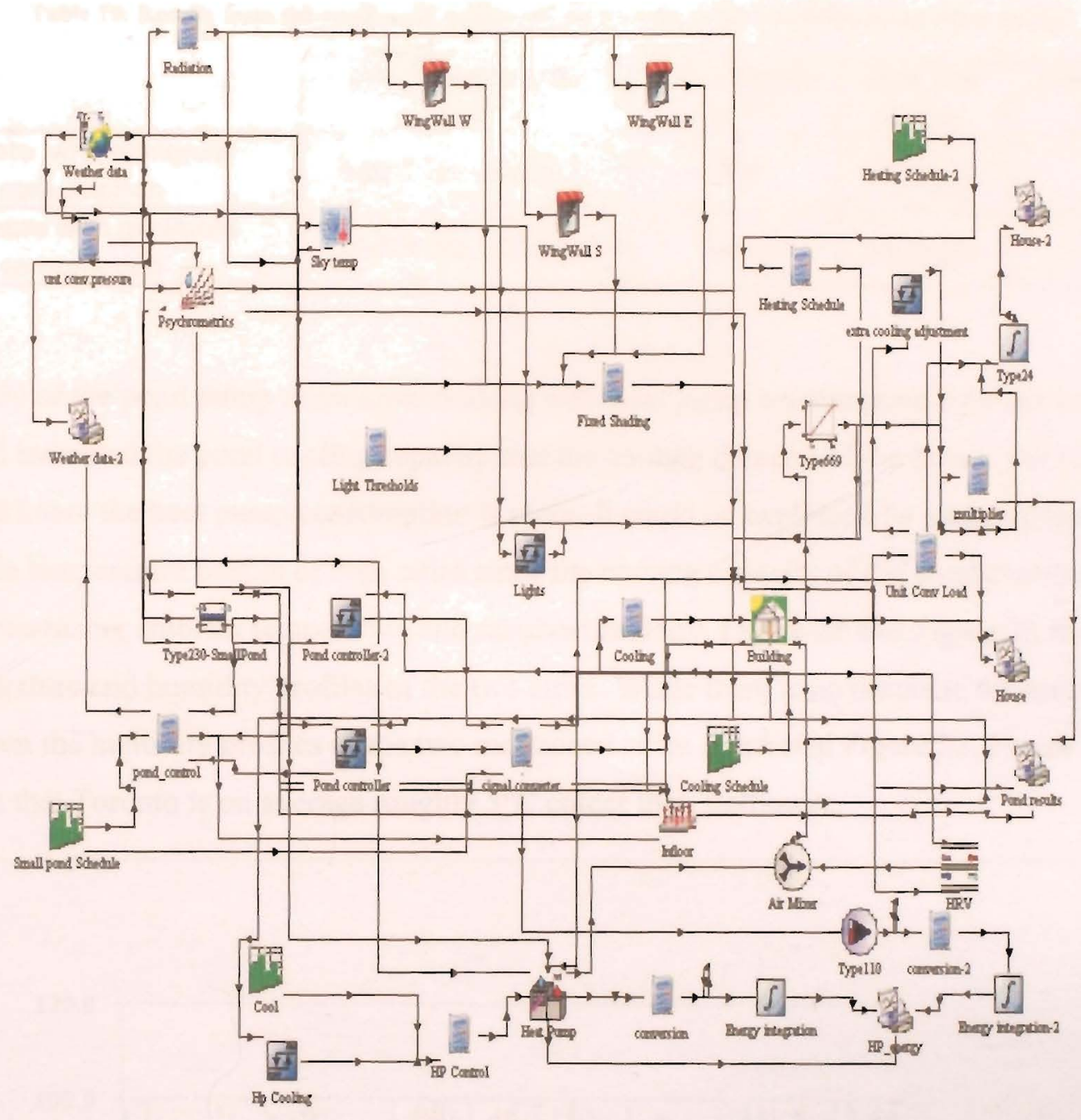

Figure 21: Design layout in TRNSYS simulation studio

\subsubsection{Simulation Results}

From the analyses, it was seen that the lowest pressure drop could be achieved by having the flow rate of $500 \mathrm{~kg} / \mathrm{hr}$ (Tables 3 and 4, Appendix B). The outside coil tube diameter of $0.029 \mathrm{~m}$ and inside of $0.027 \mathrm{~m}$ for the case of Baltimore and $0.022 \mathrm{~m}, 0.0199 \mathrm{~m}$ for Toronto were obtained when having flow rate of $500 \mathrm{~kg} / \mathrm{hr}$. All simulations were done considering that the house temperature was maintained below the required temperature of $24^{\circ} \mathrm{C}$ and above $22^{\circ} \mathrm{C}$. Comparing the scenarios between different tube lengths and diameters resulted in the minimum total pump consumption of $211 \mathrm{kWh}$ for Toronto and $271 \mathrm{kWh}$ for Baltimore as shown in Table 10. 
Table 10: Results from the small pond simulation for the cases with minimum pump consumption

\begin{tabular}{|c|c|c|c|c|}
\cline { 2 - 4 } \multicolumn{1}{c|}{} & $\begin{array}{c}\text { Coil tube diameter } \\
(\mathrm{m})\end{array}$ & $\begin{array}{c}\text { Tube length } \\
(\mathrm{m})\end{array}$ & $\begin{array}{c}\text { Flow rate } \\
(\mathrm{kg} / \mathrm{hr})\end{array}$ & $\begin{array}{c}\text { Pressure drop } \\
(\mathrm{m})\end{array}$ \\
\hline $\begin{array}{c}\text { Toronto with minimum } \\
\text { consumption }\end{array}$ & $0.022 \mathrm{OD}, 0.0199 \mathrm{ID}$ & $15 \mathrm{~m}$ & $500 \mathrm{~kg} / \mathrm{hr}$ & 0.22 \\
\hline $\begin{array}{c}\text { Baltimore with minimum } \\
\text { consumption }\end{array}$ & $0.029 \mathrm{OD}, 0.027 \mathrm{ID}$ & $10 \mathrm{~m}$ & $500 \mathrm{~kg} / \mathrm{hr}$ & 0.033 \\
\hline
\end{tabular}

A study of the pond pump consumption along with heat pump consumption over the cooling period indicated the pond cooling capacity met the cooling demand of the house. For the case of Baltimore the heat pump consumption is more. It could be explained by studying the outside temperature profile of both cities since the cooling capacity of the pond decreases with increasing ambient temperature and relative humidity. Figure 22 and Figure 23 show the temperature and humidity profiles of the two cities. While there is no dramatic difference between the humidity profiles of the two mentioned cities illustrated Figure 22, Figure 23 shows that Toronto is on average roughly $5^{\circ} \mathrm{C}$ colder than Baltimore.

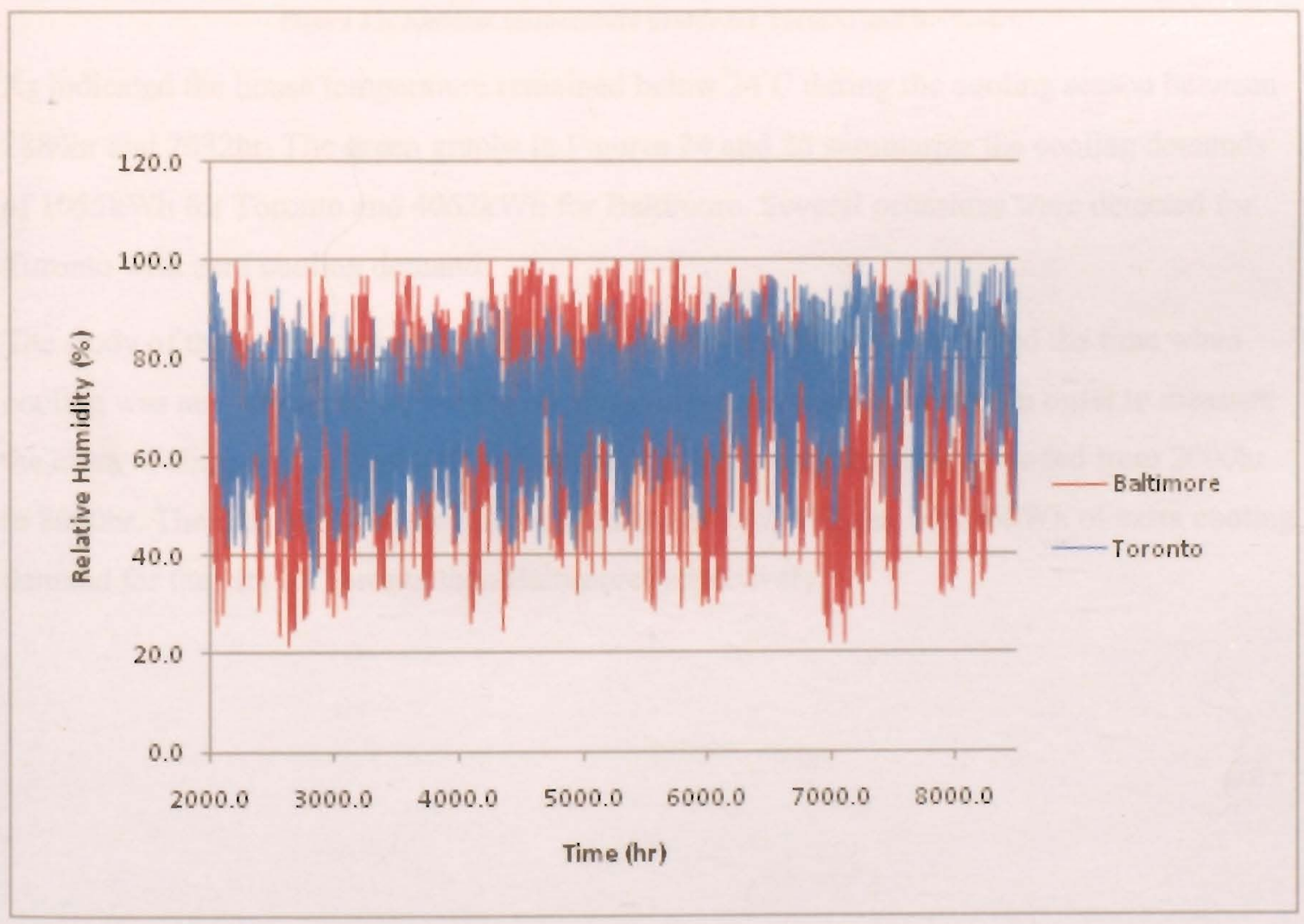

Figure 22: \%RH profiles for Toronto and Baltimore 


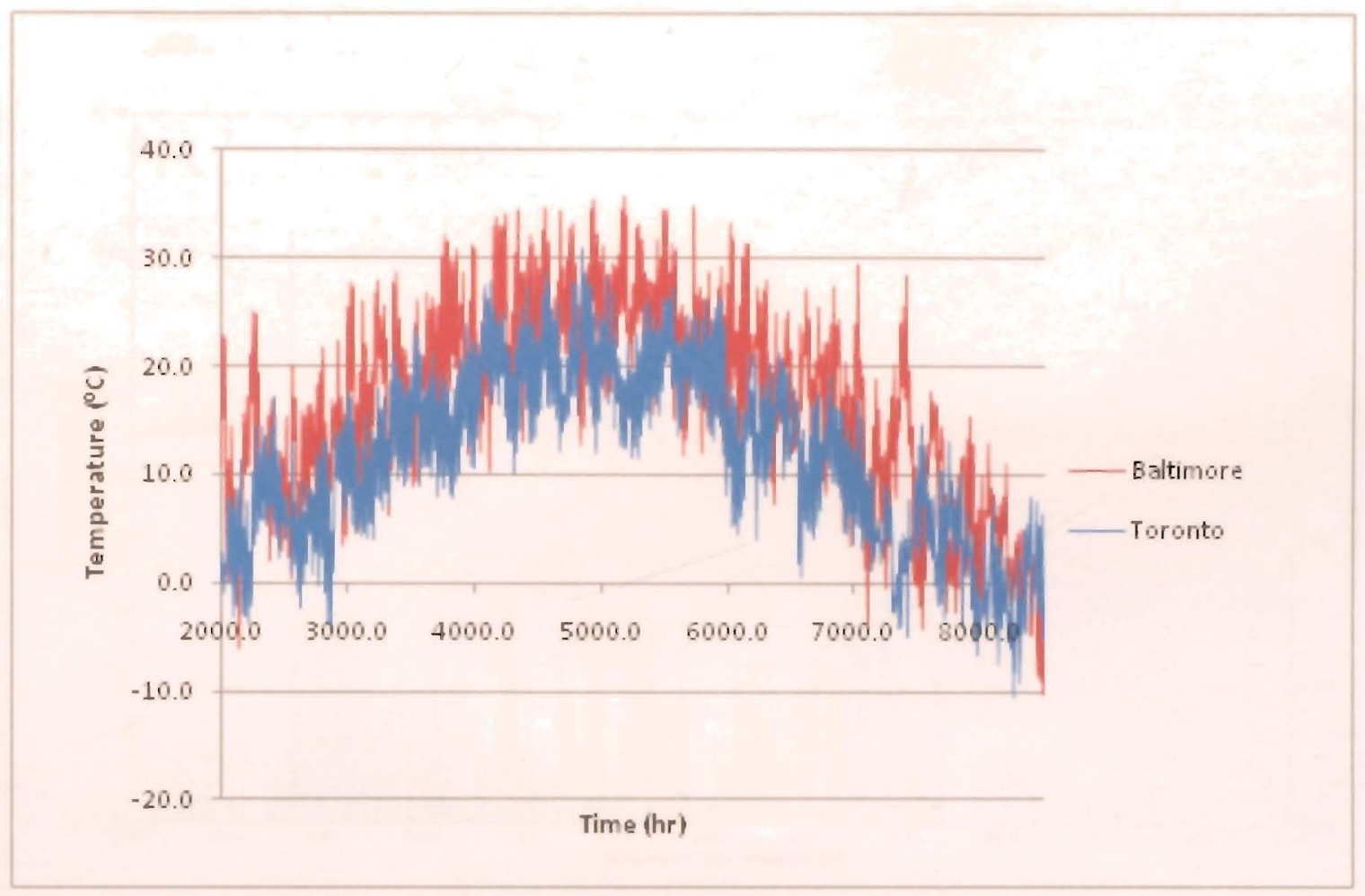

Figure 23: Ambient temperature profile for Toronto and Baltimore

As indicated the house temperature remained below $24^{\circ} \mathrm{C}$ during the cooling season between $2880 \mathrm{hr}$ and $7032 \mathrm{hr}$. The green graphs in Figures 24 and 25 summarize the cooling demands of $1055 \mathrm{kWh}$ for Toronto and $4062 \mathrm{kWh}$ for Baltimore. Several occasions were detected for Toronto with zero cooling demand.

The study of the house temperature for the case without the pond identified the time when cooling was not yet turned on but the house required to be cooled down. In order to measure the extra cooling power, simulations were conducted having the time extended from $2000 \mathrm{hr}$ to $8000 \mathrm{hr}$. The data gathered revealed a need for $835.37 \mathrm{kWh}$ and $647.96 \mathrm{kWh}$ of extra cooling demand for the city of Toronto than Baltimore respectively. 


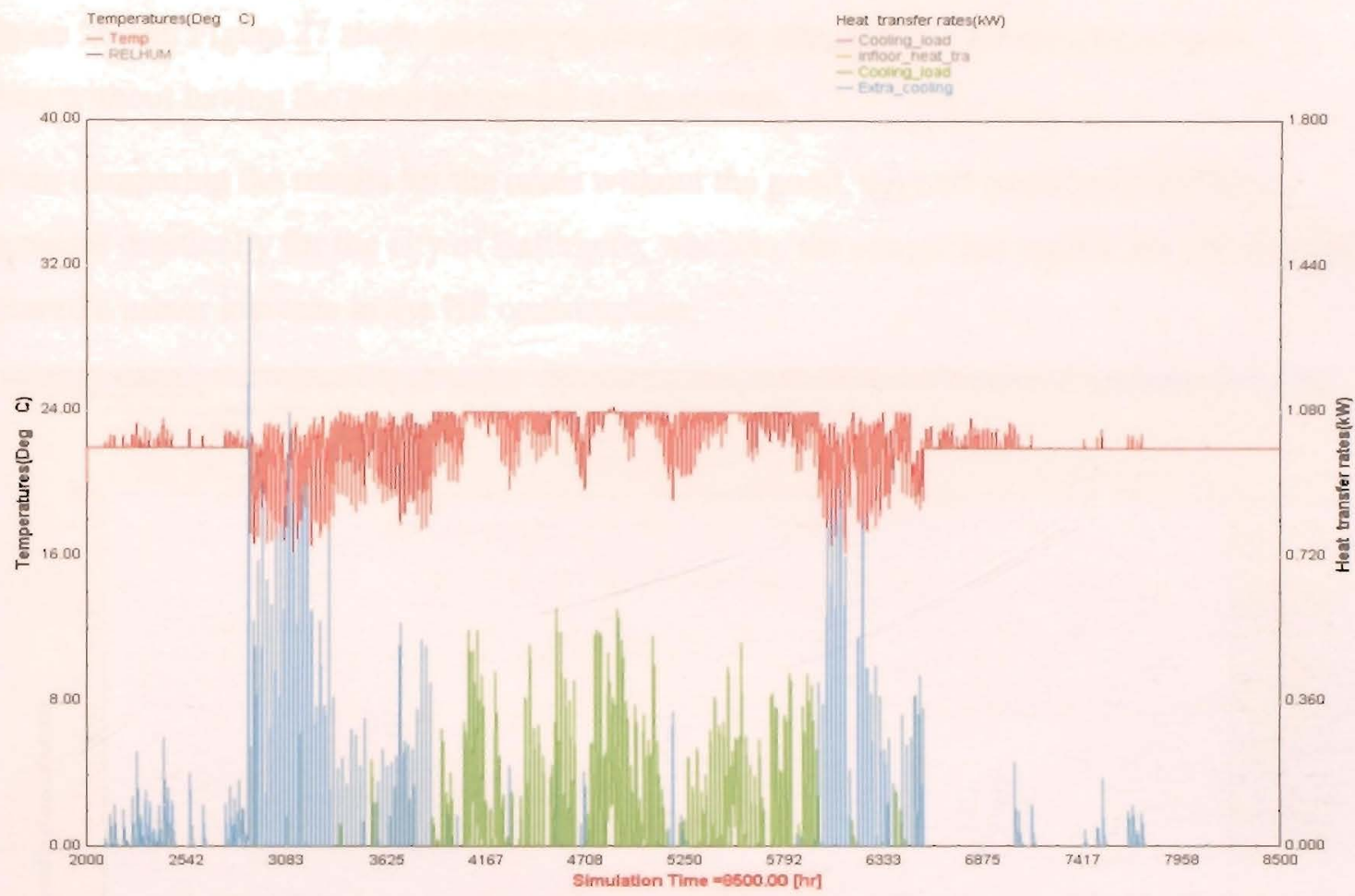

Figure 24: House temperature profile for Toronto

Temperatures(Deg is

- Teripom

Heat transfer rates(ow)

- Coding load

- cooina joad

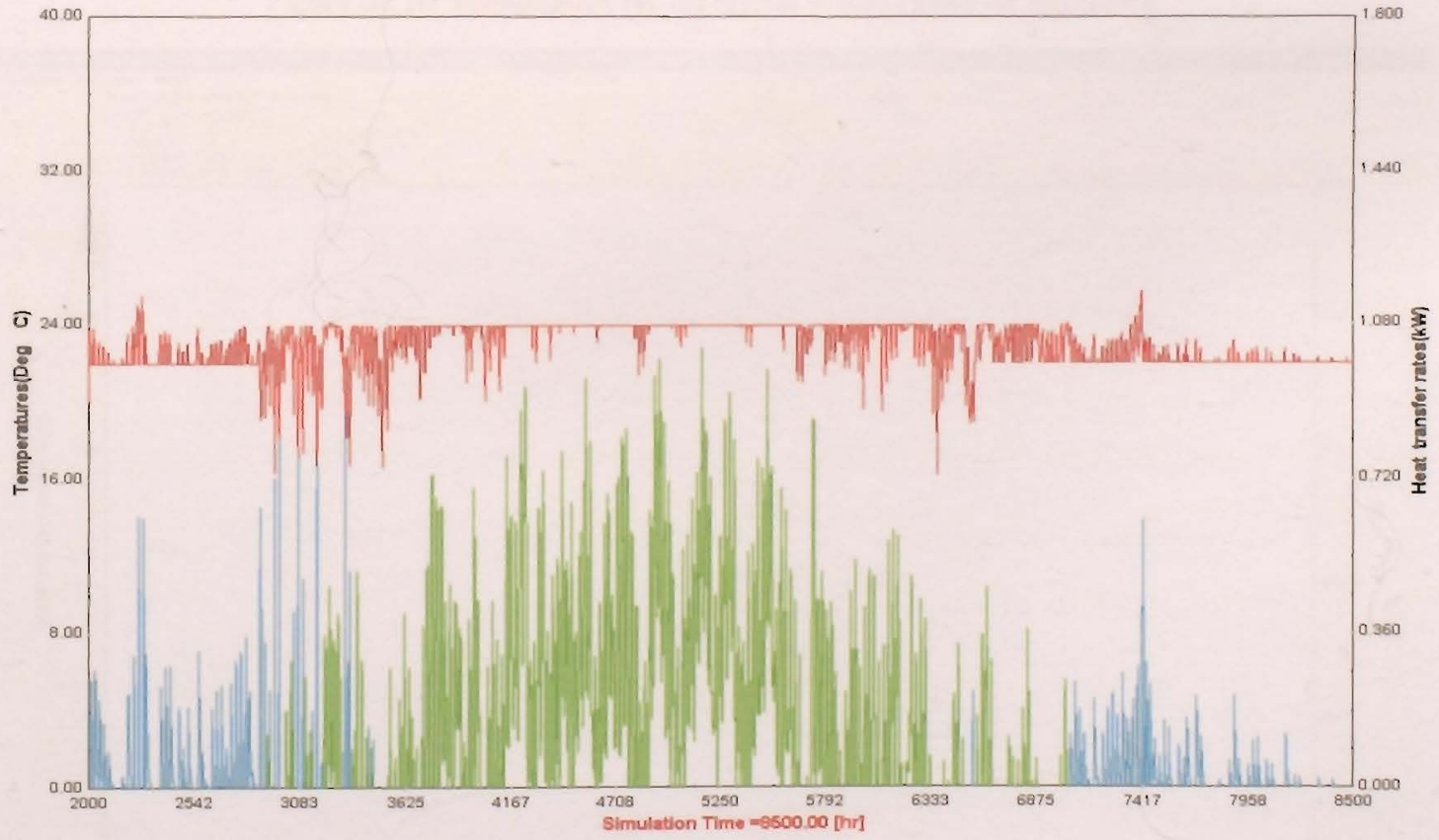

Figure 25: House temperature profile for Baltimore 
Figure 26 and Figure 27 show the varying heat pump consumption for the two cities for the cases without having the pond integrated to the system.

When comparing the results for the cases without the pond, the heat pump consumption increases drastically for the city of Baltimore; whereas, the simulation carried out for Toronto showed a minor increase in the HP consumption.

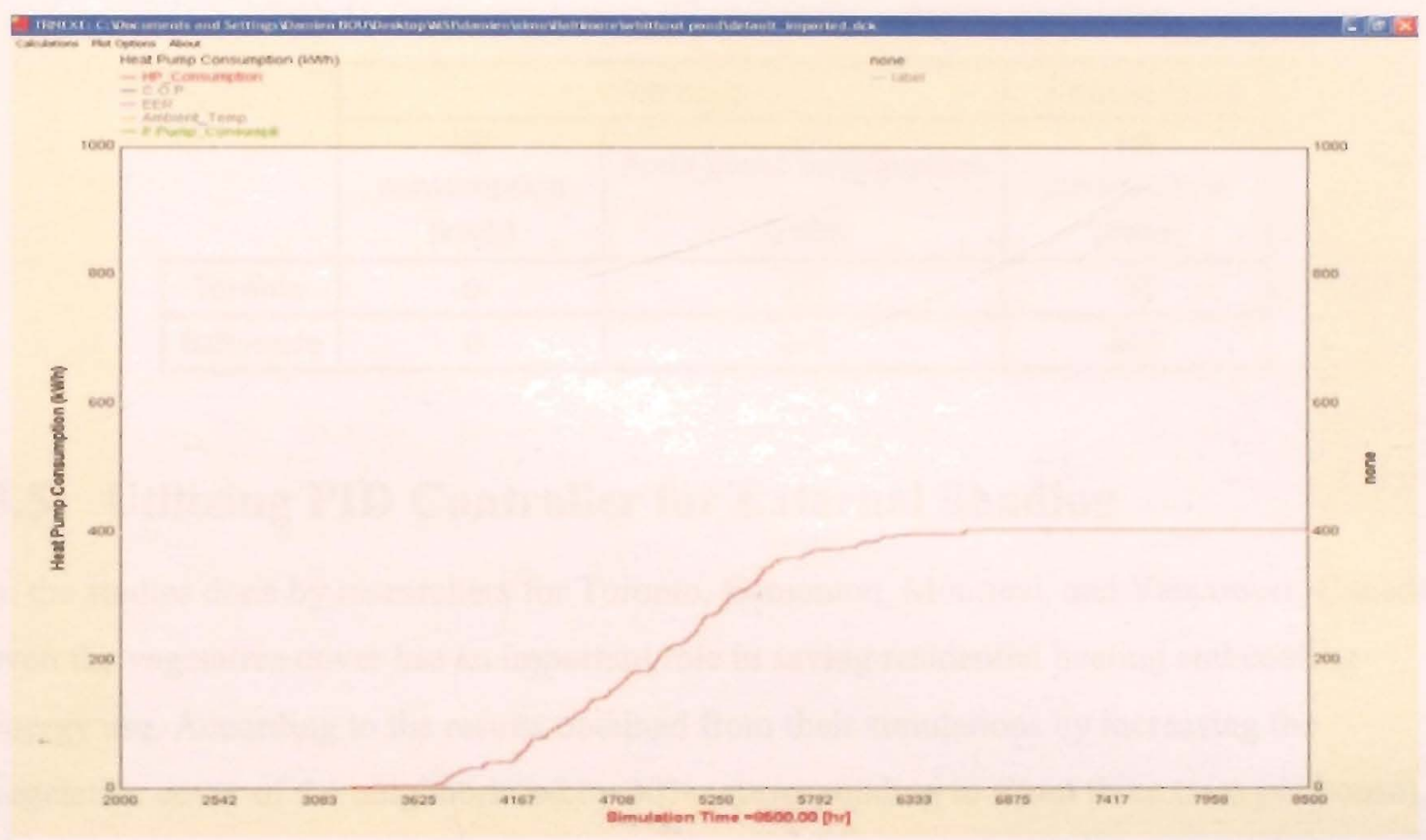

Figure 26: HP consumption for the system without pond for Baltimore

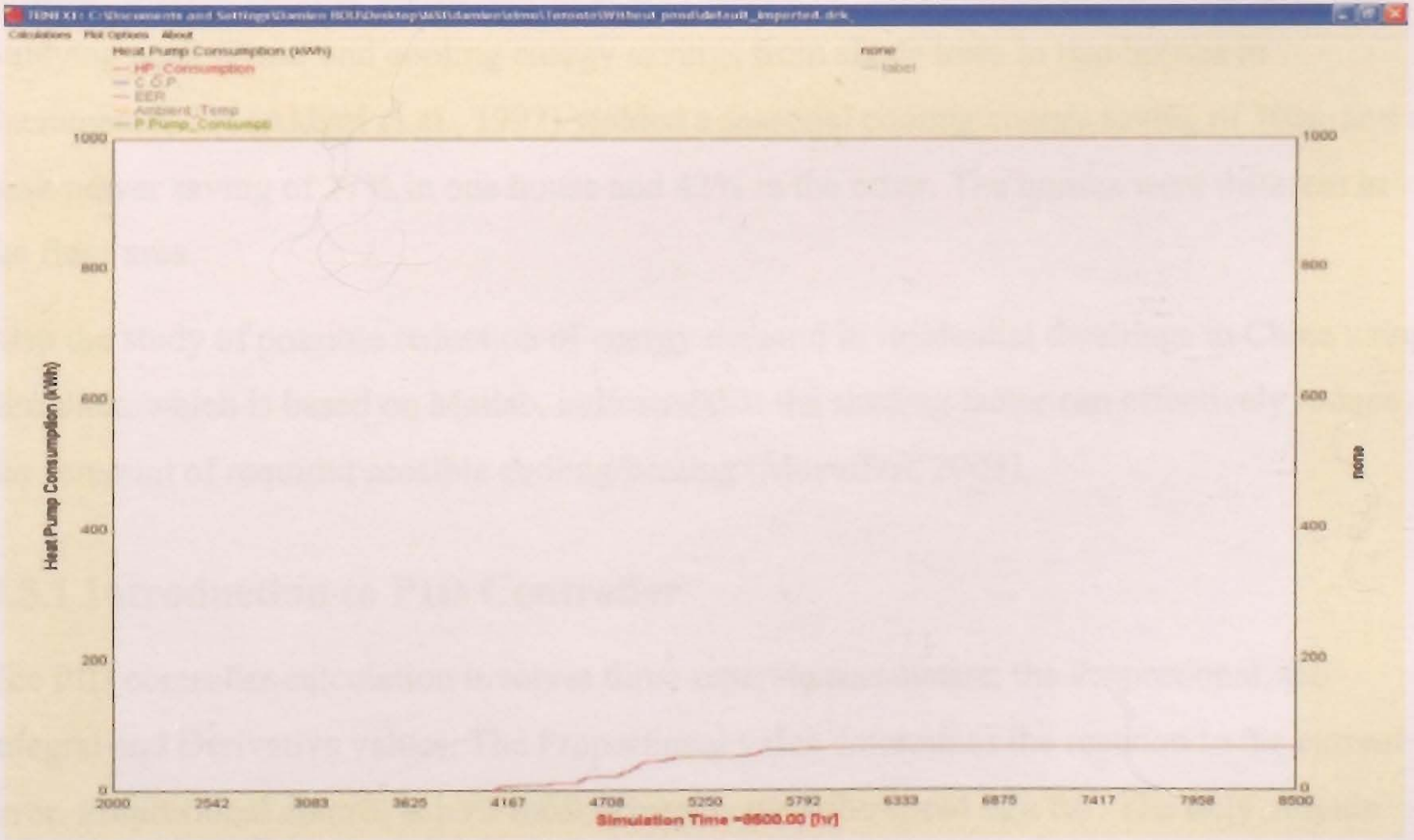

Figure 27: HP consumption for the system without pond for Toronto 
According to the obtained results indicating in table 11, it was more beneficial to use the cooling pond for the city of Baltimore. The total energy consumption of $271 \mathrm{kWh}$ for the case with the pond was estimated to be half of the case without the pond, which was around $406 \mathrm{kWh}$. In Toronto the heat pump consumption was obtained to be $67.0 \mathrm{kWh}$ which was less than the pond pump consumption of $211 \mathrm{kWh}$.

Table 11: Comparison between HP consumption and pump consumption

\begin{tabular}{|c|c|c|c|}
\cline { 2 - 4 } \multicolumn{1}{c|}{} & \multicolumn{2}{c|}{ With Pond } & Without Pond \\
\cline { 2 - 4 } & $\begin{array}{c}\text { HP } \\
\text { consumption } \\
(\mathrm{kWh})\end{array}$ & $\begin{array}{c}\text { Pond pump consumption } \\
(\mathrm{kWh})\end{array}$ & $\begin{array}{c}\text { HP } \\
\text { consumption } \\
(\mathrm{kWh})\end{array}$ \\
\hline Toronto & 0 & 211 & 67 \\
\hline Baltimore & 0 & 271 & 406 \\
\hline
\end{tabular}

\subsection{Utilizing PID Controller for External Shading}

In the studies done by researchers for Toronto, Edmonton, Montreal, and Vancouver, Canada, even the vegetative cover has an important role in saving residential heating and cooling energy use. According to the results obtained from their simulations by increasing the vegetative cover of the neighborhood by $30 \%$ (corresponding to about three trees per house), the heating energy in Toronto can be reduced by about $10 \%$ in urban houses and $20 \%$ in nural houses, whereas cooling energy can be reduced by $40 \%$ and $30 \%$ (Akbari and Taha, 1992). Studying peak power and cooling energy savings from shade trees in two houses in Sacramento, CA (Akbari et al., 1997) yielded a seasonal cooling energy saving of 30\%, and a peak power saving of $27 \%$ in one house and $42 \%$ in the other. The houses were different in the floor area.

Also the study of possible reduction of energy demand in residential dwellings in China using Simulink, which is based on Matlab, indicated that the shading factor can effectively reduce the amount of required sensible cooling/heating (Mozaffari, 2003).

\subsubsection{Introduction to PID Controller}

The PID controller calculation involves three separate parameters; the Proportional, the Integral and Derivative values. The Proportional value determines the reaction to the current error. Proportional control is how most drivers control the speed of a car. The only outputs used as a signal are not zero and one. There are proportional values from zero to one. The 
Integral value determines the reaction based on the sum of recent errors, and the Derivative value determines the reaction based on the rate at which the error has been changing. Controllers are used in industry to regulate temperature, pressure, flow rate, chemical composition, speed and practically every other variable for which a measurement exists.

\subsubsection{Simulation Scenarios}

The goal was to define a shading control strategy that could be modeled in TRNSYS simulation and also performed similar to the actual dynamic shading integrated in North House. For the pervious analyses (pond and infloor heating), the proportional controller was utilized in the model.

A PID controller was utilized to control the external shading in the simulation studio. The optimum proportional gain, integral effect and derivative effect values were determined. In order to establish these values, we proceeded by examination, step by step, changing only one parameter within each simulation.

Before running these simulations, the temperature set points were introduced. The temperatures set were at $22^{\circ} \mathrm{C}$ during heating and $24^{\circ} \mathrm{C}$ for cooling season, the values of the controlled variable could vary from 0.2 to 1 ( 1 means all the shadings were closed). The shading factor was set to be 0.2 which means $20 \%$ shading at all times.

Several comparisons of different parameter values (integral " $I$ " and derivative " $D$ " effect) were studied. The best proportional value was set to be $\mathrm{P}=0.7$ for all the season.

The "I" value was varied from 0.5 to 5 hours and the "D" was varied from 5 to 30 minutes. The simulation was run for three periods of the year, heating season, shoulder season and cooling season. Figure 28 illustrates the time intervals defined.

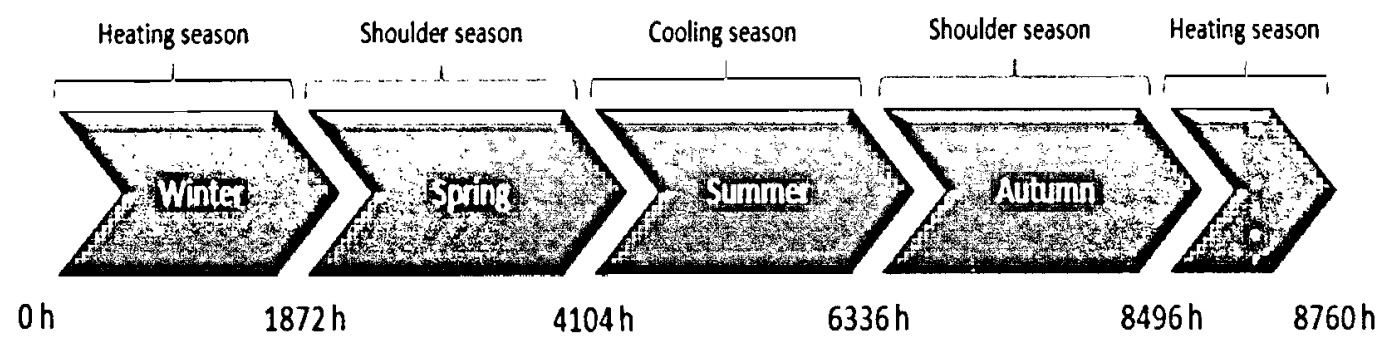

Figure 28: Definition of different time intervals over one year 
For each season, different combinations of parameters were studied based on the house temperature. The numbers of occurrences (\# of OCR), meaning when the house temperature was within the range of $22-24^{\circ} \mathrm{C}$, were calculated for each combination, and the combination with the greatest number of occurrences was selected as the best case for the corresponding season.

Table 12: Summary of the results for the cooling season

\begin{tabular}{|c|c|c|c|c|c|c|c|c|c|c|c|c|c|c|c|c|c|}
\hline I & D & $\begin{array}{l}\text { \# of } \\
\text { OCR }\end{array}$ & I & D & $\begin{array}{l}\text { \# of } \\
\text { OCR }\end{array}$ & I & D & $\begin{array}{l}\text { \# of } \\
\text { OCR }\end{array}$ & I & D & $\begin{array}{l}\text { \# of } \\
\text { OCR }\end{array}$ & I & D & $\begin{array}{l}\text { \# of } \\
\text { OCR }\end{array}$ & I D & $\begin{array}{l}\text { \# of } \\
\text { OCR }\end{array}$ \\
\hline 0.5 & 5 & 2790 & 0.5 & 10 & 4285 & 0.5 & 15 & 4262 & 0.5 & 20 & 5010 & 0.5 & 25 & 5302 & 0.5 & 30 & 4697 \\
1 & 5 & 2381 & 1 & 10 & 3389 & 1 & 15 & 3732 & 1 & 20 & 4772 & 1 & 25 & 4330 & 1 & 30 & 4372 \\
2 & 5 & 3255 & 2 & 10 & 3013 & 2 & 15 & 3919 & 2 & 20 & 3188 & 2 & 25 & 2793 & 2 & 30 & 3765 \\
3 & 5 & 4144 & 3 & 10 & 4789 & 3 & 15 & 3671 & 3 & 20 & 3584 & 3 & 25 & 4656 & 3 & 30 & 2949 \\
4 & 5 & 4902 & 4 & 10 & 4323 & 4 & 15 & 3579 & 4 & 20 & 4106 & 4 & 25 & 4389 & 4 & 30 & 5216 \\
\hline 5 & 5 & 10127 & 5 & 10 & 7734 & 5 & 15 & 8446 & 5 & 20 & 6892 & 5 & 25 & 6111 & 5 & 30 & 6590 \\
\hline
\end{tabular}

Table 13: Summary of the results for the heating season

\begin{tabular}{|c|c|c|c|c|c|c|c|c|c|c|c|c|c|c|c|c|c|}
\hline I & D & $\begin{array}{l}\text { \# of } \\
\text { OCR }\end{array}$ & I & D & $\begin{array}{l}\text { \# of } \\
\text { OCR }\end{array}$ & I & D & $\begin{array}{l}\text { \# of } \\
\text { OCR }\end{array}$ & I & D & $\begin{array}{l}\text { \# of } \\
\text { OCR }\end{array}$ & I & D & $\begin{array}{l}\text { \# of } \\
\text { OCR }\end{array}$ & I & D & $\begin{array}{l}\text { \# of } \\
\text { OCR }\end{array}$ \\
\hline 0.5 & 5 & 5841 & 0.5 & 10 & 5874 & 0.5 & 15 & 5146 & 0.5 & 20 & 5004 & 0.5 & 25 & 4812 & 0.5 & 30 & 4968 \\
\hline 1 & 5 & 4677 & 1 & 10 & 4069 & 1 & 15 & 3988 & 1 & 20 & 3788 & 1 & 25 & 3427 & 1 & 30 & 3695 \\
2 & 5 & 3352 & 2 & 10 & 3316 & 2 & 15 & 3184 & 2 & 20 & 3206 & 2 & 25 & 3235 & 2 & 30 & 3078 \\
3 & 5 & 2965 & 3 & 10 & 2657 & 3 & 15 & 3215 & 3 & 20 & 3586 & 3 & 25 & 3704 & 3 & 30 & 3474 \\
4 & 5 & 3009 & 4 & 10 & 3330 & 4 & 15 & 3698 & 4 & 20 & 3537 & 4 & 25 & 4044 & 4 & 30 & 4024 \\
5 & 5 & 4102 & 5 & 10 & 4711 & 5 & 15 & 4763 & 5 & 20 & 4890 & $\mathbf{5}$ & $\mathbf{2 5}$ & $\mathbf{4 8 2 8}$ & $\mathbf{5}$ & 30 & 4817 \\
\hline
\end{tabular}

Table 14: Summary of the results for the shoulder season

\begin{tabular}{|c|c|c|c|c|c|c|c|c|c|c|c|c|c|c|c|c|c|}
\hline I & D & $\begin{array}{l}\text { \# of } \\
\text { OCR }\end{array}$ & I & D & $\begin{array}{l}\text { \# of } \\
\text { OCR }\end{array}$ & I & D & $\begin{array}{l}\text { \# of } \\
\text { OCR }\end{array}$ & I & D & $\begin{array}{l}\text { \# of } \\
\text { OCR }\end{array}$ & I & D & $\begin{array}{l}\text { \# of } \\
\text { OCR }\end{array}$ & I & D & $\begin{array}{l}\text { \# of } \\
\text { OCR }\end{array}$ \\
\hline 0.5 & 5 & 5234 & 0.5 & 10 & 6664 & 0.5 & 15 & 6796 & 0.5 & 20 & 8444 & 0.5 & 25 & 6690 & 0.5 & 30 & 7448 \\
\hline 1 & 5 & 8276 & 1 & 10 & 5349 & 1 & 15 & 6741 & 1 & 20 & 6269 & 1 & 25 & 6681 & 1 & 30 & 6652 \\
\hdashline 2 & 5 & 7170 & 2 & 10 & 5543 & 2 & 15 & 4589 & 2 & 20 & 5588 & 2 & 25 & 4865 & 2 & 30 & 5826 \\
3 & 5 & 5138 & 3 & 10 & 5347 & 3 & 15 & 6640 & 3 & 20 & 4818 & 3 & 25 & 5782 & 3 & 30 & 4856 \\
4 & 5 & 4303 & 4 & 10 & 5481 & 4 & 15 & 5234 & 4 & 20 & 4446 & 4 & 25 & 6303 & 4 & 30 & 5664 \\
5 & 5 & 7903 & 5 & 10 & 9192 & 5 & 15 & 7568 & 5 & 20 & 7650 & 5 & 25 & 6952 & 5 & 30 & 6490 \\
\hline
\end{tabular}

Using the above approach the final values were defined for heating, cooling and shoulder seasons: 
- Heating season: $\mathrm{I}=0.5$ and $\mathrm{D}=10$

- Cooling season: $\mathrm{I}=5$ and $\mathrm{D}=5$

- Shoulder season: $\mathrm{I}=5$ and $\mathrm{D}=10$

Finally, one simulation was run for each case to study the impact of shading on the house temperature and cooling and heating power demand. Table 15 shows the average temperature (Avg temp), minimum temperature (Min temp) and maximum temperature (Max temp) of the house, without no heating and cooling supplies incorporated, along with the cooling and heating power demands of the house for different seasons.

Table 15: The effect of shading on the house temperature and heating/cooling demand

\begin{tabular}{|c|c|c|c|c|c|c|c|c|c|}
\hline Season & Shading & $\mathrm{P}$ & $\begin{array}{c}\mathrm{I} \\
(\mathrm{hr})\end{array}$ & $\begin{array}{c}\mathrm{D} \\
(\mathrm{min})\end{array}$ & $\begin{array}{c}\text { Average } \\
\text { temp } \\
\left({ }^{\circ} \mathrm{C}\right)\end{array}$ & $\begin{array}{c}\text { Min } \\
\text { temp } \\
\left({ }^{\circ} \mathrm{C}\right)\end{array}$ & $\begin{array}{c}\text { Max } \\
\text { temp } \\
\left({ }^{\circ} \mathrm{C}\right)\end{array}$ & $\begin{array}{c}\text { Cooling } \\
\text { demand } \\
(\mathrm{kW})\end{array}$ & $\begin{array}{c}\text { Heating } \\
\text { demand } \\
(\mathrm{kW})\end{array}$ \\
\hline \multirow{2}{*}{ Heating } & $\mathrm{w}$ & 0.7 & 0.5 & 10 & 10.67 & -8.16 & 24.24 & 0 & 2.22 \\
\cline { 2 - 10 } & $\mathrm{w} / \mathrm{o}$ & & & & 15.31 & -6.8 & 48.56 & 0 & 0.74 \\
\hline \multirow{2}{*}{ Cooling } & $\mathrm{w}$ & 0.7 & 5 & 5 & 24.31 & 13.44 & 30.45 & 1.95 & 0 \\
\cline { 2 - 9 } & $\mathrm{w} / \mathrm{o}$ & & & & 46.21 & 20 & 67.69 & 5.41 & 0 \\
\hline \multirow{2}{*}{ Shoulder } & $\mathrm{w}$ & 0.7 & 5 & 10 & 24.31 & 13.44 & 30.45 & 1.14 & 2.23 \\
\cline { 2 - 9 } & $\mathrm{w} / \mathrm{o}$ & & & & 35.1 & 11.09 & 59.24 & 3.91 & 0.56 \\
\hline
\end{tabular}

From the result, it seems that the heating demand is less when there is no shading. However, overheating the house can be a problem if shading is not utilized during the heating season. 


\section{Chapter 4}

\section{North House Solar Domestic Hot Water and HVAC System}

\subsection{Description of the Overall System ${ }^{\mathrm{Xx}}$}

The mechanical system in North House was designed with the goal of collecting enough solar energy to cover the majority of the domestic hot water and space heating demands throughout the year, while conserving every last watt of electrical power.

Solar thermal energy was captured through the use of two arrays of flow through evacuated tube solar-thermal collectors installed on the roof. A three-tank system was incorporated with the solar loop, including two advanced variable-capacity heat pumps. Each tank was designed to serve a certain purpose: a large preheat tank (PHT) whose temperature floated between 10 and $80^{\circ} \mathrm{C}\left(50\right.$ and $\left.176^{\circ} \mathrm{F}\right)$ stored collected solar thermal energy, a space heating tank (SHT) kept at a minimum of $30^{\circ} \mathrm{C}\left(86^{\circ} \mathrm{F}\right)$ supplied hydronic space heating, and a domestic hot water tank (HWT) kept at about $50-55^{\circ} \mathrm{C}\left(122-131^{\circ} \mathrm{F}\right)$ provided hot water for the occupants' daily activities. The tank temperatures and sizes were chosen to ensure that all space heating and domestic hot water demands were met with ease.

Collected solar energy was delivered to the preheat tank and distributed to the rest of the system. A heat dissipator system (Apricus HD-25 Heat Dissipator) was integrated into the solar thermal loop in order to prevent overheated fluid from entering the preheat tank and to prevent the collectors from getting dangerously hot. Fluid leaving the collectors was directed to the heat dissipators via a three-way solenoid valve whenever its temperature exceeded $80^{\circ} \mathrm{C}\left(176^{\circ} \mathrm{F}\right)$.

In order to save energy, only the required amount of pumping power was used. The pumps had a three-speed manually chosen setting, and were adjusted to the lowest appropriate setting. Two fully variable speed pumps controlled by Johnson temperature controllers were utilized. One controlled the amount of "desuperheat" being delivered to the hot water tank (HWT) and the other one controlled the amount of heat being transferred from the preheat

\footnotetext{
${ }^{\mathrm{xx}}$ The North House final mechanical design and the description of the system were established by the North House engineering team. However, the energy balance study of the system using TRNSYS and the analyses of the data including simulation and the actual data obtained during the competition are done solely by the author.
} 
tank to the exchanger coil of the heat pump assisted solar thermal. They automatically adjusted capacity to the minimum required.

Space heat was distributed throughout the living space via a fan coil located in the air handler. Space cooling demands were met through a second custom modulating heat pump to draw the appropriate amount of heat from the air via an evaporator coil in the air handler.

This heat was dumped to a cooling pond located in the shaded area under the deck. Figure 29 shows an overall design of the system.

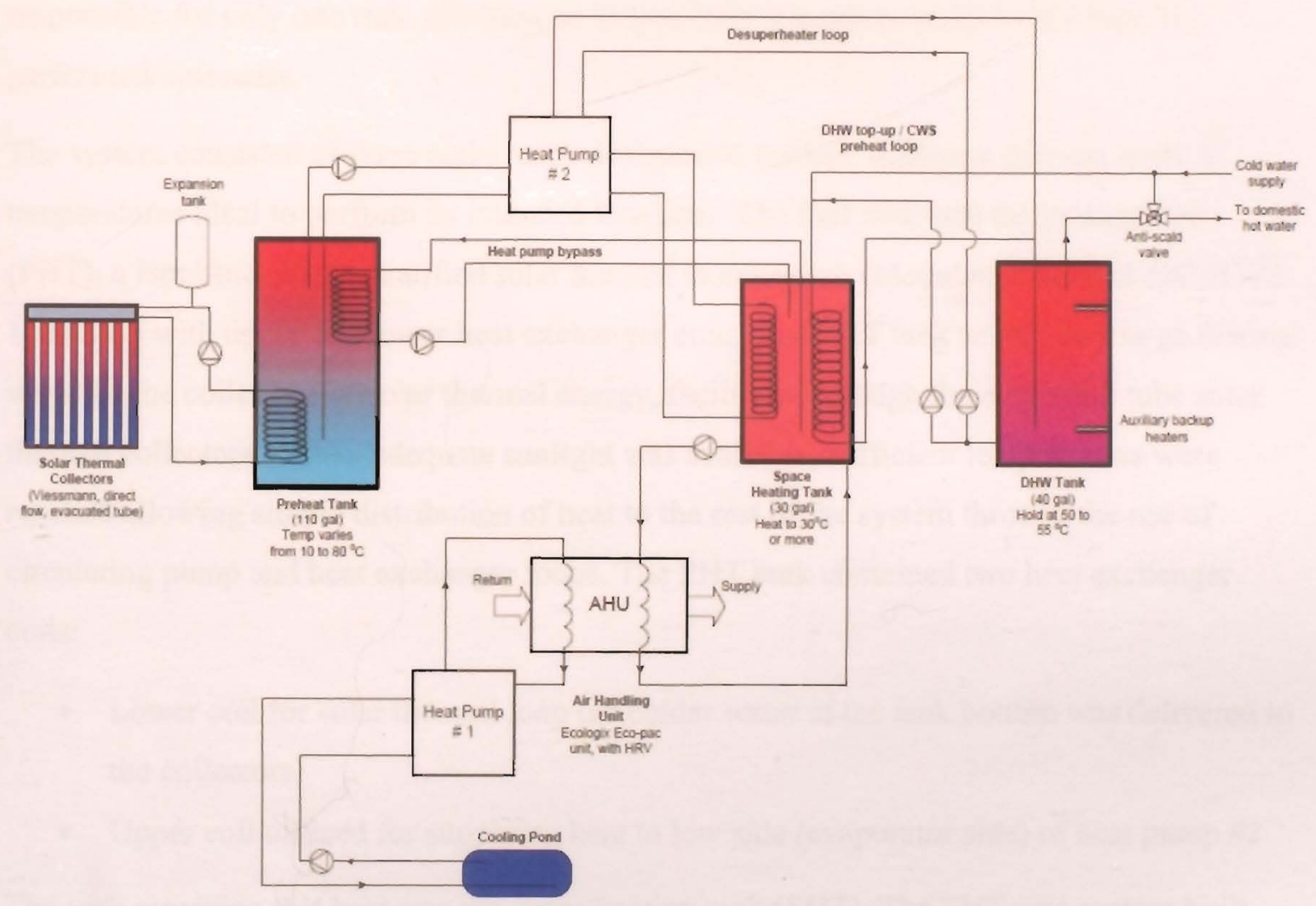

Figure 29: Schematic of the North House HVAC system

The air handler and heat recovery ventilator were controlled via a Central Home Automation Server (CHAS), which adjusted operation based on frequently measured temperature, relative humidity, and carbon dioxide content. Based on the temperature and relative humidity set points defined by the occupant, the CHAS automatically adjusted the mechanical system to deliver the desired conditions for thermal comfort. The CHAS also provided optional occupant overrides for fine adjustment of temperature and ventilation rates. The Branch Circuit Power Meter (BCPM) allowed for the measurement of power and energy readings for the grid connection, solar feed, and each breaker circuit in the main electrical panel. The CHAS also provided real-time and historical feedback regarding the performance of the 
house through the GUI, where the occupant could inquire about the status of the house as well as configure system preferences, including home control Modes.

\subsection{System Components}

\subsubsection{Three Tank System}

The solar domestic hot water system was designed with the goal of keeping each component responsible for only one task, allowing us to fine-tune the system so that each task was performed optimally.

The system consisted of three tanks, each designed to contain sufficient thermal mass at temperatures ideal to perform its intended function. The first tank was the preheat tank (PHT), a Bradford White stratified solar thermal storage tank (Model \#: Ecostar S-DC-DW2$110 \mathrm{RSW}$ ) with upper and lower heat exchanger coils. The PHT tank served as a large thermal mass for the collection of solar thermal energy, facilitated through the evacuated tube solar thermal collectors. When adequate sunlight was available, sufficient temperatures were reached allowing simple distribution of heat to the rest of the system through the use of circulating pump and heat exchanger loops. The PHT tank contained two heat exchanger coils:

- Lower coil for solar thermal loop (so colder water at the tank bottom was delivered to the collectors)

- Upper coil utilized for supplying heat to low side (evaporator side) of heat pump \#2 The tank receiving this heat was the space heating tank (SHT). The SHT was custom built from a plastic drum. It contained hand-bent copper heat exchanger coils (200 feet refrigerant tubing and 50 feet of water tubing). This $113.6 \mathrm{~L}$ ( 30 gallon) tank was responsible for maintaining a supply of warm water for the hydronic forced-air heating system ensuring there was a constant supply of warm water for space heating needs. Space-heating was achieved by cycling warm water to heat exchanger coils located in the air handler. The inner four coils (four circuits of 50 feet each) acted as a condenser for the solar assist heat pump, described in the following sub-chapter. In order to achieve the best possible performance of the solarassist heat pump, it was desirable to have direct heat exchange between the condenser coils and the hydronic fluid in the space heating tank. 
The final tank was a Bradford White typical domestic hot water tank (Model \#: M-2-HE40S6DS) with upper and lower auxiliary electric backup heaters (each $4500 \mathrm{Watt}$ ) for the absolute worst-case scenario when no solar energy was available for a long period. This tank ensured there was a constant supply of hot water for domestic needs.

To increase the effective capacity of the domestic hot water tank, the cold water supply was plumbed to enter through the hydronic heating coils in the space heating tank in order to get preheated before entering to the HWT. This causes the domestic hot water tank to immediately begin to recharge when hot water was drawn, assisting the system to have an immediate response to meet the specific heat requirements of the occupant.

If conditions are such that solar thermal alone cannot supply adequate heat, a solar-assist heat pump was activated, pulled heat from the preheat tank and upgraded its temperature for delivery to both the space heating and domestic hot water tanks. Such a heat pump assisting the solar thermal system provided a high-performance backup to the solar thermal, reducing reliance on the electric-resistance backup elements located in the HWT. More details on this heat pump are included below.

\subsubsection{Direct-Flow Solar Thermal Evacuated Tubes}

Viessman direct flow evacuated tubes were utilized (Model \#: Vistol 200-T). The tubes were installed in an east-west orientation, with 24 degrees in south-facing tilt.

\subsubsection{Variable Capacity Heat Pumps}

There were dedicated heat pumps for both cooling and heating function. The heat pump Efficiency was improved because there was no reversing valve. The heat pumps had digital scroll compressors, Copeland TM digital scroll compressors (Model \#: ZPD34K5E-PFV), allowing full modulation from $10 \%$ capacity to $100 \%$. This means that the heat exchangers were more efficient due to partial loading most of the time, and cycling losses were reduced or even eliminated. Electronic metering of refrigerant maximized efficiency of the refrigeration cycle. Large heat exchanger surfaces also contributed to improved efficiency.

There were several reasons that the digital scroll compressor (DSC) was chosen over the traditional variable capacity compressor. One was because in DSC, the drive motor stays at a constant rotational velocity which results in no inertial losses. Also, the actuation of the scroll mechanism is achieved using the high-pressure refrigerant already present in the compressor 
(animation/diagram from Copeland website) ${ }^{\mathrm{XXI}}$, and the electronic expansion control is one of the highlights of DSCs.

Currently, digital scroll compressors are only available in nominal capacities as low as three tons, as they are typically used for industrial refrigeration applications. As such, we were forced to use heat pumps with over twice as much capacity as we expected to need. However, the highly-efficient way in which the compressors modulate allowed the system to maintain high-performance at lower capacities, while achieving rapid response when demands were higher than expected.

Both heat pumps had a COP of about 5 , and a COP of up to 10 for small delta $T$ (temperature difference). The refrigerant used was $\mathrm{R}-410 \mathrm{a}$, which has no ozone depletion potential.

The system was designed to allow both heat pumps to efficiently deliver the required amount of heat to exactly where it was needed. Both heat pumps automatically adjusted their capacities in response to a signal from a Johnson temperature controller, allowing them to deliver only the required amount of heat, eliminating wasteful "cycling". For instance, heat pump \#1 (HP1) adjusted its capacity to ensure that air was delivered at $12^{\circ} \mathrm{C}\left(54^{\circ} \mathrm{F}\right)$ for ideal cooling. And heat pump \#2 (HP2) delivered most of its heat to the space heating tank (SHT) for space heating and domestic hot water purposes.

\subsubsection{Heat Pump Assisted Solar Thermal}

As the heat pump operated to upgrade the heat in the system, it could work to chill the preheat tank, inherently increasing the efficiency of the solar thermal collection. In the event of a long, cloudy period, it is even feasible to chill the tank to a temperature well below freezing (a glycol/water solution would be used), to the point below the temperature of ambient air so that the heat gain would be still possible by simply circulating fluid in the solar thermal loop.

\subsubsection{Integrated Desuperheater in Solar-Assist Heat Pump}

In order to allow the solar-assist heat pump to deliver heat to multiple tanks, an integrated desuperheater (Model \#: CDAX-5030-H) was installed, simply consisting of an appropriately-sized heat exchanger located upstream of the main condenser coils. This

\footnotetext{
${ }^{X X I}$ http://emersonclimate.com/Divisions/RefCopeland/Products/CC_001694.htm
} 
allows high-temperature heat from the superheated refrigerant to be delivered directly to the domestic hot water tank when deemed necessary. By circulating fluid in this loop via a variable speed pump, under typical operating conditions, up to about $10 \%$ of the delivered heat could be transferred to the DHW tank.

The combined use of the desuperheater and space heating loads improved efficiency by reducing combined run times and increased effective heat exchange surfaces. A detailed schematic illustrating the high-side, low-side and desuperheater exchanger is provided in Figure 30

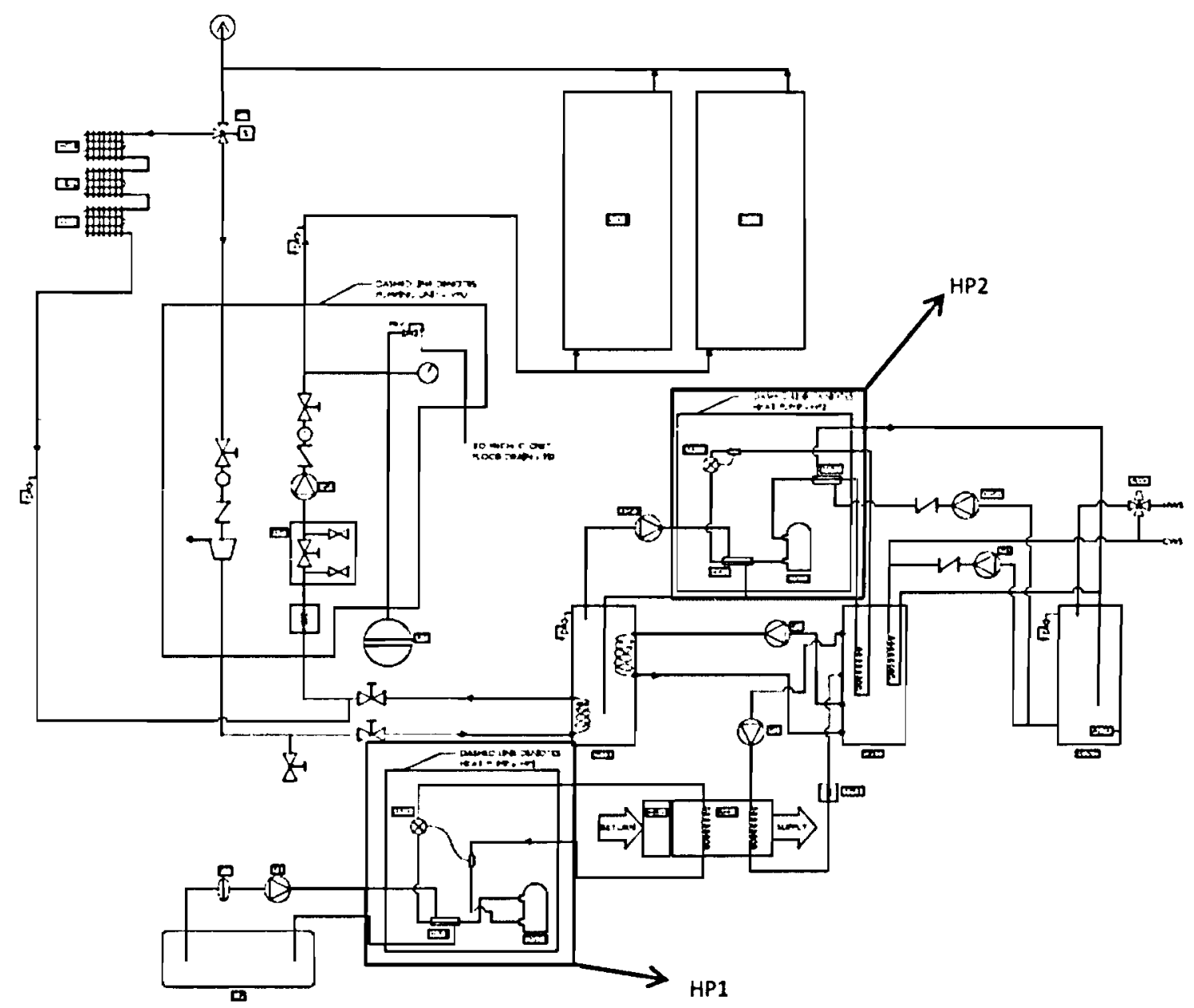

Figure 30: NH mechanical system schematic including component's details

\subsubsection{Cooling pond}

In addition to improved efficiency from the digital scroll compressor and electronic metering, heat from the building was dumped directed to a cooling pond. Therefore, the thermal lift was lower because the cooling pond was cooler than ambient air temperature and often lower 
than room temperature.

Heat pump \#1(HP1) acted as a dedicated cooling heat pump, pulled heat from evaporator coils in the air handler and delivered it to a pond located under the deck. As heat was dumped to the pond it increased the pond temperature, which then began to decrease because of the heat transferred to the ambient air through evaporative cooling and natural convection and conduction to the environment. This innovative tactic allowed us to get the benefits of a geothermal ground loop system without requiring any modification to the National Mall ground. Such a concept could be easily adapted to function with a large lake or pond located near the home, reducing the commonly high-cost of similar ground-loop systems. Figures 31 and 32 show the system lay out inside the denspack.

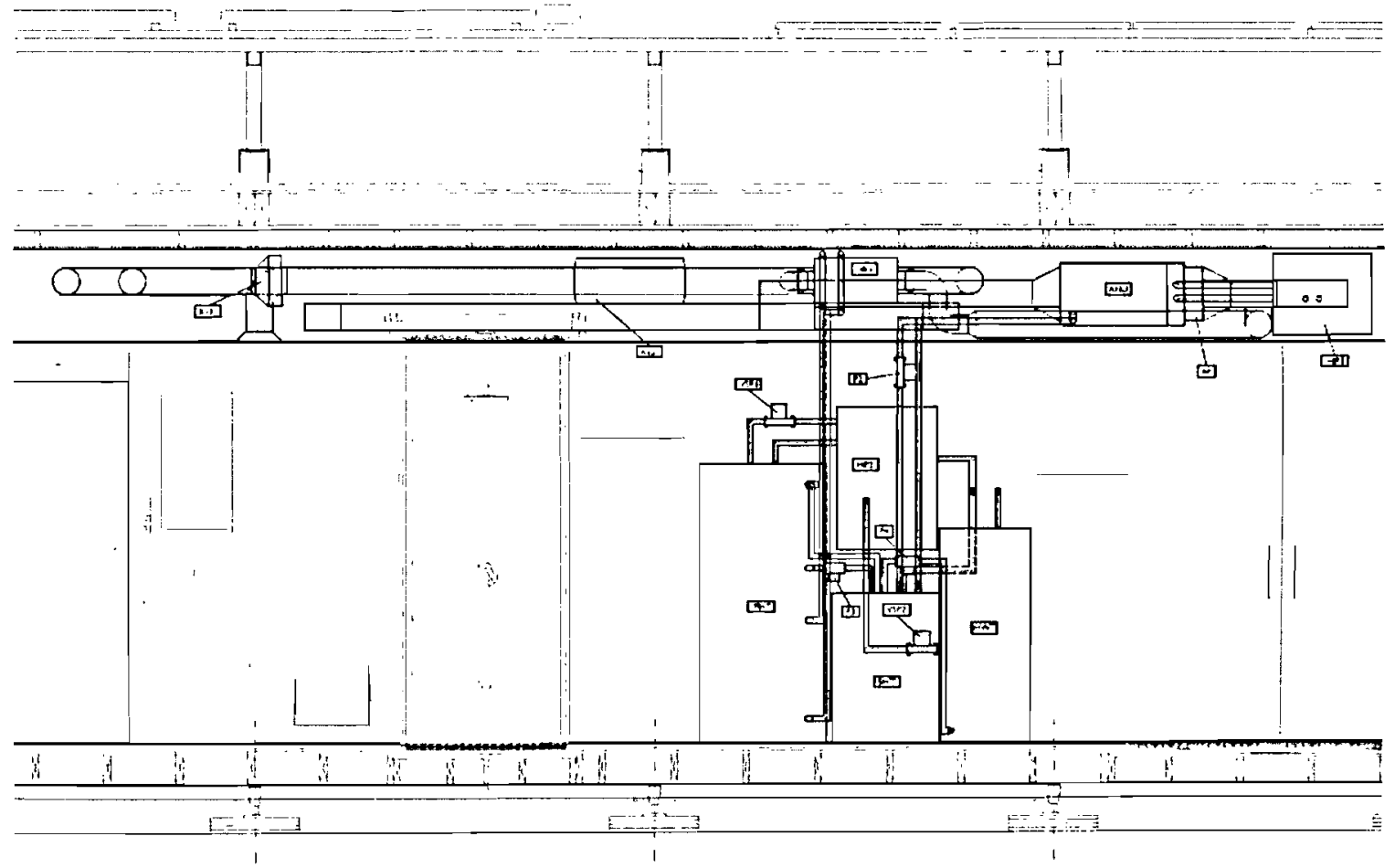

Figure 31: Lay out of the three tank system inside of the denspack 


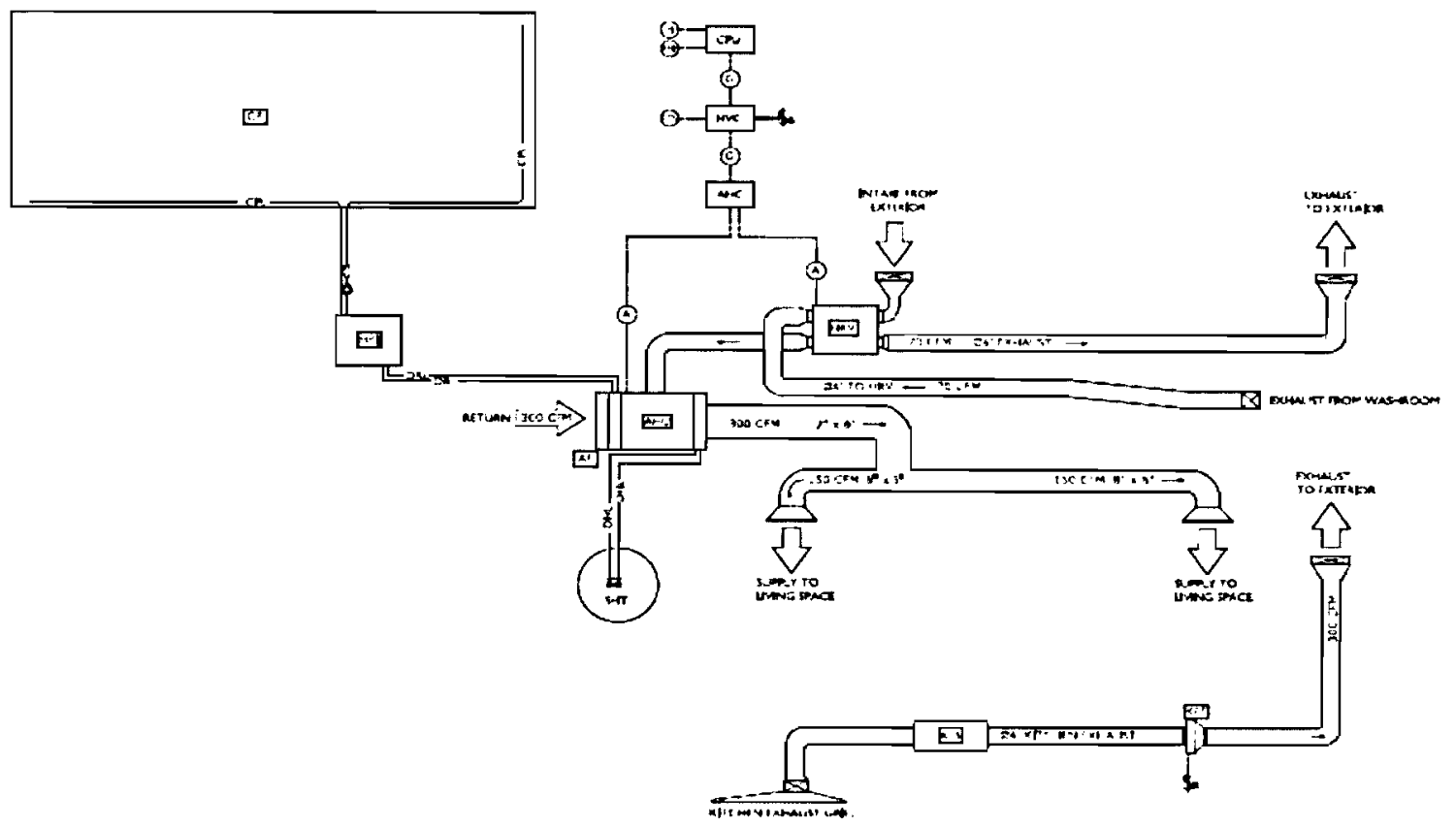

Figure 32: Ventilation system layout inside the densepack

Some of the features that improved system efficiency are summarized below.

Table 16: List of the features that improved the energy efficiency of the system

\begin{tabular}{|l|l|}
\hline Component of the system & \multicolumn{1}{|c|}{ Impact on the efficiency improvement } \\
\hline $\begin{array}{l}\text { Heat pump assisted } \\
\text { solar thermal }\end{array}$ & $\begin{array}{l}\text { Heat pump \#2 increased the quality of heat when available solar heat was reduced. } \\
\text { Therefore, reduced the need for electrical resistance heat for back-up. }\end{array}$ \\
\hline Digital scroll compressor & $\begin{array}{l}\text { A fully modulating (variable capacity) which earned a larger partial loading } \\
\text { and/or heat exchanger relative to the load ( particularly when coupled with } \\
\text { variable speed pumps)and also eliminated cycling (start up and shut down) losses. }\end{array}$ \\
\hline $\begin{array}{l}\text { Heat pump \#2 by-pass } \\
\text { space heating using } \\
\text { desuperheater }\end{array}$ & Direct transfer of solar heat to space heating and DHW loads. \\
\hline Electronic expansion valve & $\begin{array}{l}\text { This feature improved efficiency due to larger effective heat exchanger, } \\
\text { thus reduced run time }\end{array}$ \\
\hline Large heat exchangers & This component maintained accurate control of the superheat and sub-cooling \\
\hline Cooling pond & $\begin{array}{l}\text { Heat exchangers were engineered to maximize efficacy } \\
\text { thermal lift. } \\
\text { Circulator requires } 1 / 8 \text { the power to transfer equivalent amount of heat } \\
\text { compared to fan energy of air sourced unit. }\end{array}$ \\
\hline $\begin{array}{l}\text { Domestic hot water } \\
\text { preheat coil }\end{array}$ & $\begin{array}{l}\text { Cold water supply to DHW tank passed through the coil in the SHT. } \\
\text { Replacement water coming into the tank near the desired temperature required } \\
\text { less work to bring it up to temperature. }\end{array}$ \\
\hline Space Heating Tank (SHT) & $\begin{array}{l}\text { Innovative design incorporating closed loops for heat pump condenser and DHW coil. } \\
\text { Tank had direct connection to solar tank and air handler hot water coil. }\end{array}$ \\
\hline
\end{tabular}


This was the heart of the system connecting space heating loads to solar tank and heat pump while minimizing the need for pumps and heat exchangers.

\begin{tabular}{l|l} 
Variable speed pump & This feature managed the flow of heat to the domestic hot water tank to maximize
\end{tabular} on desuperheater circuit energy storage and reduced system cycling.

Variable speed pump on

This feature manages the flow of heat to the heat pump and ensures the solar tank solar tank supply to heat pump is well stratified with cold water in the bottom.

This helps maintain maximum performance of the solar collector by lowering the fluid temperature to the collectors.

\subsection{System Performance in Simulation}

The system was modeled in TRNSYS to evaluate its performance in terms of energy balance resulting in an estimation of the solar thermal energy production and the house heating demand.

By competition rules (Appendix D), in order to eam full points, the following requirements had to be met:

- Comfort Zone:

- House temperature between: $22^{\circ} \mathrm{C}-24^{\circ} \mathrm{C}$

- Relative Humidity between: $40 \%-55 \%$

- Hot Water :

- Average temperature of $43.3^{\circ} \mathrm{C}$ delivered from the tap

Various calculations and simplified simulations were performed in order to verify the performance of the solar thermal/mechanical system. A TRNSYS model of the three-tank was assembled. Many of the components used in the system could not be modeled using the available TRNSYS modules. Simplifications were made to the heat pump and heat exchanger bypass loop. The TRNSYS model aided the team in sizing mechanical equipment (heat pump, tanks, backup heaters) as well as the solar thermal collector array size.

\subsubsection{Simulation Details}

A calendar-based forcing function was set up in TRNSYS, based on the provided approximate schedule of domestic hot water (DHW) competition draws as summarized below. The following assumptions were made based on competition rules and regulations:

- A shower was set to a 10 minute, $56 \mathrm{~L}$ draw of water.

- Dishwashing was set to a 5 minute, $20 \mathrm{~L}$ draw of water. 
- Clothes washing was set to a 12 minute $60 \mathrm{~L}$ draw of water.

- Where consecutive clothes washing competitions were scheduled, a 48 minute $120 \mathrm{~L}$ draw of water was simulated.

Table 17: Domestic hot water draw (DHW) schedule

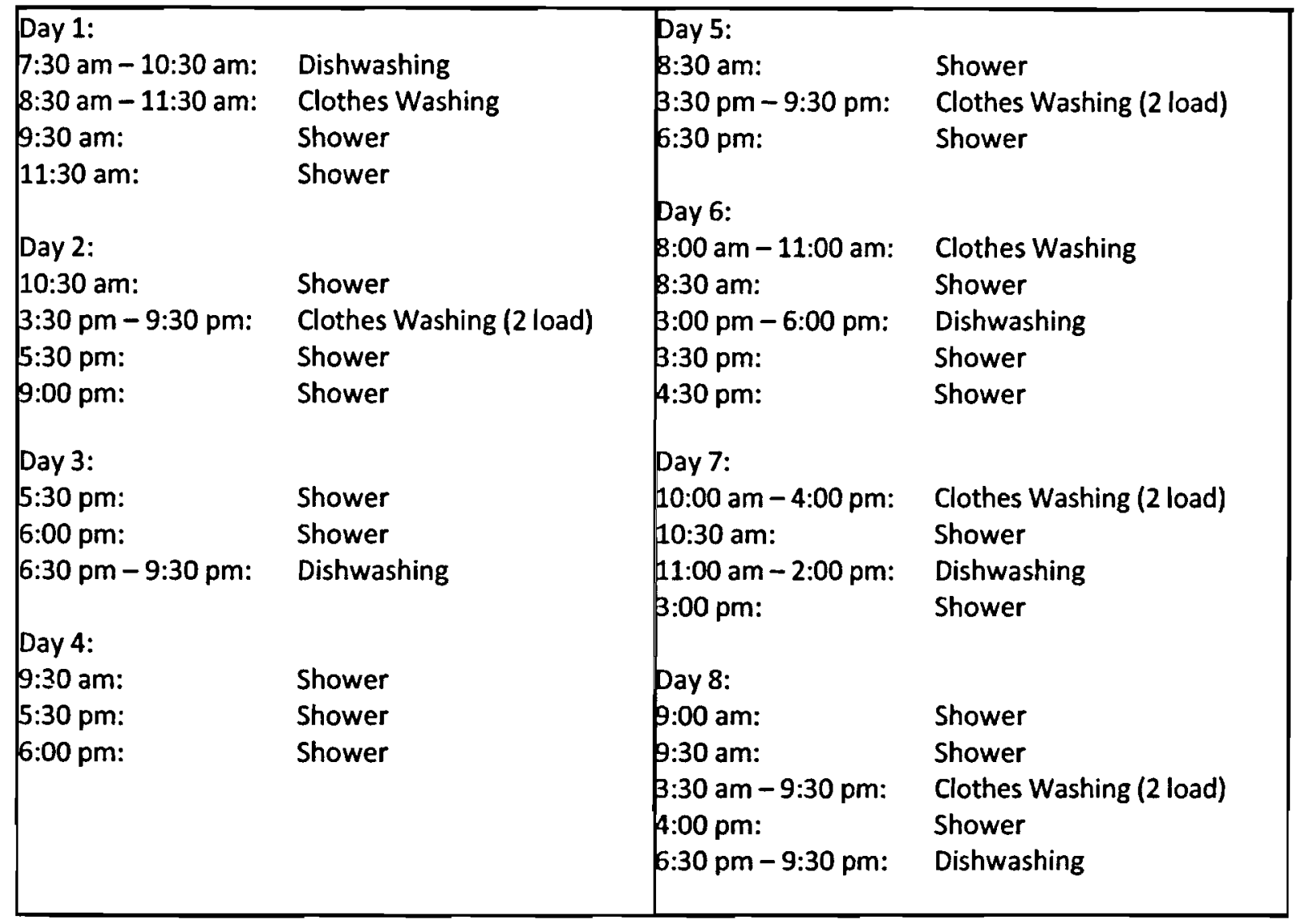

The HWT monitoring temperature was set to $50^{\circ} \mathrm{C}$ and for the SHT tank the temperature varied from $35^{\circ} \mathrm{C}$ to $80^{\circ} \mathrm{C}$ (low set-point and high set-point).

The simplifications made in the TRNSYS model are as follows:

- It was not possible to simultaneously model both a heat pump and a heat exchanger bypass loop between the preheat tank (PHT) and the space heating tank (SHT).

- It was also not possible to incorporate dynamic heating demands on the system, due to limitations on the stratified tank module used.

- Hydronic heating demand was instead simulated by increasing tank losses in the hydronic tank (SHT) as specified in the following table (corresponding to the appropriate peak heating values for each month) 
Table 18: SHT tank heat loss schedule

\begin{tabular}{|l|l|l|l|}
\cline { 2 - 4 } \multicolumn{1}{c|}{} & \multicolumn{2}{|l|}{ Max } & \multicolumn{2}{|l|}{ Average } \\
\cline { 2 - 4 } \multicolumn{1}{c|}{} & $(\mathrm{kW})$ & $(\mathrm{kW})$ & $(\mathrm{kJ} / \mathrm{hr})$ \\
\hline January & 1.7 & 0.5 & 1800 \\
February & 1.6 & 0.42 & 1512 \\
March & 1.3 & 0.23 & 828 \\
October & 0.9 & 0.06 & 216 \\
November & 1.1 & 0.28 & 1008 \\
December & 1.54 & 0.5 & 1800 \\
\hline
\end{tabular}

The simulations were run for Toronto and Baltimore and the simulation time-step was two minutes. For each city, the system energy balance was estimated for the heating season and cooling season individually. Table 19 describes how each season was defined in the simulation.

Table 19: Time intervals for heating and cooling seasons

\begin{tabular}{|c|c|c|}
\hline Heating Season & $\begin{array}{c}0-3240 \mathrm{hr} \\
6552-8760 \mathrm{hr}\end{array}$ & $\begin{array}{l}\text { (Jan 1st- April 15th) } \\
\text { (Sep 27th to Dec 31st) }\end{array}$ \\
\hline Cooling Season & $2280-6984 \mathrm{hr}$ & (April 1st- Oct 10th) \\
\hline
\end{tabular}

Figures 33 and 34 describe the reason why the heating season defined to end on April 15 and also the cooling period was set to end on October 10. 


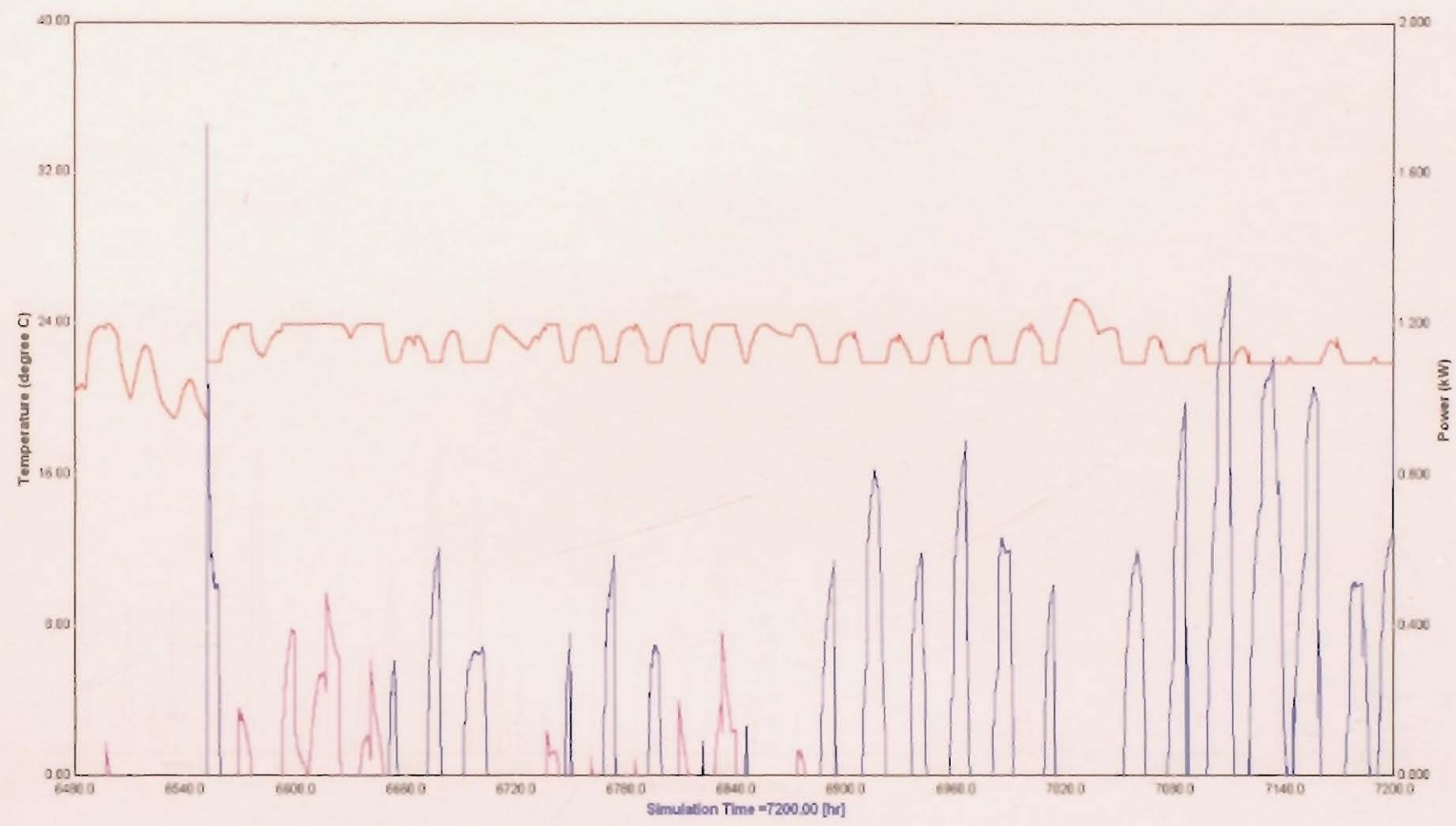

Figure 33: House temperature and heating/ cooling loads in October, Baltimore

As shown in Figure 33, the red graph describes the house temperature, the blue one is the house heating demand and the pink is the house cooling demand. The simulation showed that even in October the house would need cooling in order to maintain the temperature below $24^{\circ} \mathrm{C}$.

The same scenario was repeated to set the heating period. Figure 34 below provides an explanation in that regard. 


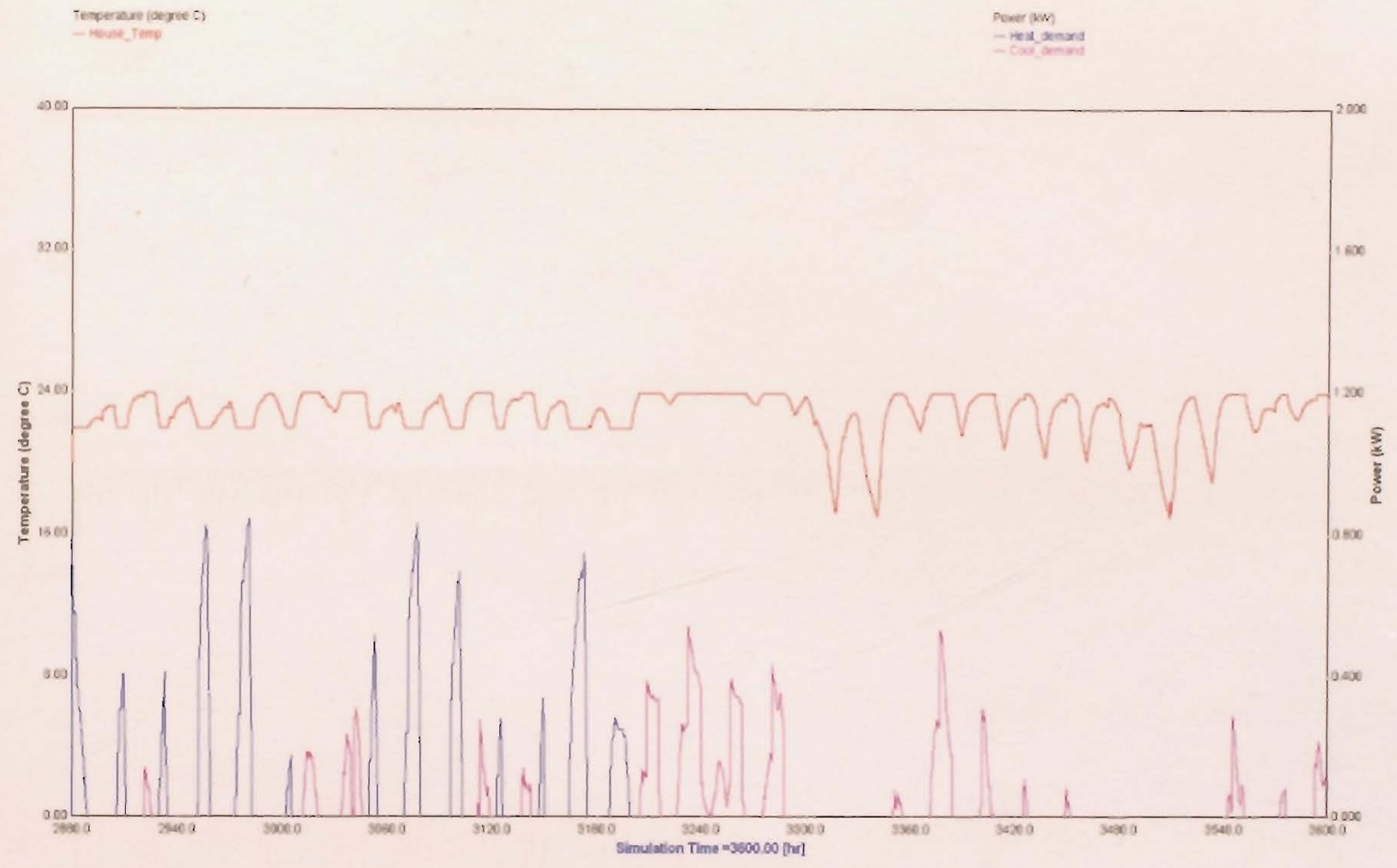

Figure 34: House temperature and heating/ cooling loads in April, Baltimore

\subsubsection{Simulation Results}

For all the simulation scenarios the supplied hot water temperature coming out of the HWT was maintained above $43.3^{\circ} \mathrm{C}$ as required by competition rules. However, the SHT temperature varied based on the heating demand but was well maintained in the temperature range set-points $\left(35-80^{\circ} \mathrm{C}\right)$.

Figures 35 and 36 show the HWT temperature and the auxiliary heater (electrical heater) signal for the case of Baltimore. The auxiliary heater set point was $50^{\circ} \mathrm{C}$ and it had an off-set of $5^{\circ} \mathrm{C}$. As illustrated in Figure 35 during the heating season, the electrical heater turned on more often than in the cooling season shown in Figure 37. 


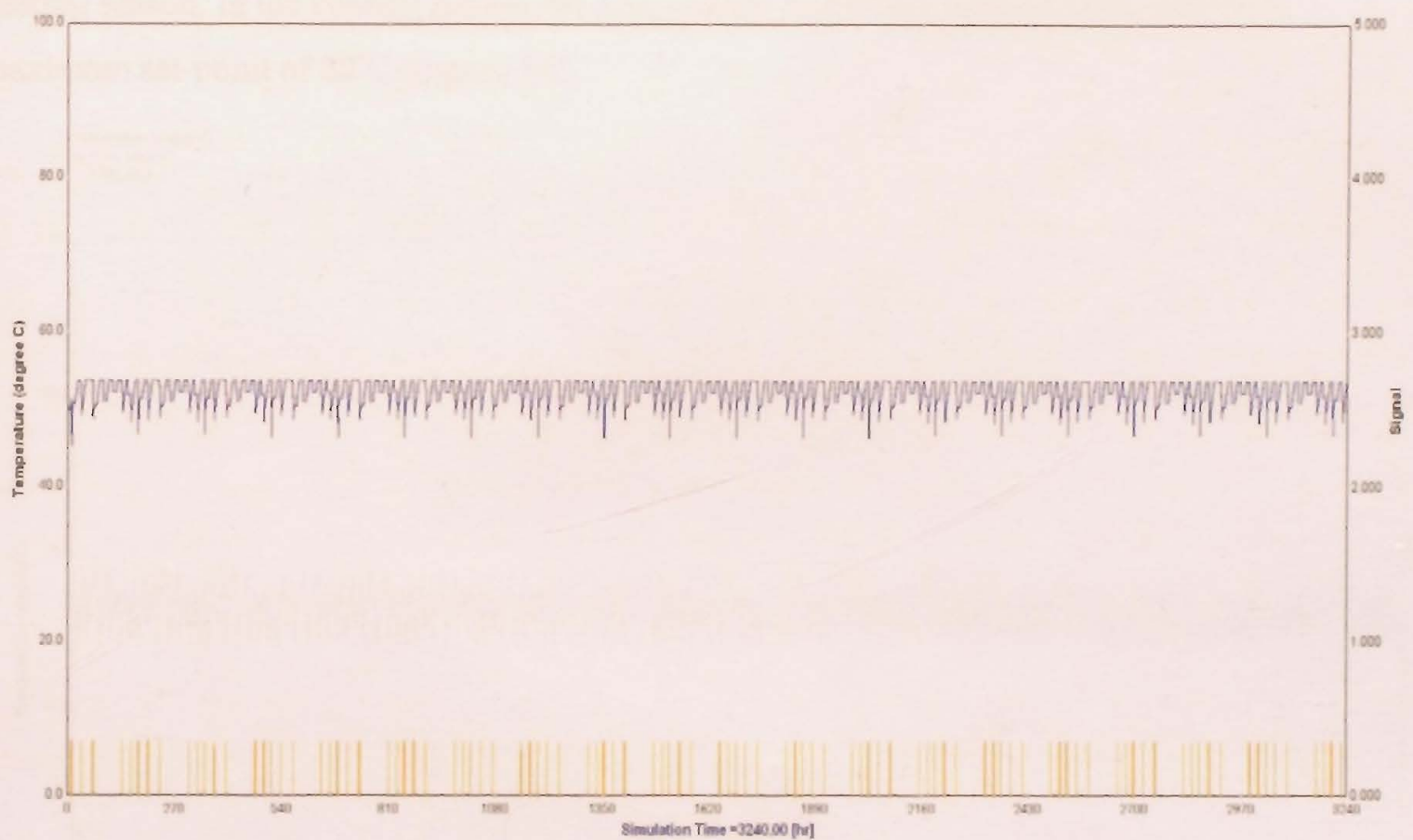

Figure 35: HWT temperature and backup electric heater signal during the heating season (Baltimore)

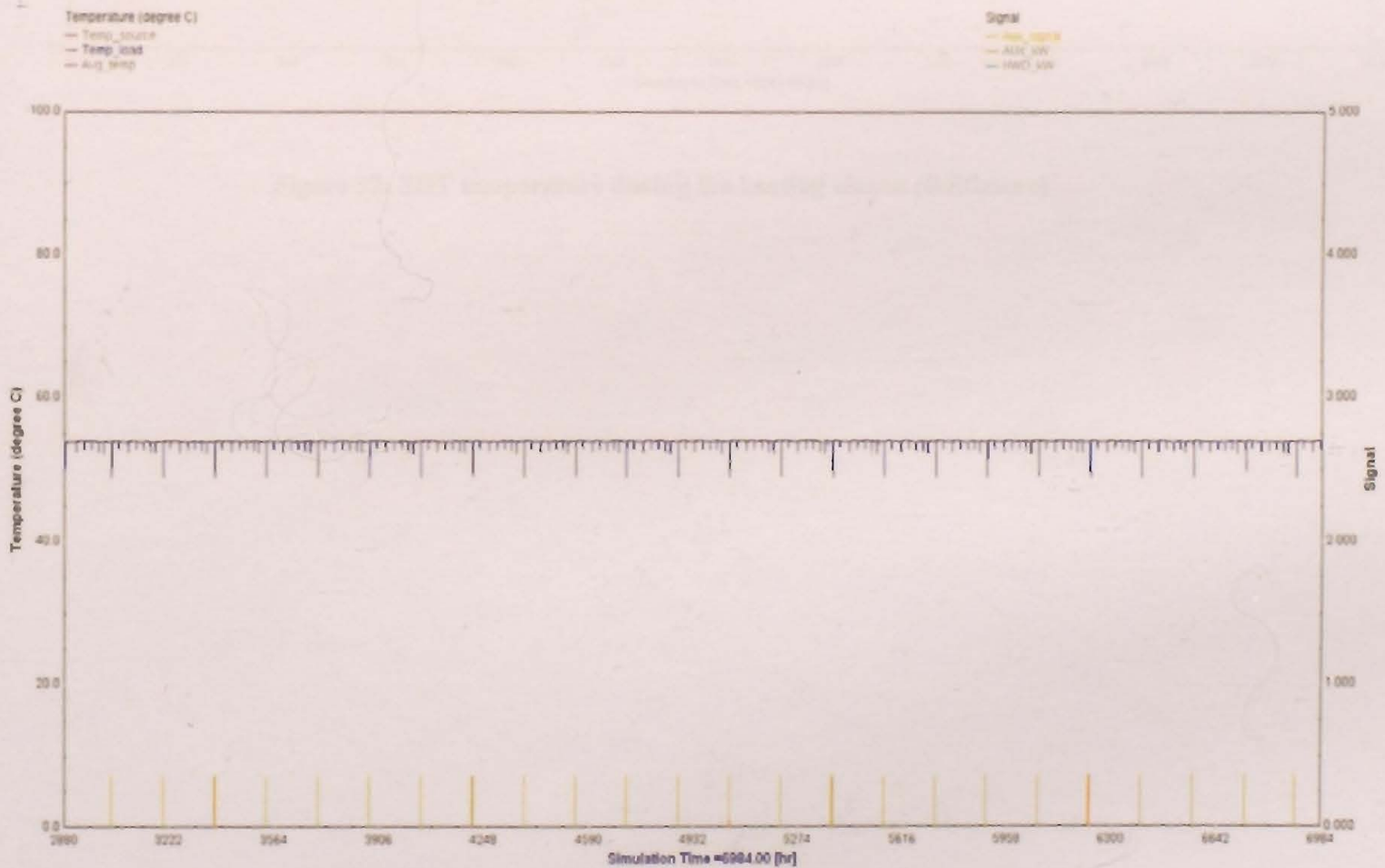

Figure 36: HWT temperature and backup electric heater signal during the cooling season (Baltimore) 
Figure 37 indicates that the SHT temperature did not drop below $50^{\circ} \mathrm{C}$ even during the heating season. In the cooling season the temperature inside this tank reached up to the maximum set-point of $80^{\circ} \mathrm{C}$ (Figure 38).

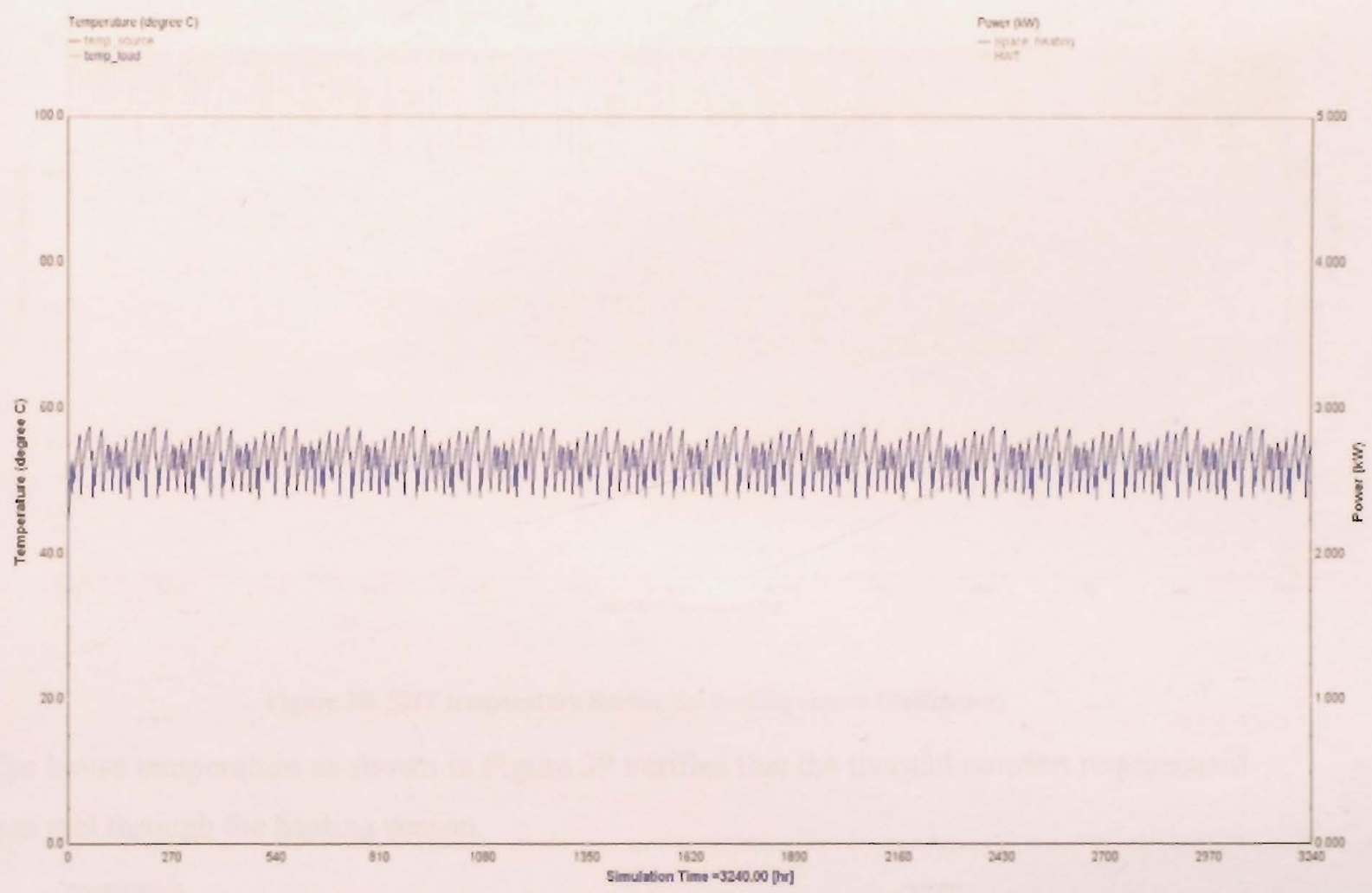

Figure 37: SHT temperature during the heating season (Baltimore) 


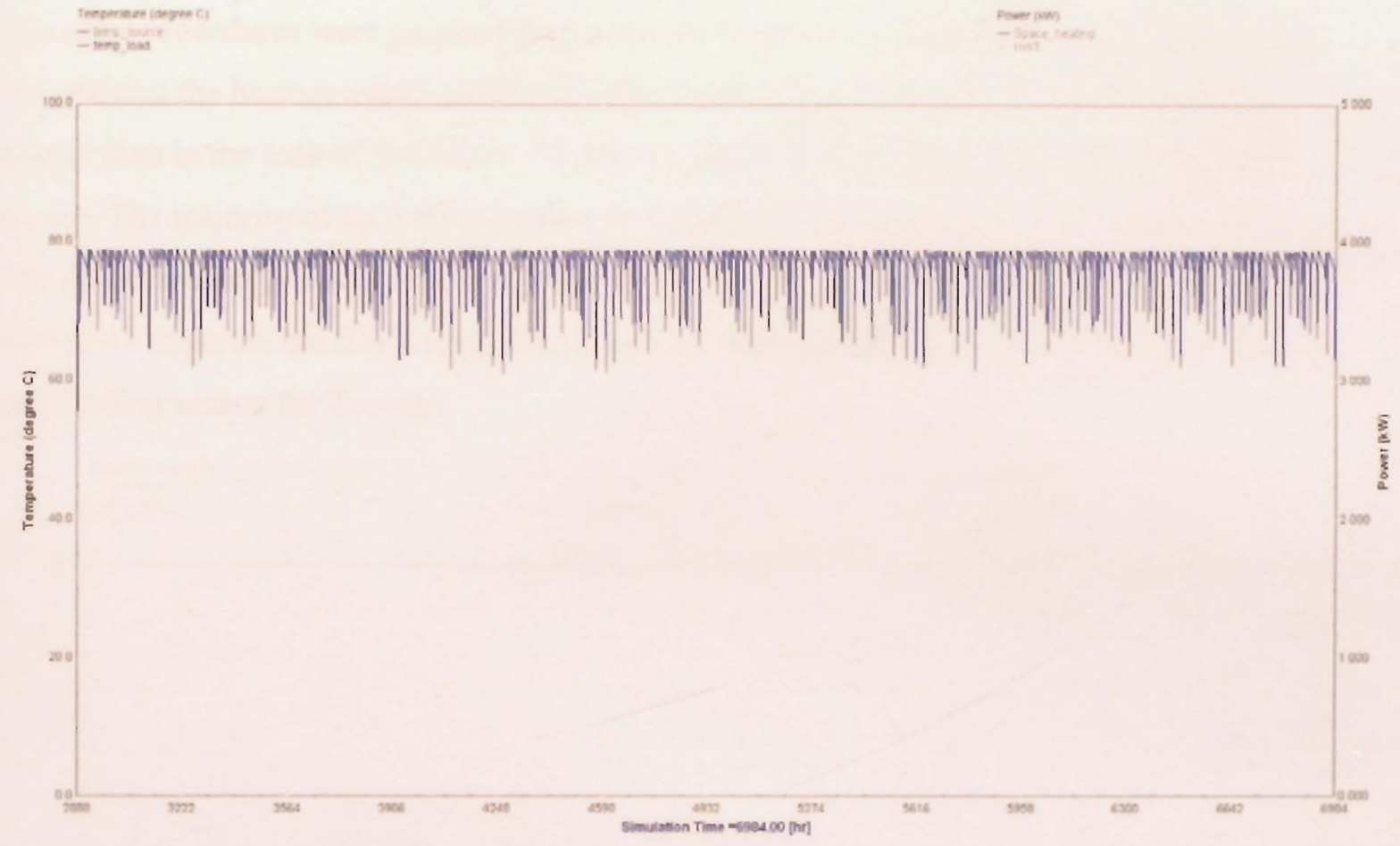

Figure 38: SHT temperature during the cooling season (Baltimore)

The house temperature as shown in Figure 39 verifies that the thermal comfort requirement was met through the heating season.

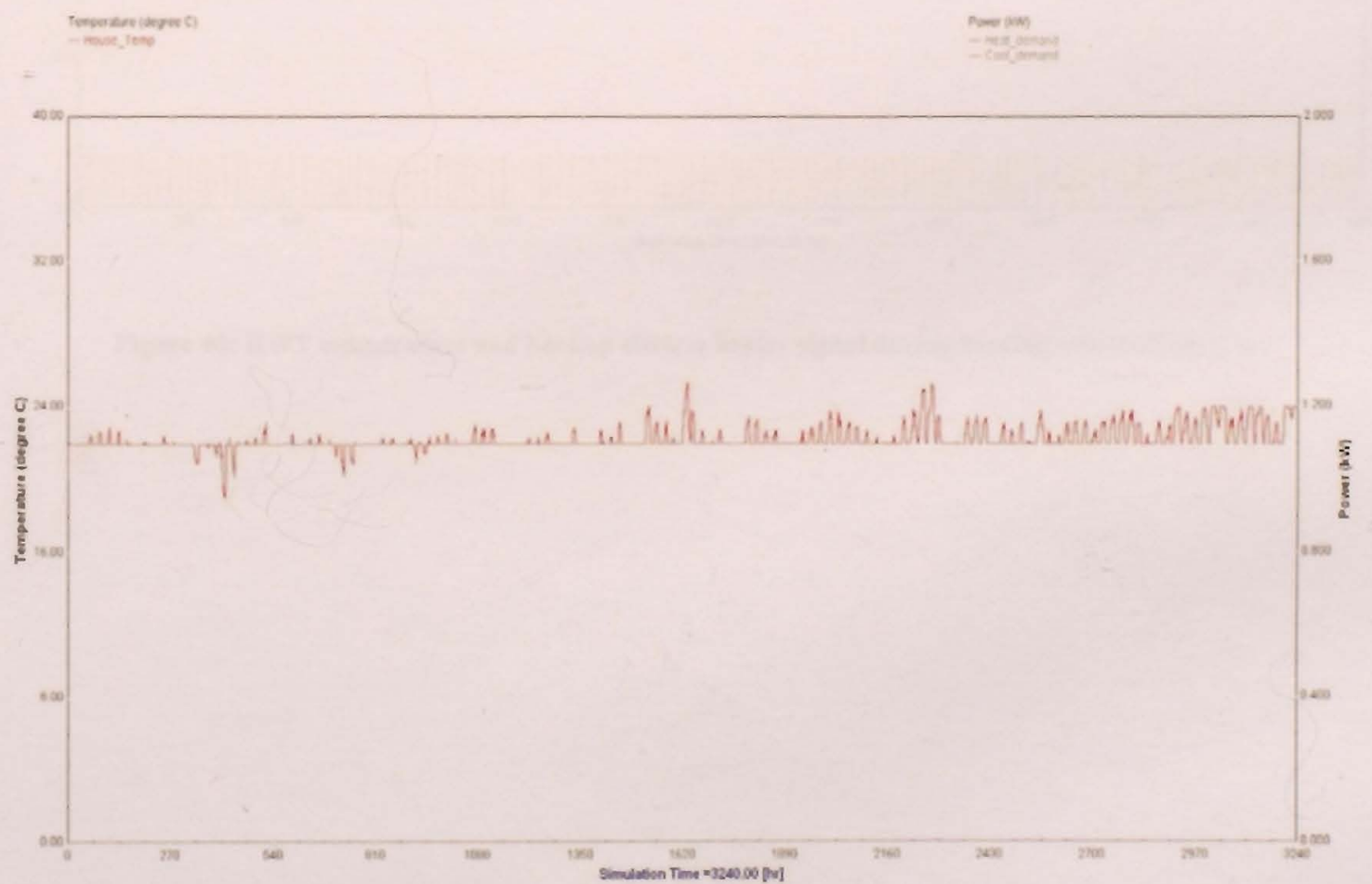

Figure 39: House temperature during the winter (Heating season, Baltimore) 
The same procedures were performed to study the tank temperature for Toronto. The results showed that the backup heater, inside the HWT, turned on more often during the heating season than in the case of Baltimore. This is due to the colder Toronto weather during the winter. The majority of the heat extracted from the SHT was used for space heating purposes. The space heating demand over one year for Toronto is 1.6 times that of Baltimore. Figures 40 and 41 illustrate the HWT temperature and backup electric heater signal during the heating and cooling season for Toronto.

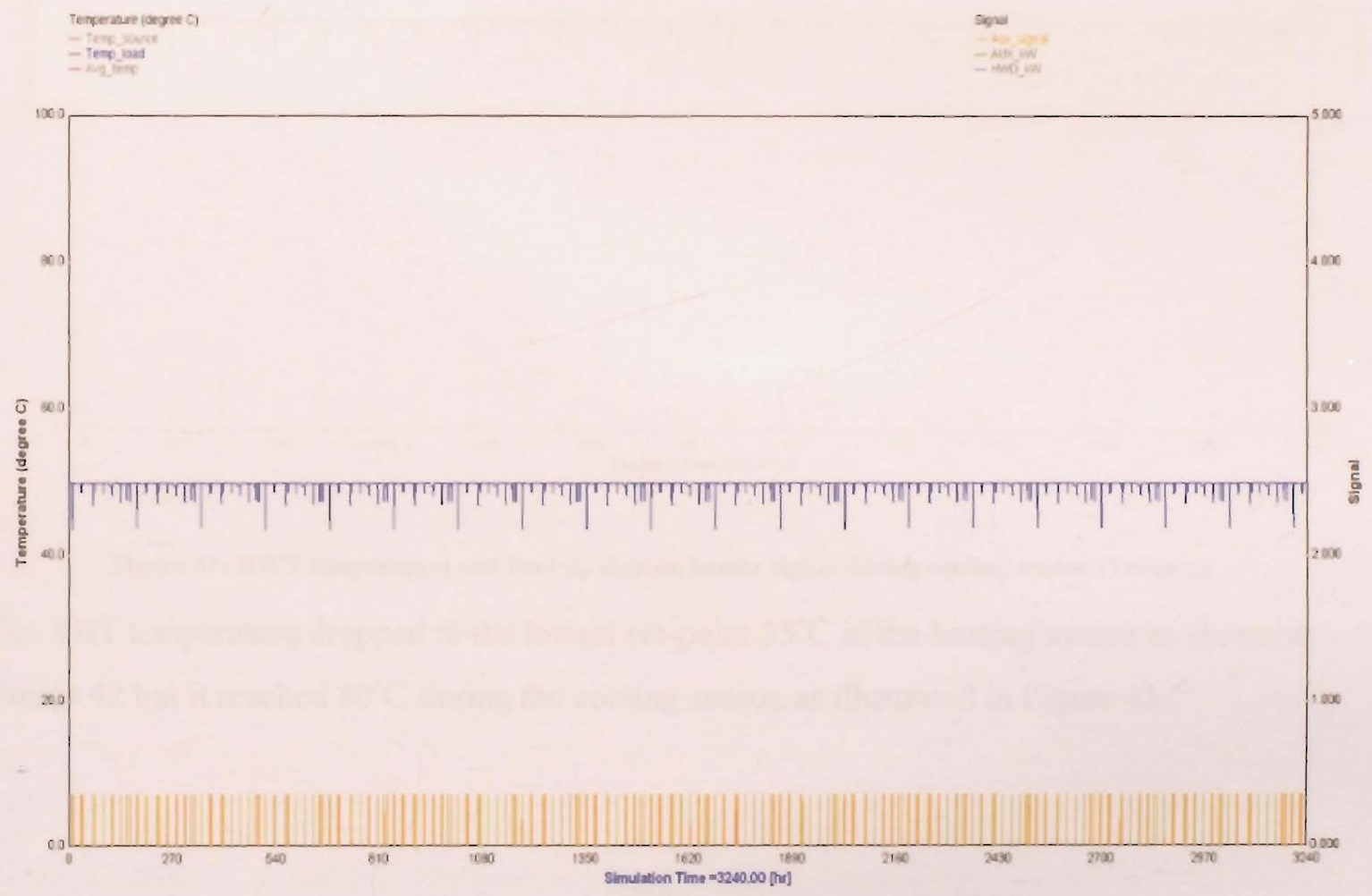

Figure 40: HWT temperature and backup electric heater signal during heating season (Toronto) 


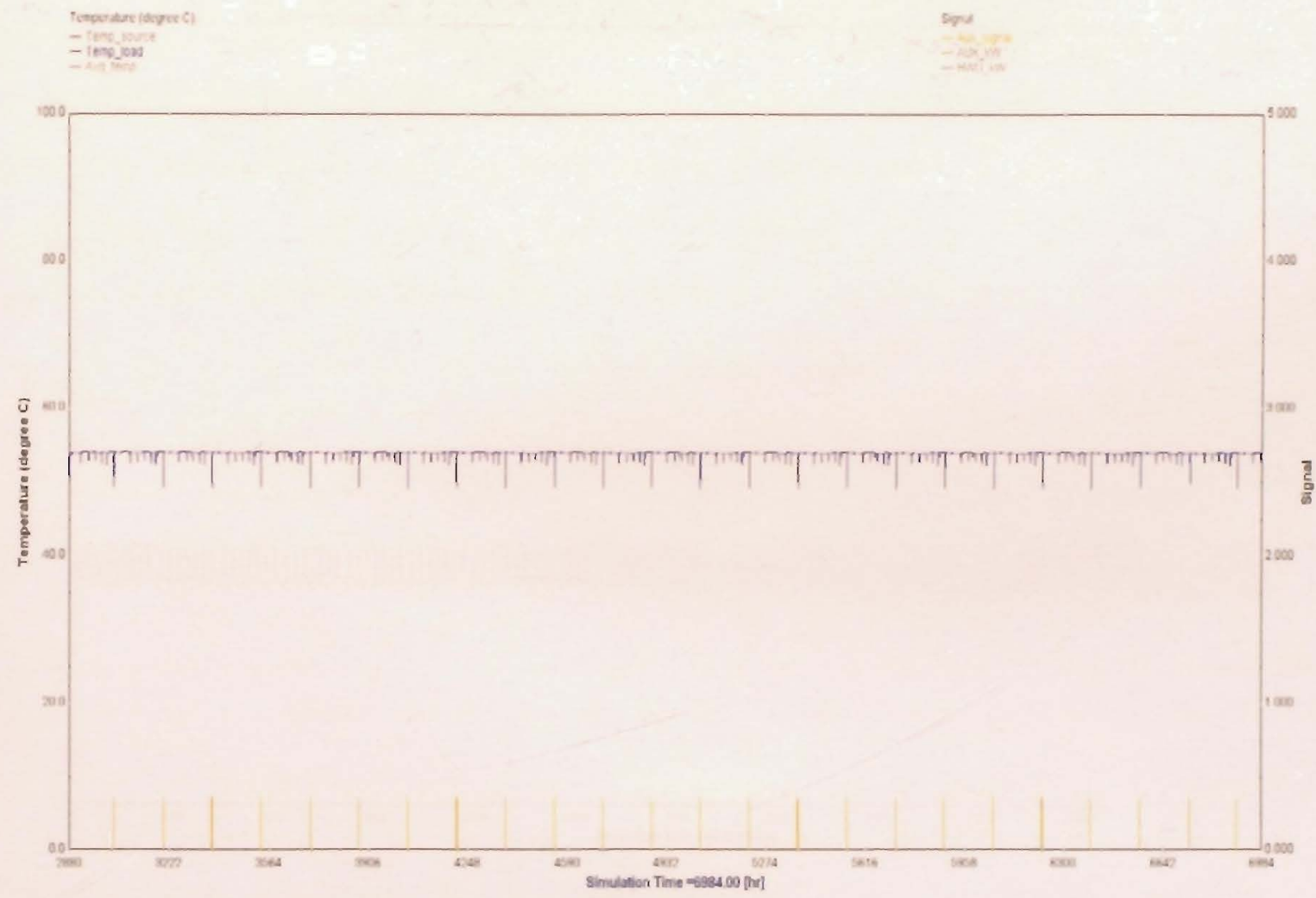

Figure 41: HWT temperature and backup electric heater signal during cooling season (Toronto)

The SHT temperature dropped to the lowest set-point $35^{\circ} \mathrm{C}$ in the heating season as shown in Figure 42 but it reached $80^{\circ} \mathrm{C}$ during the cooling season as illustrated in Figure 43. 


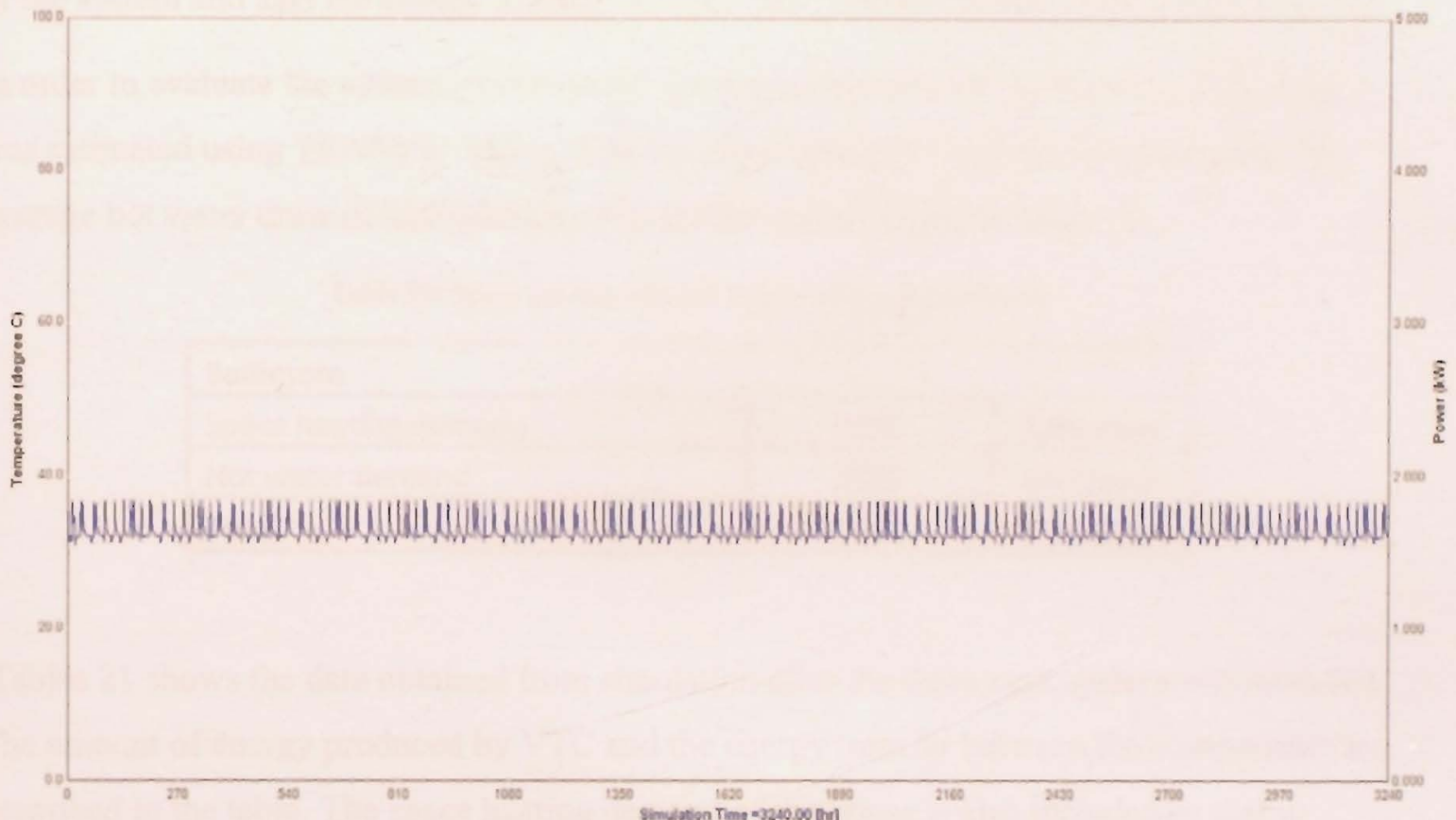

Figure 42: SHT temperature during heating season (Toronto)

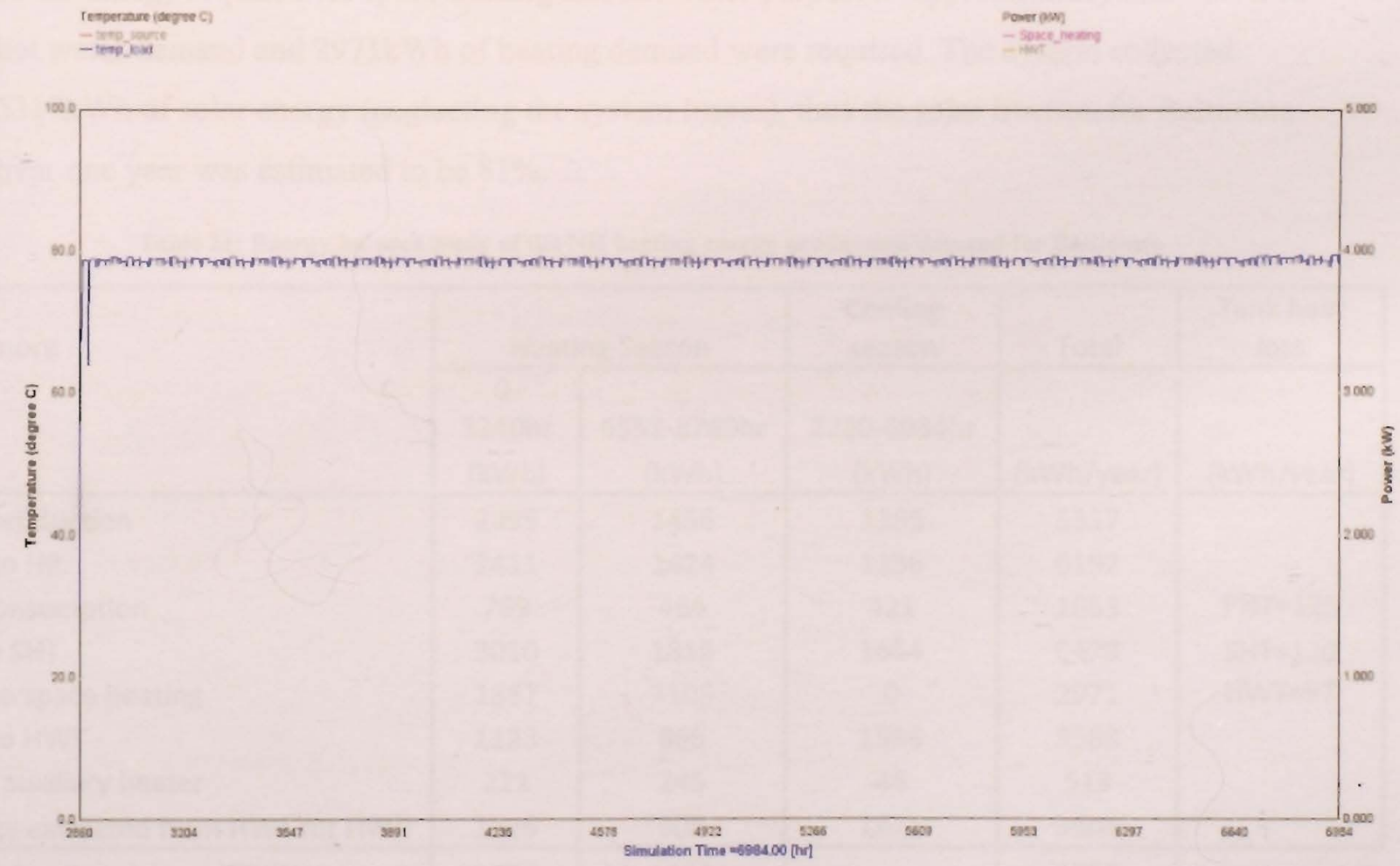

Figure 43: SHT temperature during cooling season (Toronto) 
By analyzing the data obtained from the simulation, the total solar thermal energy production of the system and also the energy transfer between components of the system were estimated. In order to evaluate the system performance, the annual space heating demand of the house was estimated using TRNSYS. The annual hot water demand was calculated based on the average hot water draw of 220 liter/day. The results are indicated in Table 20.

Table 20: Space heating and hot water energy requirements

\begin{tabular}{|l|c|l|}
\hline Baltimore \\
\hline Space heating demand & 2835 & $\mathrm{kWh} /$ year \\
\hline Hot water demand & 3737 & $\mathrm{kWh} /$ year \\
\hline Total & 6572 & $\mathrm{kWh} /$ year \\
\hline
\end{tabular}

Tables 21 shows the data obtained from simulation after the three-tank system was modeled. The amount of energy produced by VTC and the energy transfer between the components are described in the table. The space heating demand of the house is also included so that it would be easier to compare the energy provided by the solar system and energy demand by the house. According to results, the system was able to generate enough energy to meet most of the energy required for space heating and hot water purposes. Approximately $3804 \mathrm{kWh}$ of hot water demand and $2971 \mathrm{kWh}$ of heating demand were required. The system collected $5317 \mathrm{kWh}$ of solar energy (neglecting the system losses), thus the solar fraction for Baltimore over one year was estimated to be $81 \%$.

Table 21: Energy balance study of the NH heating energy production/demand for Baltimore

\begin{tabular}{|c|c|c|c|c|c|}
\hline \multirow[t]{2}{*}{ Baltimore } & \multicolumn{2}{|c|}{ Heating Season } & \multirow{2}{*}{$\begin{array}{c}\begin{array}{c}\text { Cooling } \\
\text { season }\end{array} \\
2280-6984 \mathrm{hr} \\
(\mathrm{kWh})\end{array}$} & \multirow{2}{*}{$\begin{array}{c}\text { Total } \\
\text { (kWh/year) }\end{array}$} & \multirow{2}{*}{$\begin{array}{c}\begin{array}{c}\text { Tank heat } \\
\text { loss }\end{array} \\
\\
\text { (kWh/year) }\end{array}$} \\
\hline & $\begin{array}{c}0- \\
3240 \mathrm{hr} \\
(\mathrm{kWh})\end{array}$ & $\begin{array}{c}\text { 6552-8760hr } \\
(\mathrm{kWh})\end{array}$ & & & \\
\hline VTC production & 2495 & 1456 & 1366 & 5317 & \multirow{8}{*}{$\begin{array}{l}\mathrm{PHT}=125 \\
\mathrm{SHT}=120 \\
\mathrm{HWT}=97\end{array}$} \\
\hline PHT to HP & 2411 & 1424 & 1356 & 5192 & \\
\hline HP Consumption & 769 & 464 & 421 & 1653 & \\
\hline HP to SHT & 3010 & 1816 & 1654 & 6479 & \\
\hline SHT to space heating & 1867 & 1105 & 0 & 2971 & \\
\hline SHT to HWT & 1123 & 666 & 1598 & 3388 & \\
\hline HWT auxiliary heater & 221 & 245 & 46 & 513 & \\
\hline Energy extracted from HWT for HWD & 1326 & 908 & 1571 & 3804 & \\
\hline Space heating demand(SHD) & 1777 & 1059 & & 2835 & \\
\hline Domestic hot water demand(DHWD) & & & & 3737 & \\
\hline
\end{tabular}


The solar fraction is defined as the solar thermal energy collected divided by the total thermal energy demand. For Toronto, this number was estimated to be $71 \%$ as shown in Table 22 . This should improve if a more thermally massive storage system is used (i.e., borehole storage or a larger tank).

Table 22: Energy balance study of the NH heating energy production/ demand for Toronto

\begin{tabular}{|c|c|c|c|c|c|}
\hline \multirow[t]{2}{*}{ Toronto } & \multicolumn{2}{|c|}{ Heating Season } & \multirow{2}{*}{$\begin{array}{c}\begin{array}{c}\text { Cooling } \\
\text { season }\end{array} \\
2280-6984 \mathrm{hr} \\
(\mathrm{kWh})\end{array}$} & \multirow{2}{*}{$\begin{array}{c}\text { Total } \\
\text { (kWh/year) }\end{array}$} & \multirow{2}{*}{$\begin{array}{c}\begin{array}{c}\text { Tank heat } \\
\text { loss }\end{array} \\
\text { (kWh/year) }\end{array}$} \\
\hline & $\begin{array}{c}0- \\
3240 \mathrm{hr} \\
(\mathrm{kWh})\end{array}$ & $\begin{array}{c}6552-8760 \mathrm{hr} \\
(\mathrm{kWh})\end{array}$ & & & \\
\hline VTC production & 2370 & 2300 & 1260 & 5930 & \multirow{8}{*}{$\begin{array}{l}\mathrm{PHT}=115 \\
\mathrm{SHT}=124 \\
\mathrm{HWT}=96\end{array}$} \\
\hline PHT to HP & 2328 & 2275 & 1212 & 5815 & \\
\hline HP Consumption & 782 & 465 & 405 & 1653 & \\
\hline HP to SHT & 3110 & 1855 & 1576 & 6541 & \\
\hline SHT to space heating & 2925 & 1766 & 0 & 4691 & \\
\hline SHT to HWT & 166 & 30 & 1530 & 1726 & \\
\hline HWT auxiliary heater & 1123 & 977 & 55 & 2155 & \\
\hline Energy extracted from HWT for HWD & 1273 & 941 & 1571 & 3785 & \\
\hline Space heating demand & 2874 & 1741 & & 4615 & \\
\hline SHD+DWHD & & & & 8352 & \\
\hline Solar fraction (\%) & & & & 71 & \\
\hline
\end{tabular}

The solar thermal energy production numbers were found by continuously running fluid through the collector as long as the temperature of the fluid coming out of the collector was higher than the one going in. In reality, the pump was only running when there was approximately $5^{\circ} \mathrm{C}$ difference between the inlet and outlet temperatures (as controlled by the solar thermal pump controlling unit). These numbers are therefore overestimated, but provide the team with a good approximation of the potential for thermal energy production.

The analyses were continued by running the simulation for different cities across Canada including Vancouver, Edmonton, Halifax and Montreal. The solar fraction varied from each city but it shows that the solar system contributed more than $60 \%$ of the system energy requirement. Tables $23,24,25$ and 26 show the results. 
Table 23: Energy balance study of the NH heating energy production/ demand for Vancouver

\begin{tabular}{|c|c|c|c|c|c|}
\hline \multirow[t]{2}{*}{ Vancouver } & \multicolumn{2}{|c|}{ Heating Season } & \multirow{2}{*}{$\begin{array}{c}\begin{array}{c}\text { Cooling } \\
\text { season }\end{array} \\
2280-6984 \mathrm{hr} \\
\text { (kWh) }\end{array}$} & \multirow{2}{*}{$\begin{array}{c}\text { Total } \\
\text { (kWh/year) }\end{array}$} & \multirow{2}{*}{$\begin{array}{c}\begin{array}{c}\text { Tank heat } \\
\text { loss }\end{array} \\
\text { (kWh/year) }\end{array}$} \\
\hline & $\begin{array}{c}0- \\
3240 \mathrm{hr} \\
(\mathrm{kWh})\end{array}$ & $\begin{array}{c}6552- \\
8760 \mathrm{hr} \\
(\mathrm{kWh})\end{array}$ & & & \\
\hline VTC production & 1797 & 1713 & 1281 & 4792 & \multirow{8}{*}{$\begin{array}{l}\mathrm{PHT}=126 \\
\mathrm{SHT}=130 \\
\mathrm{HWT}=97\end{array}$} \\
\hline PHT to HP & 1752 & 1692 & 1222 & 4666 & \\
\hline HP Consumption & 580 & 539 & 404 & 1523 & \\
\hline HP to SHT & 2324 & 2108 & 1606 & 6039 & \\
\hline SHT to space heating & 1845 & 1426 & 0 & 3271 & \\
\hline SHT to HWT & 472 & 630 & 1530 & 2631 & \\
\hline HWT auxiliary heater & 801 & 191 & 54 & 1047 & \\
\hline Energy extracted from HWT for HWD & 1195 & 815 & 1571 & 3581 & \\
\hline Space heating demand & 1793 & 1364 & 0 & 3158 & \\
\hline SHD+DWHD & & & & 6895 & \\
\hline Solar fraction (\%) & & & & 69 & \\
\hline
\end{tabular}

In Edmonton, Halifax and Montreal the space heating demand was relatively high. Therefore, the amount of energy consumed by the auxiliary heater inside the HWT is noticeable. The VTC production was the highest in Edmonton where the amount of space heating demand has the highest value.

Table 24: Energy balance study of the NH heating energy production/ demand for Edmonton

\begin{tabular}{|c|c|c|c|c|c|}
\hline \multirow[t]{2}{*}{ Edmonton } & \multicolumn{2}{|c|}{ Heating Season } & \multirow{2}{*}{$\begin{array}{c}\begin{array}{c}\text { Cooling } \\
\text { season }\end{array} \\
\begin{array}{c}2280-6984 \mathrm{hr} \\
(\mathrm{kWh})\end{array}\end{array}$} & \multirow{2}{*}{$\begin{array}{c}\text { Total } \\
\text { (kWh/year) }\end{array}$} & \multirow{2}{*}{$\begin{array}{c}\begin{array}{c}\text { Tank heat } \\
\text { loss }\end{array} \\
\text { (kWh/year) }\end{array}$} \\
\hline & $\begin{array}{c}0- \\
3240 \mathrm{hr} \\
(\mathrm{kWh}) \\
\end{array}$ & $\begin{array}{l}6552- \\
8760 \mathrm{hr} \\
(\mathrm{kWh}) \\
\end{array}$ & & & \\
\hline VTC production & 2723 & 1994 & 1343 & 6060 & \multirow{8}{*}{$\begin{array}{l}\mathrm{PHT}=127 \\
\mathrm{SHT}=115 \\
H W T=94\end{array}$} \\
\hline PHT to HP & 2699 & 1948 & 1286 & 5933 & \\
\hline HP Consumption & 886 & 638 & 405 & 1930 & \\
\hline HP to SHT & 3536 & 2521 & 1618 & 7676 & \\
\hline SHT to space heating & 3467 & 2476 & 0 & 5943 & \\
\hline SHT to HWT & 55 & 33 & 1530 & 1618 & \\
\hline HWT auxiliary heater & 1039 & 713 & 55 & 1807 & \\
\hline Energy extracted from HWT for HWD & 1033 & 726 & 1571 & 3331 & \\
\hline Space heating demand & 3310 & 2399 & & 5709 & \\
\hline SHD+DWHD & \multicolumn{4}{|r|}{9446} & \\
\hline Solar fraction (\%) & \multicolumn{4}{|r|}{64} & \\
\hline
\end{tabular}


Table 25: Energy balance study of the NH heating energy production/demand for Halifax

\begin{tabular}{|c|c|c|c|c|c|}
\hline \multirow[t]{2}{*}{ Halifax } & \multicolumn{2}{|c|}{ Heating Season } & \multirow{2}{*}{$\begin{array}{c}\begin{array}{c}\text { Cooling } \\
\text { season }\end{array} \\
2280-6984 \mathrm{hr} \\
(\mathrm{kWh}) \\
\end{array}$} & \multirow{2}{*}{$\begin{array}{c}\text { Total } \\
\text { (kWh/year) }\end{array}$} & \multirow{2}{*}{$\begin{array}{c}\begin{array}{c}\text { Tank heat } \\
\text { loss }\end{array} \\
\text { (kWh/year) }\end{array}$} \\
\hline & $\begin{array}{c}0- \\
3240 \mathrm{hr} \\
(\mathrm{kWh})\end{array}$ & $\begin{array}{l}6552- \\
8760 \mathrm{hr} \\
(\mathrm{kWh})\end{array}$ & & & \\
\hline VTC production & 2447 & 1357 & 1579 & 5383 & \multirow{8}{*}{$\begin{array}{l}\mathrm{PHT}=127 \\
\mathrm{SHT}=132 \\
\mathrm{HWT}=93\end{array}$} \\
\hline PHT to HP & 2396 & 1313 & 1546 & 5256 & \\
\hline HP Consumption & 802 & 435 & 497 & 1734 & \\
\hline HP to SHT & 3170 & 1778 & 1629 & 6578 & \\
\hline SHT to space heating & 2968 & 1680 & 0 & 4648 & \\
\hline SHT to HWT & 150 & 78 & 1569 & 1798 & \\
\hline HWT auxiliary heater & 1042 & 693 & 56 & 1791 & \\
\hline Energy extracted from HWT for HWD & 1139 & 766 & 1591 & 3496 & \\
\hline Space heating demand & 2851 & 1595 & & 4446 & \\
\hline SHD+DWHD & \multicolumn{4}{|r|}{8183} & \\
\hline Solar fraction (\%) & \multicolumn{4}{|r|}{66} & \\
\hline
\end{tabular}

Table 26: Energy balance study of the NH heating energy production/ demand for Montreal

\begin{tabular}{|c|c|c|c|c|c|}
\hline \multirow{2}{*}{ Montreal } & \multicolumn{2}{|c|}{ Heating Season } & \multirow{2}{*}{$\begin{array}{c}\begin{array}{c}\text { Cooling } \\
\text { season }\end{array} \\
2280-6984 \mathrm{hr} \\
(\mathrm{kWh})\end{array}$} & \multirow{2}{*}{$\begin{array}{c}\text { Total } \\
\text { (kWh/year) }\end{array}$} & \multirow{2}{*}{$\begin{array}{c}\begin{array}{c}\text { Tank heat } \\
\text { loss }\end{array} \\
\\
\text { (kWh/year) }\end{array}$} \\
\hline & $\begin{array}{c}0- \\
3240 \mathrm{hr} \\
\text { (kWh) }\end{array}$ & $\begin{array}{c}6552-8760 \mathrm{hr} \\
(\mathrm{kWh})\end{array}$ & & & \\
\hline VTC production & 2813 & 1764 & 1265 & 5841 & \multirow{8}{*}{$\begin{array}{l}\mathrm{PHT}=128 \\
\mathrm{SHT}=132 \\
\mathrm{HWT}=93\end{array}$} \\
\hline PHT to HP & 2796 & 1695 & 1222 & 5713 & \\
\hline HP Consumption & 919 & 552 & 405 & 1876 & \\
\hline HP to SHT & 3634 & 2206 & 1620 & 7460 & \\
\hline SHT to space heating & 3108 & 2114 & 0 & 5223 & \\
\hline SHT to HWT & 489 & 86 & 1530 & 2105 & \\
\hline HWT auxiliary heater & 720 & 640 & 54 & 1414 & \\
\hline Energy extracted from HWT for HWD & 1129 & 725 & 1571 & 3426 & \\
\hline Space heating demand & 3023 & 1951 & & 4974 & \\
\hline SHD+DWHD & \multicolumn{4}{|r|}{8711} & \\
\hline Solar fraction (\%) & \multicolumn{4}{|r|}{67} & \\
\hline
\end{tabular}

While studying the solar thermal system, the simulation showed that for Edmonton, Halifax and Montreal, during the heating season, when the house needs space heating, the heating 
system is required to operate over a longer period. Figure 44 shows the house temperature profile in Halifax. The pink graph indicates the space cooling demand and the red graph is the house temperature. It illustrates that even during the period defined as the cooling season, the house temperature dropped below $22^{\circ} \mathrm{C}$, as a result heating was required.

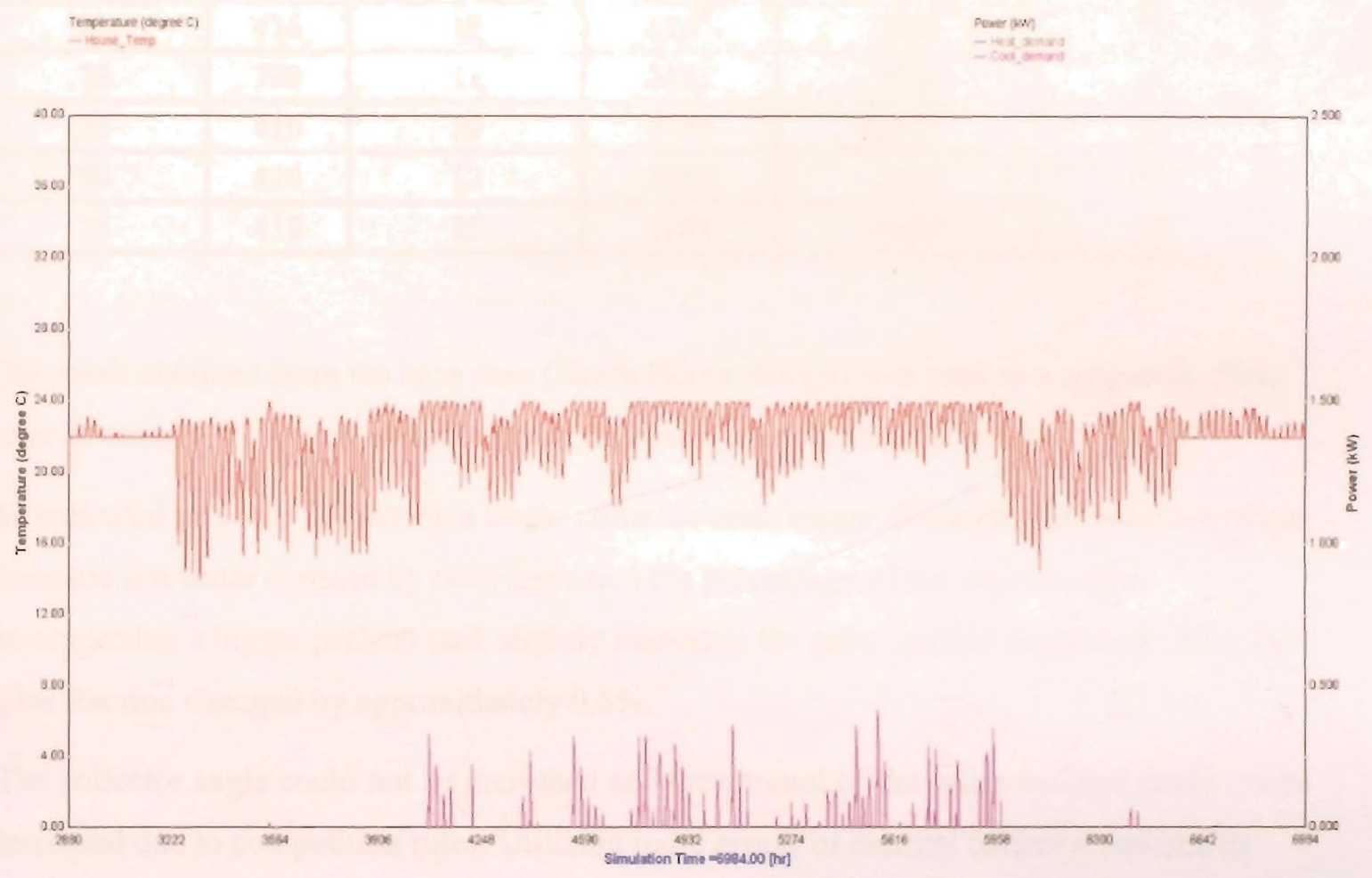

Figure 44: House temperature profile during the cooling season, Halifax

\subsection{Sensitivity Analyses}

Sensitivity analyses were performed for Toronto in order to investigate whether the design is close to optimal. In each scenario one variable was changed and the solar fraction for that particular case was calculated. Vacuum tube collector tilt angle (VTC tilt angle), preheat tank (PHT) size, solar collector area and domestic hot water demand (DHWD) were the parameters which were studied. Table 27 summarizes the results obtained from the analyses. 
Table 27: Results from the sensitivity analyses

\begin{tabular}{|c|c|c|c|c|c|}
\hline Toronto & \multicolumn{1}{|l|}{} \\
\hline VTC tilt angle & $\begin{array}{c}\text { PHT } \\
\text { size }\end{array}$ & Collector area & DHWD & VTC production & Solar Fraction \\
\hline (degree) & (liter) & $\left(\mathrm{m}^{2}\right)$ & $(\mathrm{kWh} /$ year $)$ & $(\mathrm{kWh} /$ year $)$ & $(\%)$ \\
\hline 25 & 416 & 12 & 3737 & 5930 & 71 \\
\hline 25 & 750 & 12 & 3737 & 5968 & 71 \\
\hline 25 & 416 & 24 & 3737 & 6191 & 74 \\
\hline 90 & 416 & 12 & 3737 & 5999 & 72 \\
\hline 25 & 416 & 12 & 2242 & 4994 & 73 \\
\hline
\end{tabular}

The result obtained from the base case (North House design) was used as a reference. Thus solar fraction of $71 \%$ was compared with the result from different scenarios.

As indicated in Table 27, having a larger collector area, bigger tilt angle and reduction of the domestic hot water demand by $60 \%$ increased the percentage of the solar fraction.

Incorporating a bigger preheat tank slightly increased the solar thermal production; thus, the solar fraction changed by approximately $0.5 \%$.

The collector angle could not be increased and the amount of hot water demand could not be decreased due to competition rules. Utilizing more arrays of thermal collector resulted in reducing the number of PV panels. The solar fraction of the existing system compared favorably with that of a bigger collector area; therefore, there was no need to decrease the number of $\mathrm{PV}$ panels.

\subsection{Competition Measured Data}

The system performance can be verified by analyzing the competition measured data. Except for the house temperature and relative humidity $(\% \mathrm{RH})$, which were obtained from DOE measures, the data presented in this section are the data collected by Team North. Figure 45 shows how the heating system responded to the indoor temperature. As illustrated in Figure 45 the cooling and heating signal were activated in response to the indoor temperature variations. The house temperature was well within the range. However, on October 16, due to some unfortunate circumstances, the team was forced to completely open the door during the public tour. As indicated in Figures 45 and 46, the outside temperature was relatively low and $\% \mathrm{RH}$ was high due to the weather condition. It was raining constantly for four days and it 
was cold. Therefore, the system was not able to stabilize the indoor conditions. Figure 46

explains that the house maintained, on the average, $45 \% \mathrm{RH}$ when the outside $\% \mathrm{RH}$ dramatically fluctuated. 


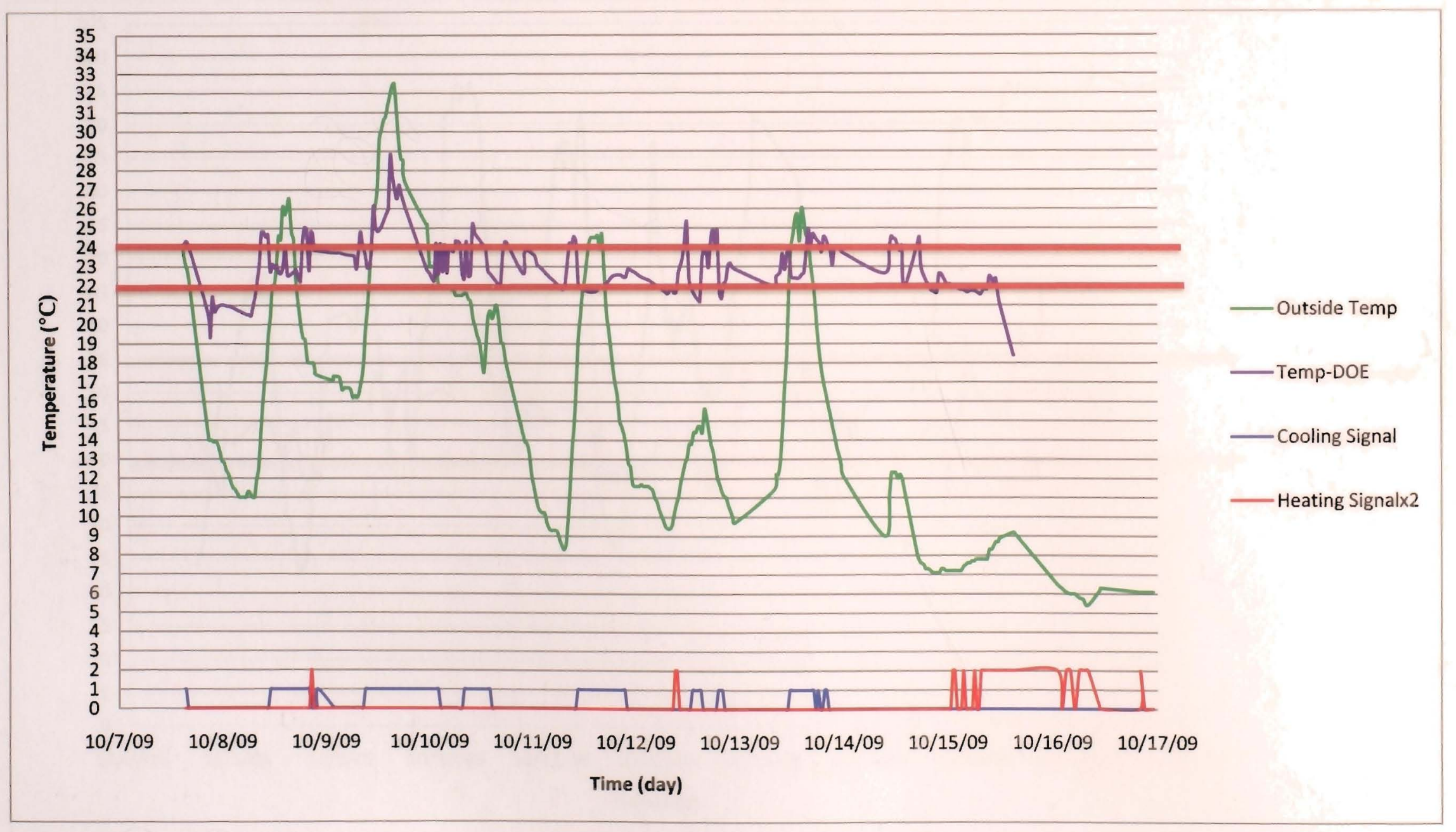

Figure 45: Response of the heating system to the temperature variations 


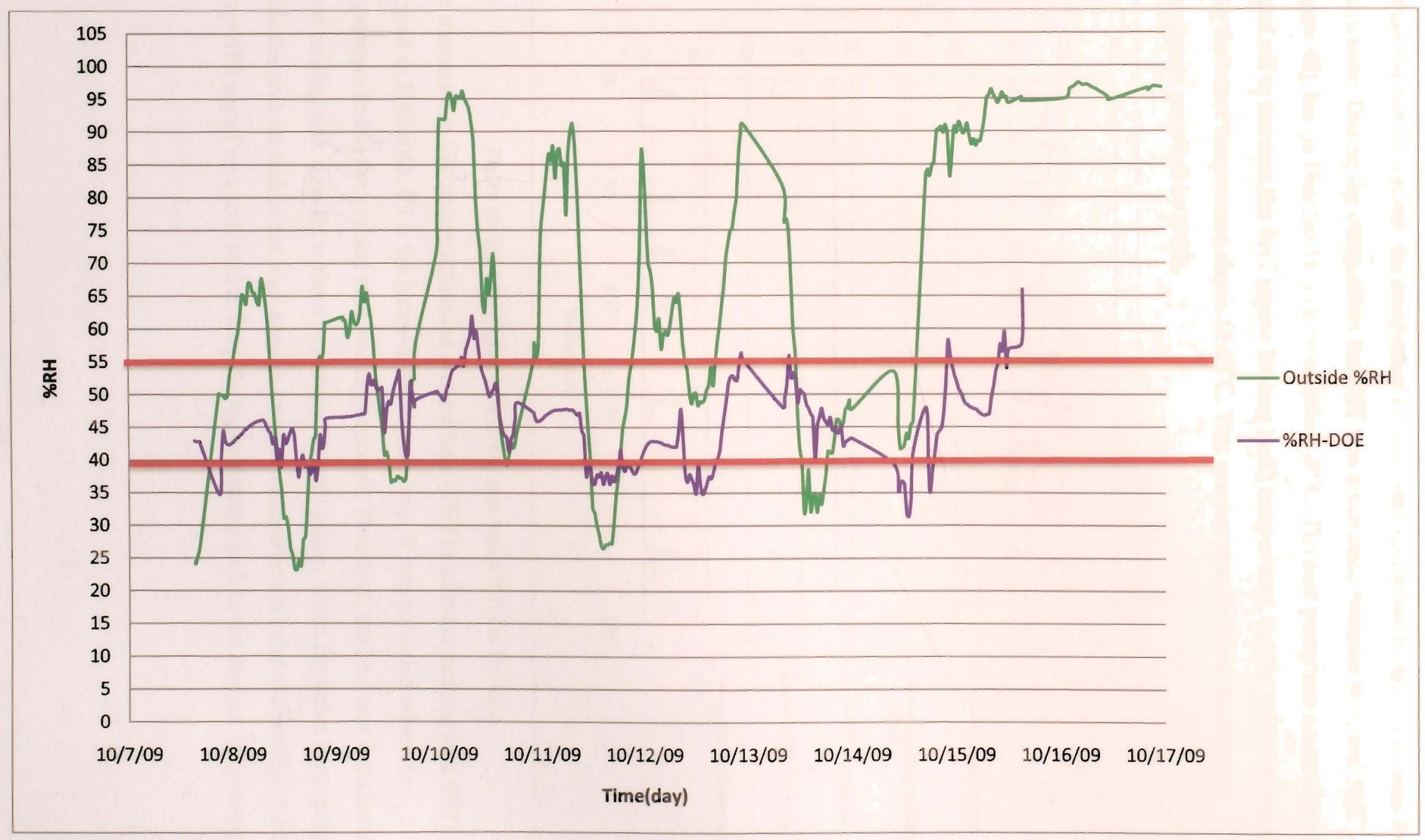

Figure 46: Comparison between the exterior \%RH and the house \%RH 
Figure 47, describes the system performance on that particular day (October 16). In order to analyze the control system, the component signals were multiplied by some numbers for clarification. During the competition the SHT was maintained between $40^{\circ} \mathrm{C}$ and $60^{\circ} \mathrm{C}$ (Figure 48), but on October 16 it dropped below $40^{\circ} \mathrm{C}$. The heat pump was constantly turning on and off to increase the SHT (space heating tank) temperature, but the system could not bring the house temperature above $18.63^{\circ} \mathrm{C}$. This number was the house maximum temperature recorded by DOE.

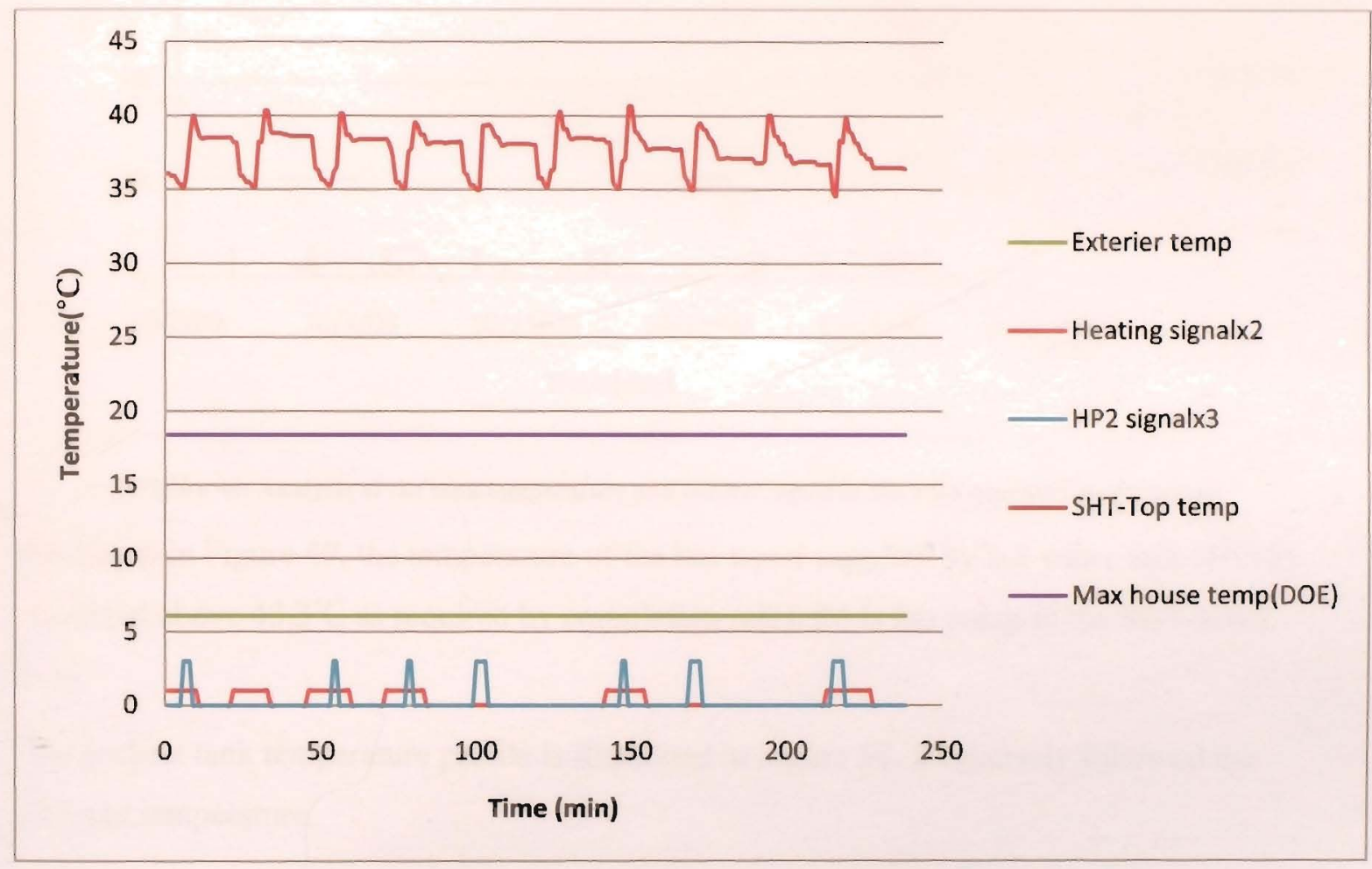

Figure 47: Space heating scenario on Oct 16th from 8:00PM to 12:00AM

The temperature fluctuation inside the preheat tank (PHT) and space heating tank (SHT) is graphed in Figure 48. P3 is the pump in the bypass loop. It was activated when the temperature inside the preheat tank was high enough. Therefore, the heat was transferred to space heating tank directly without activating the heat pump. When the water temperature inside the preheat tank is not high enough because of insufficient solar availability, the heat pump HP2 signal was activated to keep the space heating tank to the desired temperature. 


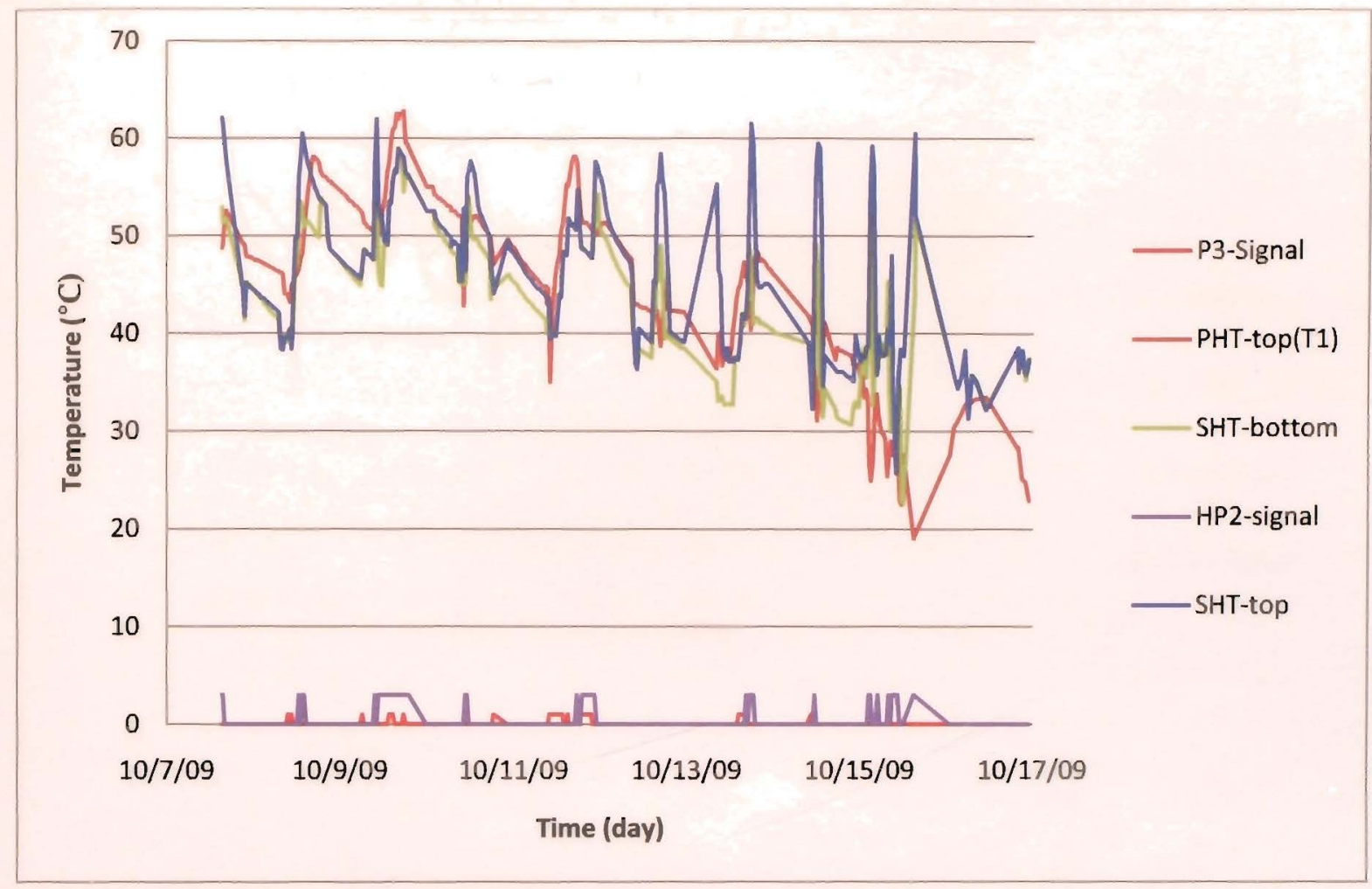

Figure 48: Analysis of the tank temperature and control signal in the PHT and SHT loop analysis

As shown in Figure 49, the temperature of the hot water supplied by hot water tank (HWT) remained above $43.3^{\circ} \mathrm{C}$ as required by completion rules. $\mathrm{P} 4$ is the pump in the SHT-HWT loop.

The preheat tank temperature profile is illustrated in Figure 50. It relatively followed the ambient temperature. 


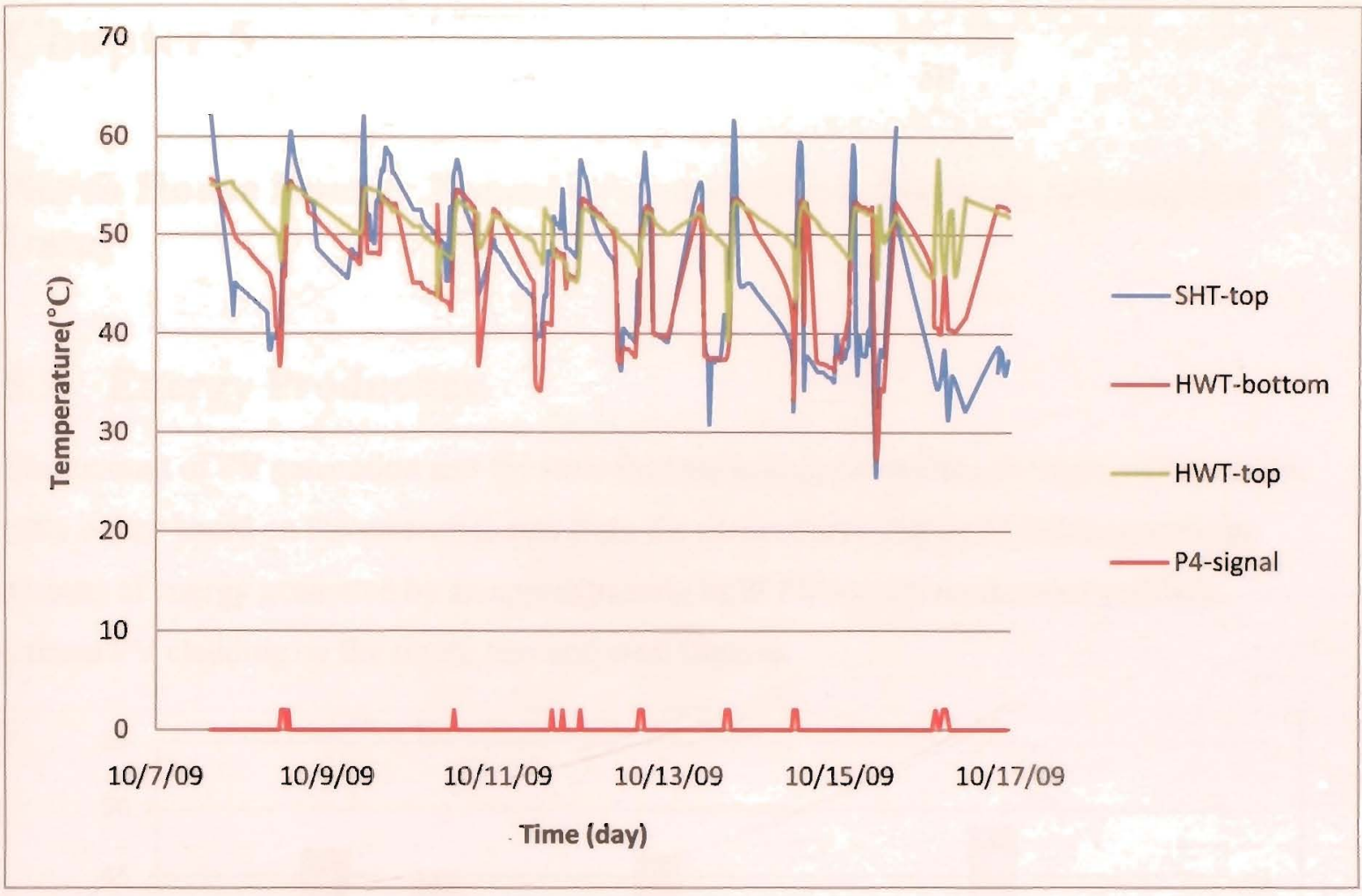

Figure 49: The analysis of the tank temperature in the SHT and HWT loop

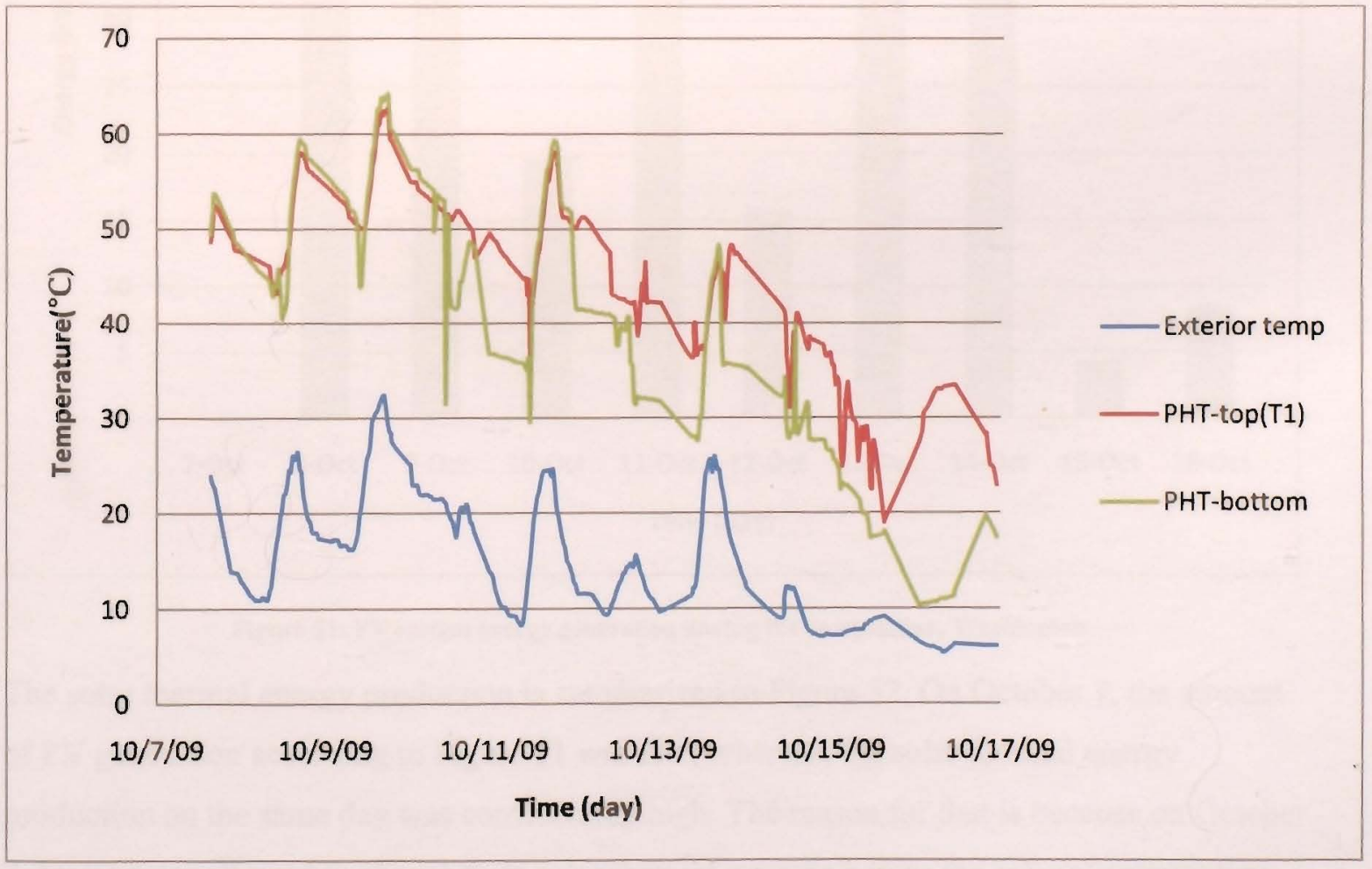

Figure 50: PHT temperature relative to outdoor temperature 


\section{Chapter 5}

\section{North House Energy Balance (Competition Data vs. Simulation Data)}

\subsection{Energy Production}

The amount of PV generation and the solar thermal energy production are summarized in the table below based on the measured data from the competition. Figure 51 below shows the amount of energy generated by an approximately $9 \mathrm{~kW} \mathrm{PV}$ system on the roof and $5 \mathrm{~kW}$ custom PV cladding on the south, east and west facades.

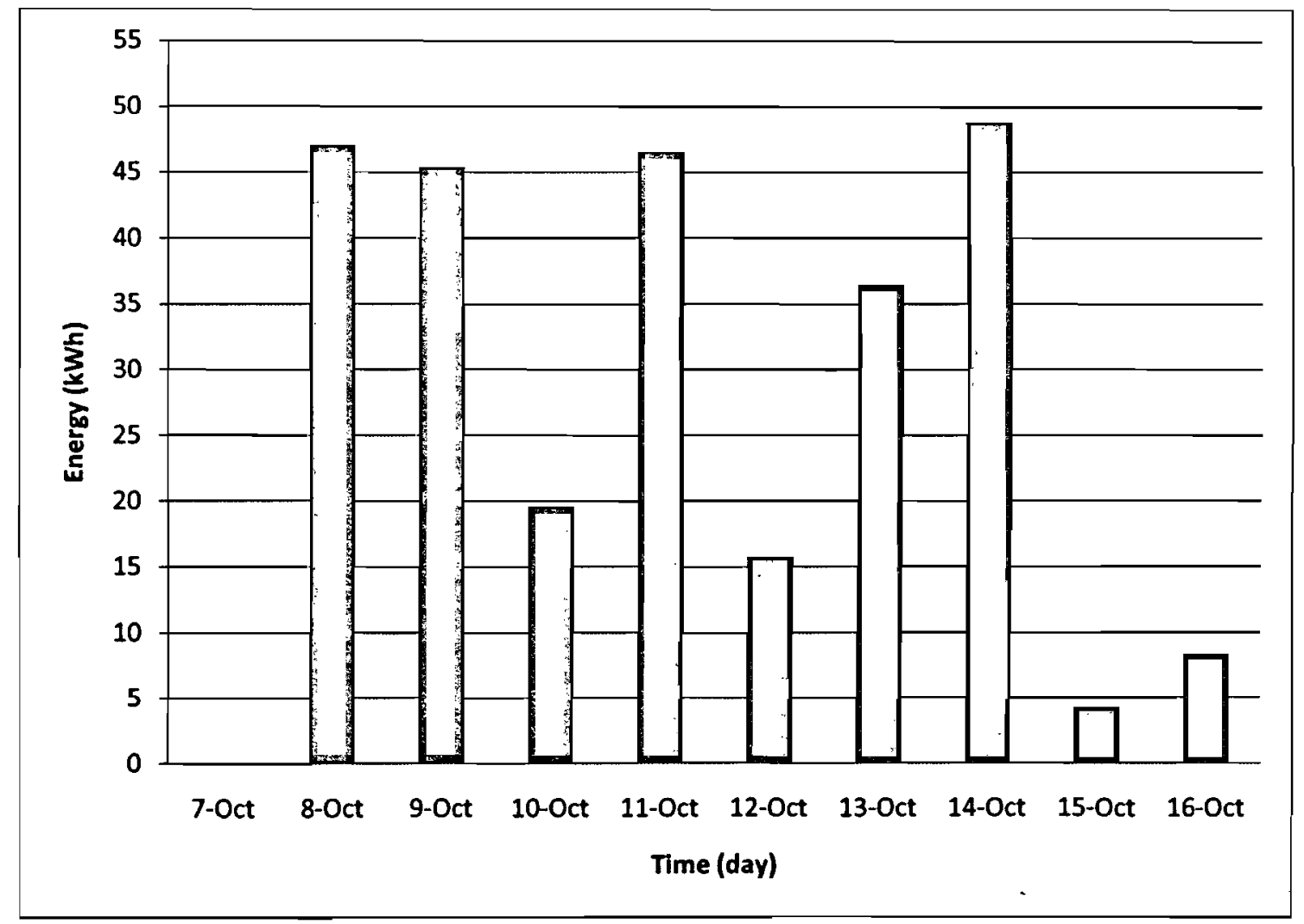

Figure 51: PV system energy generation during the competition, Washington

The solar thermal energy production is summarized in Figure 52 . On October 7, the amount of PV generation according to Figure 51 was low; whereas, the solar thermal energy production on the same day was considerably high. The reason for that is because on October 7 , teams were allowed to charge their solar thermal systems before the official competition time. 


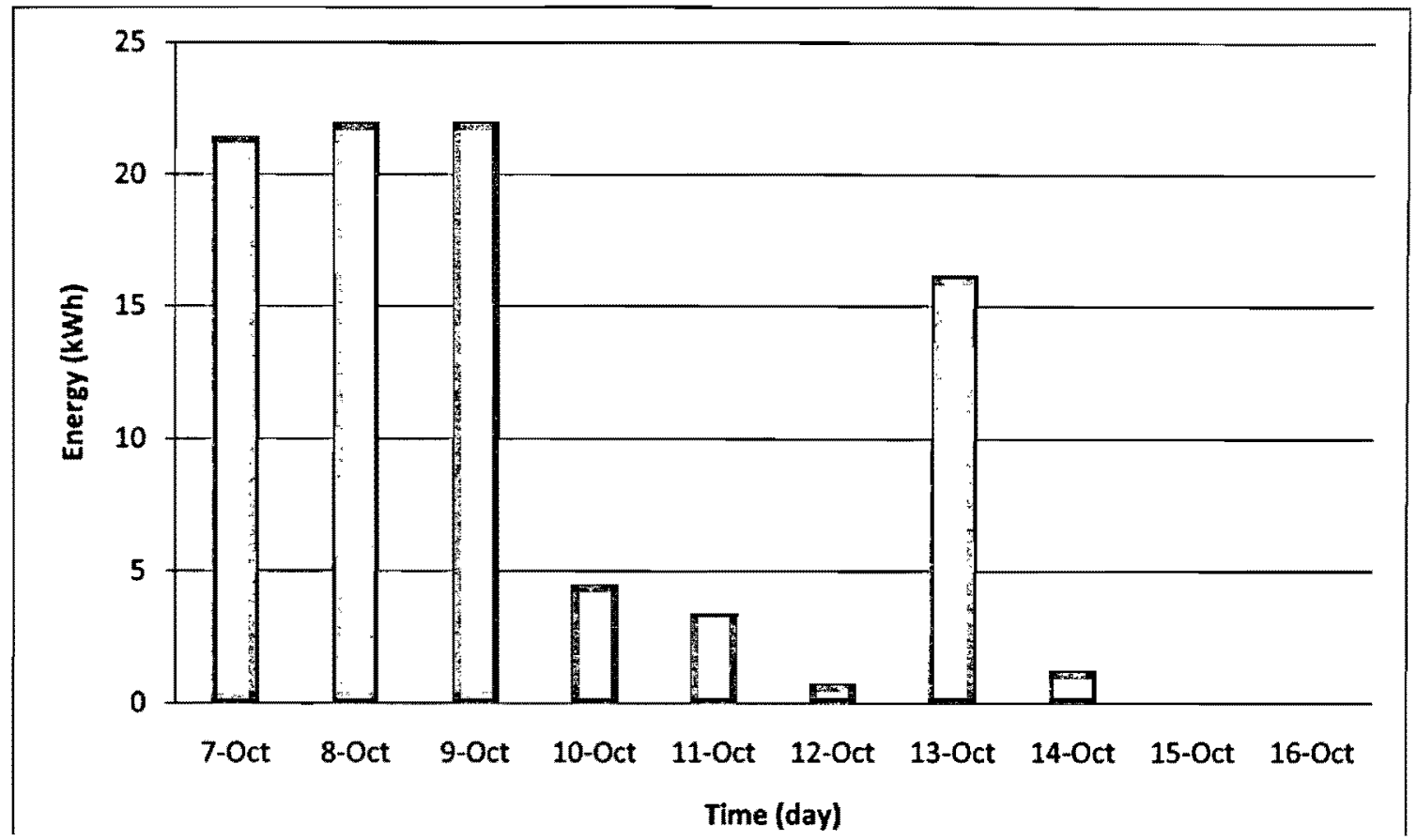

Figure 52: Solar thermal system energy production during the competition, Washington DC

The solar energy production results by the competition measures and by the simulation data are summarized in Table 28.

Table 28: Results for the solar energy production during the completion and data obtained from simulation

\begin{tabular}{|l|c|c|}
\cline { 2 - 3 } \multicolumn{1}{c|}{} & $\begin{array}{c}\text { Competition } \\
\text { (kWh/10 days) } \\
\text { Washington } \\
\text { DC }\end{array}$ & $\begin{array}{c}\text { Simulation } \\
\text { (kWh/10 days) }\end{array}$ \\
\hline Solar thermal energy production & 92 & 140 \\
\hline PV generation & 272 & 197 \\
\hline
\end{tabular}

As mentioned before, when comparing the results from the competition data and simulation data, it is necessary to remember that the competition measures are based on Washington DC weather data, and the simulation results are provided based on Baltimore weather data.

According to Table 28 the amount of the solar thermal energy production by simulation is more than that of the competition; whereas, the PV energy generation is more during the completion than the amount estimated by the simulation. The inconsistency can be explained by comparing the Baltimore and Washington ambient temperature and solar radiation data for 
the 10 days of competition. Unfortunately, the solar radiation data for Washington DC was not accessible; therefore, the comparison of the solar radiation was not investigated. Based on the data measured by the team during the competition the outside temperature was compared to the Baltimore weather data. Figure 53 shows that actual outside temperature in Washington was colder than the average outside temperature data for Baltimore.

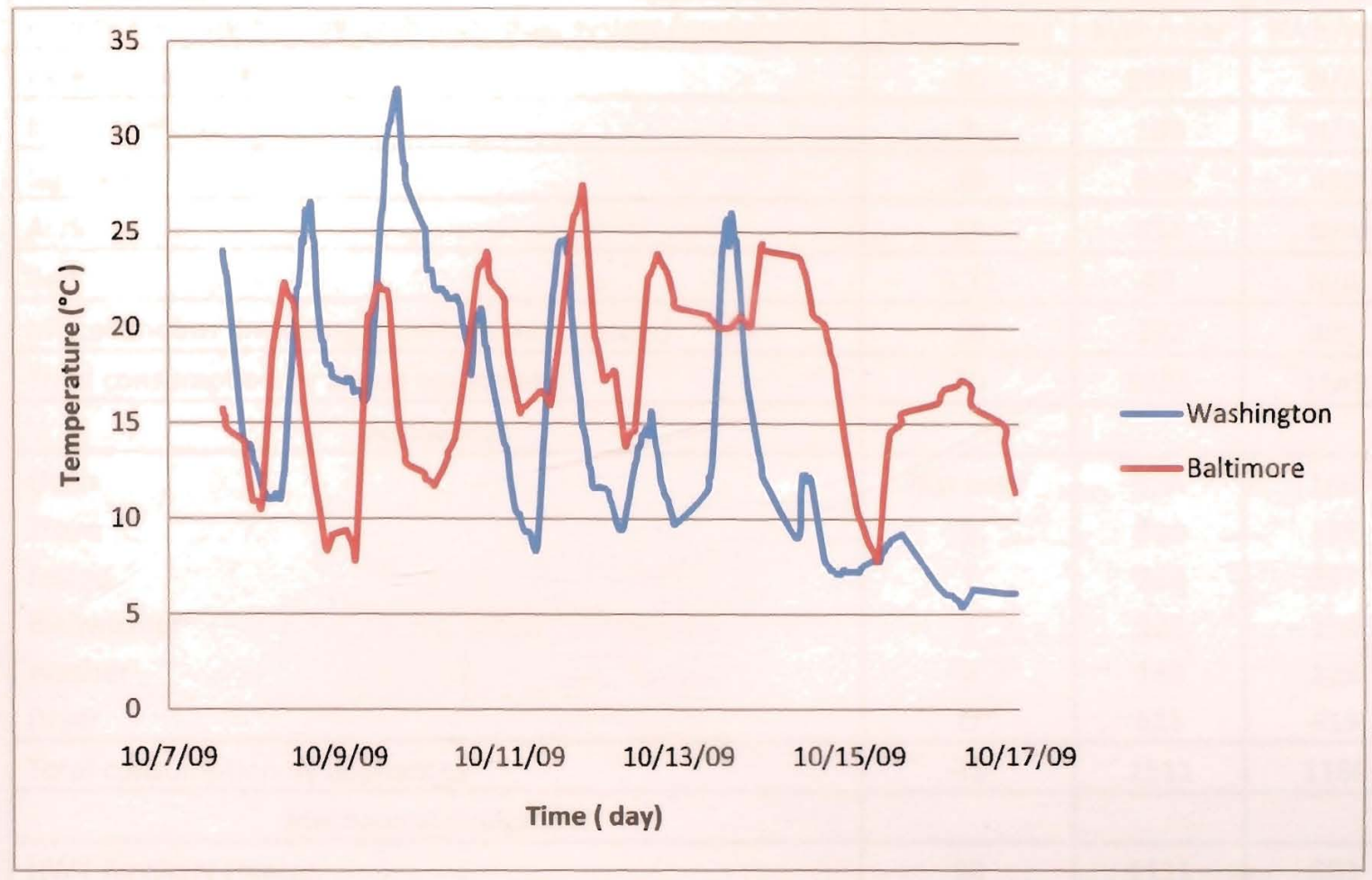

Figure 53: Comparison between Washington DC and Baltimore outside temperature for the ten days of competition

\subsection{Energy Consumption}

In order to evaluate the estimations based on the system modeled, the competition measured data require to be analyzed and compared with the expected results from simulation. From the data collected in ten days of competition, the annual consumption of each individual component and system can be estimated. Table 23 explains the deviation in the energy consumption of components when estimated by simulation and by the data collected during the competition.

While comparing the data measured during the competition and the data obtained from simulation, it is important to consider that the competition measurement was based on the Washington weather condition (actual data); whereas, the simulation estimations are based on Baltimore average long-term weather data. The weather characteristics of these two 
geographic locations are slightly different. In addition, the estimated house consumption over one year is significantly higher than the consumption obtained from simulation. The reasons for that are explained in the following sections.

Table 23: North House energy consumption by competition measures and simulation measures

\begin{tabular}{|c|c|c|c|}
\hline & Competition & Estimated & Simulation \\
\hline Energy consumption by each individual system/equipment & kWh/10days & kWh/year & kWh/year \\
\hline External Shading & 10 & 3689 & N/A \\
\hline Internal Blinds & 3 & 109 & N/A \\
\hline Lighting & 24 & 869 & 659 \\
\hline ALIS & 17 & 614 & $N / A$ \\
\hline Bed & 0.32 & 12 & N/A \\
\hline Miscellaneous (including entertainment system) & 16 & 592 & 486 \\
\hline Total consumption by above equipment & 70 & 5885 & 1145 \\
\hline \multicolumn{4}{|l|}{ Appliances } \\
\hline Oven & Not used & N/A & 166 \\
\hline Stove & 9 & 330 & 255 \\
\hline Fridge & 7 & 263 & 297 \\
\hline Dishwasher & 3 & 122 & 190 \\
\hline Washer & 5 & 183 & 129 \\
\hline Dryer & 17 & 613 & 419 \\
\hline Total consumption by appliances & 41 & 1511 & 1186 \\
\hline \multicolumn{4}{|l|}{ Mechanical equipment } \\
\hline HWT Auxiliary Heater & 30 & 1111 & 603 \\
\hline$A \dot{H} U+H R V$ & 6 & 212 & 395 \\
\hline HP\#1 (cooling) & 43 & 3256 & 674 \\
\hline HP\#2 (heating) & 37 & 2346 & 1785 \\
\hline Pumps & 3 & 126 & N/A \\
\hline HVAC Control & 18 & 662 & $\mathrm{~N} / \mathrm{A}$ \\
\hline Total consumption by mechanical equipment & 137 & 7713 & 3457 \\
\hline Total house consumption & 248 & 15109 & 5788 \\
\hline
\end{tabular}

Using the data from ten days in Washington, the energy consumption over one year was estimated by simply multiplying the energy consumption during one day by the number of days in one year (365 days). This approach was used for all the equipment except the cooling and heating heat pumps. 
In order to calculate the consumption of heat pumps, the cooling degree days and heating degree days must be measured based on the hourly outdoor temperature (Washington weather data).

A cooling degree day (CDD) is a formula measuring how hot it has been relative to a base temperature over a 24 hour period. The greater the number of cooling degree day measurement, the more the air conditioner needs to be running. A similar concept applies to that of heating degree days except a heat pump is the device expected to be working additional time. The cooling degree day is a guideline to help plan for energy usage.

The method used to determine the cooling degree day number is to use the average temperature for the day in question. This average temperature would then be subtracted from $18^{\circ} \mathrm{C}$. The result would be the cooling degree day amount for that particular day.

After using this method over ten days for Washington weather data, the accumulated CDDs and HDDs were obtained. These values were calculated for one year. Finally, knowing the heat pump consumption for CDD or HDD for ten days, the annual consumption can be calculated. The total CDD and HDD for Baltimore were estimated to be 644.8 and 2571 respectively. For the competition period in Washington DC, the total CDD was 8.5 and HDD was 40.3 .

The analyses of data in Table 23 is broken into three parts

- Case 1: External shading, Interior Blind, Lighting, Bed, ALIS and miscellaneous loads

- Case 2: Appliances

- Case 3: Mechanical equipment

\subsubsection{Case 1: External shading, Interior Blind, Lighting, Bed, ALIS}

Having an approximately $369 \mathrm{kWh}$ energy consumption for the external shading is not considered as an efficient design and it was potentially unnecessary. By either manually controlling the shading and blind, or having a simpler controller, the consumption of $478 \mathrm{kWh}$ for both interior blinds and exterior shading, could have been reduced.

The lighting in North House was initially designed to be a pioneer design in efficiency measures. However, the result shows that the electrical consumption is as high as in a typical house. According to a study done on the lighting electricity consumption per dwelling in 
Canada (Fung \& Ugursal, 1996), on the average, electricity consumption by a flat apartment in Ontario is $865 \mathrm{kWh} /$ year which is relatively close to the North House lighting consumption.

ALIS and Bed were not included in calculating in the house consumption. Miscellaneous loads including TV and laptop were close to the amount expected.

\subsubsection{Case 2: Appliances}

Expect for the washer and dryer, the appliance loads were as anticipated. In the simulation the oven was one of the appliances integrated into the house. However, during the competition it was not used.

\subsubsection{Case 3: Mechanical Equipment}

The dedicated cooling heat pump had a high consumption due to the competition public tour. During the public tour more than 1000 people walked through the house. As a result, the house temperature was increased. Therefore, to maintain the house temperature and relative humidity within the acceptable range in preparation for the test period ${ }^{\mathrm{XXI}}$ which was scheduled to take place one hour after public tours, the heat pumps were working during these events. Depending on the outside weather condition either the cooling heat pump or the heating unit was required. In some cases when the weather was cold during the day, excessively cool air entered through the open doors.

For that reason the heat pump consumptions were significantly high and since we used these numbers to estimate the annual consumption, the results show high values. The same scenario was applied to HRV and AHU.

High consumption of the HVAC control was not predicted; therefore, it was not considered as a consumption measure.

The overall results for energy production and energy consumption of North House are summarized in Figure 54. During the 10 days of competition in Washington DC, the PV system generated $271.6 \mathrm{kWh}$ of electricity, and the solar thermal system produced $91.7 \mathrm{kWh}$ while the house consumption was $249.1 \mathrm{kWh}$. According to the obtained results North House was a net-positive house to a considerable extent.

XXI Test period: When the house temperature and relative humidity were monitored by DOE 


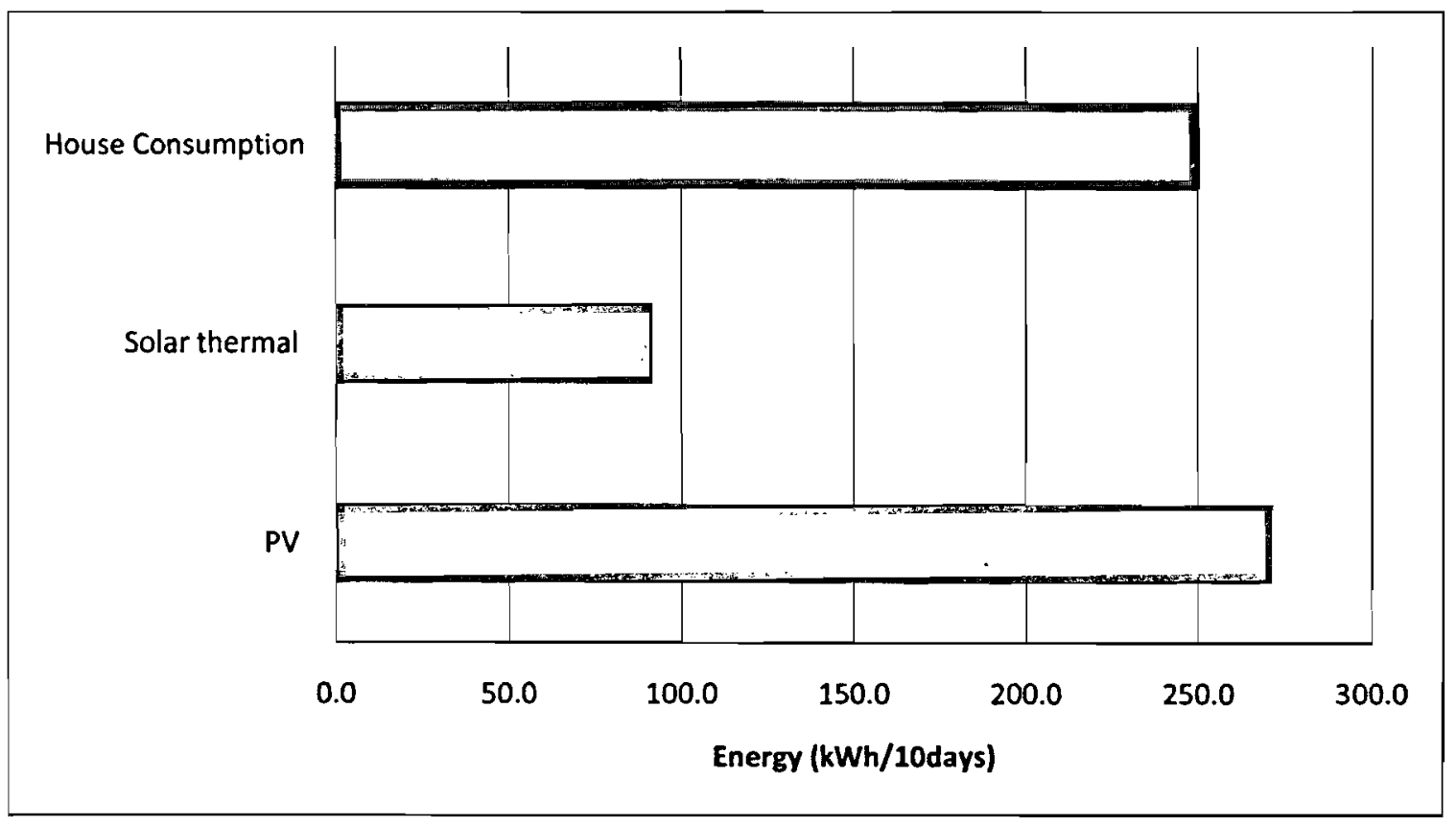

Figure 54: North House energy production/consumption during the competition

\subsection{Score of North House in US DOE 2009 Solar Decathlon}

The Solar Decathlon consisted of ten contests that centre on all of the ways in which we use energy in our daily lives. During the competition the teams received points for their performance in ten contests and opened their homes to the public (Appendix D).

Team North - Team Ontario/BC - was ranked $3^{\text {rd }}$ place in the comfort zone contest, $3^{\text {rd }}$ place in net-metering, $3^{\text {rd }}$ place in communication and 4 th place in the final competition. Figure 55 shows how the teams were ranked over competition contests. 


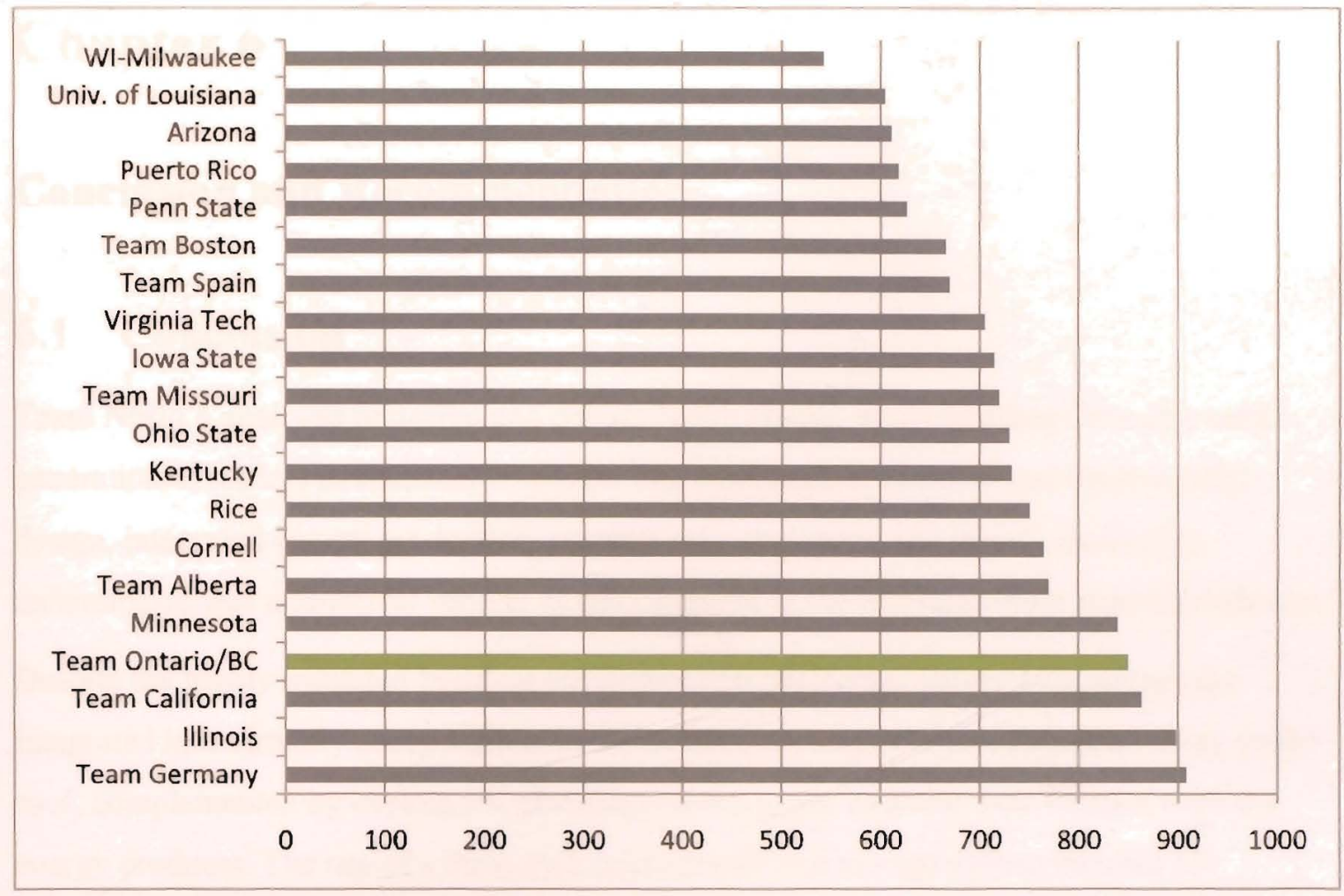

Figure 55: Scores of teams participated in the US DOE 2009 Solar Decathlon competition 


\section{Chapter 6}

\section{Conclusion and Recommendation}

\subsection{Conclusion}

Team North's goal was to design and deliver North House, while building Canada's next generation of leaders in sustainable design. The combination of active and passive solar design, integrated energy production, customized component, and mobile interactive technologies was a powerful vehicle of advancement in the Canadian New Housing industry.

Despite the highly insulated building envelope of North House, energy harnessing was integrated into virtually every surface of the building. A large photovoltaic (PV) array on the roof, complemented by custom PV claddings on the south, east and west facades were the energy producer. The use of a three-tank heat transfer and storage system enabled the evacuated-tube solar thermal collectors on the roof to meet most of the hot water and space heating demands. The house featured both active solar technologies, such as solar thermal heating and PV systems, to maximize energy collection and production, and passive technologies to minimize energy consumption. In order to maintain an optimal balance between energy-efficient operation and a high degree of occupant comfort, these technologies were complemented by an intelligent integrated control system which helped manage the energy consumption of the home while notifying the occupants of their actions.

The house was modeled in TRNSYS to initiate the system performance assessment. Analyses were conducted for the city of Baltimore, which was the closest available city to Washington D.C. in the TRNSYS weather library, and five major Canadian cities. From the simulation results, the annual energy collected by the solar thermal system was $5317 \mathrm{kWh}$, which resulted in the solar fraction of $81 \%$ for Baltimore. For Toronto the energy produced was $5920 \mathrm{kWh}$ per year and the solar fraction was $71 \%$.

The result also indicated that in different regions of Canada, some of which have extreme climate conditions, the design can still make enough energy to meet most hot water and space heating demands.

As indicated in Figure 56, in Vancouver, Edmonton, Halifax and Montreal the solar fraction was estimated to be $69 \%, 64 \%, 66 \%$ and $67 \%$ respectively. Studying the energy balance of 
the system also indicated that for each of these cities the heating season definition needs to be extended to some extent, meaning that in order to maintain the desired temperature inside the house the space heating system needs to be activated over a longer period than that of Toronto and Baltimore.

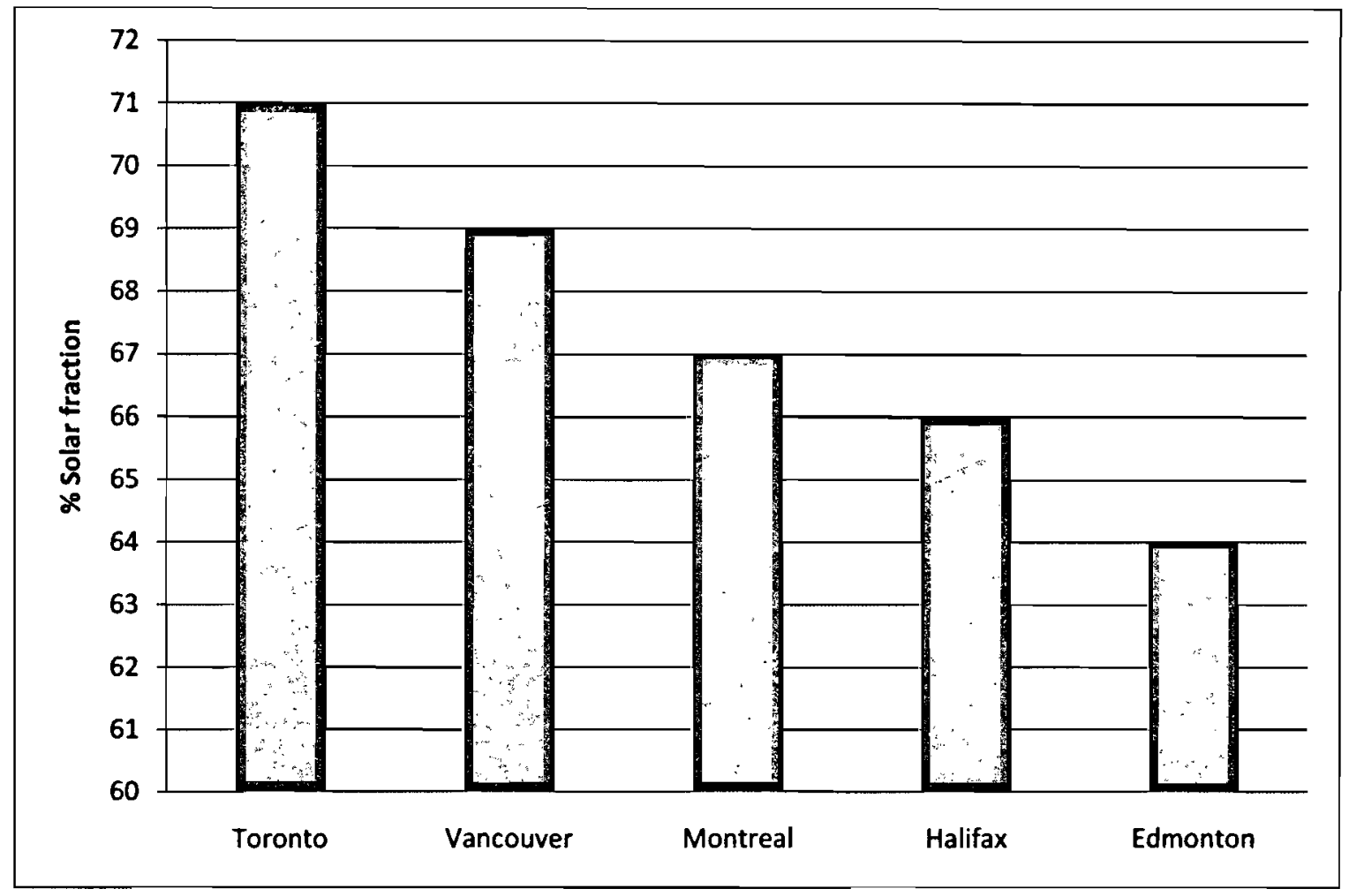

Figure 56: $\%$ solar fraction for different cities across Canada

North House was predicted to annually consume less energy than it consumed during the competition. Results from the competition measures revealed that there were some unforeseen measures that should have been addressed. These miscellaneous, unpredicted consumptions increase the house energy consumption level. Some of these surprisingly high consumptions included the external shading blinds, ALIS, HVAC control and lighting.

The cooling HP and heating HP were two devices which consumed surprisingly more energy that what expected. However, there were some explanations for some of these higher than normal heat pump consumptions. Unlike a typical house mechanical system, the North House heating and cooling systems had to operate in parallel during the competition period. The heating and cooling systems were required to operate simultaneously due to the weather conditions and occupancy level. Having more than 1000 people walking through the house on a cold and humid day required the heating system to prevent the temperature level from dropping significantly due to the cold air entering the house from open doors, and the cooling 
system had to run when the occupancy level inside the house was high to avoid high temperature. In addition, both heating and cooling were required to maintain the indoor \% $\mathrm{RH}$ level duo to higher than usual unwanted infiltration because of the public tour.

Despite the fact that North House experienced severe weather changes during the ten days of competition, it was identified as one of the net-positive houses while maintaining the required level of thermal comfort. The house energy generation in ten day was $363.3 \mathrm{kWh}(\mathrm{PV}+\mathrm{solar}$ thermal) while consuming $249.2 \mathrm{kWh}$. As a result, the house used $69 \%$ of the energy it produced. This number could have been even less if more consideration had been taken to utilize more energy efficient equipment.

The result of this combination of technologies produced a home that produced a surplus of energy annually, making the home net energy positive.

\subsection{Recommendations and Future Work}

Change requires action. To significantly conserve, increase and smartly distribute the energy generation to meet our energy targets - and thereby bring us closer to an innovation which is more than a net positive house - adaption of the following measures should be considered:

It is desirable to utilize more energy efficient appliances and reduce the lighting consumption by reconsidering the lighting options.

The automated components that consume high amount of energy, such as exterior blinds, HVAC controller, need to be replaced by a simpler, thus more energy efficient equipment. The electronic retractable bed which consumed considerable amount of energy could be either optional or removed.

The heating and cooling heat pumps need to be replaced by the same type but smaller capacity since the capacities of the heat pumps were oversized for the North House application. When reducing the HP capacity the energy consumption will be significantly reduced.

Utilizing an economizer with HRV is another option to reduce the energy demand by the house. The HRV and economizer can be manufactured as one unit. The economizer will be considered as mechanical equipment that helps to cool down the house. There is no heat exchanger inside the economizer to transfer the heat. During the time interval when cooling is 
required the economizer can help to reduce the energy demand under certain conditions. In the early morning or during the night if the outside temperature and relative humidity are less than the house temperature and \%RH , the economizer will by-pass the HRV heat exchanger and send the cooler outside fresh air inside and take the exhaust air out without transferring any heat between two streams. The only difference when economizer is operating is that depending on the amount of cooling required, the fan speed might be on the high cycle. Integrating infloor heating and cooling are the other option that assists in reducing the house energy demand. The infloor cooling can for some cases, such as Baltimore, eliminate the heat pump energy consumption as shown in section 3.4.

Utilizing water conservation appliances, ultra low shower head and aerators are the solutions towards reduction of hot water demand. In addition, using a gray water heat recovery system assists in reducing the energy demand by solar hot water system.

Having more thermal mass inside the building reduces the heating and cooling demand. PCMs can be added to the ceiling and walls to achieve this goal.

A more significant step needs to be taken toward house energy analysis by having a regular progress report based on monitoring the system. The house needs to be monitored over a long period to investigate the performance of the system in more detail. 


\section{References}

Abrahamse, W., Steg, L., Vlek, C., \& Rothengatter, T. (2007). The effect of tailored information, goal setting, and tailored feedback on household energy use, energy-related behaviors, and behavioral antecedents. Journal of Environmental Psychology 27 (4) , 265 276.

Akbari, H., \& Taha, H. (1992). The impact of trees and white surfaces on residential heating and cooling energy use in Canadian cities. Energy 17, 141-149.

Akbari, H., Kurn, D. M., Bretz, S. E., \& Hanford, J. W. (1997). Peak power and cooling energy savings of shade trees . Energy and buildings $25,139-148$.

Architecture2030. (2007). Climate change, global warming, and the built environment: Architecture 2030. Architecture 2030.

ASHRAE. (2005). "Energy Estimating and Modeling Method". In ASHRAE HandbookFundementals. Atlanta, GA: American Society of Heating, Refrigeration, and AirCondotioning Engineers.

Ayoub, J., Dignard-Balley, L., \& Filton, A. (2000). Photovoltaics for buildings:

Opportunities for Canada. CANMET Energy Diversification Research Laboratory, Natura IResources of Canada.

Bakos, G. C., Soursos, M., \& Tsagas, N. F. (2003). Techno economic assessment of a building-integrated PV system for electrical energy saving in residential sector. Energy and Buildings, 35 , 757-762.

Barnes, B. P., Martinez, L., Esram, T., Newell, T., \& Chapman, P. (2009). Design, simulation and preliminary results of an all electric net-zero energy solar home .2008 Proceedings of the 2nd International Conference on Energy Sustainability (pp. 313-320). Jacksonville, FL: ES 20082.

BC Hydro. (2002). BC Hydro Conservation Potential Review 2002. BC Hydro.

Bradley, D. E., Kummert, M., \& McDowell, T. P. (2004). Experiences with and interpretation of standard test methods of building energy analysis tools. eSim 2004 (p. 8). Vancouver: IBPSA (International Building Performance Simulation Association). 
Cabeza, L., Ibáñez, M., Solé, C., Roca, J., \& Nogués, M. (2006). Experimentation with a water tank including a PCM module . Solar Energy Materials and Solar Cells 90 (9) , 1273 1282.

CanWEA. (2003). Wind energy in Canada: Status and challenges. Pollution Probe Conference. Canadian Wind Energy Association (CanWEA).

Chen, B., Bonsell, J., \& Bourne, R. C. (1990). Conceptualization of utilizing water source heat pumps with cool storage roofs. The 15th National Passive Solar conference (pp. 139144). Solar 90.

Chen, B., Kasher, J., Maloney, J., Girgis, A., \& Clark, D. (1991). Determinatin of the clear sky emissivity for use in cool storage roof pond applications. American Solar Energy Society (p. pp.6). Denvor: ASES.

Choudhary, R., Augenbroe, G., Gentry, R., \& Hu, H. (2008). Simulation-enhanced prototyping of an experimental solar house. Building Simulation Vol.1 No.4, 336-355.

Comakli, O., Kaygusuz, K., Ayhan, T., \& Arslan, F. (1993). Experimental Investigation and a Dynamic Simulation of the Solar-Assisted Energy-Storaged Heat Pump System. Solar Energy 51 (2) , 147-158.

Commision, T. B. (1987). Our Common Future.

DOE. (2008). Building Energy Software Tools. US DOE - Energy Efficiency and Renewable Energy: Building Technologies Program.

EIA. (2005). Annual Energy Report 2004. Washington DC: U.S. Department of Energy, Energy Information Administration (EIA).

Elizondo, H., Lebassi, B., \& Gonzalez-Cruz, J. (2009). Modeling and validation of building thermal performance of the 2007 santa clara university solar decathlon house . 2008 Proceedings of the 2nd International Conference on Energy Sustainability (pp. 279-286). Jacksonville, FL: ES 20082.

Floras Phelps, A., Torres, C., Riley, D., \& Horman, M. (2007). Building-centred community development as a method to promote social, environmental, and economic sustainability. WIT Transactions on Ecology and the Environment 102 , 251-260.

Freeman, T., \& Mitchell, J. A. (1979). Performance of Combined Solar-Heat Pump System. Solar Energy $22,125-135$. 
Fung, A. S., \& Ugursal, V. I. (1996). Residential Lighting Energy Use in Canada. Energy Study Reviews, Vol.8, Iss. 3 , 246-268.

Garrison, M. (2008). The 2007 Solar D house. WIT Transactions on Ecology and the Environment 117, 355-361.

Greening, L., Ting, M., \& Krackler, T. (2001). Effects of changes in residential end-uses and behavior on aggregate carbon intensity: Comparison of 10 OECD countries for the period 1970 through 1993 . Energy Economics 32 (2) , 153-178.

Haddad, K., Purdy, J., \& Laouadi, A. (2007). Comparison of the Performance of a Forced-Air and a Radiant Floor Residential Heating System Connected to Solar Collector. Journal of Solar Energy Engineering 129, 465-472.

Houvila, P. (2007). Building and climate change, Status, challenge and opportunities. Nairobi, KENYA: United Nations Environment Programme, Sustainable Building Construction Initiatives.

Johnson, J. (2007). News of the week: Alternative energy: Universities compete in third Solar Decathlon. Chemical and Engineering News 85 (43) , pp. 15.

Kharrufa, S. N., \& Adil, Y. (2008). Roof pond cooling of buildings in hot arid climates. Building and Environment $43,82-89$.

Lecoufle, D., Lawless, R., \& Hample, M. (2009). Large Scale Plants in North Africa and the Middle East. Germany: Lahmeyer International Gmbh, Renewable Energy Division.

Martin, V., \& Setterwall, F. (2009). Compact Heat Storage for Solar Heating Systems. Journal of Solar Energy Enginnering, Vol.131, No.4 , 041011-1-041001-6.

McDowell, T. P., E., B. D., Thornton, J. W., \& Kummert, M. (2004). Converging on a Recommended Set of Interpretations and Assumptions in Applying Standard Tests to Energy Analysis Tools. SimBuild 2004 (p. 10). Boulde, USA: IBPSA (International Building Performance Simulation Association).

Mills, E. (2004). Inter-comparison of North American residential energy analysis tools. Energy and Buildings 36 (9) , 865-880.

MKJA, \& Marbek Resource Consultant. (2006). Demand Side Management Potential in Canada: Energy Efficiency Study. Marbek Resource Consultant Ltd. and M.K. Jaccard and Associates Inc. 
Mozaffari, H. (2003). Energy demand reduction in rsidential buildings in residential buildings in Beijing-China. 4th International Symposium on Heating, Ventilation and Air Conditioning, (pp. 1156-1163). Beijing, China.

Năssén, J., Holmberg, J., Wadeskog, A., \& Nyman, M. (2007). Direct and indirect energy use and carbon emissions in the production phase of buildings: An input-output analysis. Energy 32 (9) , 1593-1602.

Niles, P. (1976). Thermal evaluation of a house using a movable insulation and cooling system. Solar Energy 18 (5) .

NRCan. (2006b). Canada's Energy Outlook:The Reference Case 2006. National Resources Canada.

NRCan. (2006a). Energy efficiency Trends in Canada: 1990 to 2004. Natural Resources Canada.

NRCan. (2008). Energy Efficiency Trends in Canada: 1990 to 2005. National Resources Canada.

NRCan. (2007). Moving Forward on Energy Efficiency in Canada: A foundation for Action. National Resources Canada.

NRTEE. (2006). Advice on a Long-Term Strategy on Energy and Climate Change. National Round Table on the Environment and the Economy.

Nurzia, G., Franchini, G., \& Perdichizzi, A. (2008). Combined solar heating and cooling system: Simulation and design optimization. 2nd International Conference on Energy Sustainability. Jacksonville, FL: ES 2008.

Ontario Energy Association. (2006). Ontario's IntegratedPower System Plan-Discussion Paper 3: Conservation and Demand Management, and Discussion Paper 2: Load Forcast. Ontario Energy Association.

Pelland, S., McKenney, D. W., Poissant, Y., Morris, R., Lawrence, K., \& Campbell, K. (2006). The development of photovoltaic resource maps for Canada. Canadian Solar Buildings Conference. Concordia University.

Raeissi, S., \& Taheri, M. (1996). Cooling load reduction of building using passive roof options. Renerwable Energy 7 (3) , 301-313. 
Renn, O., Jäger, A., Deuschle, J., \& Weimer-Jehle, W. (2009). A normative-functional concept of sustainability and its indicators. Int. J. Global Environmental Issues, Vol 9, No.4, 291-317.

Robinson, D., Haldi, F., Kämpf, J., Leroux, P., Perez, D., Rasheed, A., Wilke, U. (2009).

City-Sim:Comprehensive micro-simulation of resource flows for sustainable urban planning. Eleventh International IBPSA Conference (p. 8). Glasgow, Scotland: Building Simulation 2009.

Rosen, M. A. (2002). Energy efficiency and sustainable development. Int. J. Global Energy Issues $17(1 / 2)$, p. 12.

Rosiek, S., \& Battlles, F. (2009). Integration of the solar thermal energy in the construction: Analysis of the solar-assisted air-conditioning system installed in CIESOL building.

Renewable energy 34, 1423-1431.

Sahin, A. D. (2004). Progress and recent trends in wind energy. Progress in Energy and Combustion Science, 30, 501-543.

SEL, TRANSSOLAR, CSTB, \& TESS. (2004). TRANSYS Simulation Manual. Madison, US: Solar Energy Laboratory(SEL), University of Wisconsin-Madison, TRANSSOLAR Energietechnik GmbH, Center Scientifique et Technique du Batiment(CSTB), Thermal Energy System Specialists( TESS).

Spanaki, A. (2007). Comparative studies on different type of roof ponds for coolng purpose. Stein, J., \& Meier, A. (2000). Accuracy of home energy rating systems. Energy 25 (4) , 339354.

Syed, A., Fung, A., \& Ugursal, V. (2008). Environmental and Economic Impacts of Integrating Photovoltaic and Wind-Turbine Energy Systems in the Canadian Residential Sector. Bulletin of Sience Technology Society $28,210-219$.

Tang, R., \& Etzian, Y. (2004). On thermal performance of an improved roof pond for cooling buildings. Building and Environment 39, 201-209.

(October 2009). The Power to Liive Green, Toronto's Sustainable Energy Strategy. Toronto: City of Toronto. 
Torecellini, P., Pless, S., \& Deru, M. (2006). Zero Energy Buildings: A Critical Look at the Definition. NREL: National Renewable Energy Laboratory (p. 14). Pasific Grove, California: NREL.

Trinkl, C., Zorner, W., \& Handy, V. (2004). A Review on Solar-Assisted Heat Pumps for Domestic Heating. Fifth ISES Europe Solar Conference (Europe 2004). Frieburg, Germany.

Trinkl, C., Zorner, W., \& Handy, V. (2009). Simulation study on a Domestic Solar/Heat Pump Heating System Incorporating Latent and Stratified Thermal Storage. Journal of Solar Energy Engineering 131 (4) , 041008-1 - 041008-8.

Voorthuysen, E. d. (2009). Two scenarios for a solar world economy. Int. J. Global Environmental Issues, Vol. 8, No. 3, 233-247.

Voorthuysen, E. M. (2006). Large-scale Concentrating Solar Power (CSP) technology: Solar electricity for the whole world. In V. Badescu, R. B. Cathcart, \& R. D. Schuiling, MarcoEngineering: A Challenge for the Future (pp. 31-44). Groningen, Netherlands: Springer Netherlands.

Wang, N., Esram, T., Martinez, L., \& McCulley, M. (2009). A marketable all-electric solar house: A report of a Solar Decathlon project . Reneable Energy 34 (12) , 2860-2871.

Wojdyga, K. (2009). An investigation into the heat consumption in a low-energy building. An International journal of Renewable Energy, 34, 2935-2939.

Wu, D., \& Liang, L. (2009). Ecological Footprint forecasting and estimating using neural networks and Data Envelopment Analysis. Int. J. Global Environmental Issues, Vol. 9, No. 3 , 249-258. 


\section{Appendices}

\section{Appendix A}

\section{Appliances Energy Consumption}

Major Appliances:

Table 1 summarizes the energy consumption of the major appliances utilized in the North House and the SUI House projects. These appliances are also compared to a typical home's appliances assumed by CMHC standards (National Rescores Canada, 2005) in terms of their energy consumptions. Energy consumption of appliances is based on product specifications modified where necessary. For example for North house, double occupancy was expected.

Table 1: Comparison of the appliances energy consumption of the North Hose, SUI House and a Typical House

\begin{tabular}{|c|c|c|c|c|c|}
\hline \multicolumn{2}{|c|}{ North House } & \multicolumn{2}{|c|}{ SUI House } & \multicolumn{2}{|c|}{ Typical House by CMHC Standards } \\
\hline Appliances & $\begin{array}{c}\text { Energy } \\
\text { Consumption } \\
\text { (kWh/year) }\end{array}$ & Appliances & $\begin{array}{c}\text { Energy } \\
\text { Consumption } \\
\text { (kWh/year) }\end{array}$ & Appliances & $\begin{array}{c}\text { Energy } \\
\text { Consumption } \\
\text { (kWh/year) }\end{array}$ \\
\hline $\begin{array}{l}\text { Refrigerator/Freezer } \\
\text { Liebherr HC1060 } \\
\end{array}$ & 297.0 & $\begin{array}{l}\text { Refrigerator/Freezer } \\
\text { GE Monogram 48" }\end{array}$ & 592.0 & $\begin{array}{c}\text { Refrigerator/Freezer } \\
\text { min. capacity of } 440 \mathrm{~L}(15.5 \\
\mathrm{ft} 3)\end{array}$ & 693.0 \\
\hline $\begin{array}{c}\text { Dishwasher } \\
\text { Gaggenau DF } 261760\end{array}$ & 190.0 & $\begin{array}{l}\text { Dishwasher } \\
\text { Asko D3531 }\end{array}$ & 194.0 & $\begin{array}{l}\text { Dishwasher } \\
\text { min. capacity of } 150 \mathrm{~L} \\
\text { volume }\end{array}$ & 615.0 \\
\hline
\end{tabular}




\begin{tabular}{|c|c|c|c|c|c|}
\hline Estimated Energy/ year for North House & 114.0 & & & & \\
\hline $\begin{array}{c}\text { Oven } \\
\text { Gaggenau BO 250-611 } \\
\text { Cooktop } \\
\text { Gaggenau VI } 221 \\
\end{array}$ & $\begin{array}{r}166.4 \\
254.8 \\
\end{array}$ & $\begin{array}{c}\text { Stove } \\
\text { Frigidaire BFEF323C* }\end{array}$ & 438.0 & $\begin{array}{c}\text { Stove } \\
\text { min. } 4 \text { burners and } \\
\text { min. } 60 \mathrm{~L} \text { capacity for oven }\end{array}$ & 758.0 \\
\hline $\begin{array}{c}\text { Clothes Dryer } \\
\text { Bosch Axxis condensation } \\
416 \text { cycles/year in quoted energy consumption } \\
\text { Estimated Energy/year for North House } \\
208 \text { cycles/year }\end{array}$ & $\begin{array}{l}419.0 \\
209.5\end{array}$ & $\begin{array}{c}\text { Clothes Dryer } \\
\text { Miele T9800 } \\
416 \text { cycles/year } \\
\text { in quoted energy consumption }\end{array}$ & 537.0 & $\begin{array}{c}\text { Clothes Dryer } \\
\text { min. capacity of } 140 \mathrm{~L}\end{array}$ & 848.0 \\
\hline $\begin{array}{c}\text { Clothes Washer } \\
\text { Bosch Axxis plus } \\
392 \text { cycles/year in quoted energy consumption } \\
\text { Estimated Energy/year for North House } \\
156 \text { cycles/year }\end{array}$ & $\begin{array}{l}129.0 \\
51.3\end{array}$ & $\begin{array}{l}\text { Clothes Washer } \\
\text { Whirlpool WFW8500SR }\end{array}$ & 152.0 & $\begin{array}{c}\text { Clothes Washer } \\
\text { min. tub capacity of } 60 \mathrm{~L} \\
\text { volume }\end{array}$ & 802.0 \\
\hline $\begin{array}{c}\text { Flat Screen TV } \\
\text { Samsung LN-R3228W 32" }\end{array}$ & 127.8 & $\begin{array}{c}\text { Color TV } \\
26^{\prime \prime}-36^{\prime \prime} \\
\text { Active mode (Table 2) } \\
\text { Standby mode (Table 2) }\end{array}$ & $\begin{array}{c}179.4 \\
36.7 \\
\end{array}$ & $\begin{array}{l}\text { Color TV } \\
\text { Refer to SUI }\end{array}$ & \\
\hline $\begin{array}{l}\text { Desktop Computer } \\
\text { Assume average draw of } 70 \mathrm{~W} \text { with LCD display }\end{array}$ & 76.4 & $\begin{array}{l}\text { Desktop Computer } \\
\text { Active mode (Table 2) }\end{array}$ & 70.5 & $\begin{array}{l}\text { Desktop Computer } \\
\text { Refer to SUI }\end{array}$ & \\
\hline
\end{tabular}




\begin{tabular}{|c|c|c|c|c|} 
& & Standby mode (Table 2) & 12.0 & \\
\hline Misc. Plug Loads & & Misc. Plug Loads & Misc. Plug Loads \\
Assume average load of 25W & 218.4 & Refer to Table 1 & Refer to SUI \\
\hline
\end{tabular}

According to the above table energy consumption of the major appliances of the North House and the SUI house were significantly improved. Comparing with the typical home appliances, excluding the miscellaneous appliances, the energy consumption was reduced by $57 \%$ and $45 \%$ for the case of the North House and the SUI house respectively.

\section{Minor and Miscellaneous Appliances:}

Energy consumption by minor and miscellaneous appliances and electronic devices is highly variable on the ownership and discretionary usage of the number and type of equipment available. In North House project, plug loads were based on anticipated usage schedule and average power draws. Table 2 indicates the minor appliances suggested for the SUI house. Utilizing selected minor appliances resulted in average $69 \%$ reduction in the energy consumption to compare with typical appliances (Fung et al. 2007). The following is a table of certain categories of electronics that could have been used. Values were taken from different manufacturers.

Table 29: List of minor appliances with their electronic requirement, time of usage and the resultant energy consumption (Fung et al., 2003)

\begin{tabular}{|c|c|c|c|c|c|c|c|c|c|c|c|c|}
\hline \multirow[b]{3}{*}{ Appliance } & \multirow{2}{*}{\multicolumn{2}{|c|}{$\frac{\text { Active Mode }}{\text { (Watt) }}$}} & \multirow{3}{*}{$\begin{array}{c}\text { Usage } \\
\text { (hr/week) }\end{array}$} & \multirow{2}{*}{\multicolumn{2}{|c|}{$\begin{array}{c}\begin{array}{c}\text { Total Active } \\
\text { Consumption }\end{array} \\
\text { (kWh/year) }\end{array}$}} & \multirow{2}{*}{\multicolumn{2}{|c|}{ Standby Mode }} & \multirow{3}{*}{$\begin{array}{c}\begin{array}{c}\text { Standby } \\
\text { Time }\end{array} \\
\text { (hr/week) }\end{array}$} & \multirow{2}{*}{\multicolumn{2}{|c|}{$\begin{array}{c}\text { Total Standby } \\
\text { Consumption } \\
\text { (kWh/year) }\end{array}$}} & \multirow{2}{*}{\multicolumn{2}{|c|}{$\begin{array}{c}\begin{array}{c}\text { Final } \\
\text { Consumption }\end{array} \\
\text { (kWh/year) }\end{array}$}} \\
\hline & & & & & & & & & & & & \\
\hline & Min & Average & & Min & Mean & Min & Average & & Min & Mean & Min & Mean \\
\hline Color TV, <26" & 29.0 & 60.8 & 20.1 & 30.4 & 63.6 & 0.0 & 2.7 & 147.9 & 0.0 & 21.0 & 30.4 & 84.7 \\
\hline
\end{tabular}




\begin{tabular}{|c|c|c|c|c|c|c|c|c|c|c|c|c|}
\hline Color TV, 26"-36" & 55.4 & 86.2 & 40.0 & 115.3 & 179.4 & 0.0 & 5.5 & 128.0 & 0.0 & 36.7 & 115.3 & 216.1 \\
\hline TV/NCR Combo & 37.5 & 54.4 & 17.7 & 34.5 & 50.1 & 2.5 & 8.4 & 150.3 & 19.5 & 65.7 & 54.1 & 115.9 \\
\hline VCR & 6.8 & 15.1 & 11.2 & 4.0 & 8.8 & 0.6 & 4.9 & 156.8 & 4.9 & 39.9 & 8.9 & 48.7 \\
\hline Game Console & 5.9 & 22.2 & 7.2 & 2.2 & 8.3 & 0.0 & 0.4 & 160.8 & 0.0 & 3.2 & 2.2 & 11.5 \\
\hline Computer & 25.0 & 58.5 & 23.2 & 30.1 & 70.5 & 0.0 & 1.6 & 144.8 & 0.0 & 12.0 & 30.1 & 82.6 \\
\hline Laptop Computer & 13.4 & 20.7 & 14.8 & 10.3 & 15.9 & 0.4 & 1.7 & 153.3 & 3.2 & 13.7 & 13.5 & 29.7 \\
\hline Computer Monitor,17" & 36.0 & 71.9 & 28.2 & 52.8 & 105.4 & 0.0 & 0.7 & 139.8 & 0.0 & 4.8 & 52.8 & 110.3 \\
\hline Computer Monitor,19" & 38.0 & 77.7 & 50.5 & 99.8 & 204.0 & 0.0 & 1.1 & 117.5 & 0.0 & 6.7 & 99.8 & 210.7 \\
\hline Computer Monitor, $21 "$ & 75.0 & 113.1 & 60.0 & 234.0 & 352.7 & 0.0 & 0.7 & 108.0 & 0.0 & 3.7 & 234.0 & 356.4 \\
\hline Inkjet Printer & 2.3 & 12.4 & 14.0 & 1.7 & 9.0 & 0.0 & 2.7 & 154.0 & 0.0 & 21.3 & 1.7 & 30.3 \\
\hline Laser Printer & 23.0 & 34.0 & 7.2 & 8.6 & 12.8 & 0.0 & 1.8 & 160.8 & 0.0 & 14.7 & 8.6 & 27.4 \\
\hline External Modem, Dial-up & 0.0 & 4.1 & 3.5 & 0.0 & 0.7 & 0.1 & 0.4 & 164.5 & 0.9 & 3.0 & 0.9 & 3.7 \\
\hline Clock & 0.2 & 5.0 & 2.8 & 0.0 & 0.7 & 0.1 & 0.9 & 165.2 & 0.9 & 7.7 & 0.9 & 8.5 \\
\hline Microwave & 1000.0 & 1359.5 & 2.1 & 110.2 & 149.8 & 0.0 & 2.1 & 165.9 & 0.0 & 18.4 & 110.2 & 168.2 \\
\hline Musical Electronics & 3.0 & 9.9 & 5.9 & 0.9 & 3.1 & 0.0 & 0.5 & 162.1 & 0.0 & 3.9 & 0.9 & 6.9 \\
\hline Portable Audio & 0.4 & 4.9 & 2.8 & 0.1 & 0.7 & 0.0 & 0.9 & 165.2 & 0.0 & 8.1 & 0.1 & 8.8 \\
\hline Radio & 1.0 & 3.1 & 1.9 & 0.1 & 0.3 & 0.0 & 0.3 & 166.1 & 0.0 & 2.6 & 0.1 & 2.9 \\
\hline Desktop Audio, 1 Disk & 1.8 & 11.2 & 10.8 & 1.0 & 6.3 & 0.0 & 2.1 & 157.2 & 0.0 & 17.1 & 1.0 & 23.4 \\
\hline Component Stereo System & 13.1 & 37.1 & 32.6 & 22.2 & 62.8 & 0.0 & 2.1 & 135.4 & 0.0 & 15.1 & 22.2 & 78.0 \\
\hline $\begin{array}{l}\text { Miscellaneous Stereo } \\
\text { Comps. }\end{array}$ & 1.2 & 17.3 & 22.9 & 1.4 & 20.6 & 0.0 & 5.6 & 145.1 & 0.0 & 42.6 & 1.4 & 63.2 \\
\hline Stereo CD Player & 5.5 & 8.8 & 19.9 & 5.7 & 9.1 & 0.0 & 2.2 & 148.1 & 0.0 & 16.6 & 5.7 & 25.7 \\
\hline
\end{tabular}




\begin{tabular}{|c|c|c|c|c|c|c|c|c|c|c|c|c|}
\hline Stereo Receiver & 12.1 & 28.4 & 21.1 & 13.3 & 31.1 & 0.0 & 3.1 & 146.9 & 0.0 & 23.8 & 13.3 & 54.8 \\
\hline Stereo Tape Player & 3.6 & 8.8 & 1.4 & 0.3 & 0.6 & 0.0 & 0.6 & 166.6 & 0.0 & 5.4 & 0.3 & 6.1 \\
\hline
\end{tabular}




\section{Appendix B}

Small Pond Data

Table 1: Data for Toronto

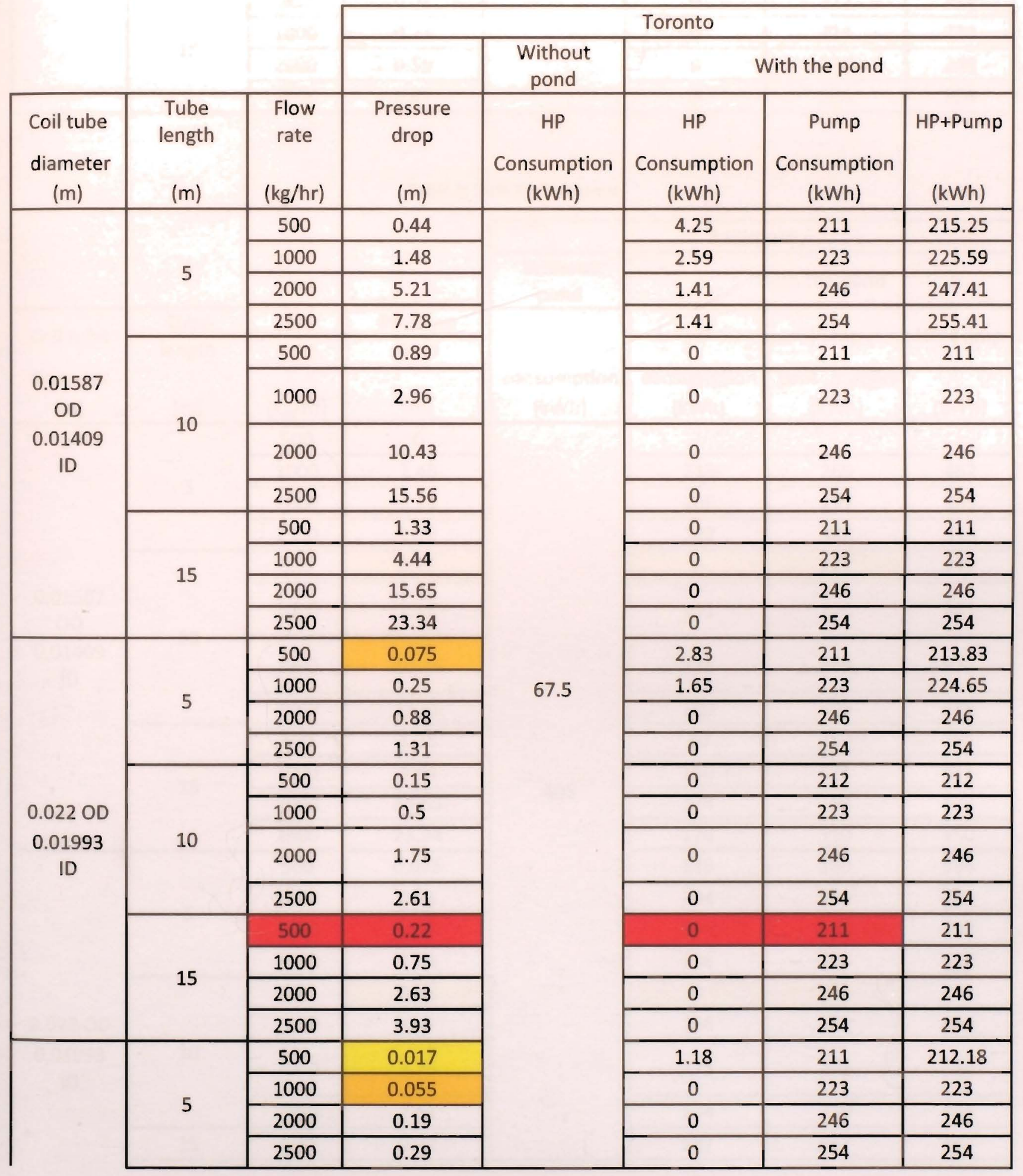




\begin{tabular}{|c|c|c|c|c|c|c|}
\hline \multirow{8}{*}{$\begin{array}{c}0.02857 \\
\text { OD } \\
0.02679 \\
\text { ID }\end{array}$} & \multirow{4}{*}{10} & 500 & 0.033 & 0 & 212 & 212 \\
\hline & & 1000 & 0.11 & 0 & 223 & 223 \\
\hline & & 2000 & 0.39 & 0 & 246 & 246 \\
\hline & & 2500 & 0.58 & 0 & 254 & 254 \\
\hline & \multirow{4}{*}{15} & 500 & 0.05 & 0 & 212 & 212 \\
\hline & & 1000 & 0.17 & 0 & 223 & 223 \\
\hline & & 2000 & 0.59 & 0 & 246 & 246 \\
\hline & & 2500 & 0.87 & 0 & 254 & 254 \\
\hline
\end{tabular}

Table 2: Data for Baltimore

\begin{tabular}{|c|c|c|c|c|c|c|c|}
\hline \multirow[b]{3}{*}{$\begin{array}{l}\text { Coil tube } \\
\text { diameter } \\
\text { (m) }\end{array}$} & \multirow[b]{3}{*}{$\begin{array}{l}\text { Tube } \\
\text { length }\end{array}$} & \multirow[b]{3}{*}{$\begin{array}{l}\text { Flow } \\
\text { rate }\end{array}$} & \multirow[b]{3}{*}{$\begin{array}{c}\text { Pressure } \\
\text { drop }\end{array}$} & \multicolumn{4}{|c|}{ Baltimore } \\
\hline & & & & \multirow{2}{*}{$\begin{array}{c}\begin{array}{c}\text { Without } \\
\text { pond }\end{array} \\
\text { HP } \\
\text { consumption } \\
\text { (kWh) }\end{array}$} & \multicolumn{3}{|c|}{ With the pond } \\
\hline & & & & & $\begin{array}{c}\text { HP } \\
\text { consumption } \\
\text { (kWh) }\end{array}$ & $\begin{array}{c}\text { Pump } \\
\text { consumption } \\
\text { (kWh) }\end{array}$ & $\begin{array}{c}\text { HP+Pump } \\
\text { (kWh) }\end{array}$ \\
\hline \multirow{12}{*}{$\begin{array}{c}0.01587 \\
\text { OD } \\
0.01409 \\
\text { ID }\end{array}$} & \multirow{4}{*}{5} & 500 & 0 & \multirow{21}{*}{405} & & & \\
\hline & & 1000 & 1.48 & & 213 & 269 & 482 \\
\hline & & 2000 & 5.21 & & 206 & 297 & 503 \\
\hline & & 2500 & 7.78 & & 202 & 308 & 510 \\
\hline & \multirow{4}{*}{10} & 500 & 0.89 & & 0 & 271 & 271 \\
\hline & & 1000 & 2.96 & & 191 & 270 & 461 \\
\hline & & 2000 & 10.43 & & 179 & 299 & 478 \\
\hline & & 2500 & 15.56 & & 180 & 309 & 489 \\
\hline & \multirow{4}{*}{15} & 500 & 1.33 & & 30 & 269 & 299 \\
\hline & & 1000 & $4 . \overline{44}$ & & 180 & 271 & 451 \\
\hline & & 2000 & 15.65 & & 174 & 299 & 473 \\
\hline & & 2500 & 23.34 & & 170 & 310 & 480 \\
\hline \multirow{9}{*}{$\begin{array}{c}0.022 \text { OD } \\
0.01993 \\
\text { ID }\end{array}$} & \multirow{4}{*}{5} & 500 & 0.075 & & 126 & 260 & 386 \\
\hline & & 1000 & 0.25 & & 204 & 269 & 473 \\
\hline & & 2000 & 0.88 & & 194 & 298 & 492 \\
\hline & & 2500 & 1.31 & & 196 & 308 & 504 \\
\hline & & 500 & 0.15 & & 0 & 271 & 271 \\
\hline & & 1000 & 0.5 & & 156 & 272 & 428 \\
\hline & 10 & 2000 & 1.75 & & 175 & 299 & 474 \\
\hline & & 2500 & 2.61 & & 174 & 310 & 484 \\
\hline & 15 & 500 & 0.22 & & 187 & 257 & 444 \\
\hline
\end{tabular}




\begin{tabular}{|c|c|c|c|c|c|c|}
\hline & & 1000 & 0.75 & 176 & 271 & 447 \\
\hline & & 2000 & 2.63 & 168 & 299 & 467 \\
\hline & & 2500 & 3.93 & 166 & 310 & 476 \\
\hline \multirow{12}{*}{$\begin{array}{c}0.02857 \\
\text { OD } \\
0.02679 \\
\text { ID }\end{array}$} & \multirow{4}{*}{5} & 500 & 0.017 & 213 & 255 & 468 \\
\hline & & 1000 & 0.055 & 201 & 269 & 470 \\
\hline & & 2000 & 0.19 & 192 & 298 & 490 \\
\hline & & 2500 & 0.29 & 188 & 308 & 496 \\
\hline & \multirow{4}{*}{10} & 500 & 0.033 & 0 & 271 & 271 \\
\hline & & 1000 & 0.11 & 180 & 271 & 451 \\
\hline & & 2000 & 0.39 & 171 & 300 & 471 \\
\hline & & 2500 & 0.58 & 170 & 310 & 480 \\
\hline & \multirow{4}{*}{15} & 500 & 0 & & & 0 \\
\hline & & 1000 & 0.17 & 172 & 271 & 443 \\
\hline & & 2000 & 0.59 & 163 & 300 & 463 \\
\hline & & 2500 & 0.87 & 164 & 310 & 474 \\
\hline
\end{tabular}




\section{Appendix C}

\section{Mechanical Equipment Specification}

North House

May 28,

2009

2009

Equipment

Schedule

Total: 54063 Totals (W):

\begin{tabular}{|c|c|c|c|c|c|c|c|}
\hline \multirow[b]{2}{*}{$\underset{\mathrm{ol}}{\text { Symb }}$} & \multirow[b]{2}{*}{ Quant } & \multirow[b]{2}{*}{ Description } & \multirow[b]{2}{*}{ Product Name } & \multirow[b]{2}{*}{ Volts } & \multicolumn{2}{|c|}{ Amps 225.26} & Amp \\
\hline & & & & & $\begin{array}{c}\text { Equipm } \\
\text { ent } \\
\text { Amps }\end{array}$ & $\begin{array}{c}\text { Equipm } \\
\text { ent } \\
\text { Watts }\end{array}$ & $\begin{array}{c}\text { Connectio } \\
\mathbf{n} \\
\text { Comments }\end{array}$ \\
\hline $\mathrm{CT}$ & 2 & Cooktop & Gaggenau VI 221 & 240 & 16 & 7200 & \\
\hline ov & 2 & bven & Gaggenau BO 250-611 & 240 & 16 & 3700 & \\
\hline FF & 1 & Fridge/freezer & Leibherr HC1060 & 120 & 15 & 180 & \\
\hline EF & 1 & Exhaust fan & Fantech FG6 & 120 & 1.02 & 122.4 & \\
\hline DW & 1 & Dishwasher & Gaggenau DF 261760 & 120 & 12 & 2300 & \\
\hline DRY & 1 & Dryer & Bosch Axxis condensation & 240 & 13 & 3120 & \\
\hline WSH & 1 & Washing machine & Bosch Axxis plus & 240 & 12 & 2880 & \\
\hline AHU & 1 & AHU - ECO-Pac EP30 & Ecologix EP-30 & 120 & 5.5 & 660 & \\
\hline HRV & 1 & $\begin{array}{l}\text { HRV - Fantech } \\
\text { SH704 }\end{array}$ & Fantech & 120 & 0.36 & 40 & \\
\hline HP & 2 & Hydronic heat pump & $\begin{array}{l}\text { Copeland Digital Scroll } \\
\text { Comp. }\end{array}$ & 240 & 23 & 11040 & ZPD34KSE-PFV \\
\hline VSP & 2 & Variable speed pump & Grundfos UPS $15-42 F / V S$ & 120 & 0.74 & 177.6 & \\
\hline PIC & 2 & PI controller & Johnson controls & & & & \\
\hline $\mathbf{P}$ & 4 & eirc pump & Grundfos UPS 15-58FC/FRC & 120 & 0.75 & 360 & \\
\hline AUX & 1 & Backup DHW heating & $\begin{array}{l}\text { Bradford White M-2-HE- } \\
40560 S\end{array}$ & 240 & & 6000 & $2 \times 3000$ \\
\hline$D C$ & 2 & $\begin{array}{l}\text { Difference setpoint } \\
\text { control }\end{array}$ & Techmar 156 & $24 \|$ & & 3 & \\
\hline STC & 1 & Solar controller & Viesmann SCU-124 & 120 & 1.2 & 144 & \\
\hline SP & 1 & Solar circ. pump & Viesmann & 120 & 0.8 & $90 \|$ & \\
\hline
\end{tabular}




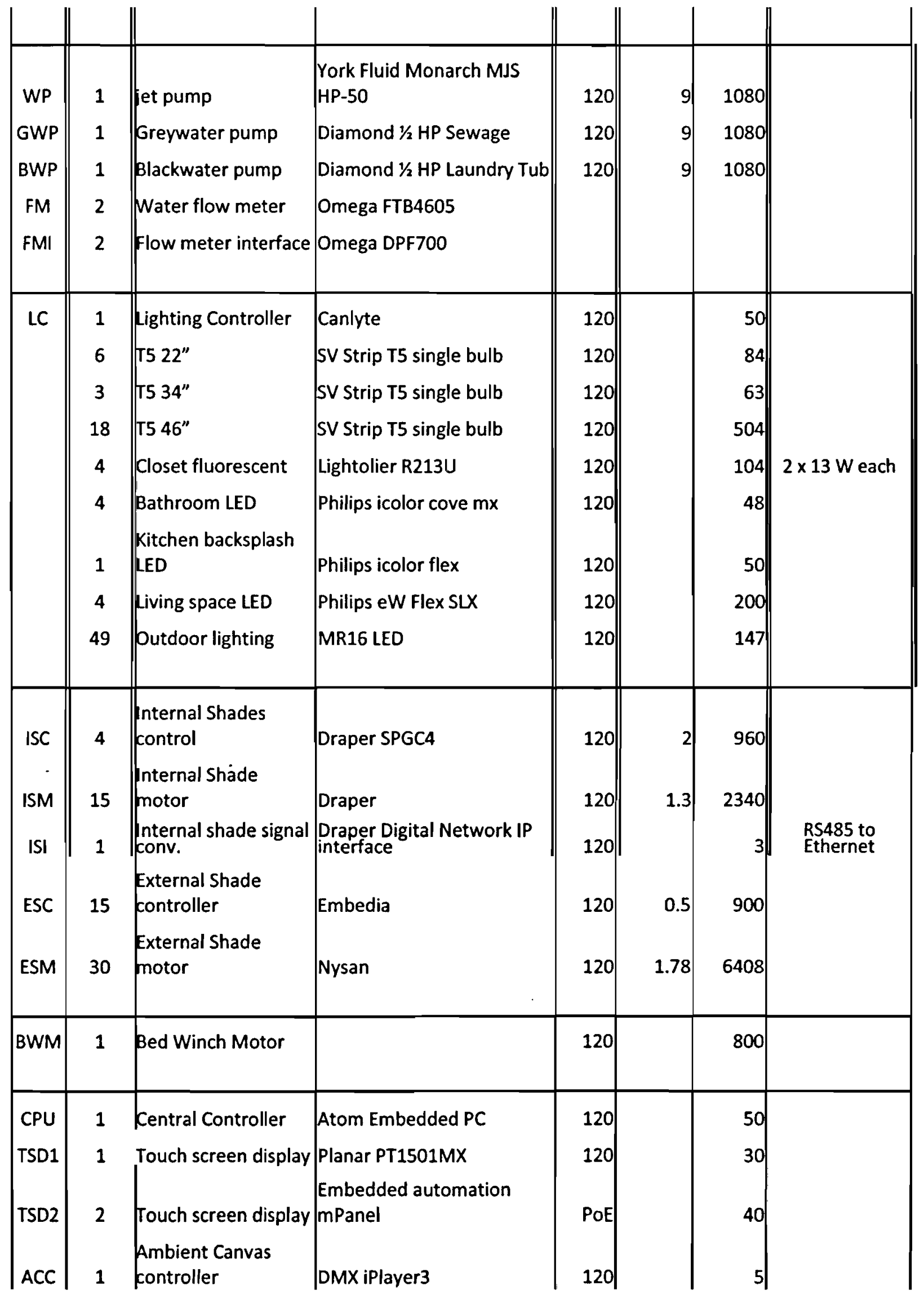




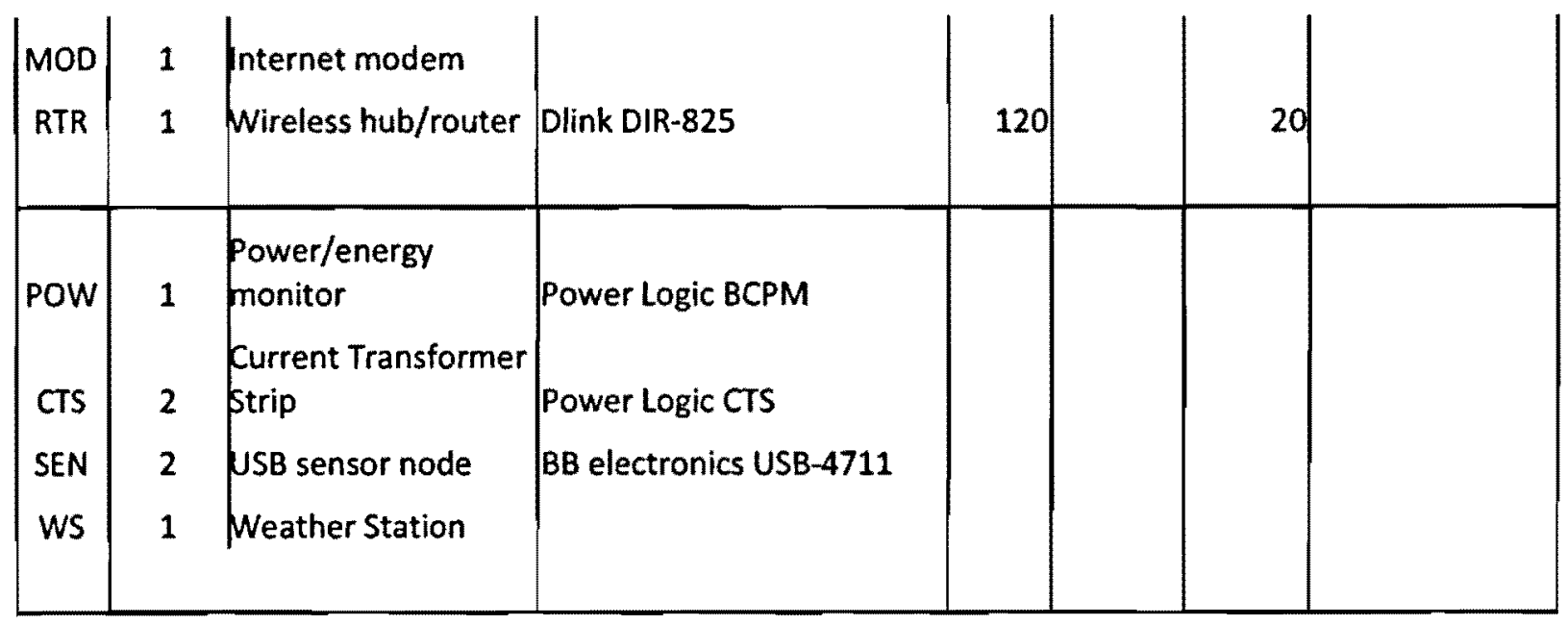




\section{Appendix D}

Competitions Rules and Regulations 


\section{9}

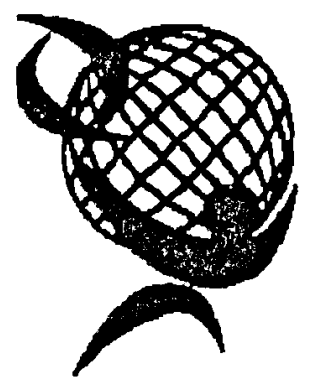

SOLAR DECATHLON RULES

Last Updated: March 21, 2008 


\section{Contents}

SECTION I:

DEFINITIONS

SECTION II:

GENERAL RULES

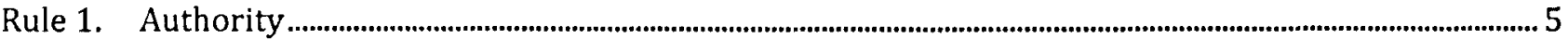

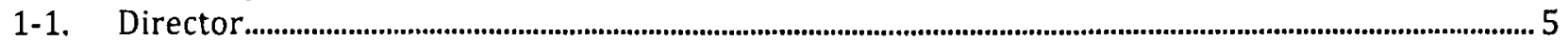

1-2. Competition Manager ...................................................................................................................................... 5

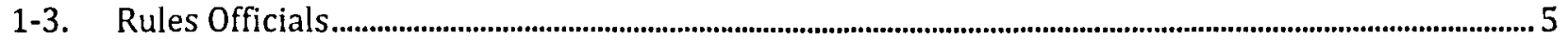

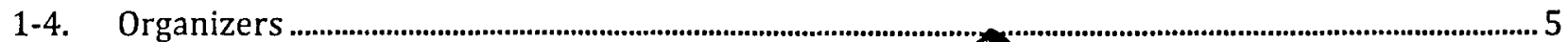

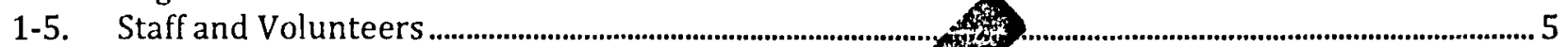

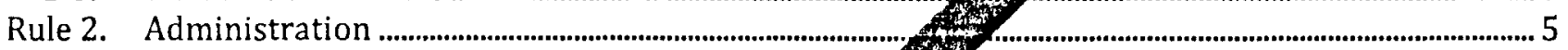

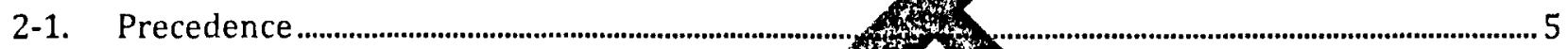

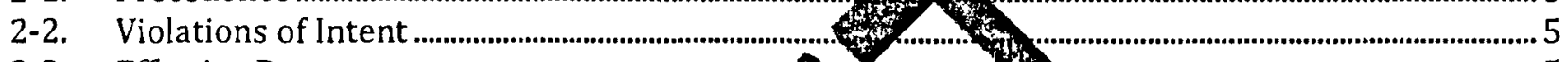

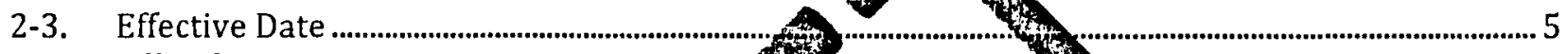

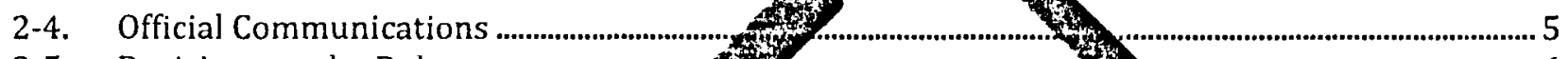

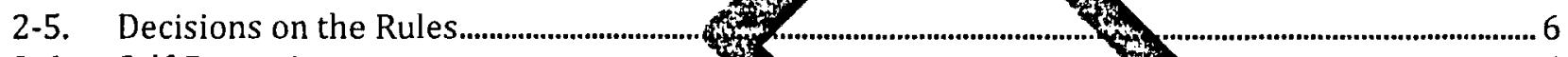

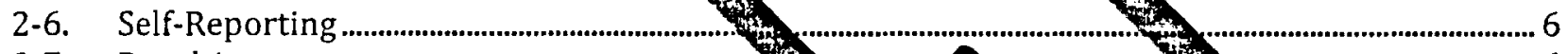

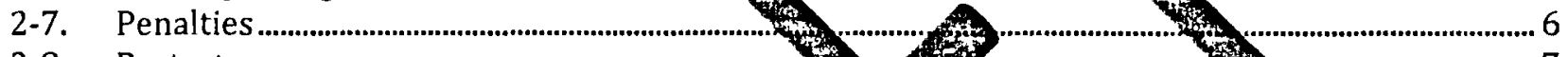

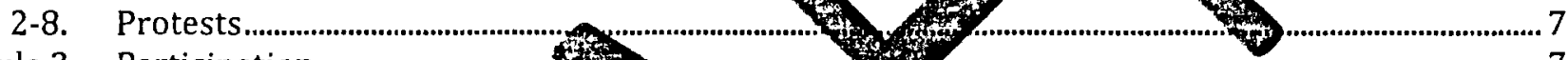

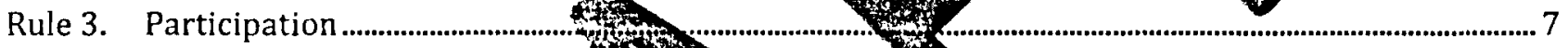

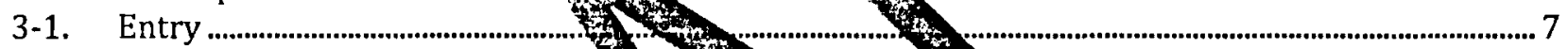

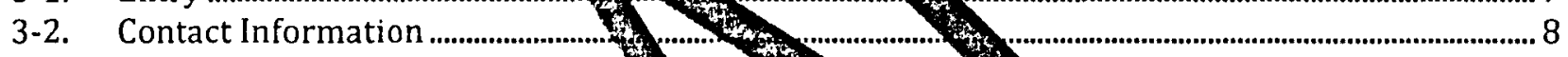

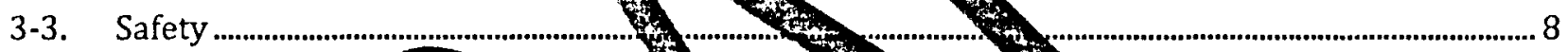

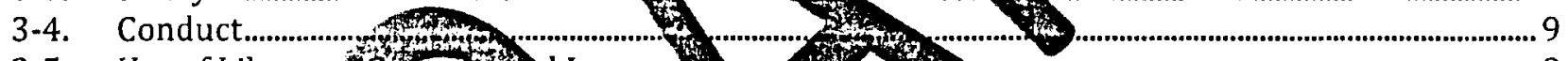

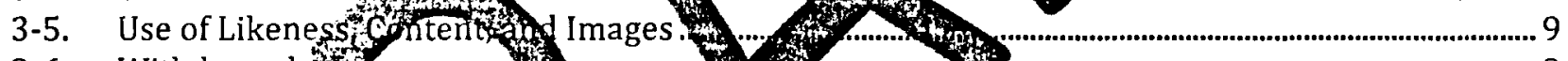

3-6. Withdrawals

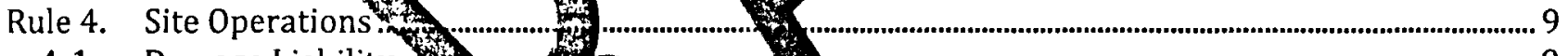

4-1. Damage Liability ....t.

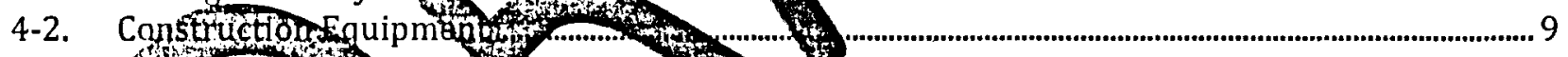

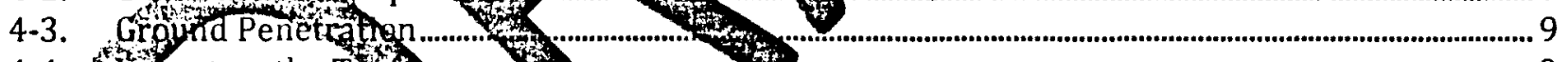

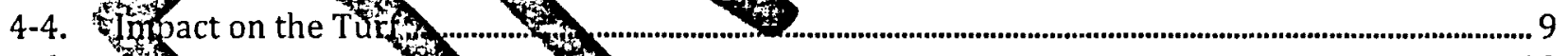

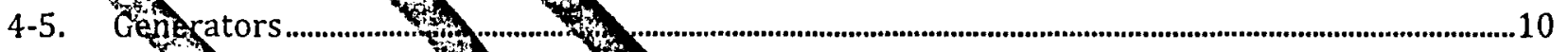

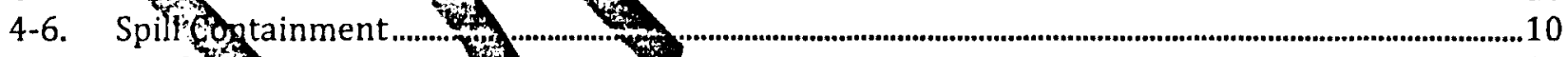

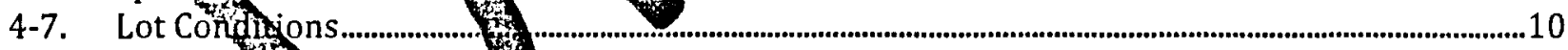

Rule 5. The SolarEp elope ...........

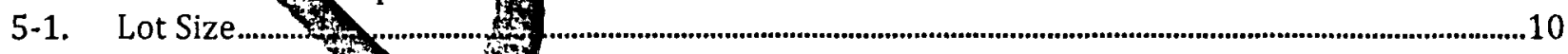

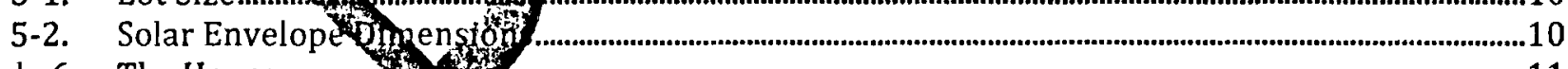

Rule 6. The House ...................

6-1. Structural Design Apj oval ...............................................................................................................................11

6-2. Maximum Architectural Footprint .............................................................................................................12

6-3. Minimum Conditioned Space.............................................................................................................................112

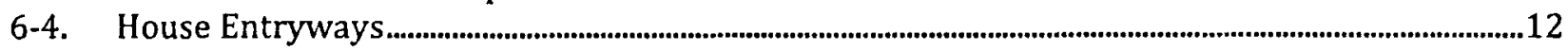

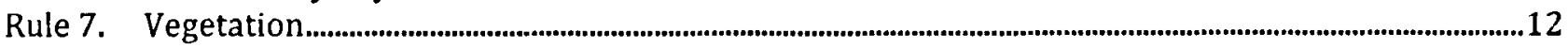

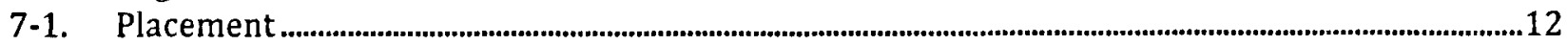

7-2. Watering Restrictions.........................................................................................................................................12

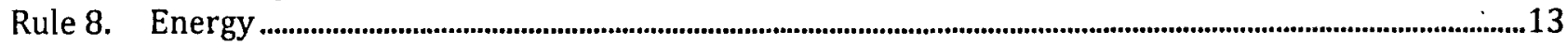

8-1. PV Technology Limitations...............................................................................................................................13

8-2. Energy Sources ...........................................................................................................................................................13

8-3. Thermal Energy Storage ................................................................................................................................................13

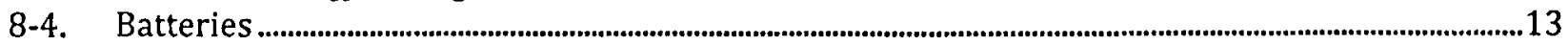




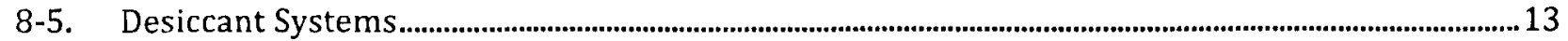

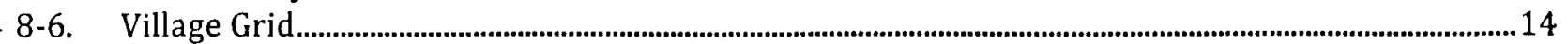

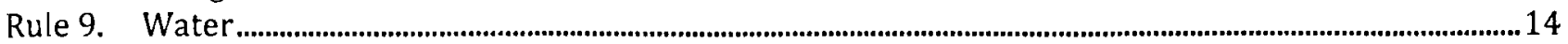

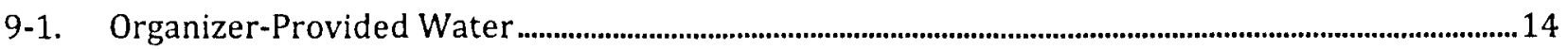

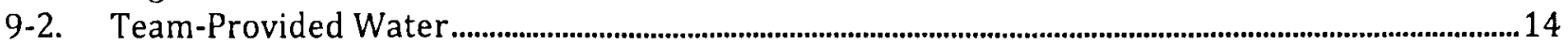

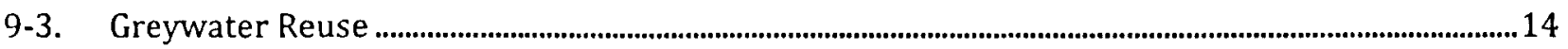

9-4. Rainwater Collection .................................................................................................................................... 14

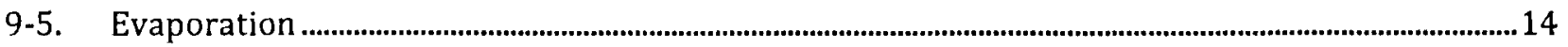

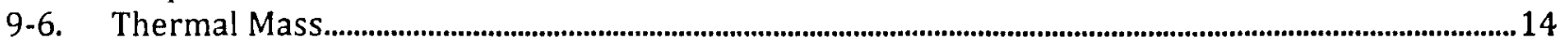

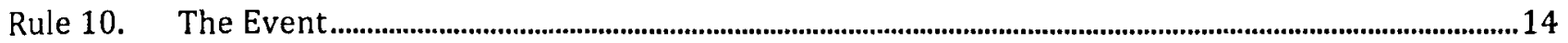

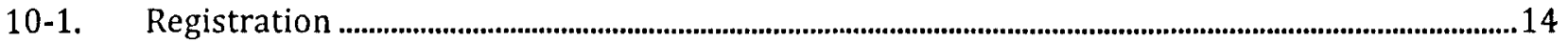

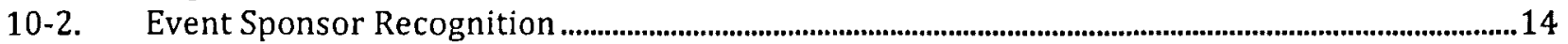

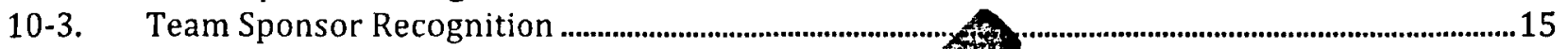

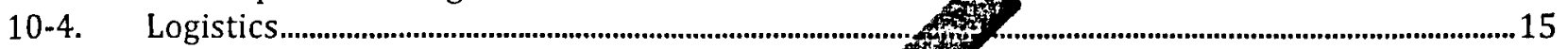

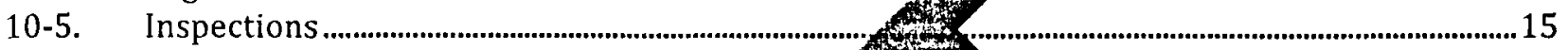

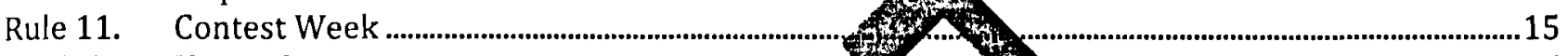

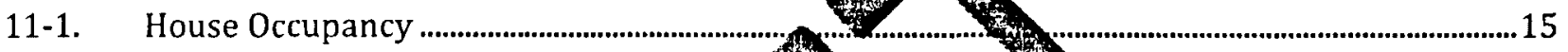

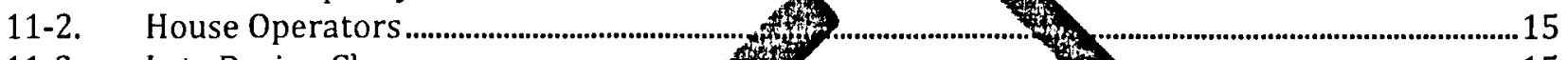

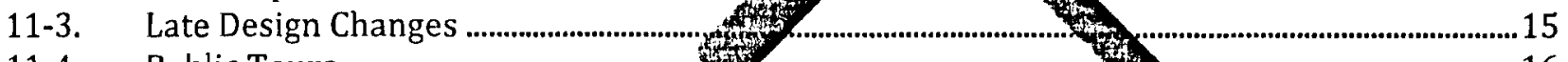

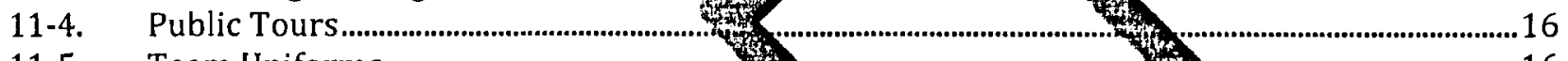

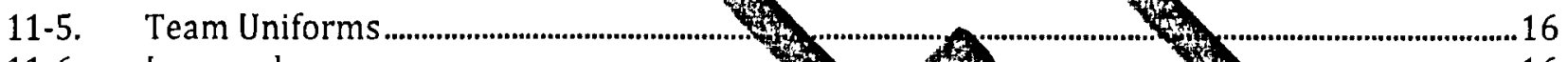

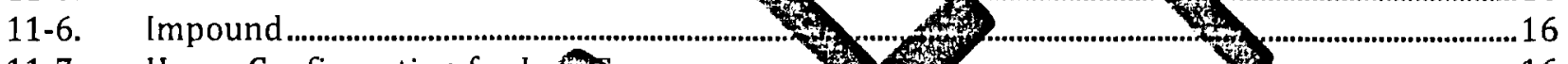

11-7. House Configuration for Jug

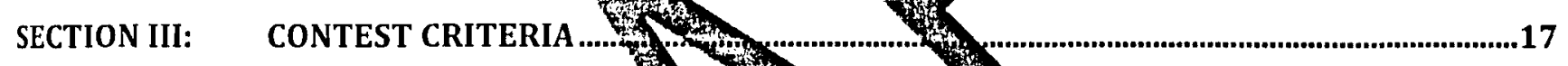

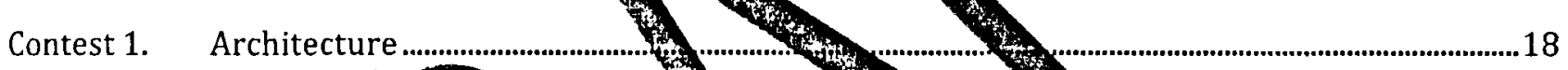

Contest 2. Market Viability

Contest 3. Engineering

Contest 4. Lightingt Q esgn.............

Contest 5. Communicath

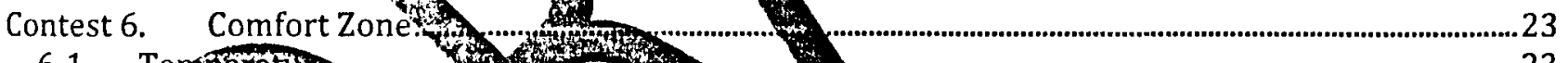

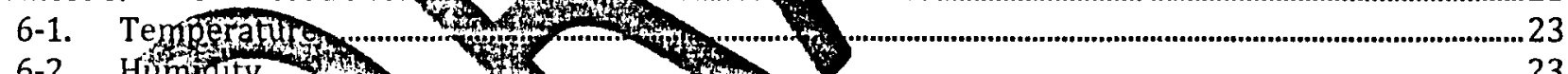

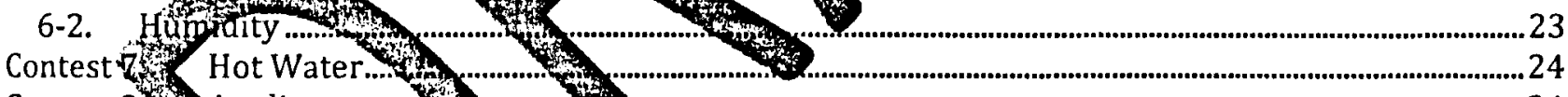

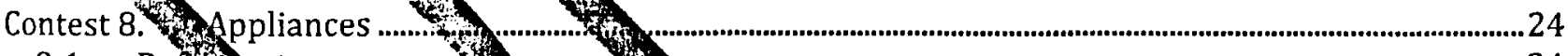

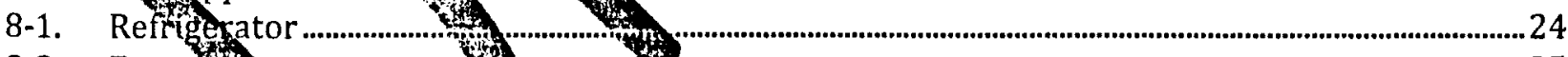

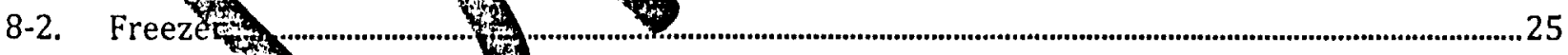

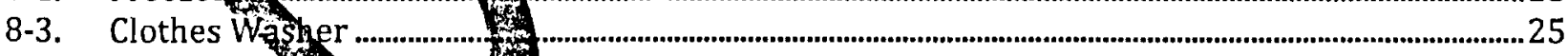

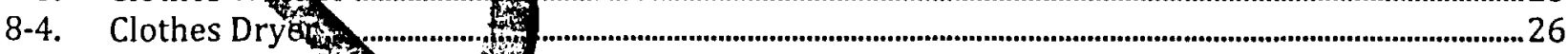

8-5. Dishwasher ......

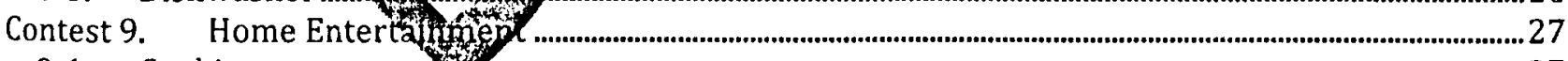

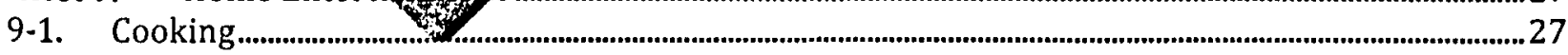

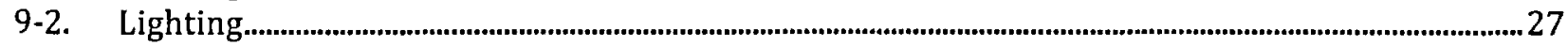

9-3. Dining .................................................................................................................................................................... 28

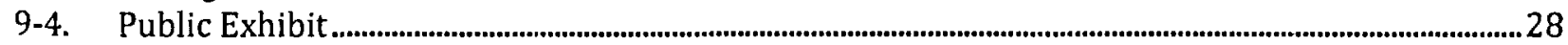

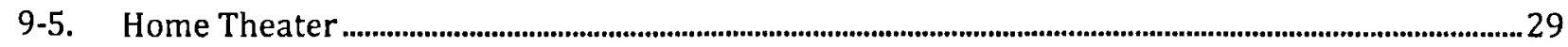

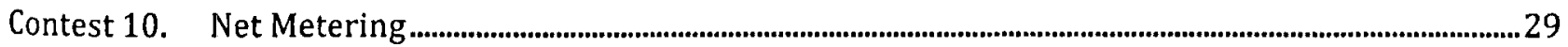

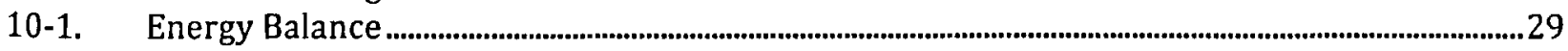

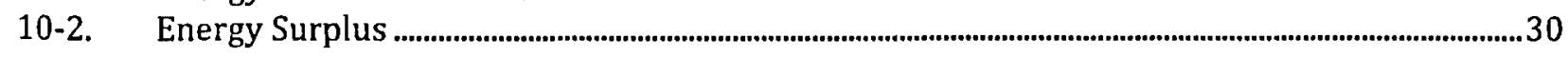

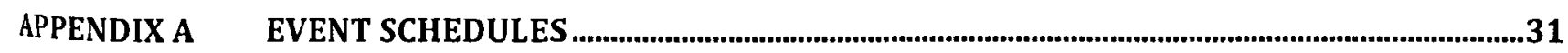

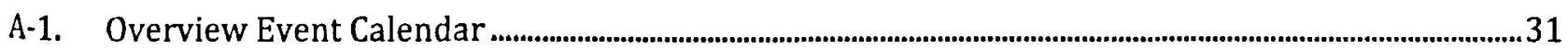

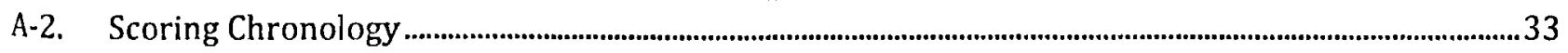




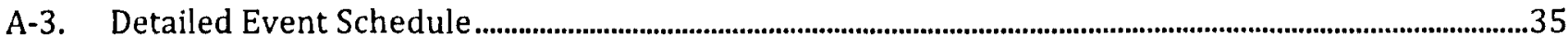

APPENDIX B SUBJECTIVE SUB-CONTEST GUIDELINES .....................................................................................41

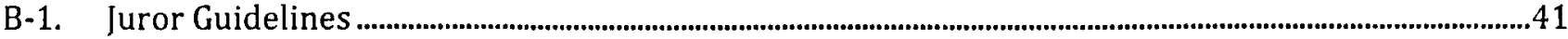

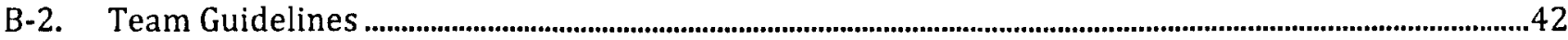

APPENDIX C OBJECTIVE SUB-CONTEST GUIDELINES ................................................................................45

C-1. Measured Performance Sub-Contests .........................................................................................................................45

C-2. Task Completion Sub-Contests.......................................................................................................................................4

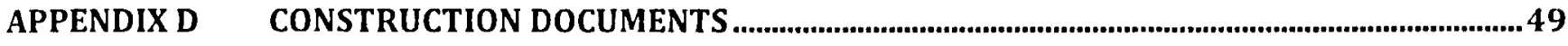

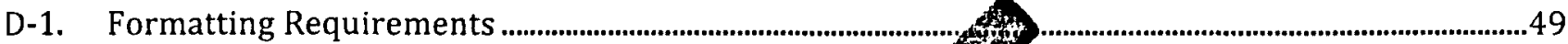

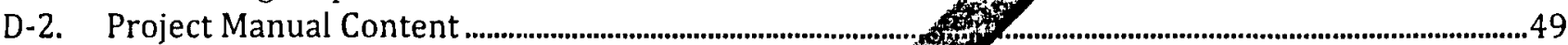

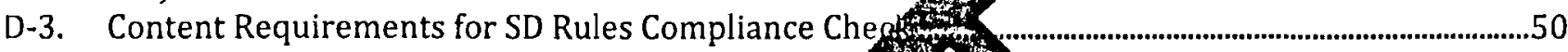

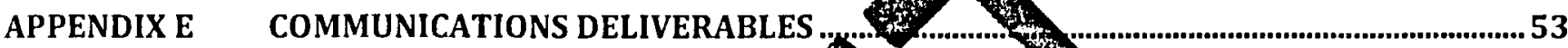

E-1. Preliminary Communications Plan and Web

E-2. Final Communications Plan and Web Site

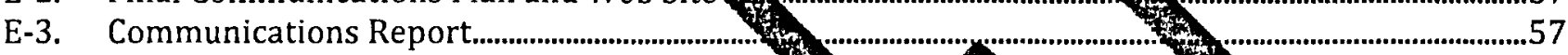

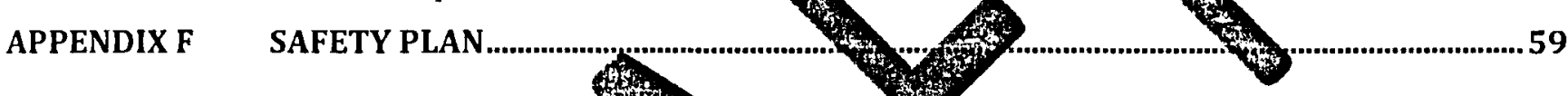

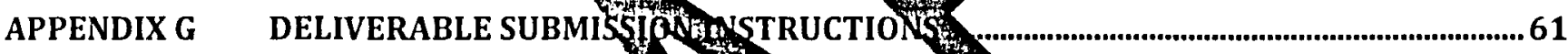

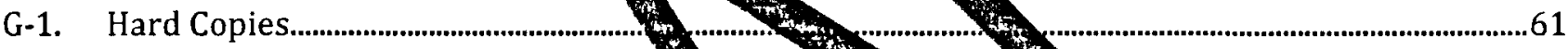

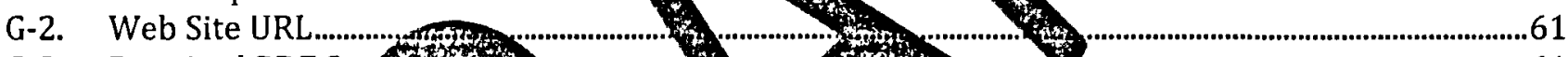

G-3. Required PDF Spefifi

G-4. Required Graphtc

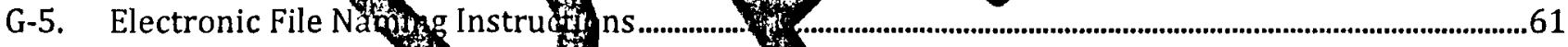

G-6. Electronic File Subnf

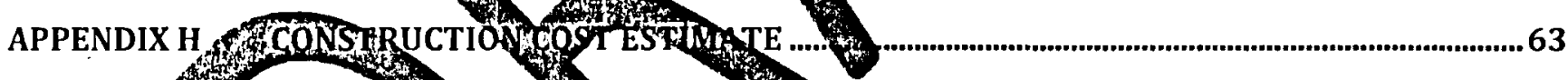




\section{SECTION I: DEFINITIONS}

\section{Assembly}

The period of time between the arrival of trucks and the beginning of the contests on the competition site

\section{Communications materials}

All printed or electric publications designed to convey information to the public

\section{Competition}

All aspects of the Solar Decathlon related to the 10 contests and the scoring of those contests

\section{Competition Manager}

The organizer responsible for writing and enforcing the rules and condug a fair and compelling competition

\section{Contest}

See the introduction to Section III

\section{Contest Official}

A Rules Officials selected by the Competition Manager the 10 contests; a Contest Official is only authorized to interpret the rules of the cotht st(s) to which he or shet assigned

\section{Contest week}

The period of approximately 7 to 9 days on the competition

\section{Decathlete}

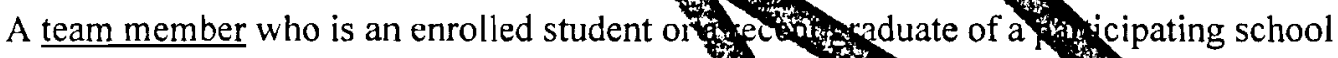

\section{Decision}

The Rules Officials ' interpretatoniongrafication th rule

Decisions on the Solaphecathlon pules

The compilation of all decistonsmade by hules Offes's' during the project

\section{Director}

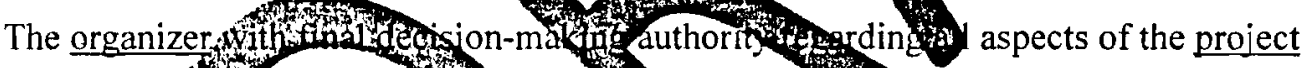

\section{Disassembly}

The period of between the consion somplic tours and the completion of compen

\section{Event}

The series of activitiestion take place 6 the competition site. Event activities include, but are not limited to, registration, assembly, instations, contes s, special events, hours of public access, and disassembly.

\section{Event Production Manage}

The organizer responsible for thect's public outreach, communications, special events, and volunteer activities

\section{Event Sponsor}

An entity selected by the Director to support the project. The U.S. Department of Energy (DOE) is the primary sponsor of the Solar Decathlon. DOE partners with other institutions-such as its National Renewable Energy Laboratory (NREL)-to support the project.

\section{Faculty Advisor}

A team member who is a faculty member at one of the participating schools and who provides guidance to the team on an as-needed basis throughout the project and obtains appropriate signatures on documents that require the school's or schools' concurrence or authorization 


\section{Interconnection Application}

A form submitted by the team's electrician to the Site Operations Manager; it provides the technical details needed to determine the suitability of the team's electrical system for interconnection to the village grid

Juror

Individuals selected by the organizers to make subjective evaluations of the projects

Jury

A group of jurors evaluating a specific aspect of each team's project

Objective sub-contest

See the introduction to Section III

\section{observer}

A person assigned by the Competition Manager to observe team actiyffesturing contest week. An observer shall report observed rules infractions to the Rules Officials and record tut provide official interpretations of the Solar Decathlon Rules.

\section{Organizer}

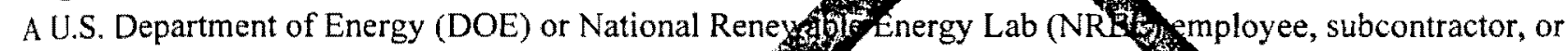
abserver working on the project and having the authowescribed in Rule 1-4

\section{Project}

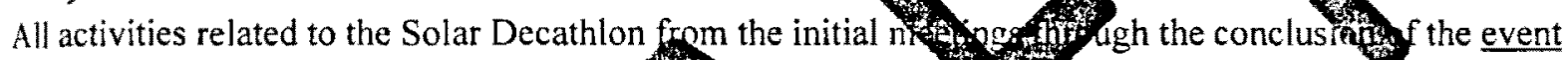

\section{Protest Resolution Committee}

The group of individuals selected by the organtzrs the competition

Rule

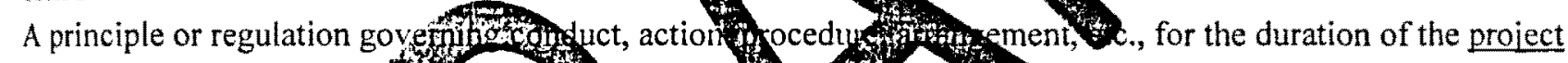

Rules Official

An organizer authorized to infepget the rile. The Comper tion Manager is the lead Rules Official.

\section{Scored period}

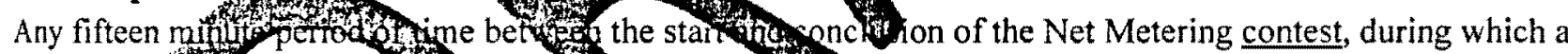

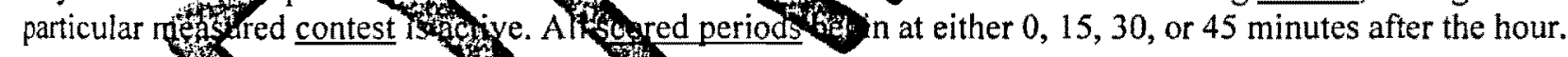

\section{Scorekeeper}

The individual setect by the organize to operand maintain the scoring spreadsheet during the competition

\section{Scoring spreadshee}

A detailed Microsoft Excd

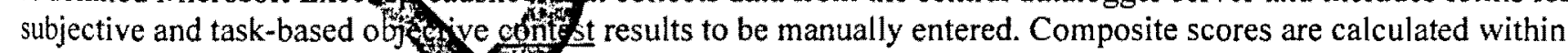
the spreadsheet.

\section{Site Operations Manager}

The organizer responsible for all event site operations, except those listed as responsibilities of the Competition Manager and Event Production Manager

\section{Solar Decathlon Building Code}

A set of design and construction standards set forth and enforced by the Solar Decathlon Building Official for the protection of public health and safety during the event

\section{Staff}

An individual working for the organizers on the project

\section{Sub-contest}

See the introduction to Section III. 


\section{Subjective sub-contest}

See the introduction to Section III.

\section{Team Crew}

A person who is integrally involved with a team's project, but is unaffiliated with the participating schools; contractors, volunteers, and sponsors are examples of team crew

\section{Team Member}

An enrolled student, recent graduate, faculty member, or other person who is affiliated with one of the participating schools and is integrally involved with a team's project activities; Decathletes, Faculty Advisors, and involved staff from a participating school are all considered team members

\section{Yahoo Group}

See Rule 2-4a

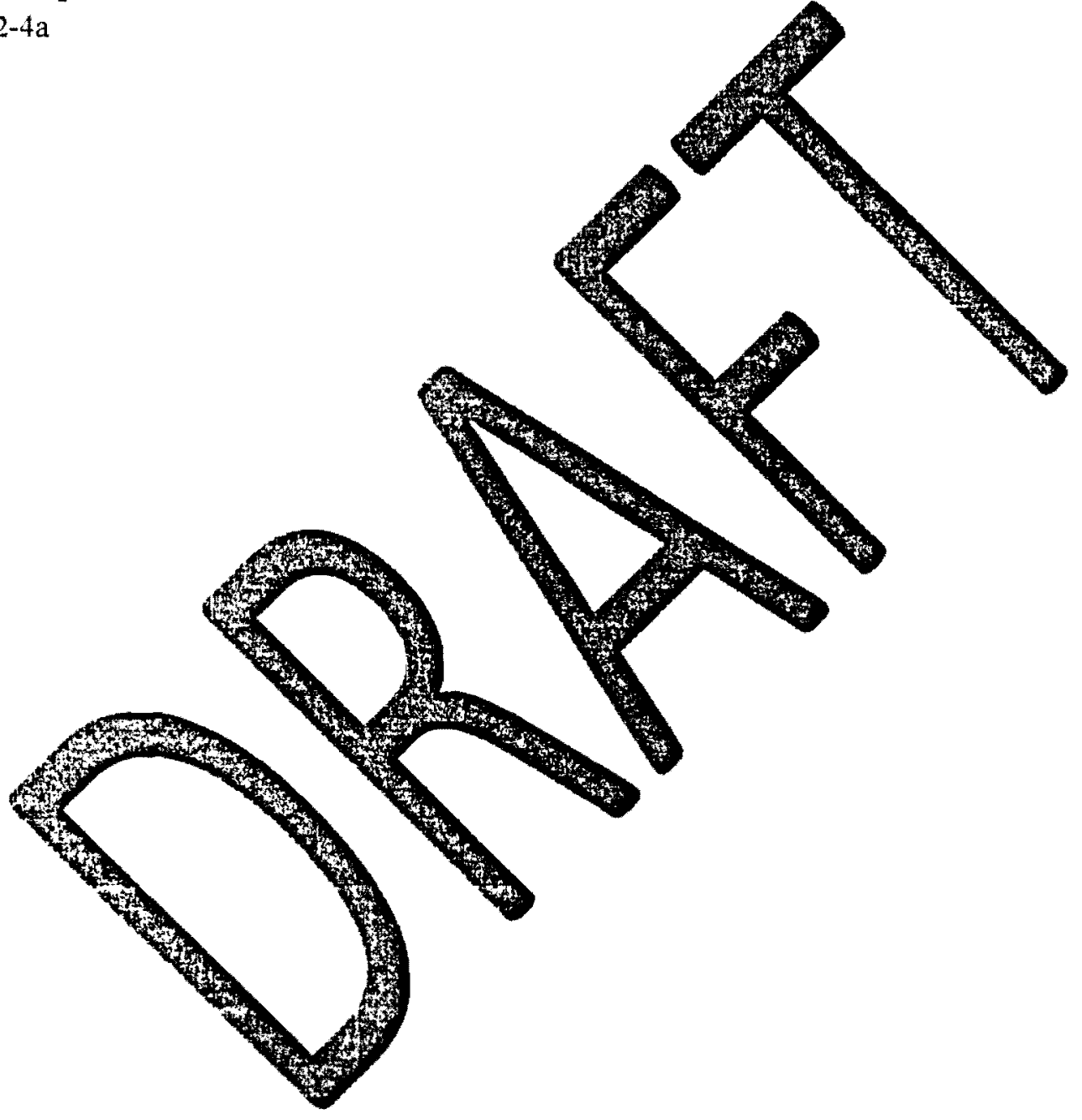


The Director represents the U.S. Department of Energy and has the final decision-making authority in all aspects of the project.

Why

The Competition Manager is the only Rules Officials authorized to write and modify the rules.

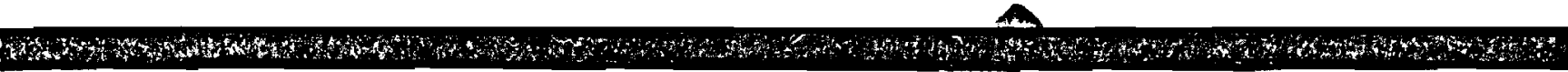

The Rules Officials are the only organizers authorized to interpret

a. If there is any doubt or ambiguity as to the wording or int the decision of the Officials shall prevail.

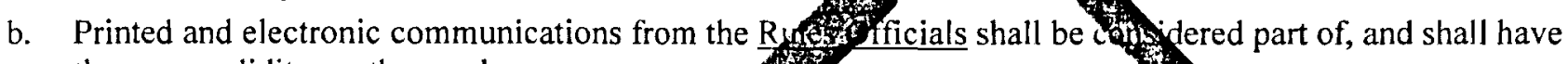
the same validity, as these rules.

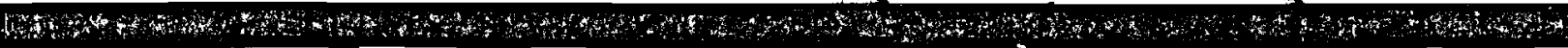

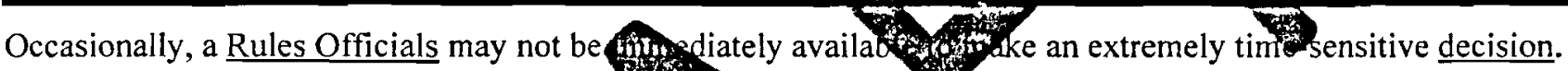

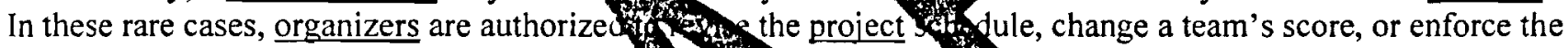

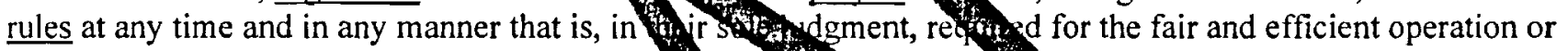
safety of the competition.

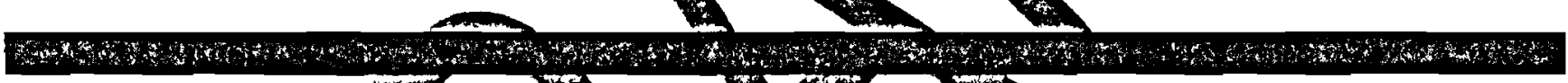

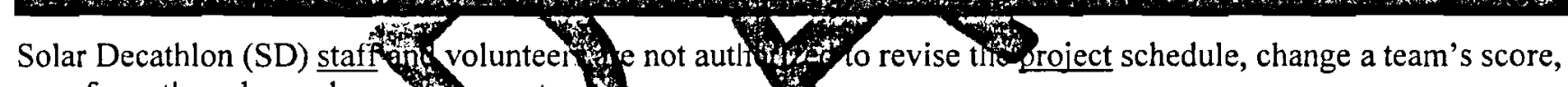
or enforce the rules under any oumstan

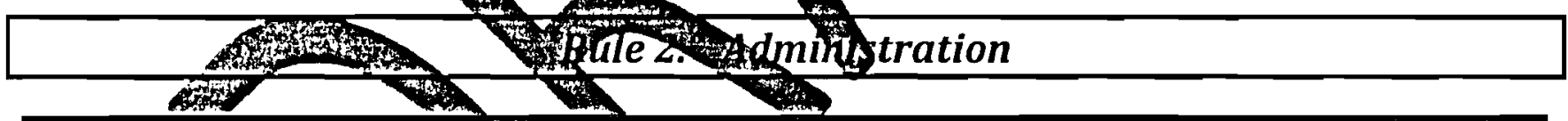

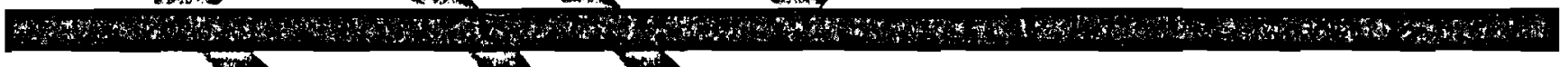
If there is a conflytween two or the rules, rule having the later date takes precedence.

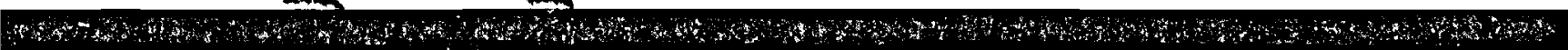
A violation of the intent of the rule itself.

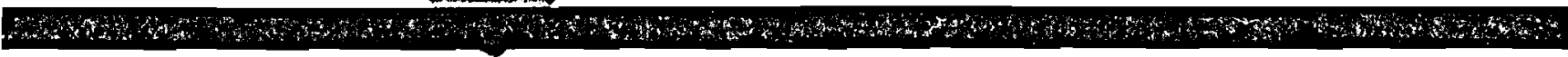

The latest version of the rules posted on the Yahoo Group and dated for the year of the event are the rules in effect.

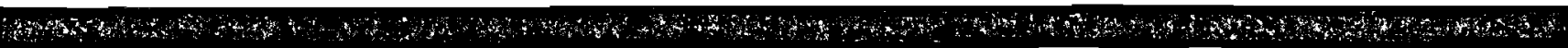

It is the team's responsibility to stay current with official communications regarding the project. Official communication between the teams and the organizers will occur through, but not be limited to, one or all of the following:

a. Yahoo Group (http://groups.yahoo.com/group/SD2009/): All official communications suitable for viewing by all teams will be posted on the Yahoo Group message board. The Yahoo Group includes a section for posting files. If files are too large for the Yahoo Group, they will be posted on the FTP Site, and the teams will be notified via the Yahoo Group as to where they can locate the files. The Yahoo Group calendar 
indicates official deadlines for project deliverables. Other Yahoo Group features will be used for various purposes. Instructions for joining the Yahoo Group will be provided to each team immediately following the selection of teams.

b. Competition Manager's email (sdrules@nrel.gov): For confidential communications or the transfer of small, confidential files, teams should email the Competition Manager. The content of communications sent to this email address will remain confidential, unless the team grants permission to the Competition Manager to divulge the content of these communications to the other teams. See Rule 2-5 for more information about confidentiality.

c. Dropbox (http://dropbox.yousendit.com/SolarDecathlon): The dropbox will be used by the organizers and teams to transfer large, confidential files. Notification of or requests for file transfers will be made via the Yahoo Group or email.

d. FTP Site (ftp://ftp2.nrel.gov/pub/solar decathlon): The FTP site will be used by the organizers to make large files available to the teams.

e. Conference calls: Teams are strongly encouraged to participat gularly scheduled conference calls with the organizers. Invitations and instructions for participation 14 the calls will be provided via the Yahoo Group.

f. Meetings: Before the event, the teams and organizers likely have aty person meeting. Notification of the date and agenda of this meeting will be made ydy y yoo Group. DNo the event, a meeting will be held the day before assembly begins. Meetings whe held on a daily basis the hout the event.

g. Postings at headquarters: During the event, a bulkthoard (or other obvious for posting

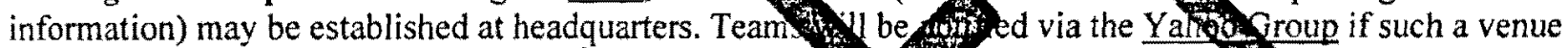
is established and the purpose for which been estably

h. Email: For expediency and to protect che

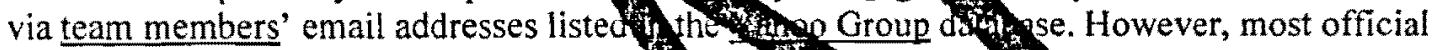
communication will occur via the Yahoo ofong mestzenoard.

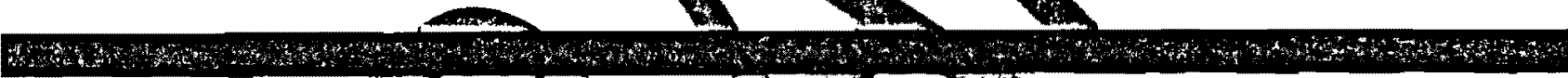

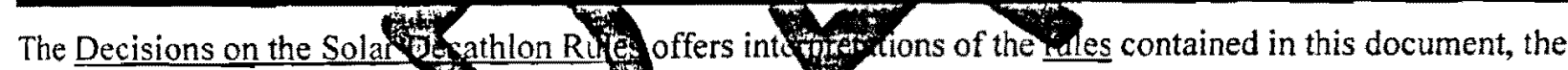
Solar Decathlon Rules.

After the Rules Officials make a forkionthom in theit inion, directly or indirectly affect the strategies of

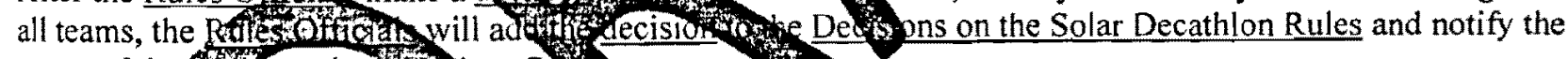

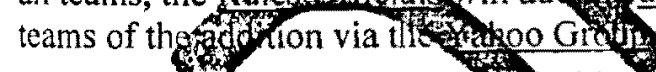

Exception: 6 the hotificatio hould unthy reveal the strategies of one or more individual teams, the

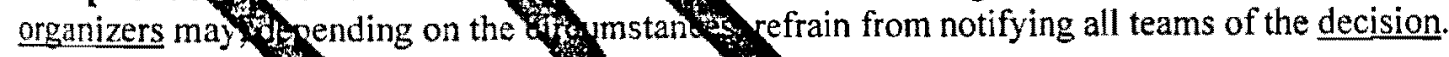

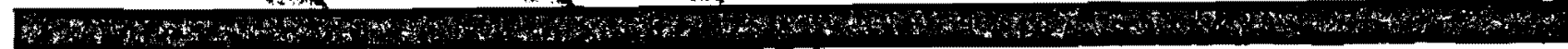
Teams shall self-report defiste or posstit rules infractions that have occurred or may occur.

a. The rules do not addres 3 ry 30 le scenario that may arise during the competition. Therefore, a team considering an action that decision before proceeding whin the action. If the team does not ask for an official decision, it puts itself at risk of incurring a penalty.

b. The Rules Officials and Director exercise discretion when determining the penalty for a rules infraction. Rules infractions observed by Rules Officials and organizers, i.e., not self-reported by the team, may be subject to more severe penalties than self-reported rules infractions.

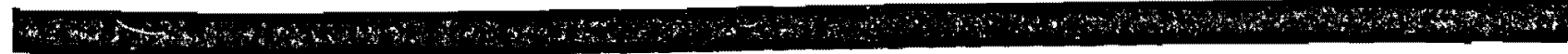

Teams committing rules infractions are subject to one or more of the following penalties, depending on the severity of the infraction: 1) point penalty applied to one or more contests; 2) disqualification from part of, or all of, one or more sub-contests; or 3) disqualification from the competition.

a. The Rules Officials shall determine the severity of rules infractions and classify them as minor or major. 
b. The Rules Officials are authorized to apply point penalties and disqualify a team from part of, or all of, one or more sub-contests as a consequence of minor rules infractions.

c. The Rules Officials shall report to the Director all major rules infractions. The Director is solely authorized to apply point penalties or disqualify a team from the competition or from part of, or all of, one or more subcontests for major rules infractions.

d. Disqualification from the competition requires prior notice to the tcam and an opportunity for the team to make an oral or written statement on its own behalf.

e. The Competition Manager shall notify all teams via the Yahoo Group when a penalty has been assessed against any team. The notification shall include the identity of the team committing the infraction, a brief description of the infraction, including its severity, and the nature of the penalty.

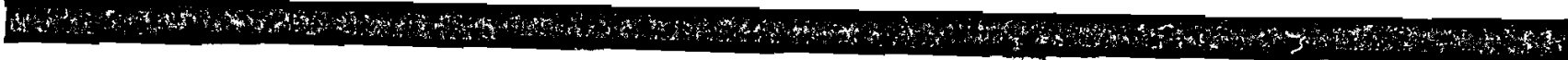

Official written protests may be filed by teams for any reason.

a. Teams are encouraged to communicate with the Rules Officizis $\mathrm{n}$ attempt to resolve issues and complaints before resorting to the protest process. Protests 6 Officials are not able to resolve the dispute themselves 100 ) the te engage in discussions that may resolve the dispute.

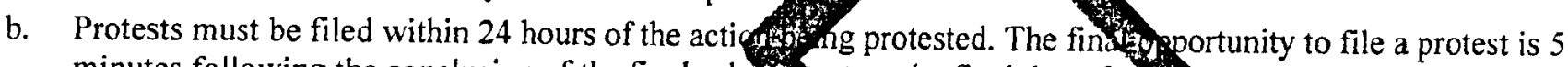
minutes following the conclusion of the final sub-

Exception: The results of one or more sub-contests nthe annond during the awards ceremony. The results of sub-contests announced during the final andits

c. The protest shall be submitted to the chatumion Manager and signature of a team members, the curyond time, an rowledgement that a 10-point filing fee

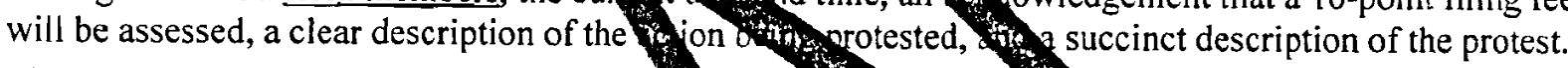

d. The protest resolution procedure follows:

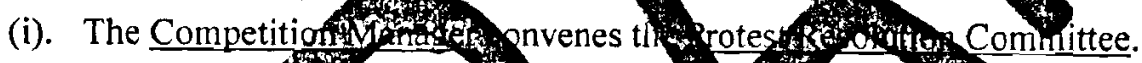

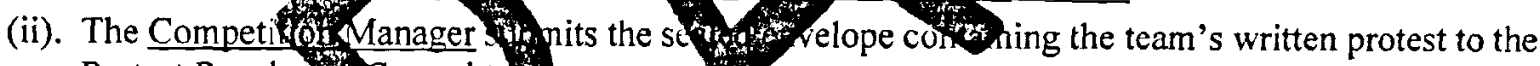
Protest Resolutin Sommitte

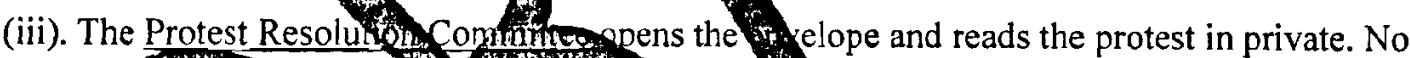

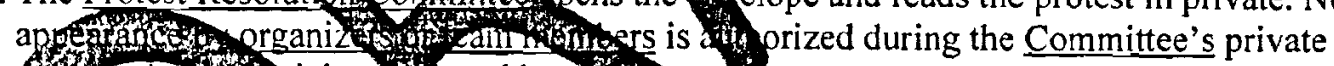
dofitions.

(iv) 1 Protest Resolto Com to notifies the Competition Manager if it would like to call any ing iduals for testing The o Thetition Manager notifies individuals called for testimony.

(v). The Roust Resolution formittee the Competition Manager of its decision, and indicates how mut if any, of the fing fee has been refunded. The decision of the Protest Resolution

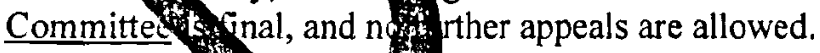

(vi). If the decisiont ives aftig ges to a team's score or a refund of some, or all, of the filing fee, the Competition Makgentof les the Scorekeeper of the changes, and the Scorekeper applies the changes to the scoring readsheet.

\section{Rule 3. Participation}

18 -

The project is open to colleges, universities, and other post-secondary educational institutions. Entry is determined through a proposal process. All proposals are reviewed, scored, and ranked. Subject to the quantity and quality of proposals, a limited number of teams will be selected for entry. 
Improper conduct or the use of alcohol or illegal substances will not be tolerated. Improper conduct may include, but is not limited to, improper language, unsportsmanlike conduct, unsafe behavior, distribution of inappropriate media, or cheating.

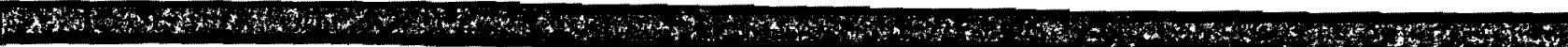

Team members and team crew agree to the use of their names, likenesses, content, graphics, and photos in any communications materials issued by the organizers and event sponsors.

Exception: If a team submits content or images that it would like to be kept confidential, it should make that request, with an explanation, in writing to the requestor of the content or images. Every effort will be made to honor requests for confidentiality. All confidentiality requests expire on a date specified in the Yahoo Group calendar.

a. Content and images (graphics and photos) and any publications 1 (x) be viewable and made available to the general public via the 1 (6) Web sites with unrestricted use.

b. The organizers and event sponsors will make all reasonte efforts to the sources of content and images, although they may be published without croffor onsure proper of and credit for images, teams should submit photos and graphics by follow the instructions for sibitting images located in Appendix G.

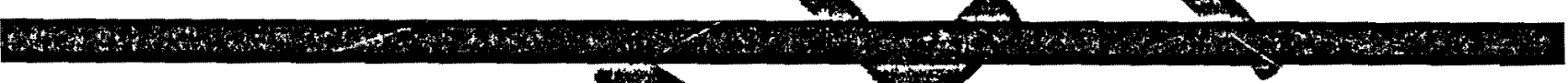

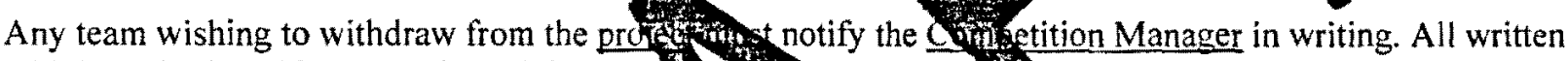
withdrawals signed by a Faculty Advisor are

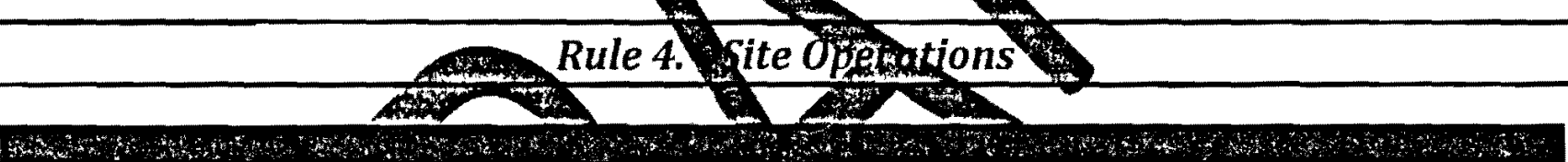
Each team is financially respon for aryage it cals to the competition site.

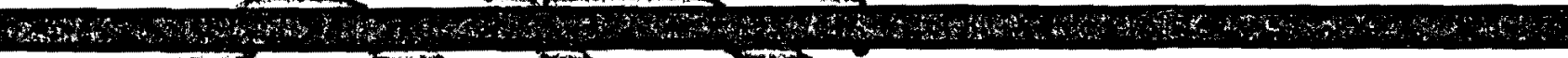

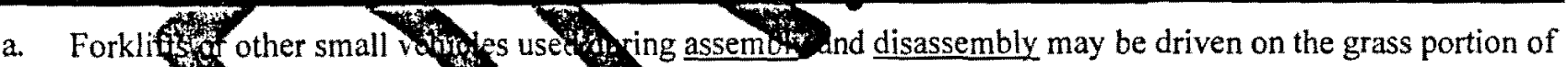
the comption site only if vehic driven on an aproved product designed to protect the grass.

b. Truck-mounty cranes, trailers, under special cownstances appr d by the Site Operations Manager, trailers and semi-trailers may be driven on the grastoption of the 6 hpetition site on the approved product designed to protect the grass.

What

Ground penetration is permitted anfor the installation of tie-downs needed to meet wind loading requirements and for the installation of grounding means for the house's electrical system. Tie-downs are limited to an 18-in. $(45.7-\mathrm{cm})$ vertical depth.

a. At certain times during assembly, a qualified utilities locator will be on site to identify an acceptable location near each house for the installation of grounding means. Grounding means shall be installed at a 45-degree angle.

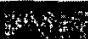

Low-impact footings shall be used to support all house and site components located on the grass portion of the competition site. 
a. Properly designed footings comply with the soil bearing pressure criteria specified in the Solar Decathlon Building Code, but do not have an excessive safety factor that results in the load being distributed over an unnecessarily large area.

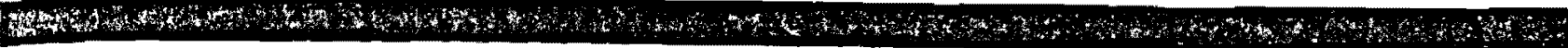

Generators are permitted to power tools and construction lights during stand-alone assembly and stand-alone disassembly.

a. Engine generators shall meet the National Park Service (NPS) noise regulation stated in 36CFR2.12. This regulation allows a maximum $60 \mathrm{~dB}$ (A) at $15 \mathrm{~m}$ ( 50 feet) under full load. Note that a given $\mathrm{dB}$ level at one distance can be converted to an equivalent $\mathrm{dB}$ at a different distance.

b. Operation and refueling of generators is limited to times approved by the organizers.

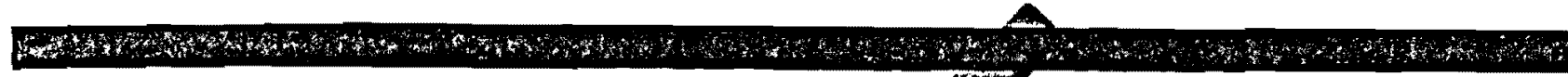

a. Generators must be equipped with secondary containment sy acthe can acommodate all of the oil, and coolant that the generator contains at maximum capacife

b. The release of water on the competition site or into nexp storm drainforohibited.

14.4. Up to 18 inches of vertical elevation change may exist a lot. Planaccordingly.
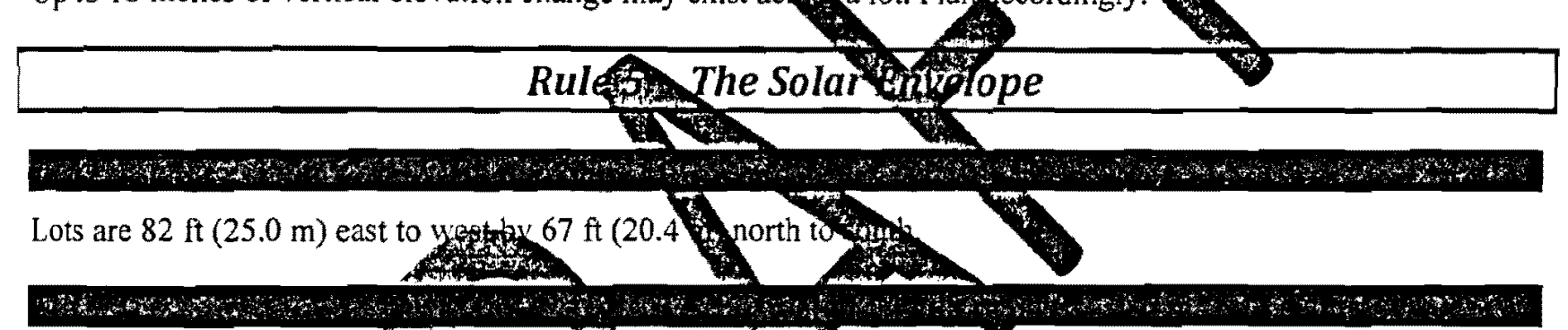

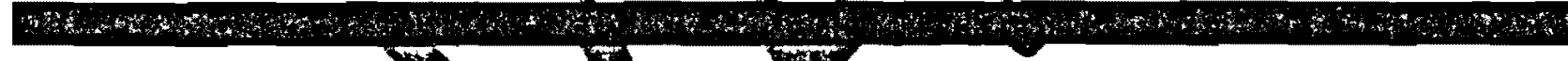
To protect a neighbor's right the sun, tw ouse and a) te components on a team's lot must stay within the solar envelope shown in Figure 4 ind Find

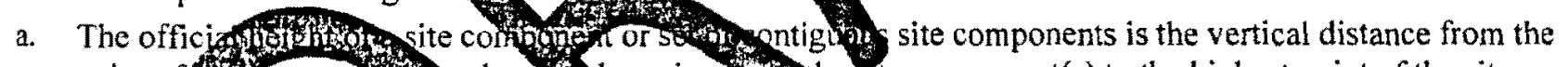

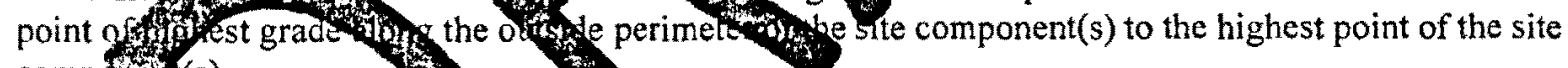
composits $(\mathrm{s})$.

b. Small wetite stations, antenta air veks and other similar components may be specifically exempted from the solar envoge if all of the foldying cctitions are met:

(i). The teanges a reques the Competition Manager for an exemption.

(ii). The team chaterove to the mpetition Manager's satisfaction that the component is not significantly rting ghting gor's right to the sun.

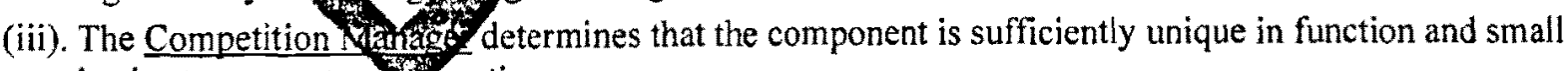
in size to warrant an mption. 
North Side View
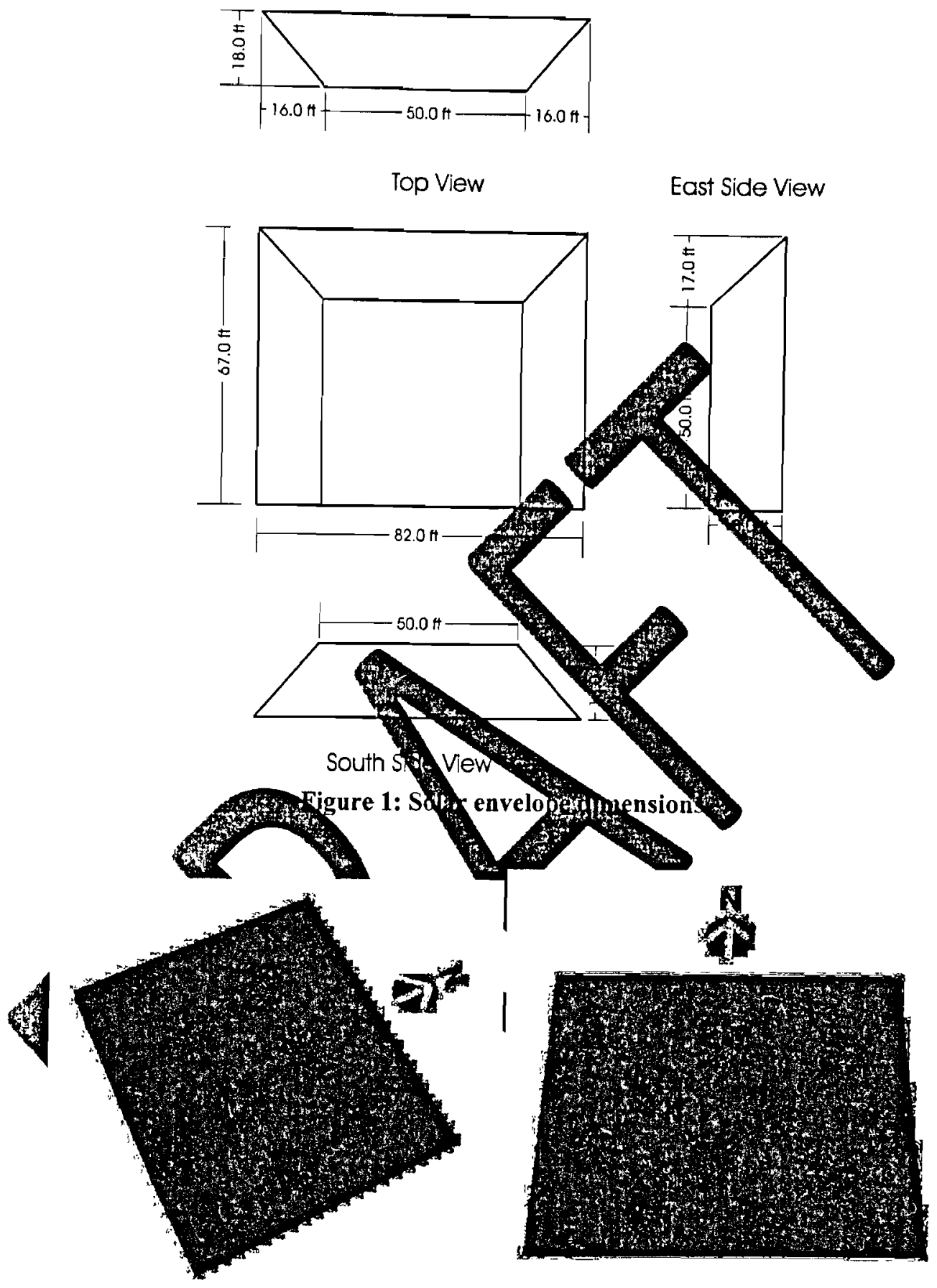

Figure 2: 3-D views of solar envelope

\section{Rule 6. The House}

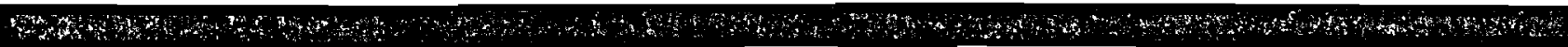

Each team shall submit structural drawings and calculations that have been stamped by a qualified licensed professional.

a. By stamping the structural drawings and calculations, the licensed professional certifies that the structural provisions of the Solar Decathlon Building Code have been met by the design, and that the structure is safe for the public to enter if it has been built as designed. 
The architectural footprint, as defined below, shall not exceed $800 \mathrm{ft}^{2}\left(74.3 \mathrm{~m}^{2}\right)$.

a. Both the building and the components involved in the building's conversion of and shading from solar energy are included in the footprint.

b. The maximum observed footprint of each component during jury tours, public hours, or the contests counts toward the architectural footprint of record. For example, if a team deploys a motorized awning during public hours to demonstrate its operability, then the additional footprint attributable to the deployed awning counts toward the architectural footprint of record.

c. The footprint includes the entire area within the defined footprint perimeter. There are no exceptions for "openings" or "holes" located within the footprint.

d. The Rules Officials shall apply the following guiding principles to determine whether a particular component is located within the footprint perimeter:

(i). Incentivize the building integration of active solar (e.g 4 nd solar thermal) and passive solar (e.g., shading) devices to reduce construction costs residential buildings, or both.

(ii). Incentivize intelligent roof overhang design.

(iii). Simplify the measurements and calculationfored to determine footprint area.

e. The following components are exempt from Rulet?

(i). Vegetation and small pots

(ii). Handrails with open baluster/ngael systems

(iii). Most windows and doors

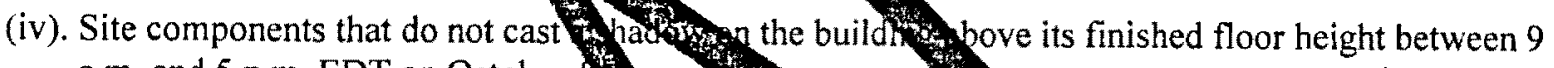
a.m. and 5 p.m. EDT on October

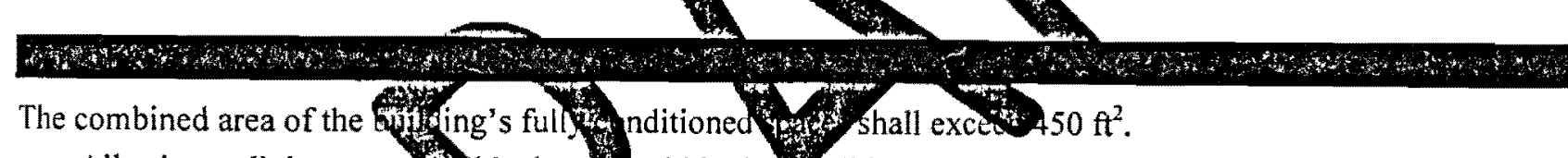

a. All primary living areas be locats within the aditioned space.

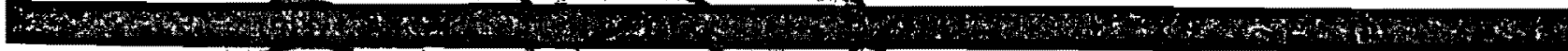

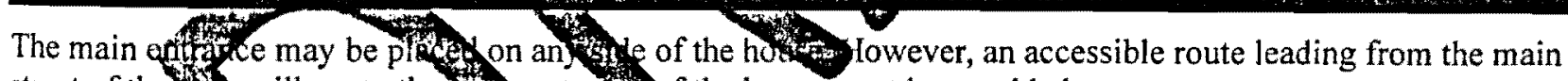
street of the village to the entrate the house must be provided.

\section{Rule\%. Vegetation}

The use of potted vegetation permitt 6 All potted vegetation must comply with Rules 4-4 and 4-6.

H4

Vegetation may be moved around the lot until the beginning of contest week, after which it shall remain stationary until the conclusion of contest week unless the construction documents clearly show how some or all vegetation is designed to be moved as part of an integrated system.

Why

Grey water that may possibly contain organisms that may go septic shall not be used to water vegetation. 


\section{Rule 8, Energy}

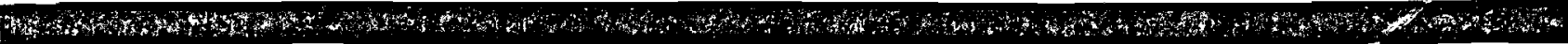

a. Bare photovoltaic cells must be commercially available to all teams by the beginning of the event at a price not exceeding US $\$ 5$ per peak watt at Standard Test Conditions [STC]. Teams may pay extra for cutting, tabbing, or lamination of the cells.

b. Encapsulated photovoltaic modules must be commercially available to all teams by the beginning of the event at a price not exceeding US $\$ 10$ per peak watt at STC

c. Substantial modification of the crystal structure, junction, or metallization constitutes manufacture of a new cell and is not allowed

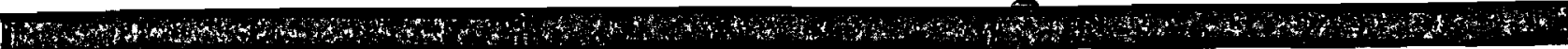

Global solar radiation incident upon the lot and the energy in smallytry batteries (see Rule 8-4 for limitations) are the only sources of energy that may be consumed in the oper 3 souse without the requirement of subsequent energy offsets.

a. All other energy sources, such as AC grid energy, conted in the operyos of the house must be offset by an equal or greater amount of energy produced, onerated, by the hous

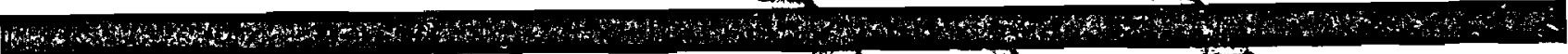

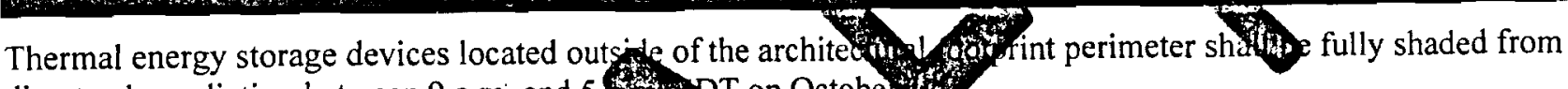
direct solar radiation between 9 a.m. and 5 th october

direct solar radiation between 9 a.mi and 5

W

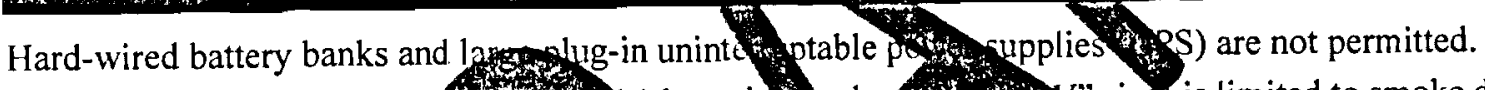

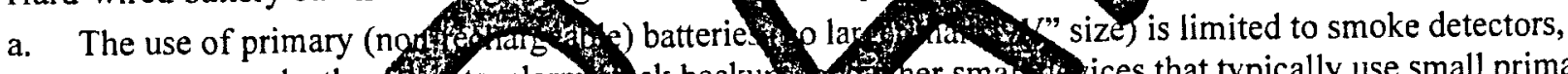

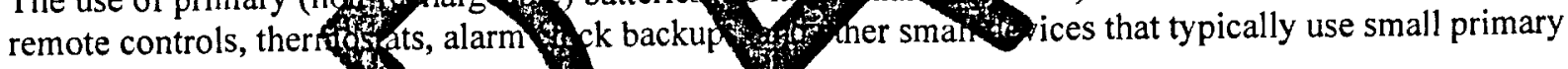
batteries.

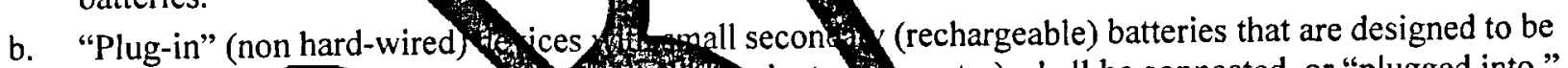

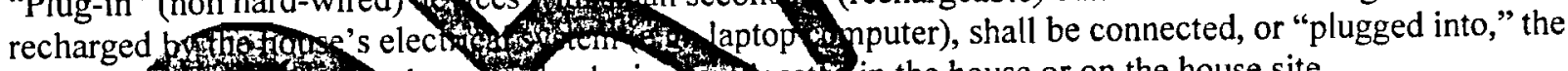

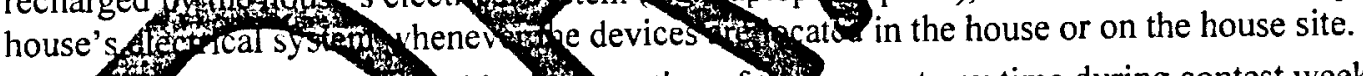

Exception. If they are nowsed in thoration of thonse at any time during contest week, portable exception: If they are notrod in the without havitgato be plugged ing he hous electrical system.

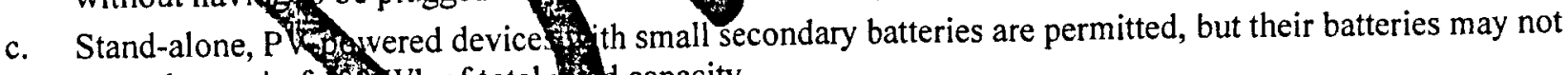
exceed a total of $\mathrm{Now}$ h of total th capacity.

w

If a desiccant system is used, it nftsentive regenerative.

a. To ensure that the desiccant has been fully regenerated by the conclusion of the Net Metering contest, the desiccant material or device must be easily measurable.

b. In most cases, the material or device will be measured prior to and at the conclusion of the Net Metering contest. In some cases, a measurement at the conclusion of the Net Metering contest may not be necessary.

c. At the conclusion of the Net Metering contest, the weight of the desiccant material or device shall be less than or equal to its initial weight.

d. Some desiccant systems with very low moisture storage capacities may be exempt from this requirement.

Exemptions will be granted on a case-by-case basis. 
The organizers shall provide the village with an electric power grid that provides $A C$ power to or accepts AC power from the houses.

a. The organizers shall provide the necessary service conductors and connect the conductors at the utility

b. A team shall notify the organizers if its house operates with an AC service other than $60 \mathrm{~Hz}, 120 / 240 \mathrm{~V}$ splitphase with neutral.

\section{Rule 9. Water}

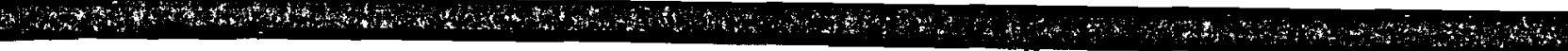

Details to be determined

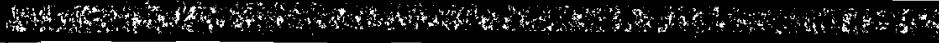

A team may provide its own water for the following purpo

a. Personal hydration

b. Irrigation

c. Cooking.

\section{2}

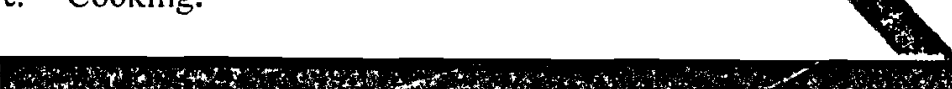

A team may reuse greywater for irrigation ort

a. Greywater reuse systems shall comply witk

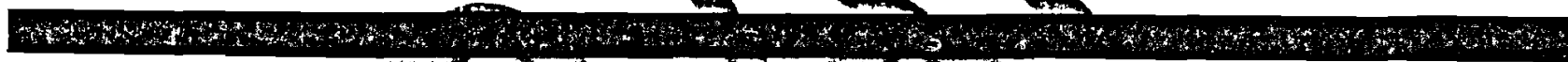

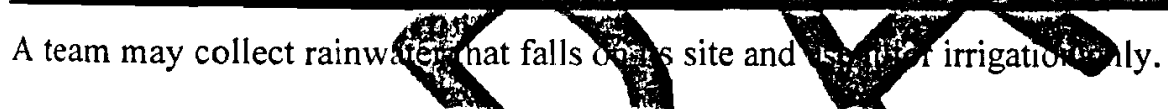

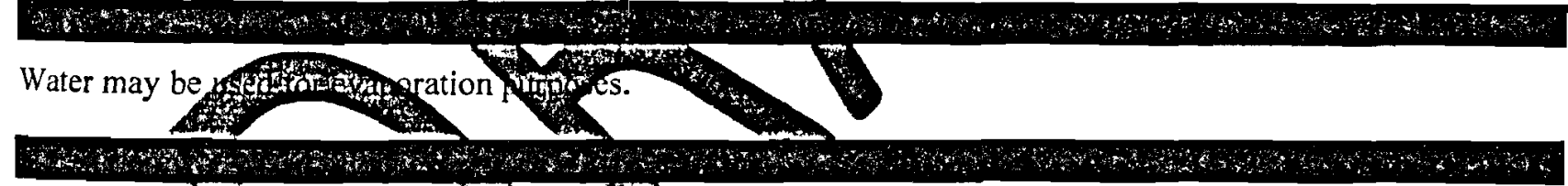

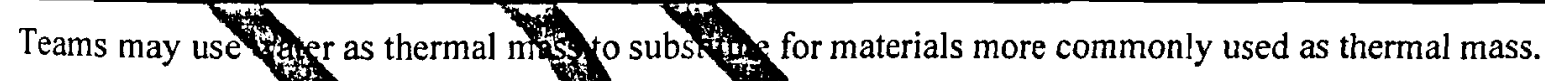

a. Water used forth purpose shal o be mix * with any other substance.

b. Water used for the shall ontained in a stand-alone system, which will be sealed off after the initial filling.

\section{Rule 10. The Event}

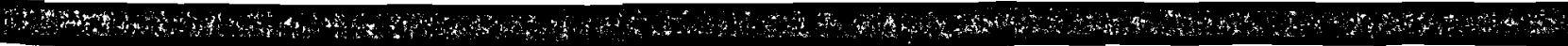

Details to be determined

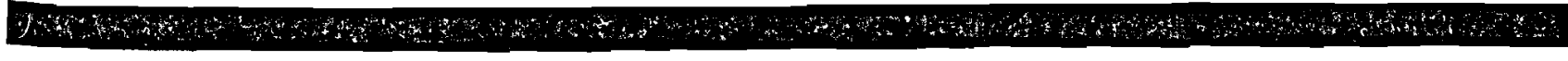

All communications materials produced by the teams concerning or referring to the project shall refer prominently to the project as the Solar Decathlon and shall credit the U.S. DOE, NREL, and additional event sponsors as indicated by the organizers.

a. The Solar Decathlon shall be recognized with text and logo wherever other logos are used. 
b. Information regarding current event sponsors, artwork for the Solar Decathlon, and event sponsors logos are available on the Yahoo Group.

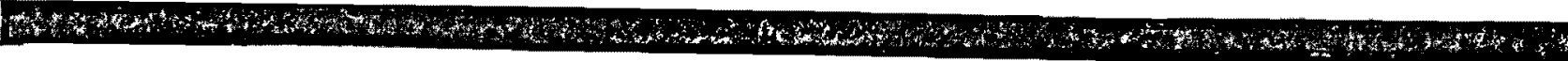

Team sponsors may be recognized with text, logos, or both, but the text and logos must appear in conjunction with the Solar Decathlon text and logo and may not be larger than one-third the size of the Solar Decathlon text and logo.

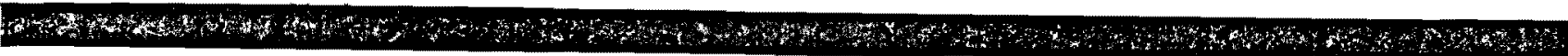

a. A team is responsible for the transport of its house, the house's contents, and all necessary tools and equipment, and shall be responsible for any damage to or loss of such items.

b. A team is responsible for procuring all necessary equipment, tools. Ax supplies.

c. A team is responsible for transportation, accommodations, lodging $60 d$, and beverages (including drinking water).

d. A team is responsible for making its own reservations and

f

Each project shall be inspected for compliance with the rules and the Solar Dectiteo Building Code.

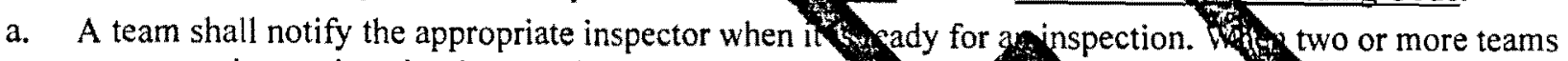

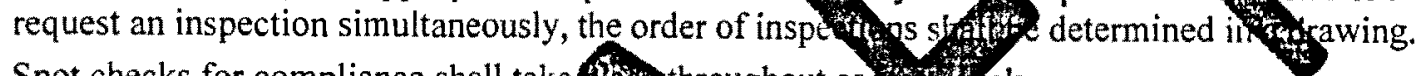

b. Spot checks for compliance shall take 19pthroughout cons thek.

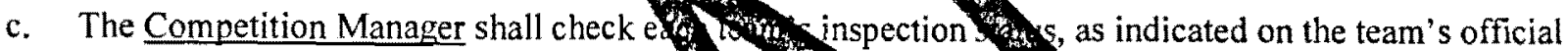
inspection card, to determine which house engris to participus in the contest. All final inspections shall be passed by the end of the inspectors' worky for a to be elfyto to participate in the following day's contest.

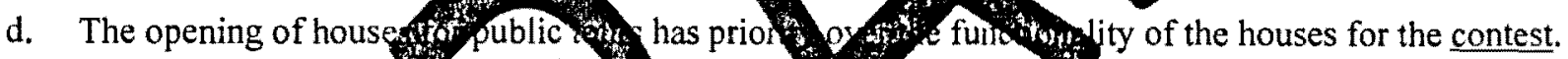

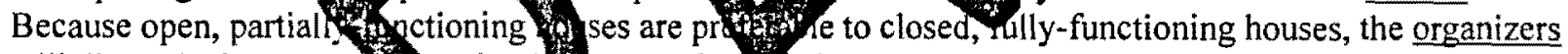
will direct the inspectors 8 quire th an unsafe cotion be corrected so tours can occur, even if, as a

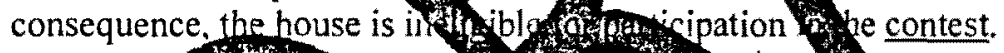

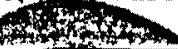

(

What When the occupancy is in effect, 7 nore than six (6) people may be located in the house at any one time.

a. Toward the end of day of collte theek, the Competition Manager shall post a message on the Yahoo Group message boardfoldicating g $_{\text {g }}$ hours during which the occupancy rule is in effect the following day.

b. The occupancy rule is autorgent suspended during jury tours and whenever the Comfort Zone contest measurements are suspended

c. Organizers are not counted toward the number of house occupants.

A

Only Decathletes are permitted to operate the house and participate in the contest during contest week.

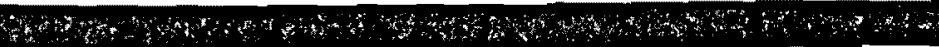

The final project assembled on the competition site shall be consistent with the design and specifications presented in the construction documents.

a. If there are known inconsistencies between the final project and the construction documents, the team is strongly encouraged to document these inconsistencies and submit the documentation to the Competition 
Manager as soon as possible after the inconsistency is known. The Competition Manager will then subrit this documentation or a summary of the documented inconsistencies to the respective juries and inspectors at the appropriate time.

b. If undocumented inconsistencies are discovered during inspections, the Competition Manager will compile a summary of the inconsistencies and submit the summary to the respective juries at the appropriate time.

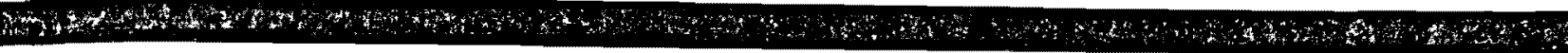

a. Teams are required to provide an accessible route to all areas of the house and site that are available to the public during tours.

b. Teams are permitted to give one and only one informational brochure/handout to each member of the general public. No other handouts are permitted.

c. Teams are prohibited from selling items to the general public on thespetition site.

d. Only organizer-approved vendors may provide food and beverag the general public on the competition site.

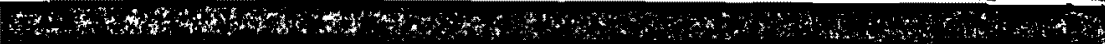

a. During contest week and special events specified of hrganizers, all tew ombers present on the competition site or the site of a special event shat an uforms representing

b. Team uniforms are exempt from Rule 10-3.

c. Team sponsor logos are approved to be visible ONLY she bat, hat, or other wearable item). Team sponsor lagosball not be vis the front of the team.

W Each house shall be impounded on specified nigh under thect supetson of the organizers or staff. Team

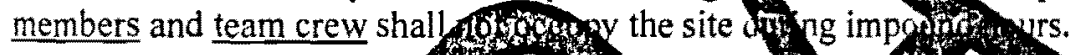

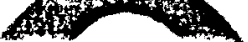

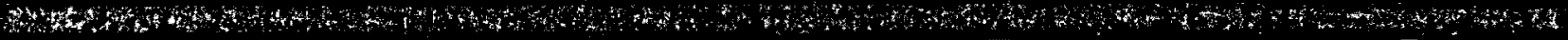

Teams shall show the Architectro,

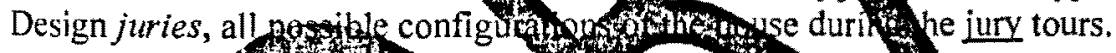

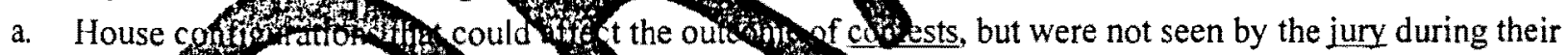
tours, arg tohibited dum ontest

(i). Xygnificant moveablompong such as a room, wall, or bed

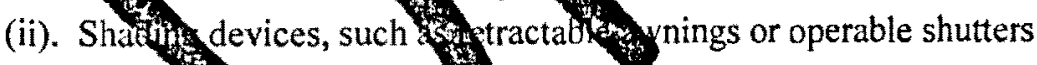

(iii). Towel-tolug locations

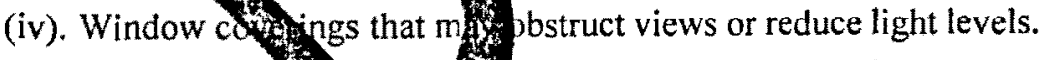

b. If there is insufficient to dg the reconfiguration during jury tours, teams may use some other method, such as photographs or vitumgow all reconfigurable features in their various configurations. Reconfigurable features that not actually be reconfigured at any time during contest week need not be reconfigured during jury tours.

c. All plug-in or portable appliances that may be used during contest week shall be in their fully deployed locations and configurations during jury tours. Also be aware that juries may request that plug-in, portable, or hard-wired appliances be turned on so they can evaluate noise levels or other characteristics of the appliances that may not be evident when the appliance is off. 


\section{SECTION III: CONTEST CRITERIA}

The Solar Decathlon competition consists of 10 separately scored contests. Each contest contains one or more sub-contests. For example, Contest 6: Comfort Zone consists of two separately scored sub-contests: Temperature and Humidity. The team with the highestal points at the end of the competition wins. Table 2 shows the competition structure.

Table 2: Competition strughute

\begin{tabular}{|c|c|c|c|c|c|c|c|}
\hline 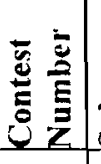 & 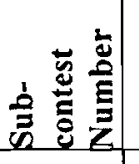 & Contest Name & 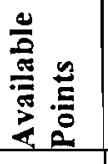 & $\begin{array}{l}\text { Sub-contest } \\
\text { Name }\end{array}$ & 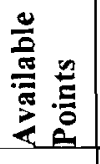 & Sut & Brief Desciptions of Subjective Evaluations and Objective Tasks \\
\hline 1 & $\mathrm{n} / \mathbf{a}$ & Architecture & 100 & $\mathrm{n} / \mathbf{a}$ & $\mathrm{n} / \mathbf{a}$ & & Construction Documents and final constructed project \\
\hline 2 & $\mathrm{n} / \mathbf{a}$ & Market Viability & 100 & $\mathrm{n} / \mathbf{a}$ & $\mathrm{n} / \mathbf{a}$ & & ion Documents, Cost Estimate, and final \\
\hline 3 & $\mathbf{n} / \mathbf{a}$ & Engineering & 100 & $\mathbf{n} / \mathbf{a}$ & a & & Ing Jury evaluates Construction Documents and final constructed project \\
\hline 4 & $\mathbf{n} / \mathbf{a}$ & Lighting Design & 75 & n/a & $\mathbf{n} / \mathbf{a}$ & & Construction Documents and final constructed project \\
\hline 5 & $\mathbf{n} / \mathbf{a}$ & Communications & 75 & $\mathbf{n} / \mathbf{a}$ & & & $\begin{array}{l}\text { ions Jury evaluates Construction Documents, Final Communications Plan, } \\
\text { d final constructed proiect }\end{array}$ \\
\hline \multirow{2}{*}{6} & $\frac{6-1}{6}$ & \multirow{2}{*}{ Comfort Zone } & \multirow{2}{*}{100} & & & & one temperature in $72^{\circ} \mathrm{F}-76^{\circ} \mathrm{F}$ range \\
\hline & $6-2$ & & & Hum & & & zone relative humidity in $40 \%-55 \%$ range \\
\hline 7 & n/a & Hot Water & 100 & $\mathbf{n} / \mathbf{a}$ & & & $\begin{array}{l}\text { Deliver } 15 \text { gallons of water at average } 110^{\circ} \mathrm{F} \text { temperature within } 10 \text { minutes; } 20 \text { water } \\
\text { draws during contest week }\end{array}$ \\
\hline \multirow{5}{*}{8} & $8-1$ & \multirow{5}{*}{ Appliances } & & & & & Keep refrigerator temperature in $34^{\circ} \mathrm{F}-40^{\circ} \mathrm{F}$ range \\
\hline & $8-2$ & & & & & $\$$ & Keep refrigerator temperature in $-20^{\circ} \mathrm{F}-5^{\circ} \mathrm{F}$ range \\
\hline & $8-3$ & & & & & & Successfully wash a load of laundry; 10 loads of 6 bath towels during contest week \\
\hline & 8-4 & & & & & & $\begin{array}{l}\text { Return a load of laundry to its original weight, } 10 \text { loads of } 6 \text { bath towels during } \underline{\text { contest }} \\
\text { week }\end{array}$ \\
\hline & $8-5$ & & & & & Ob. Lask L Task & Successfully wash a load of dishes; 5 loads of 6 place settings during contest week \\
\hline \multirow{5}{*}{9} & $9-1$ & \multirow{5}{*}{$\begin{array}{l}\text { Home } \\
\text { Entertainment }\end{array}$} & \multirow{5}{*}{100} & 8 & & 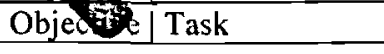 & Vaporize 5 tb of water in less than 2 hours; 4 cooking tasks during contest week \\
\hline & $9-2$ & & & & 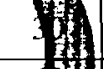 & Objective | Task/Measured & $\begin{array}{l}\text { C9-2a: Keep work surface } @ 50 \text { foot-candles minumum ( } 5 \text { pts), C9-2b: All interior and } \\
\text { exterior lights on at full levels at night ( } 25 \text { pts) }\end{array}$ \\
\hline & 9-3 & & & Dinir & 4 & Subjective & Host 2 dinner parties for 8 people; teams score each other \\
\hline & $9-4$ & & & Public EXT & (3) & $\begin{array}{l}\text { Objective } \text { Measured } \\
\end{array}$ & Operate TV, computer, and other exhibit devices \\
\hline & $9-5$ & & & Home Theat & & Subjective & Invite neighbors to watch a movie on the home theater system: teams score each other \\
\hline \multirow[b]{2}{*}{10} & $10-1$ & \multirow[b]{2}{*}{ Net-Metering } & \multirow[b]{2}{*}{150} & Energy Balance & 100 & \begin{tabular}{l|l} 
Objective & Measured \\
\end{tabular} & Achieve zero net AC energy during contest week \\
\hline & $10-2$ & & & Energy Surplus & 50 & Objective | Measured & $\begin{array}{l}\text { Produce surplus net AC energy during contest week: } 50 \text { pts for team with max } \mathrm{kWh} \\
\text { surplus, other teams with surplus get } x \% \text { of } 50 \text { pts, where } x \text { is } \% \text { of max team's } \mathrm{kWh}\end{array}$ \\
\hline \multicolumn{3}{|c|}{ TOTALS } & 1000 & & & 465 subj pts, 535 obj pts & Total of 5 on-site juries \\
\hline
\end{tabular}


There are three ways to earn points:

- Task completion

- Measured performance

- Jury evaluation.

Sub-contests based on task completion or measured performance are called objective sub-contests; sub-contests based on a jury evaluation are called subjective sub-contests.

Points for task completion are awarded as a function of "closeness to completion." Points for measured performance are either awarded at the end of each scored period throughout contest week, at the end of each day, or at the conclusion of contest week when performance requirements are met or partially met.

The scoring of the subjective sub-contests is more flexible than the scoring of the objective sub-contests described above. However, for the sake of faimess, it is important that there is consistency. To increase the consistency of the scoring in subjective sub-contests, the jurors shall use the evaluatiog to hod described in Appendix B.

\section{Contest 1. Archifertats}

A jury of architects shall assign an overall score for the dsy s architecturalthit and implementation by

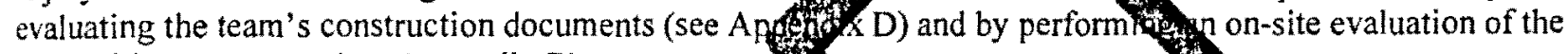
competition prototype (see Appendix B).

The jury shall consider the following specific criteria in its yation

Design and Implementation

- Was the team effective in its use of arch

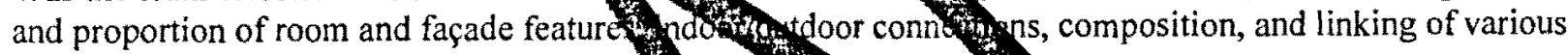
home elements?

- Did the team create a holigrofessy that will surrounding environmen

- Will the design offer a

\section{Documentation}

- Did the constretiondocumentenath of arrival atghe ompettiongite?

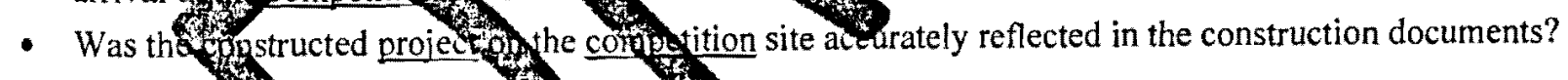

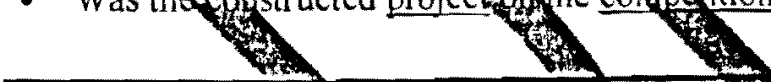

\section{Raptest Market Viability}

A jury of professionals frow the homebuting ding industry shall assign an overall score for the house's market viability by evaluating the te cos costrit ction documents (see Appendix D) and competition prototype cost estimate (see Appendix H), and of orming an on-site evaluation of the competition prototype (see Appendix B).

The jury shall consider the following specific criteria in its evaluation of the responsiveness of the design to the needs and desires of a team-defined target market (see Table 3 for examples of target market descriptions):

\section{Livability}

- Does the design offer the occupant(s) a safe, functional, convenient, comfortable, and enjoyable place to live (see Table 4 for examples of livability considerations)?

- Are the unique needs and desires of the target market met by the design?

\section{Buildability}

- Are the construction documents of sufficient quality and detail to enable a contractor to generate an accurate, detailed construction cost estimate? 
- Are the construction documents of sufficient quality and detail to enable a contractor to construct the building as the design team intended it to be built?

\section{Marketability}

- Does the house exhibit curb appeal, interior appeal, and quality craftsmanship?

- Do the house's sustainability features and strategies make a positive contribution to its marketability?

- Does the house offer potential homebuyers within the target market a good value?

\section{Cost Estimate}

Is the construction cost estimate for the competition prototype sufficiently detailed and accurate?

\section{Table 3: Examples of target market descriptions}

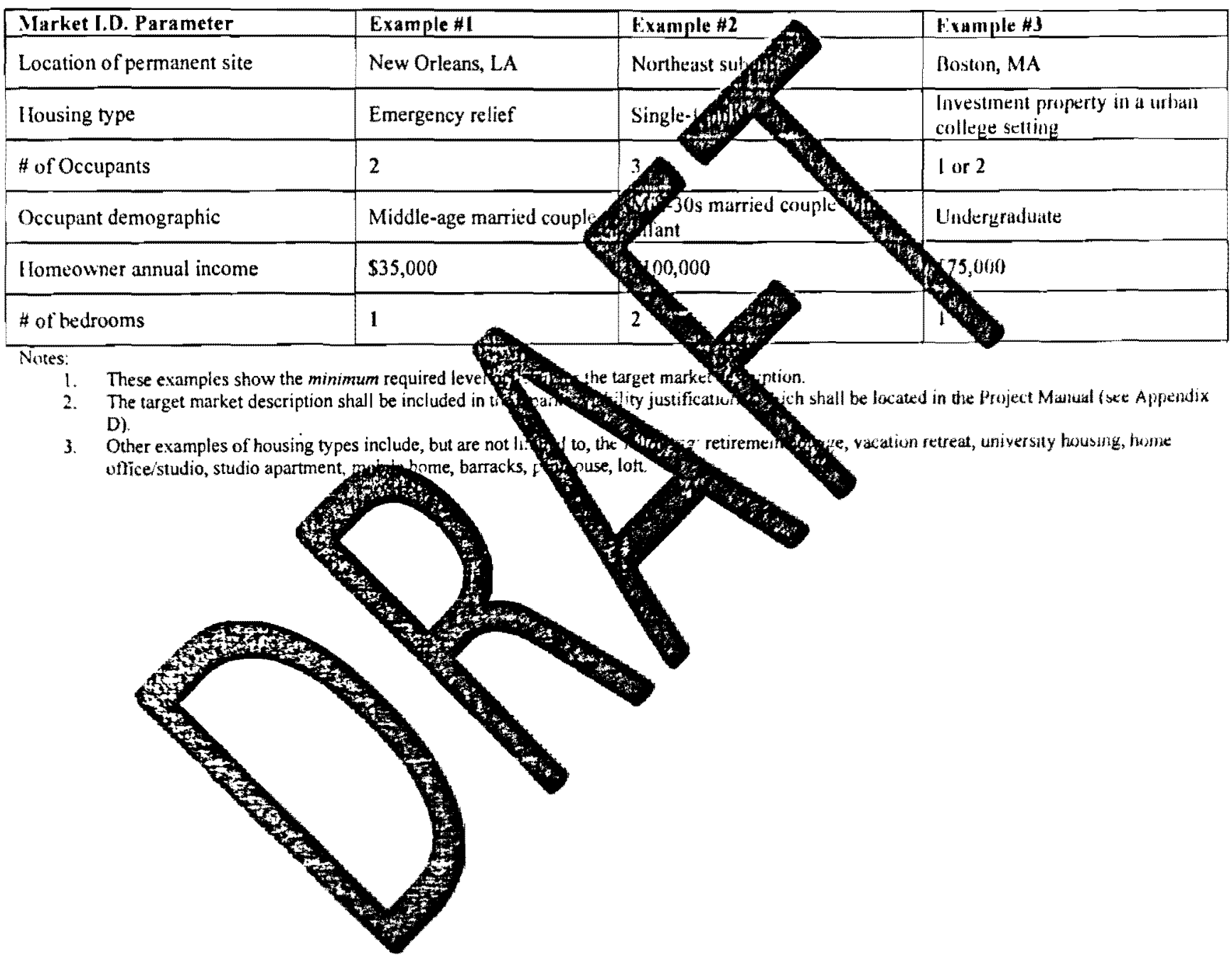


Table 4: Example livability considerations (NOTE: This list is not exhaustive, and all considerations do not apply to all projects.)

\begin{tabular}{|c|c|}
\hline Aesthetics & $\begin{array}{l}\text { How well does the design respond to aesthetic tastes of the entire range of people within the target market? } \\
\text { How are the views to the outside? }\end{array}$ \\
\hline Maintenance & $\begin{array}{l}\text { Will snow block the PV or solar collectors? If so, how will the homeowner remove the snow? } \\
\text { How do the exterior surfaces hold up to environmental conditions? How frequent and conventent is reguired maintenance? } \\
\text { How will water and dirt affect the floors and countertops? Are they easy to clean with standard houltidycleaning products? } \\
\text { Are there interior surfaces, corners, or crevices that are difficult to keep free of dirt or dust? } \\
\text { How is the oven cleaned? How is the freezer defrosted? } \\
\text { How frequently must vegetation be watered? Is watering conventent? } \\
\text { Is the car protected in inclement weather? } \\
\text { Can appliances and furniture be easily noved for cleaning or maintenance? } \\
\text { Is mold or rust likely to fom anywhere in or on the house? } \\
\text { When a house component or finish breaks or is damaged, is it easy to find a repiacement? }\end{array}$ \\
\hline Comfort & 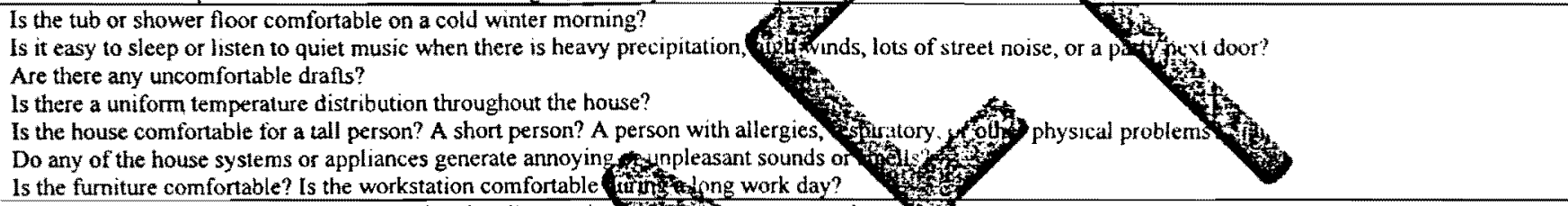 \\
\hline Privacy & 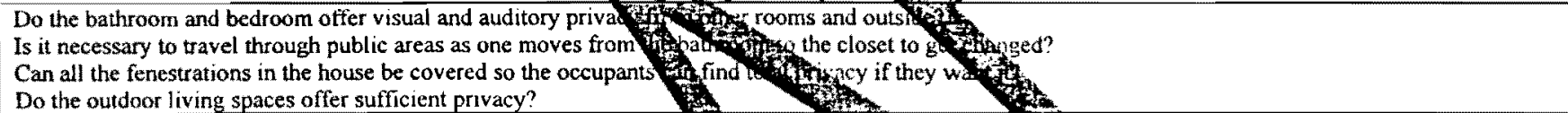 \\
\hline Convenience & 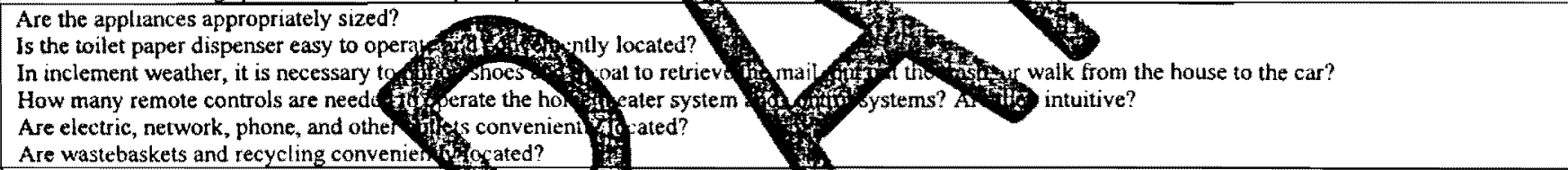 \\
\hline Functionality & 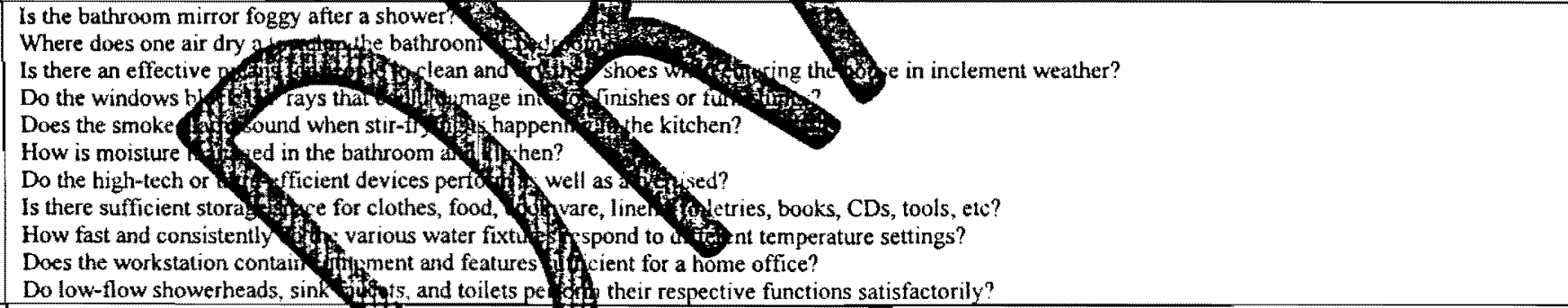 \\
\hline $\begin{array}{l}\text { Special } \\
\text { Features }\end{array}$ & 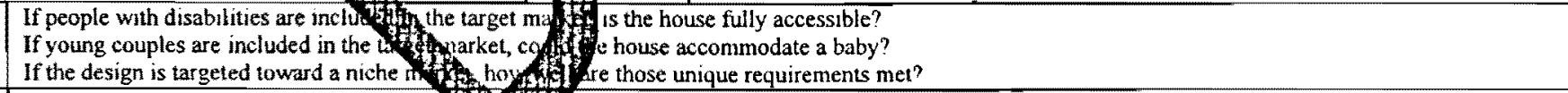 \\
\hline Flexibility & $\begin{array}{l}\text { If the house is sold to new owners with diffs } \\
\text { If the target market includes people with varyilly } \\
\text { Is the house wired to accommodate future breakthroughs in consumer electronics and/or home controls? }\end{array}$ \\
\hline Safety & $\begin{array}{l}\text { Is it difficult for a potential thief to break in? } \\
\text { Do daily or seasonal maintenance tasks present any hazards? } \\
\text { Do appliances pose any hazard to children? } \\
\text { Is the workstation ergonomically comfonable? Does the workstation offer a conventent opportunity to relax one's eyes after starmg at the monitor for a while? }\end{array}$ \\
\hline
\end{tabular}


A jury of engineers shall assign an overall score for the design's engineering merit and implementation by evaluating the team's construction documents (see Appendix D), and by performing an on-site evaluation of the competition prototype (see Appendix B).

The jury shall consider the following specific criteria in its evaluation:

\section{Functionality}

Will the systems function as intended?

\section{Efficiency}

Relative to conventional systems, how much energy will the systems sfot the course of an entire year?

\section{Innovation}

- Were any unique approaches used to solve design challeng

- Do the proposed innovations have true market potentia

\section{Reliability}

- How long are the systems expected to operate at a level of performance?

- How much maintenance is required to keep them oper at a higurel?

Documentation

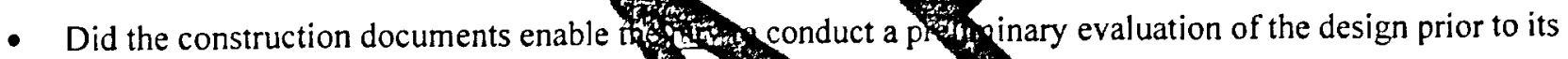
arrival at the competition site?

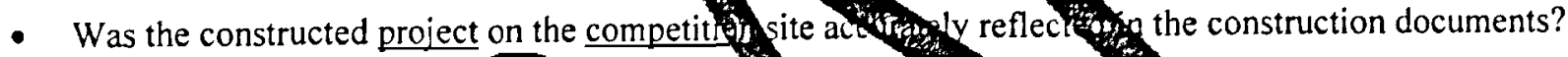

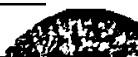

Contest 4. Thiffing Deston

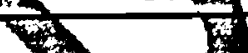

A jury of lighting designers and stry shall ass th an overall score for the lighting design's merit and

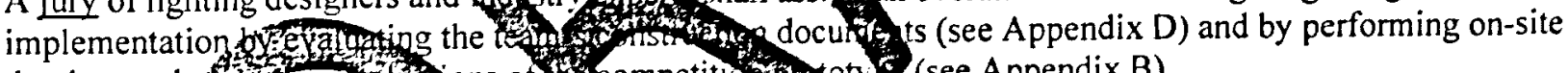
daytime and fof

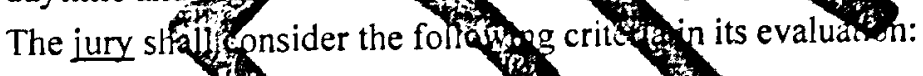

\section{Electric Lightingouality}

- Are the lightedpes rich and vate Do the have adequate light for tasks? Do they have good color rendition?

- Are the luminaires attage? Do the properly distribute light?

\section{Daylighting Quality}

- Have human factors, such as 1 siology, perception, preferences, and behavior, been addressed?

- What are the effects of daylight on all materials, including furniture, artwork, and plants?

- Is the admission of direct and diffuse sunlight effectively controlled?

\section{Ease of Operation}

Is the operation of the manual and automatic lighting controls intuitive?

\section{Flexibility}

Can the lighting system accommodate all activities and aesthetic requirements in all seasons?

\section{Energy Efficiency}

Do the lighting controls facilitate a reduction in lighting energy consumption throughout the year? 
Note: Only the energy efficiency attributable to lighting controls shall be assessed in this contest. The energy efficiency of the lamps is evaluated in several of the objective contests.

\section{Building Integration}

Have the luminaires, fenestration, interior geometry and finishes, and manual and automatic lighting controls been effectively integrated into the building?

\section{Documentation}

- Did the construction documents enable the jury to conduct a preliminary evaluation of the design prior to its arrival at the competition site?

- Was the constructed project on the competition site accurately reflected in the construction documents?

\section{Contest 5. Communications}

A jury of communications professionals shall assign an overall sofs team's communications plan and implementation by evaluating the team's construction documer 6 se A dix D), Final Communications Plan (see Appendix E), and Web Site (see Appendix E), and by dererming an oftote evaluation of the implemented communications plan (see Appendix B).

The jury shall consider the following specific criteria evaluation:

\section{Compliance}

- Were the communications deliverables

- Does the Web site meet minimum codifigrexpirements?

- Do the on-site communications materials y y y Team Sponsor Recognition?

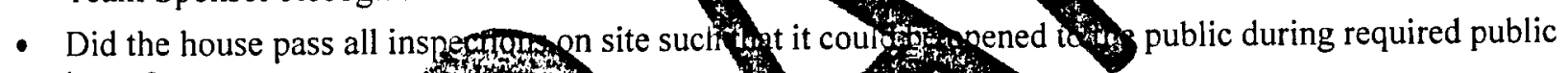
hours?

\section{Planning and Audience Arighis}

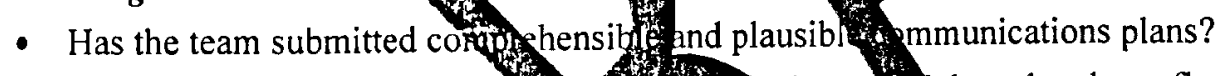

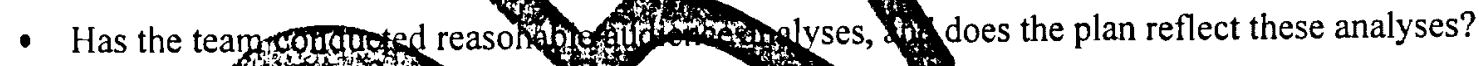

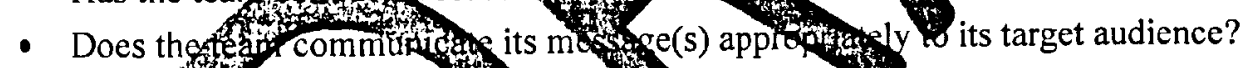

\section{Content}

Has the teamed hed to professing best praces?

- Audience-chpopriate languayestond tone

- Correct spellinzond grammar

- Originality or properation ontent

\section{Presentation}

Has the teamed adhered to professitunal best practices?

- Design: graphics, photos, colors, and typography

- Information architecture (Web site organization): usability, consistency, comprehensibility, simplicity, representing the hierarchical structure of the Web site

- Web site graphical elements: easy to use, consistent, well integrated with content and design.

Is the on-site presentation for the public pleasant? Logical? Can appropriate information be located easily? Are plans flexible enough to accommodate large crowds and long lines? Are waiting visitors engaged in the presentation?

\section{Branding}

Did the communications materials help make the project identifiable or memorable in any way? 


\section{Functionality}

- Are the Web site and on-site presentation usable by people of all abilities?

- Is the intended functionality of the communications materials appropriate to target audiences, to delivering the team's message, and to the setting of the solar Decathlon solar village on the National Mall?

- Do communications materials function as intended?

\section{Innovation}

- What original and creative methods are used to control lines and wait times, and to engage visitors waiting in line during the public hours? Are they effective?

- What creative effort is being made to communicate with visitors to the village outside of the public hours (after the houses are closed)? Is it effective?

- What creative effort is being made to engage public off site (i.e., arofig the U.S. and the world) in the team's participation in the event?

- What original and creative methods are used to capture users'

\section{Contest 6. Cojptort Zone}

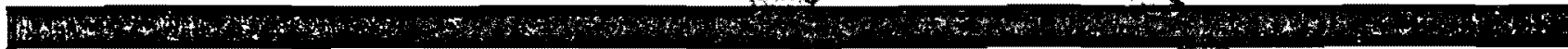

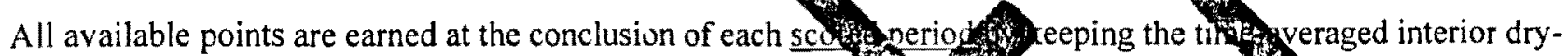
bulb temperature between $72.0^{\circ} \mathrm{F}\left(22.2^{\circ} \mathrm{C}\right) \mathrm{g} 76.0^{\circ} \mathrm{F}(24.4 \mathrm{cos}$. schedule of scored periods and for the numbentapailable points

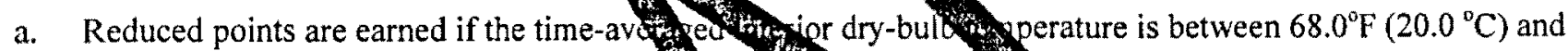

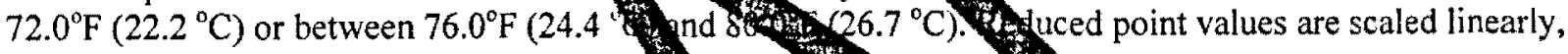
as shown in Figure 3.

b. In multi-zone houses, $\mathrm{l}$ temperature of record
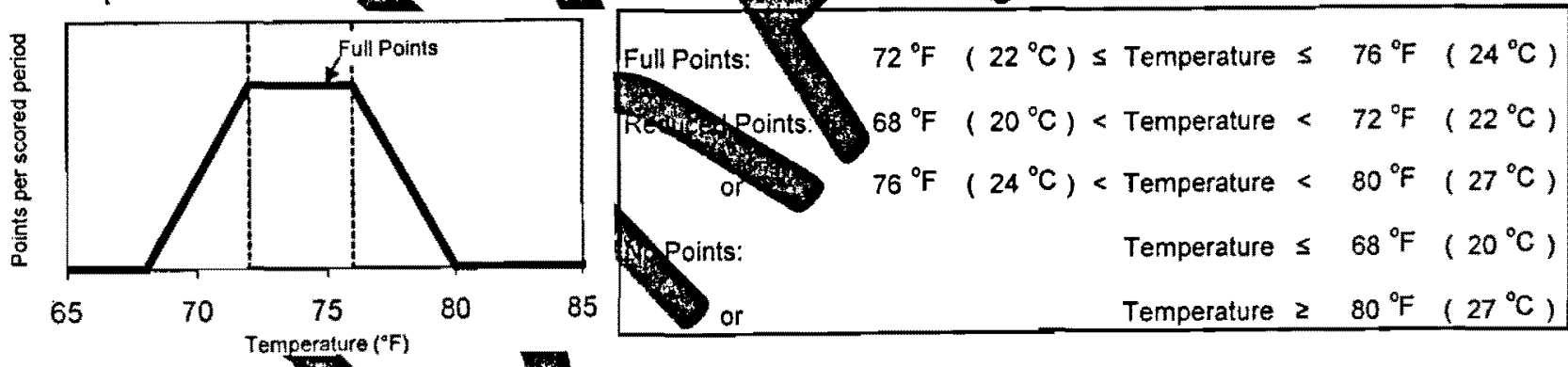

g function for the Temperature sub-contest

4h,

All available points are earned at conclusion of each scored period by keeping the time-averaged interior relative humidity between $40.0 \%$ and $55.0 \%$ during the scored period. See Appendix A for the schedule of scored periods and for the number of available points per scored period.

a. Reduced points are earned if the time-averaged interior relative humidity is between $25.0 \%$ and $40.0 \%$ or between $55.0 \%$ and $60.0 \%$. Reduced point values are scaled linearly, as shown in Figure 4.

b. In multi-zone houses, the zone humidity deviating farthest from the target humidity range is the zone humidity of record. 


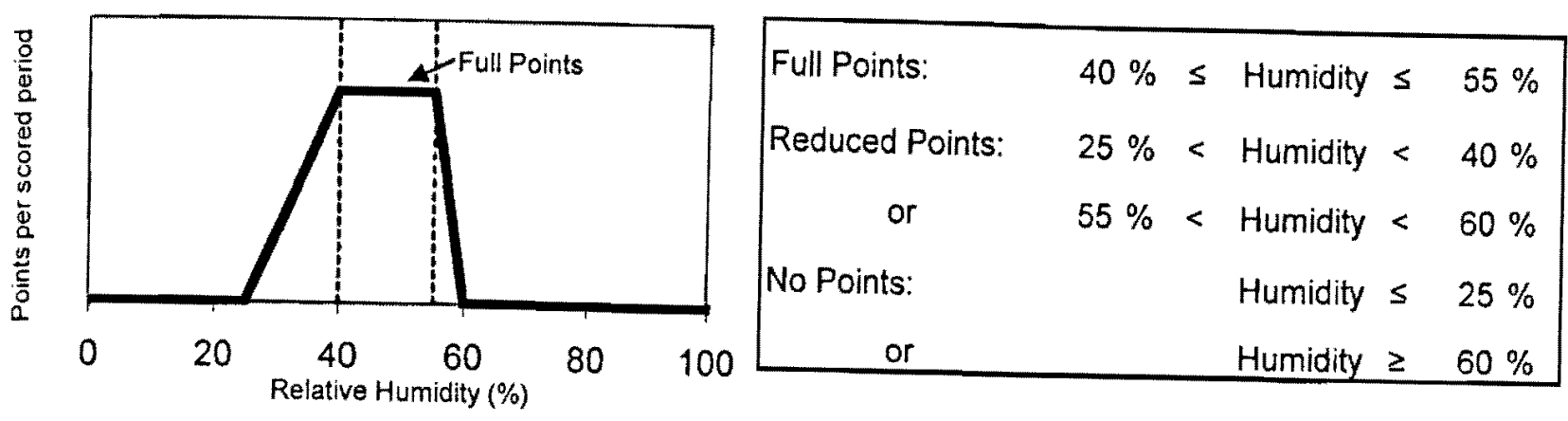

Figure 4: Scoring function for the Humidity sub-contest

\section{Contest 7. Hot Watef}

Hot water draws will occur at the approximate times specified into 15 gallons (U.S.) (56.8 liters) of hot water shall be delivered in no more tha 10 mint to qualify for points. All available points are earned by delivering an average temperature of $4 \mathrm{H}_{\mathrm{f}} \mathrm{st} 110^{\circ} \mathrm{F}(43 . \mathrm{W}$. An average temperature below $100^{\circ} \mathrm{F}\left(37.8^{\circ} \mathrm{C}\right)$ earns no points. For temperatures betwe $8^{\circ} 0^{\circ} 00^{\circ} \mathrm{F}\left(37.8^{\circ} \mathrm{C}\right)$ and $8^{\circ} \mathrm{F}\left(43.3^{\circ} \mathrm{C}\right)$, points are scaled linearly, as shown in Figure 5.

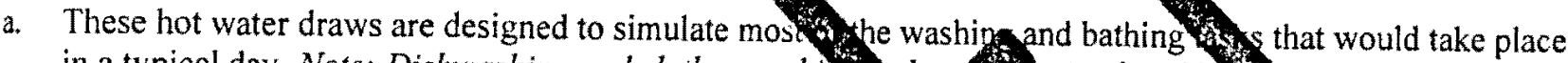

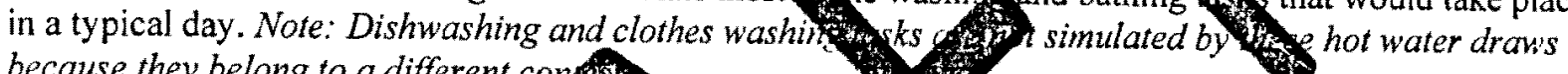
because they belong to a different con

b. The schedule for hot water draws will now vary from of the next, just as it does in a typical home.

c. The maximum number of hot water draws the day ot exces occur consecutively.

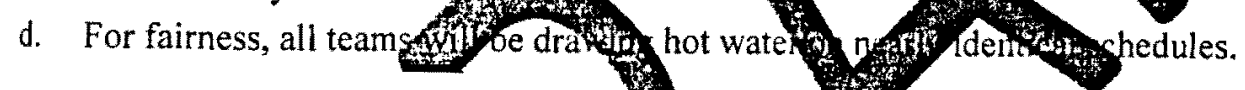

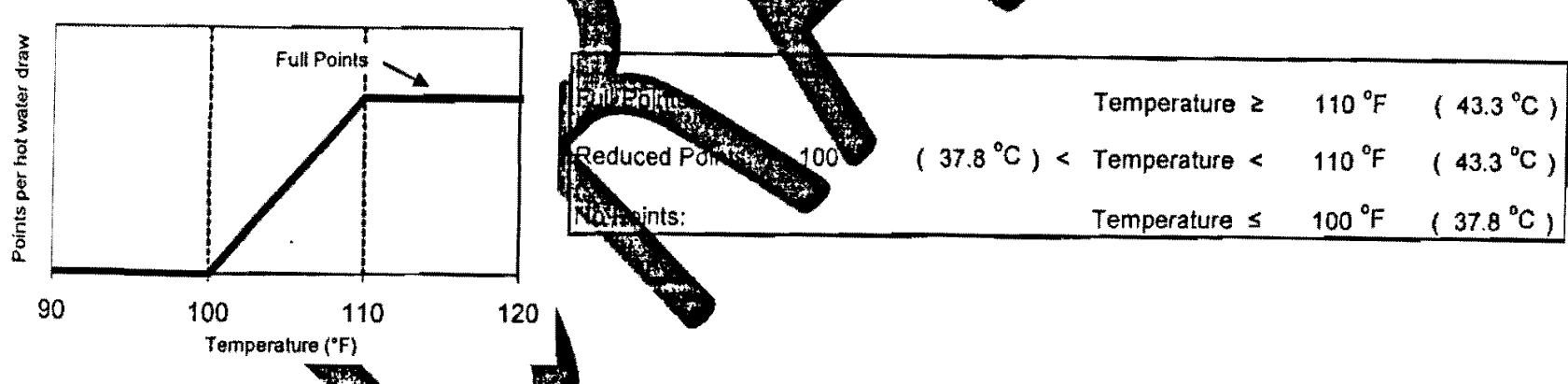

Figurg Scoring function for hot water draws

\section{Contest 8. Appliances}

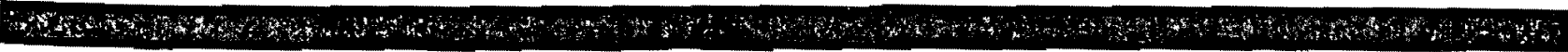

All available points are earned at the conclusion of each scored period by keeping the time-averaged interior temperature of a qualifying refrigerator between $34.0^{\circ} \mathrm{F}\left(1.11^{\circ} \mathrm{C}\right)$ and $40.0^{\circ} \mathrm{F}\left(4.44^{\circ} \mathrm{C}\right)$ during the scored period. See Appendix $A$ for the schedule of scored periods and for the number of available points per scored period.

a. Reduced points are earned if the time-averaged interior refrigerator temperature is between $32.0^{\circ} \mathrm{F}\left(0.00^{\circ} \mathrm{C}\right)$ and $34.0^{\circ} \mathrm{F}\left(1.11^{\circ} \mathrm{C}\right)$ or between $40.0^{\circ} \mathrm{F}\left(4.44^{\circ} \mathrm{C}\right)$ and $42.0^{\circ} \mathrm{F}\left(5.56^{\circ} \mathrm{C}\right)$. Reduced point values are scaled linearly, as shown in Figure 6.

b. The refrigerator volume published in the manufacturer's specifications shall be a minimum of $6.0 \mathrm{ft}^{3}(170 \mathrm{~L})$.

c. The refrigerator may be used to store food and beverages. 


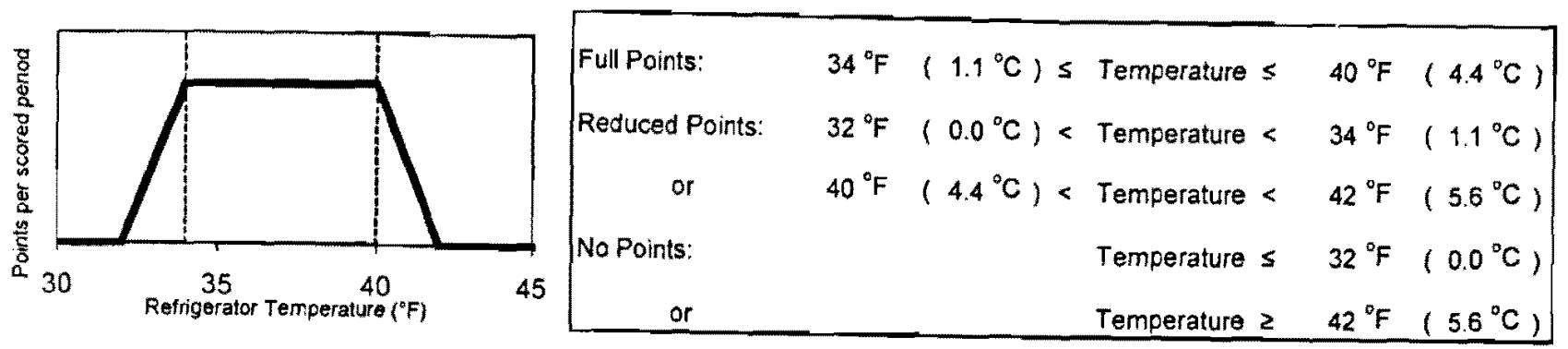

Figure 6: Scoring function for the Refrigerator sub-contest

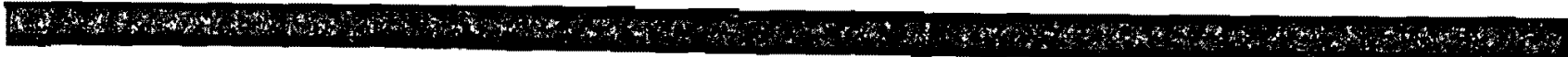

All available points are earned at the conclusion of each scored period bygeping the time-averaged interior temperature of a qualifying freezer between $-20.0^{\circ} \mathrm{F}\left(-28.9^{\circ} \mathrm{C}\right)$ and $\left.5.045 .0^{\circ} \mathrm{C}\right)$ during the scored period. See Appendix A for the schedule of scored periods and for the number 1 tilable points per scored period.

a. Reduced points are earned if the time-averaged interior fra ${ }^{\circ} \mathrm{cm}$ theture is between $-30.0^{\circ} \mathrm{F}\left(-34.4^{\circ} \mathrm{C}\right)$ and $-20.0^{\circ} \mathrm{F}\left(-28.9^{\circ} \mathrm{C}\right)$ or between $5.0^{\circ} \mathrm{F}\left(-15.0^{\circ} \mathrm{C}\right)$ and $15.2 \mathrm{~g}\left(-4.44^{\circ} \mathrm{C}\right)$. shown in Figure 7.

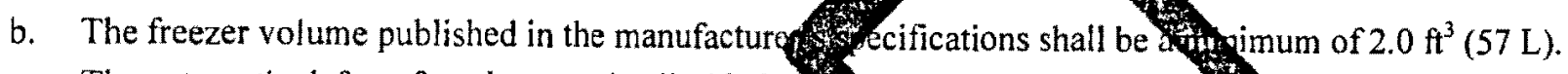

c. The automatic defrost function may be disabled.

d. The freezer may be used to store food and only enough 4 to fil
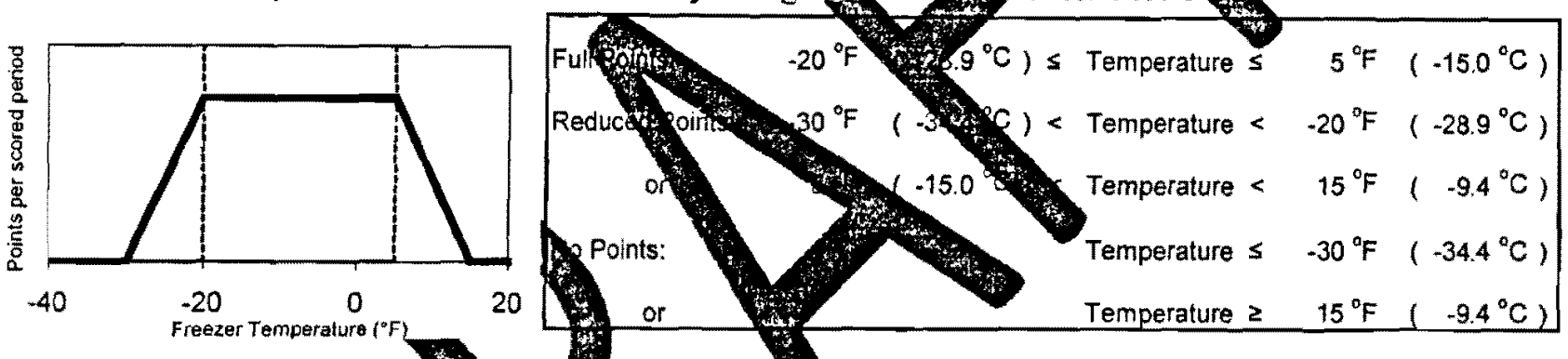

Figting: Softion function the Freezer sub-contest

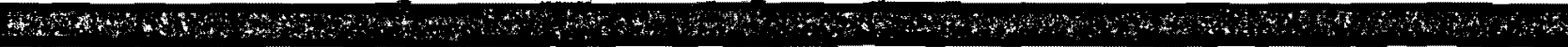

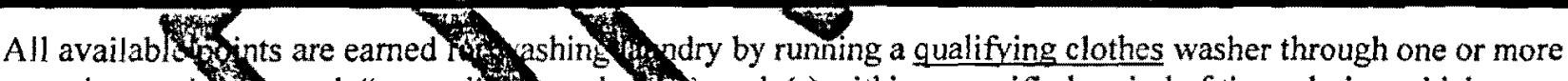

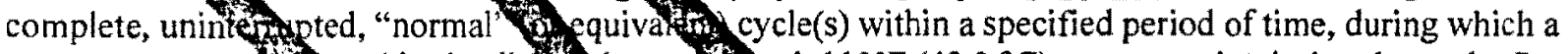

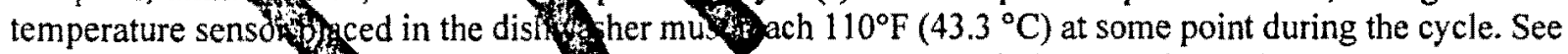
A ppendix A for spectetails regarct the number of points per clothes washing task and the time periods designated for clothes wing tasks.

a. Half of the available pros are $\mathrm{d}$ if the temperature sensor reaches $105^{\circ} \mathrm{F}\left(40.6^{\circ} \mathrm{C}\right)$, but does not reach $110^{\circ} \mathrm{F}\left(43.3^{\circ} \mathrm{C}\right)$.

b. A load of laundry is defined organizer-supplied bath towels.

c. The clothes washer shall operate automatically, have at least one wash and rinse cycle.

d. One or more complete, uninterrupted, "normal" (or equivalent) cycle(s) in an automatic clothes washer shall be used to wash the laundry.

e. On several days during contest week, two loads of laundry are required to be washed. Teams have the option to combine double loads and wash them in one clothes washer cycle.

f. For redundancy, 2 temperature sensors shall be placed in the clothes washer for each test. The higher of the 2 readings is the temperature of record, unless it is determined that the sensor with the higher reading is defective, in which case the lower of the 2 readings is the temperature of record.

g. The drying function in a combination washer/dryer shall be disabled until the completion of the wash cycle and removal of the temperature sensors. 
h. Cycle "interruption" includes the adjustment of supply temperature or flow in a manner not anticipated by the manufacturer or addressed in its operation manual.

i. Cycle completion shall be confirmed by the observance of an audible or visible signal.

j. The organizers will consult the operation manual to identify appropriate cycle settings. "Normal" or "regular" settings shall be selected, if available. Otherwise, settings most closely resembling typical "normal" or "regular" settings shall be selected.

\section{If}

All available points are earned by returning a load of laundry to a total weight less than or equal to the towels' total weight before washing. Clothes drying shall be completed within a specified period of time. See Appendix A for specific details regarding the number of points per clothes drying task and the time periods designated for laundry tasks

a. Reduced points are earned if the "dry" towel weight is between $16 \%$ and $110.0 \%$ of the original towel weight. Reduced point values are scaled linearly, as shown in 8 .

b. A load of laundry is eligible for clothes drying points only to 10 tomperienced a complete, uninterrupted cycle in an automatic clothes washer. However, scoringmolits in the prerequisite for scoring points in the Clothes Dryer

c. The drying method may include active drying (e en clothes line), or any combination of active or passive drying. A 1 king methods that require towels to be visible must be demonstrated to the Architecture and Market Viab juries ands they tour

d. On several days during contest week, tyo loads of launds oped to be dried.

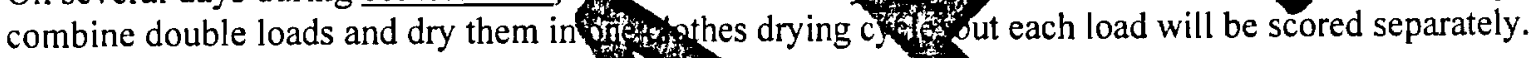

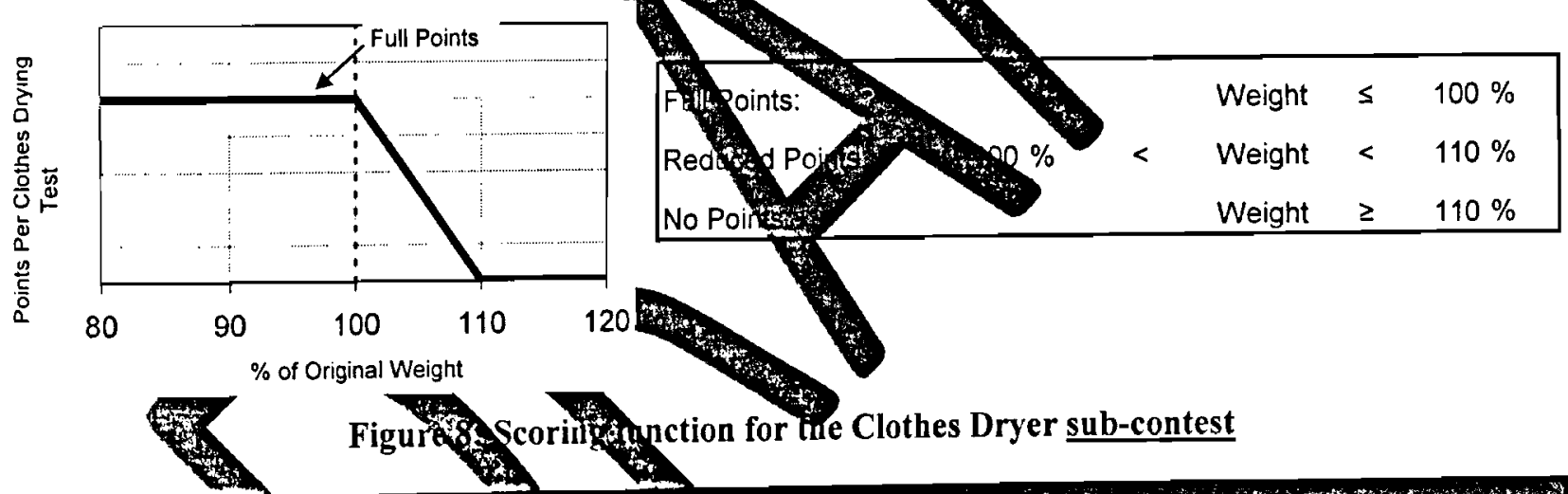

\section{W.}

All available points afegned by runit. a qualifying dishwasher through a complete, uninterrupted, "normal" (or equivalent) cycle witto specified of tod time, during which a temperature sensor placed in the dishwasher must reach $120^{\circ} 8.9^{\circ} \mathrm{G} / 3$ some point during the cycle. See Appendix A for specific details

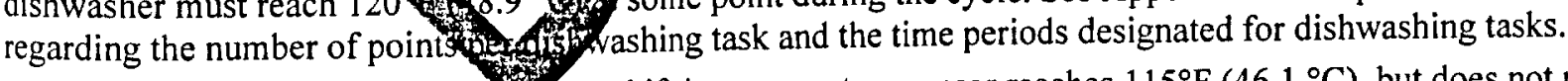

a. Half of the available points ake arned if the temperature sensor reaches $115^{\circ} \mathrm{F}\left(46.1^{\circ} \mathrm{C}\right)$, but does not reach $120^{\circ} \mathrm{F}\left(48.9^{\circ} \mathrm{C}\right)$.

b. For redundancy, 2 temperature sensors shall be placed in the dishwasher for each test. The higher of the 2 readings is the temperature of record, unless it is determined that the sensor with the higher reading is defective, in which case the lower of the 2 readings is the temperature of record.

c. The dishwasher shall operate automatically, have at least one wash and rinse cycle, and have a minimum capacity of 6 place settings according to the manufacturer's specifications.

d. If the dishwasher has a heated drying option, this option shall be disabled.

e. Cycle "interruption" includes the adjustment of supply temperature or flow in a manner not anticipated by the manufacturer or addressed in its operation manual.

f. Cycle completion shall be confirmed by the observance of an audible or visible signal. 
g. The organizers will consult the operation manual to identify appropriate cycle settings. "Normal" or

"regular" settings shall be selected, if available. Otherwise, settings most closely resembling typical

"normal" or "regular" settings shall be selected.

h. The dishwasher may be run empty, partially loaded, or fully loaded; the load may be soiled or clean.

\section{Contest 9. Home Entertainment}

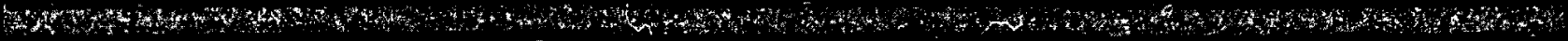

All available points are earned by using a kitchen appliance to vaporize 5.000 pounds $(80.00$ ounces or $2.268 \mathrm{~kg}$ ) of water within a specified period of time. See Appendix A for specific details regarding the number of points per cooking task and the time periods designated for cooking tasks.

a. Reduced points are earned if between 1.000 pound $(16.00$ ounce $454 \mathrm{~kg}$ ) and 5.000 pounds $(80.00$ ounces or $2.268 \mathrm{~kg}$ ) are vaporized. Reduced point values are $5 \mathrm{ft}$. (inearly, as shown in Figure 9.

b. Any kitchen appliance may be used, but it must operate in the water.

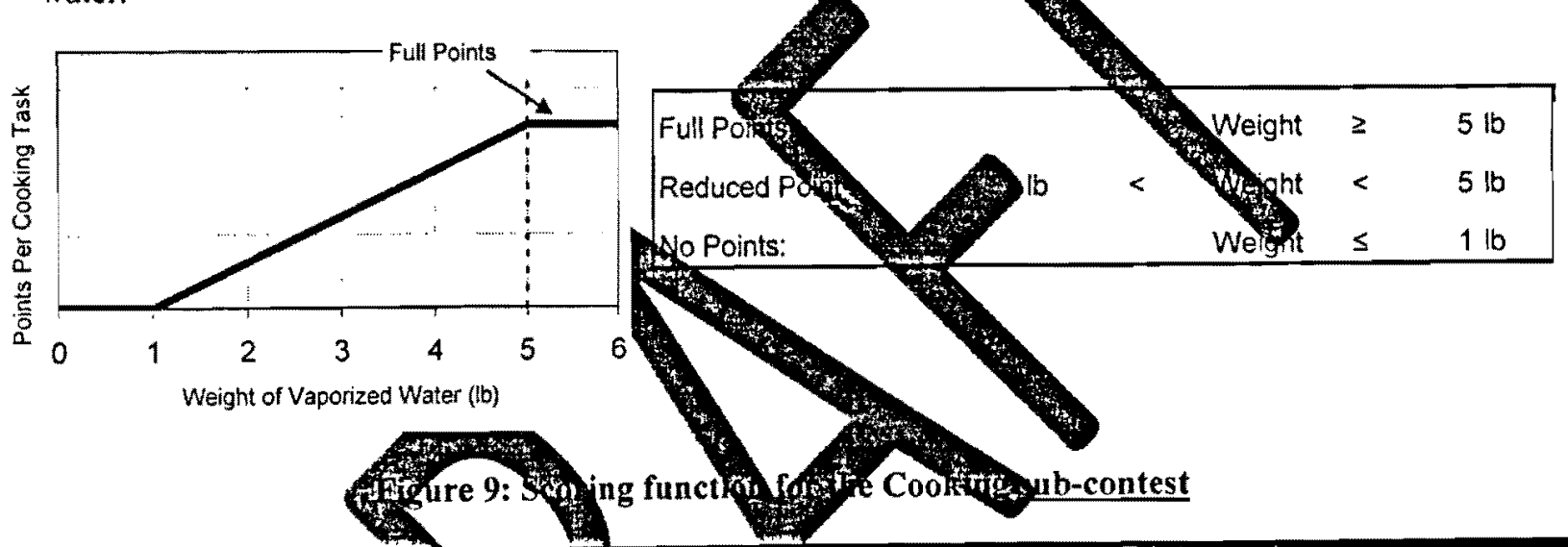

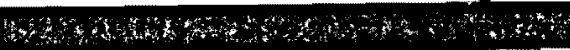

\section{a. Workstatiogeginging}

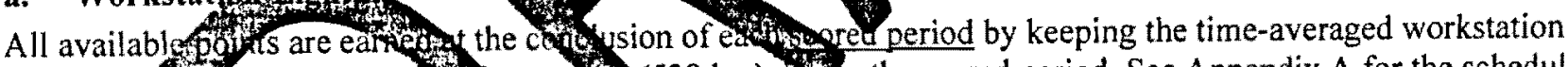

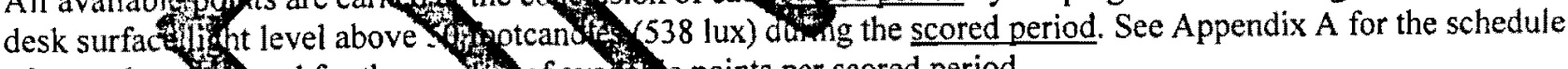
of scored perikg

(i). Redice points are earte if the thered veraged work surface light level is between 25.0 footcandles (269 luxpl 50.0 footcifites (538 lux). Reduced points are scaled linearly, as shown in Figure 10.

(ii). Light-emittudevices with $18 \mathrm{in} .(45.7 \mathrm{~cm})$ of the sensors are not permitted.

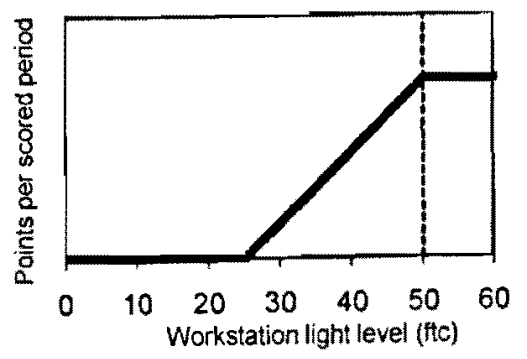

Full Points: $\quad$ Light Level $\geq 50 \mathrm{ftc}$ ( 538 lux ) Reduced Points: $25 \mathrm{ftc}(269 \mathrm{lux})<$ Light Level $<50 \mathrm{ftc}$ ( 538 lux )

No Points: Light Level $\leq 25 \mathrm{ftc}(269$ lux $)$

Figure 10: Scoring function for the Workstation Lighting sub-contest

\section{b. House Lighting}

All available points are earned for keeping all interior and exterior house lights on during specified periods of time. See Appendix A for specific details regarding the number of points per House Lighting task and the time periods designated for House Lighting tasks. 
(i). All dimmers shall be adjusted to their highest positions and all other lighting control equipment shall be disabled or overridden so that the controlled lamps are fully and continuously on during the specified periods.

(ii). Partial credit will be awarded for partial compliance. However, a team is only eligible for partial credit if it notifies its observer before turning selected lamps on or off.

Each team shall host two dinner parties for its neighbors during contest week. See Appendix A for the dinner party schedule and the number of available points per dinner party. Each pair of guests from a guest team shall assign a score to the host team after each dinner party. The quality of the meal, ambiance, and overall experience shall be considered in the evaluation.

a. To maintain consistency among the subjective contests and sub-conters, guest teams shall use the scoring methodology described in the "Phase III: Deliberation" section of 1 ndix $B$. Each of the 3 guest teams shall submit 3 percentage integer scores, i.e., 1 score for quality 4 ,eal, 1 score for ambiance, and 1 score for overall experience, to the Contest Officials by 10 p.m. Thts the maximum available points in the scoring spreadsheet to nerate nal score for each dinner party. Percentage integer scores may range from $0 \%$ (lowest

b. The village will be organized into five small "neigh6" wods." Each neight neighboring houses. The guest list for the dinner 17 shall be limited to two from each of the three neighboring houses. Each host team shall prepare dit for at leasteight people guests and two team members.

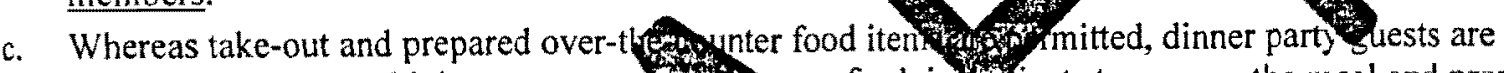
encouraged to assign higher scores to toght lim use fresh ingtents to prepare the meal and prepare/cook the meal entirely in the house.

d. The meal shall be served and eaten indoors the eantion desights in the construction documents.

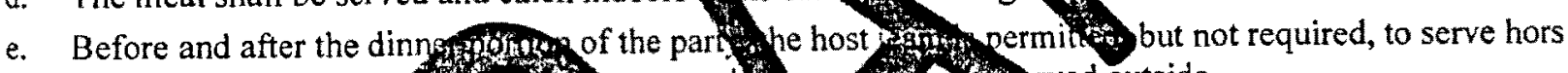

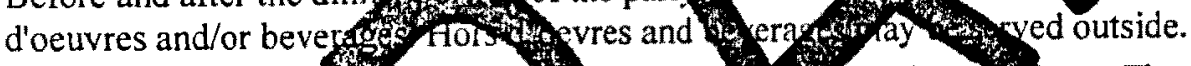

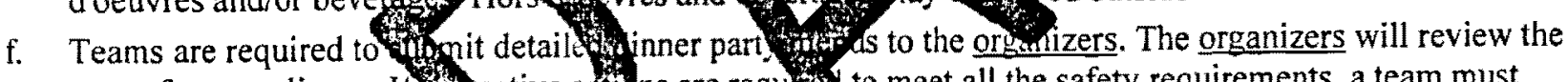
menu for compliance. It of submit an updated version of mytom

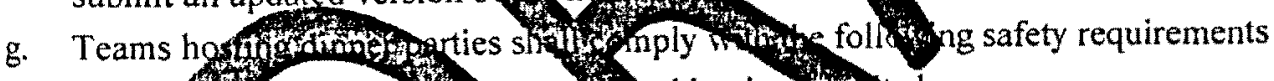

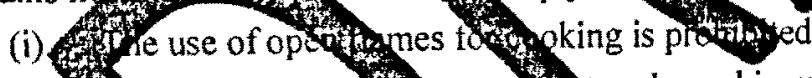

(ii). whe

(iii). All the used for cook and drithing shall be drinking water purchased in sealed containers

(iv). All dishy cookware foll be washed with hot water and soap and rinsed prior to use

(v). Normal donteste wastey may go into the wastewater tank

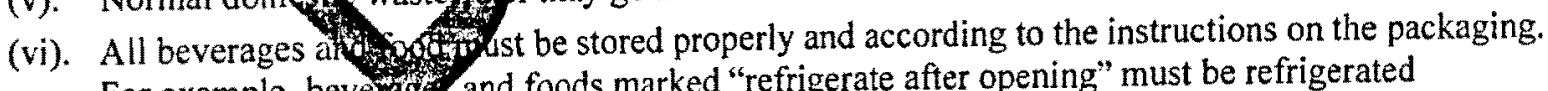
For example, bevergis and foods marked "refrigerate after opening" must be refrigerated appropriately after opening

(vii). Some dinner party guests may have food allergies. Common food allergies are: milk/dairy products, eggs, peanuts, tree nuts (walnut, cashew, pecans, etc.), fish, shellfish, soy, and wheat. To help prevent allergic reaction, teams create a list of ingredients for each of the items being served at each meal.

Immediately following the Communications jury tour, the power draw of a qualifying TV, qualifying computer, and other devices used during the jury tour and public exhibit will be measured over a 30 -minute period to establish the baseline power draw of the dedicated exhibit circuit(s). All available points are earned by operating these devices during specified scored periods and drawing at least $90 \%$ of the baseline power during the scored 
period. See Appendix A for the schedule of scored periods and for the number of available points per scored
period.

a. The TV shall be a minimum of 19 in. $(48.3 \mathrm{~cm})$ according to the manufacturer's stated display size. The computer display shall be a minimum of $17 \mathrm{in} .(43.2 \mathrm{~cm})$ according to the manufacturer's stated display size. The computer may be a notebook, laptop, or desktop computer. The computer and video displays shall be able to be operated simultaneously and controlied independently of each other.

b. Small mobile devices containing rechargeable batteries shall not be recharged on the dedicated exhibit circuit(s). The batteries in these devices shall be recharged at appropriate times on another house circuit so that the devices are useable at all times during public hours. The organizers and observers will conduct spot checks to verify that this requirement is being met.

c. Some scored periods will occur prior to the Communications jury tour and the establishment of the baseline power draw of the dedicated exhibit circuit(s). Points earned during these scored periods shall be awarded retroactively, after the completion of the final Communications iux

d. Teams shall notify the organizers prior to the event of any exhidofices that, under normal operation, are likely to fluctuate outside of $\pm 10 \%$ of the 30 -minute averagg

e. Teams with continuous audio loops may request special per ssion the volume of the audio during

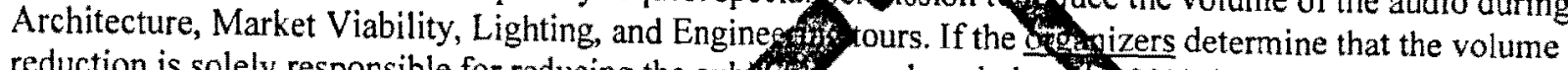
reduction is solely responsible for reducing the expofower draw below $190 \%$ threshold, points will be
restored for the affected scored periods.

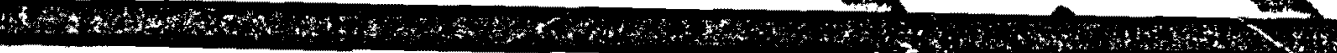

Each team shall host a movie night for its 9 of Eche Appendix A for the movie night

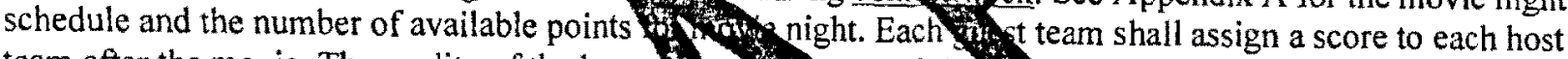
team after the movie. The quality of the home ate shom and desty be considered in the evaluation.

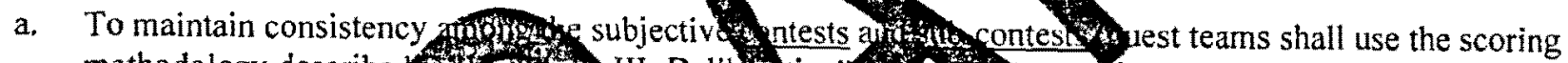
methodology describedy

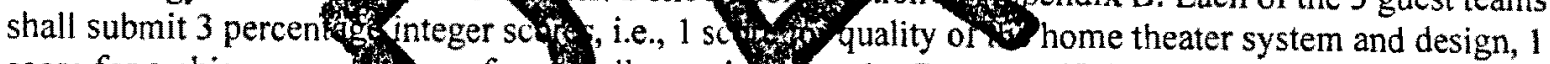
score for ambiance, and 4 re for ofe all experie to the Contest Official by 10 p.m. These 9 scores will

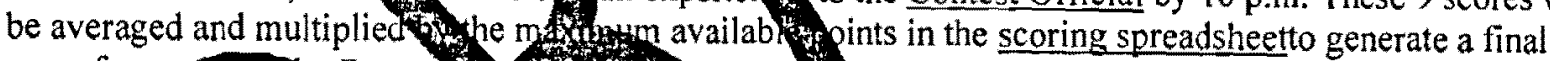

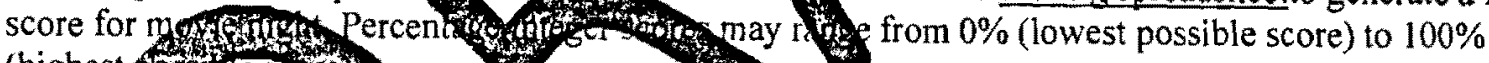
(highes 1055 tre scrath

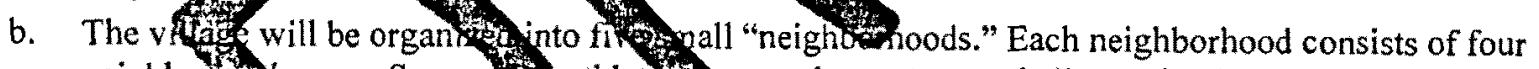
neighbologouses. Several teathlet movie in eato its neighbors ses.

c. The Temperatut Humidity sontests are suspended during movie night. Therefore, the occupancy rule, Rule 11-1, is of in effect on vie night.

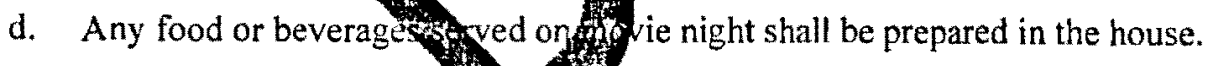

e. Prior to the event, team metres movies selected by the orgatizes. The movie receiving the most votes shall be provided by the organizers on the day of movie night and shall be the movie shown in all houses on movie night. The selected movie shall be available in several of the most popular video formats, so that each team may request the format most suitable for its home theater system.

\section{Contest 10. Net Metering}

All available points are earned at the conclusion of the specified net metering period (see Appendix A for the net metering schedule) for producing a net amount of AC electrical energy of $0.0 \mathrm{kWh}$ or more. 
a. Reduced points are earned if the net $A C$ energy is between $-10.0 \mathrm{kWh}$ and $0.0 \mathrm{kWh}$. Reduced points are scaled linearly, as shown in Figure 11.

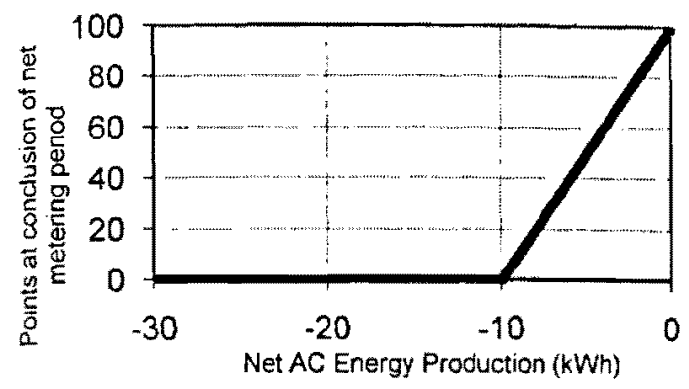

\begin{tabular}{|lr|}
\hline Full Points: & Net AC Energy $\geq 0 \mathrm{kWh}$ \\
Reduced Points: & $-10 \mathrm{kWh}<$ Net AC Energy $<0 \mathrm{kWh}$ \\
No Points: & Net AC Energy $\leq-10 \mathrm{kWh}$ \\
\hline
\end{tabular}

Figure 11: Scoring function for the Energy Balance sub-contest $1 \mathrm{c}$

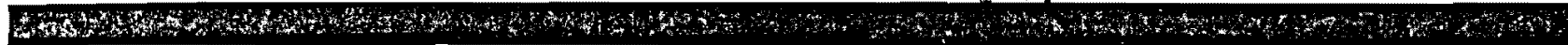

All available points are earned at the conclusion of the specified metering schedule) by the team that produced the greatest surpis of net lectrical energy.

a. Reduced points are earned if the net AC energy is befe $0.0 \mathrm{kWh}$ and $\mathrm{net}$ net $\mathrm{AC}$ energy of the team with the greatest surplus. Reduced points are scaled linftef as shown in Figure
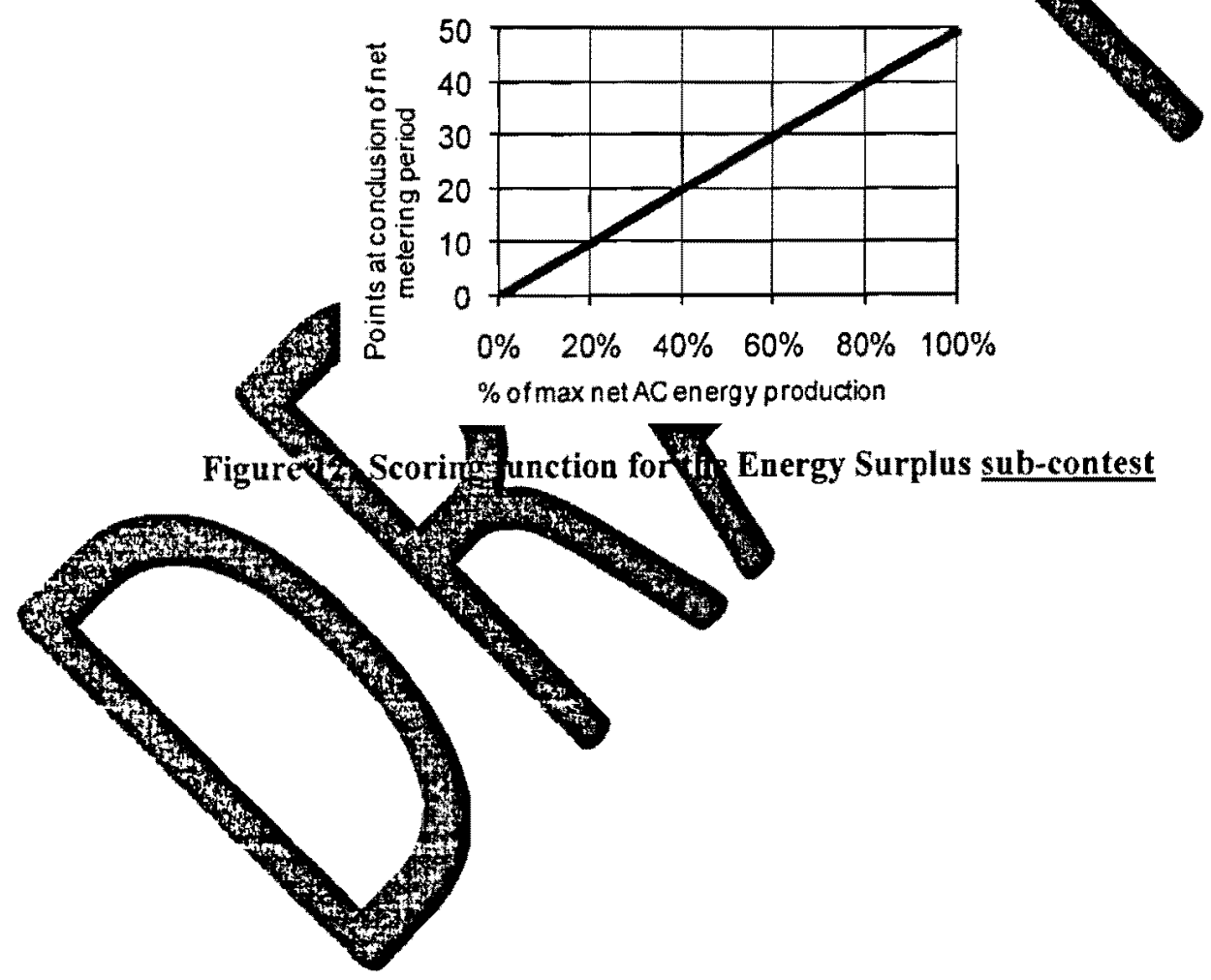


\section{Appendix A Event Schedules}

\section{A-1. Overview Event Calendar}

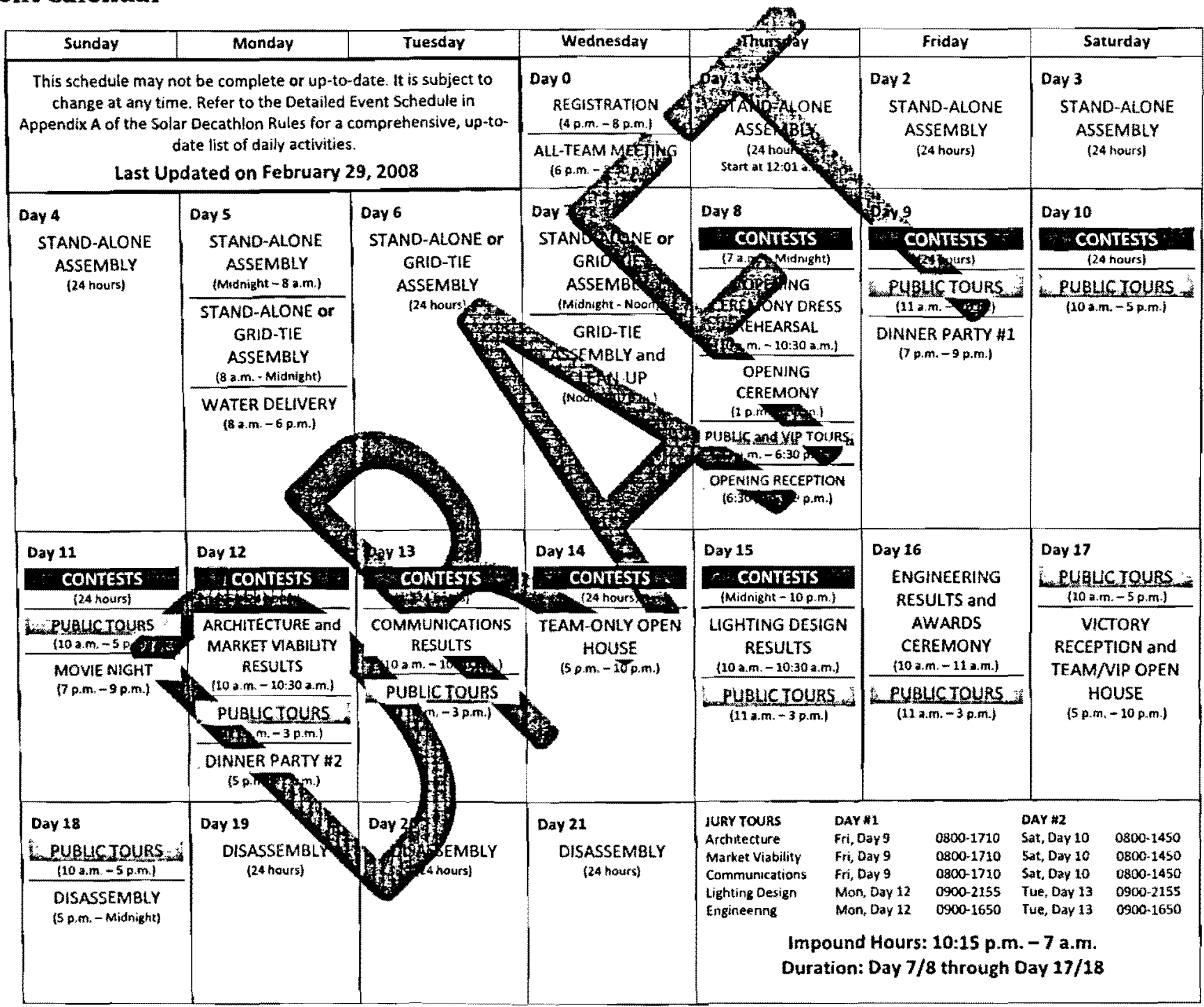


A-2. Scoring Chronology

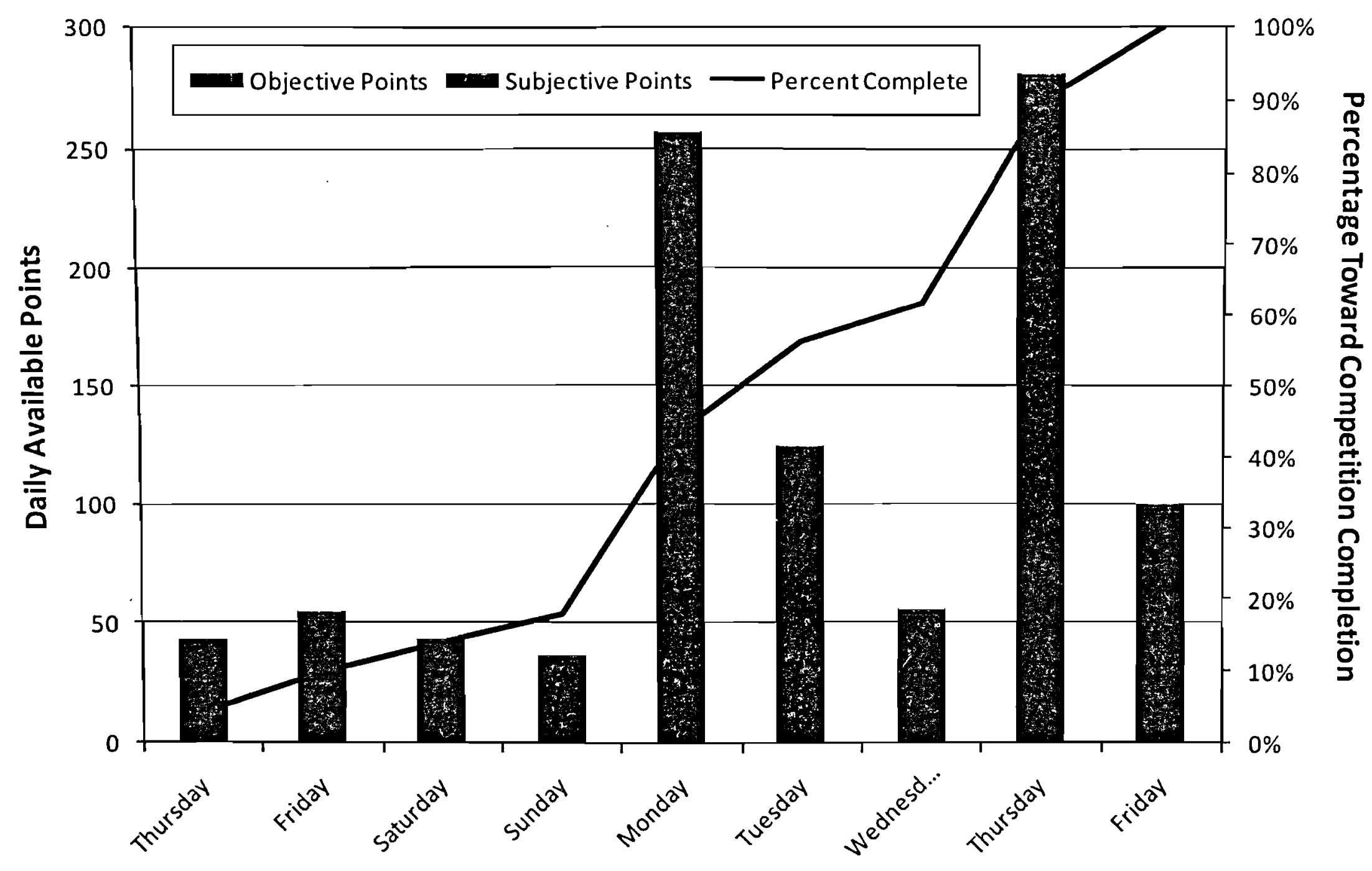




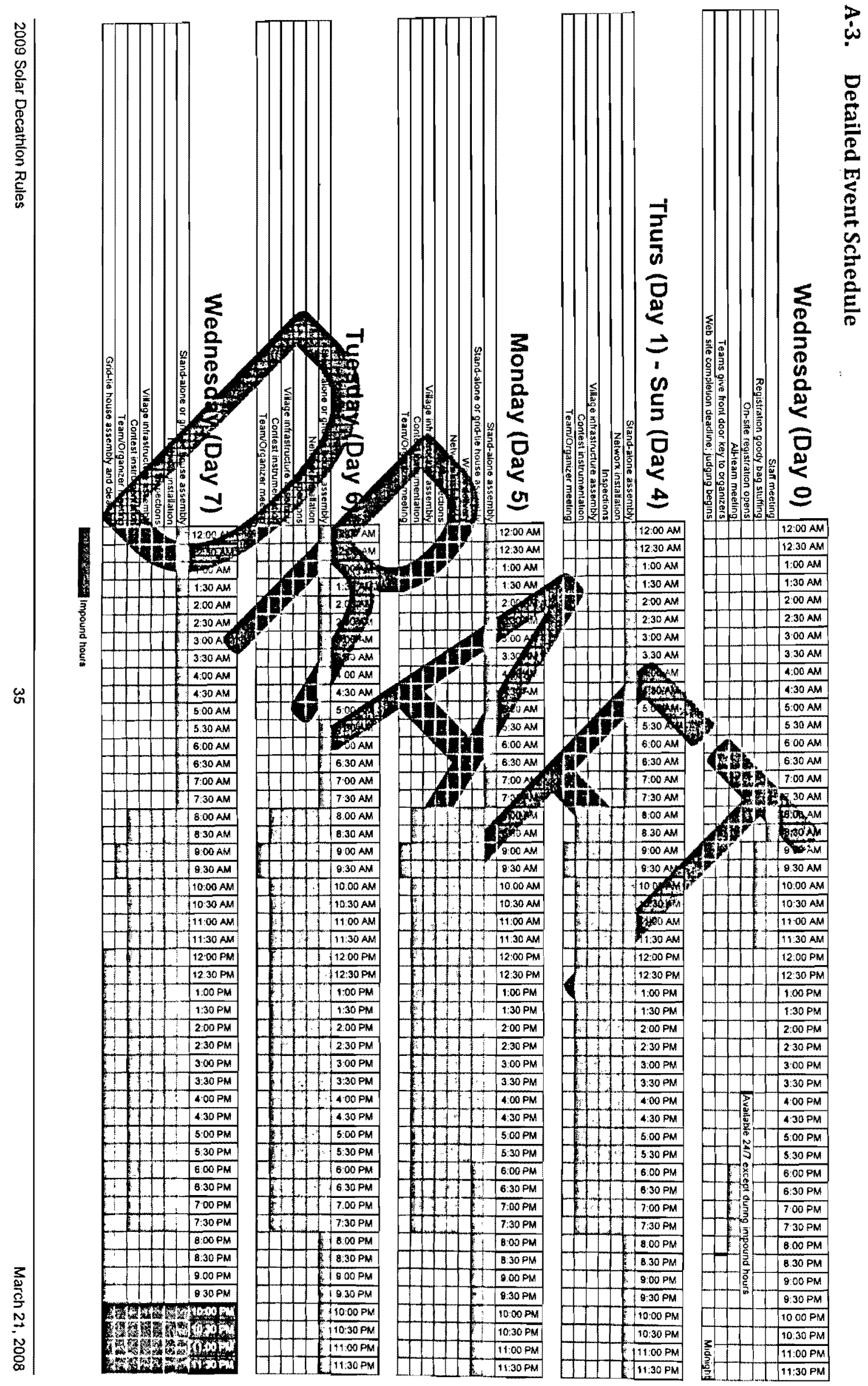




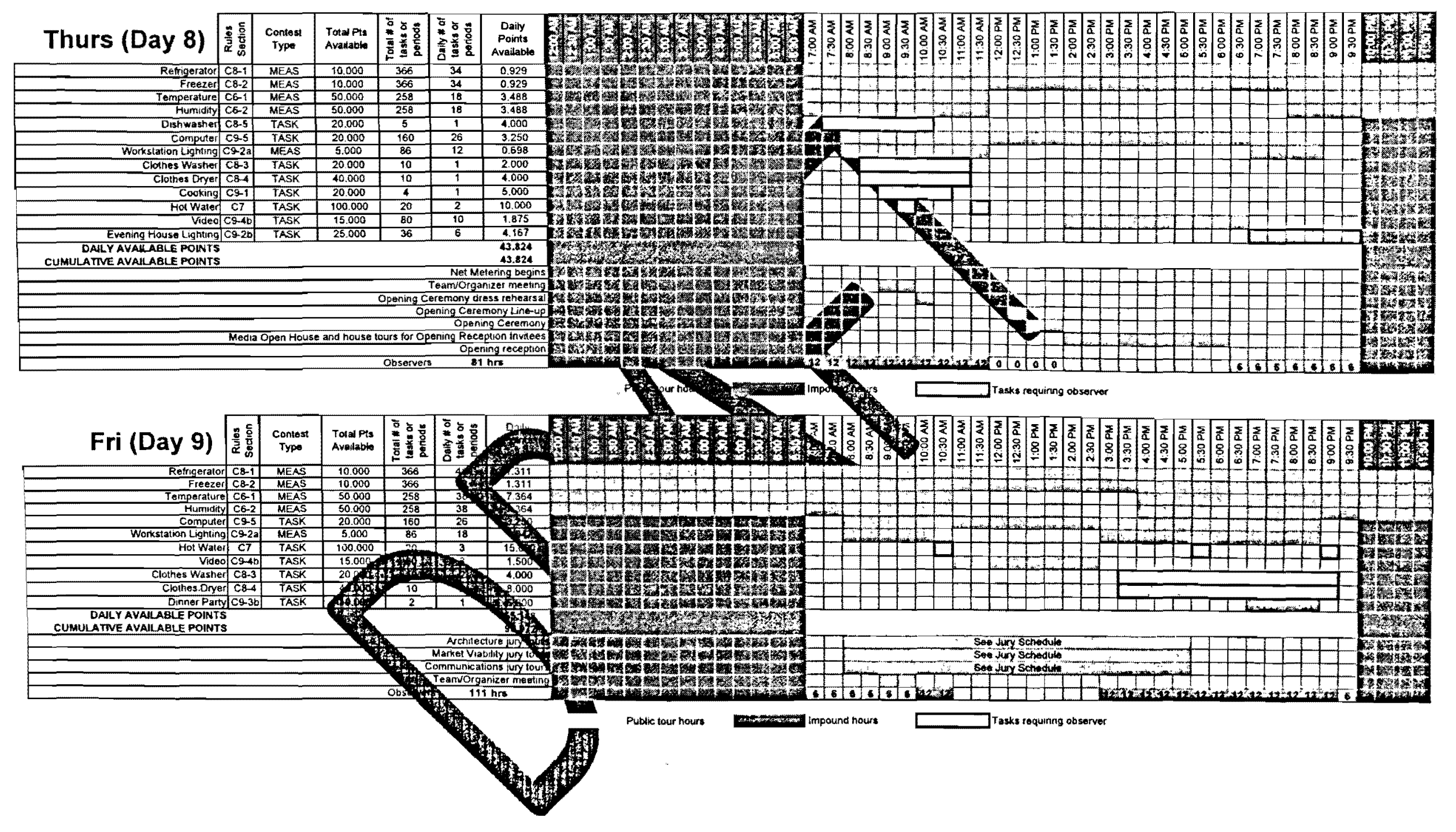




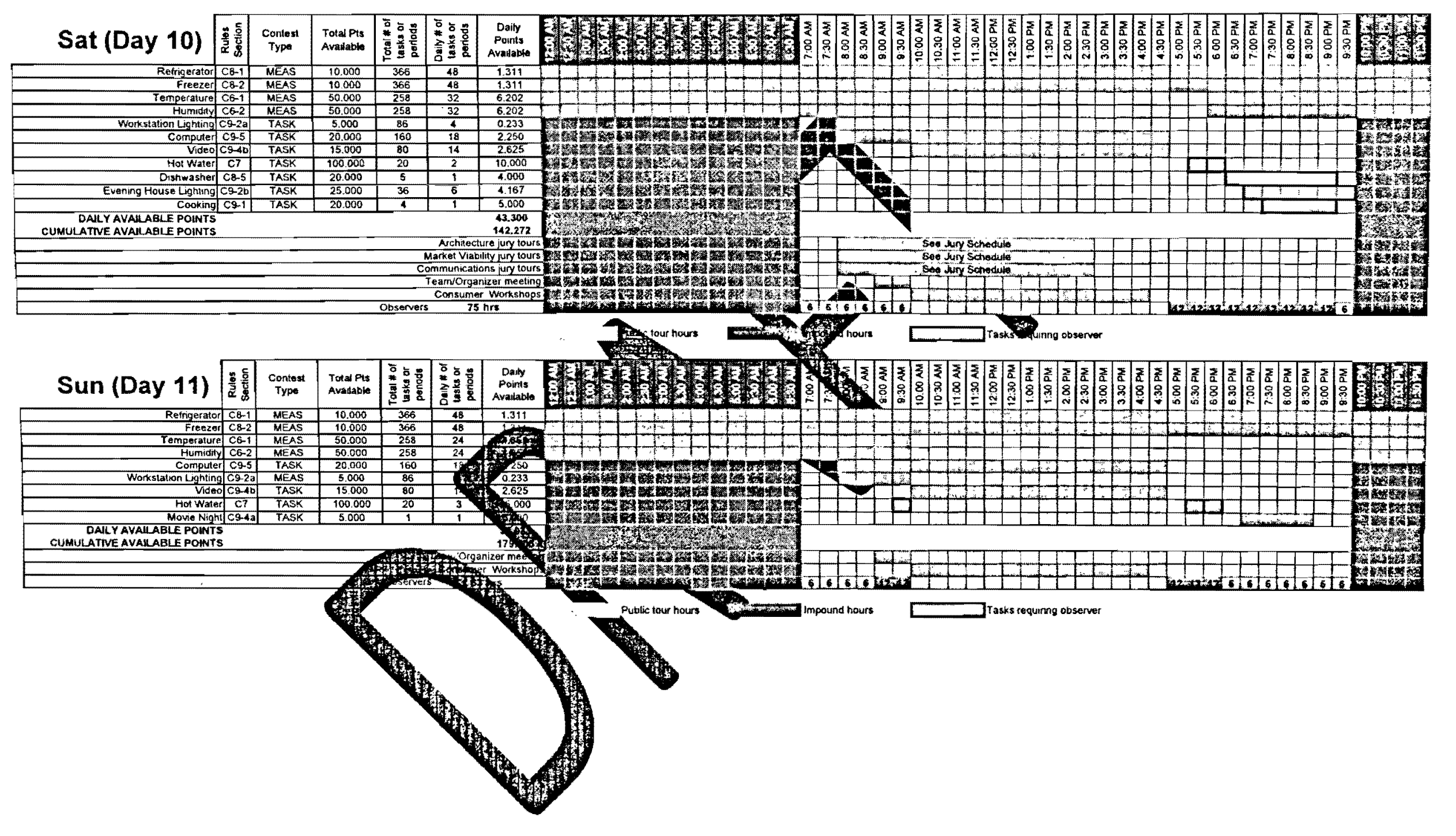




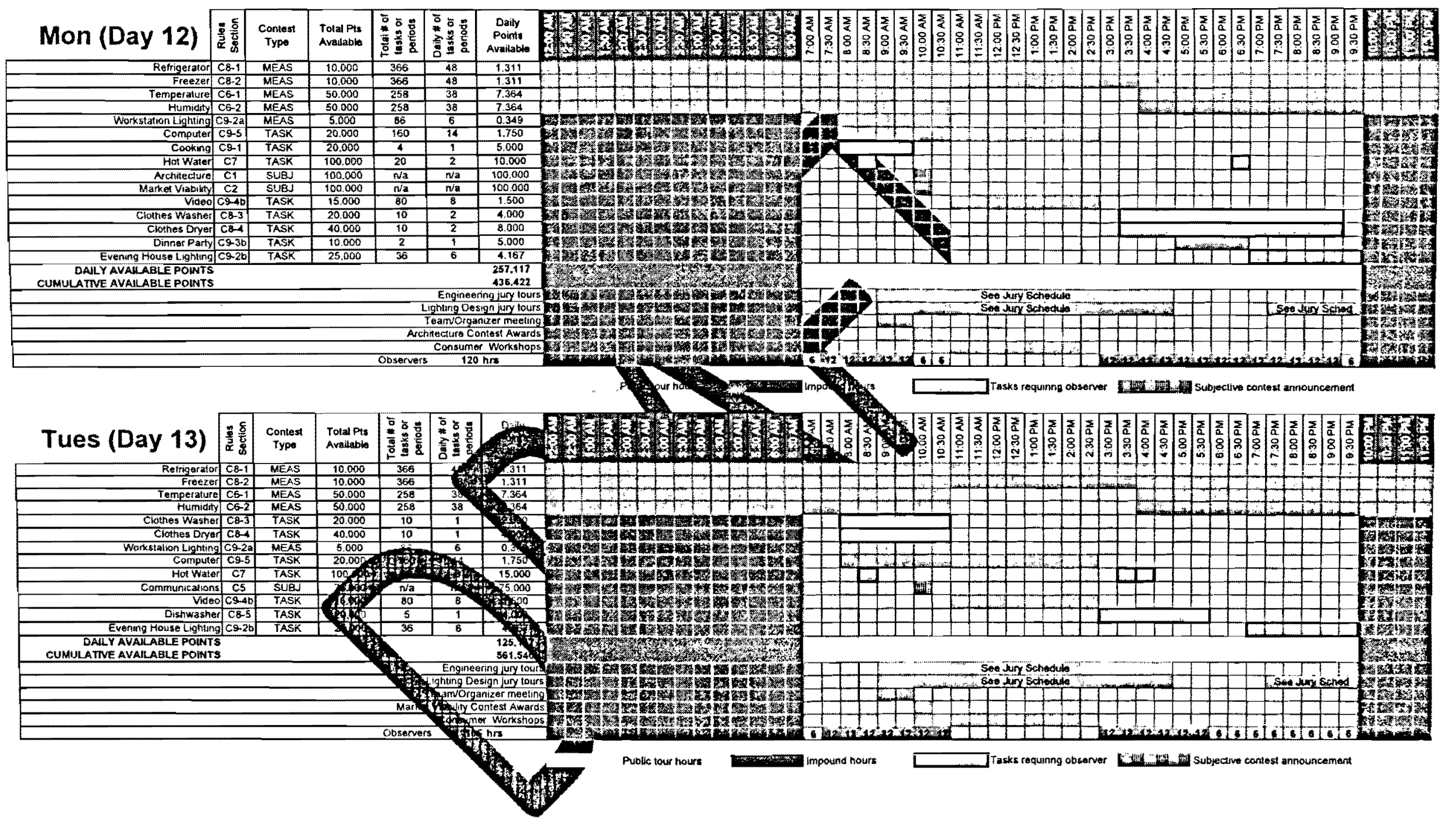




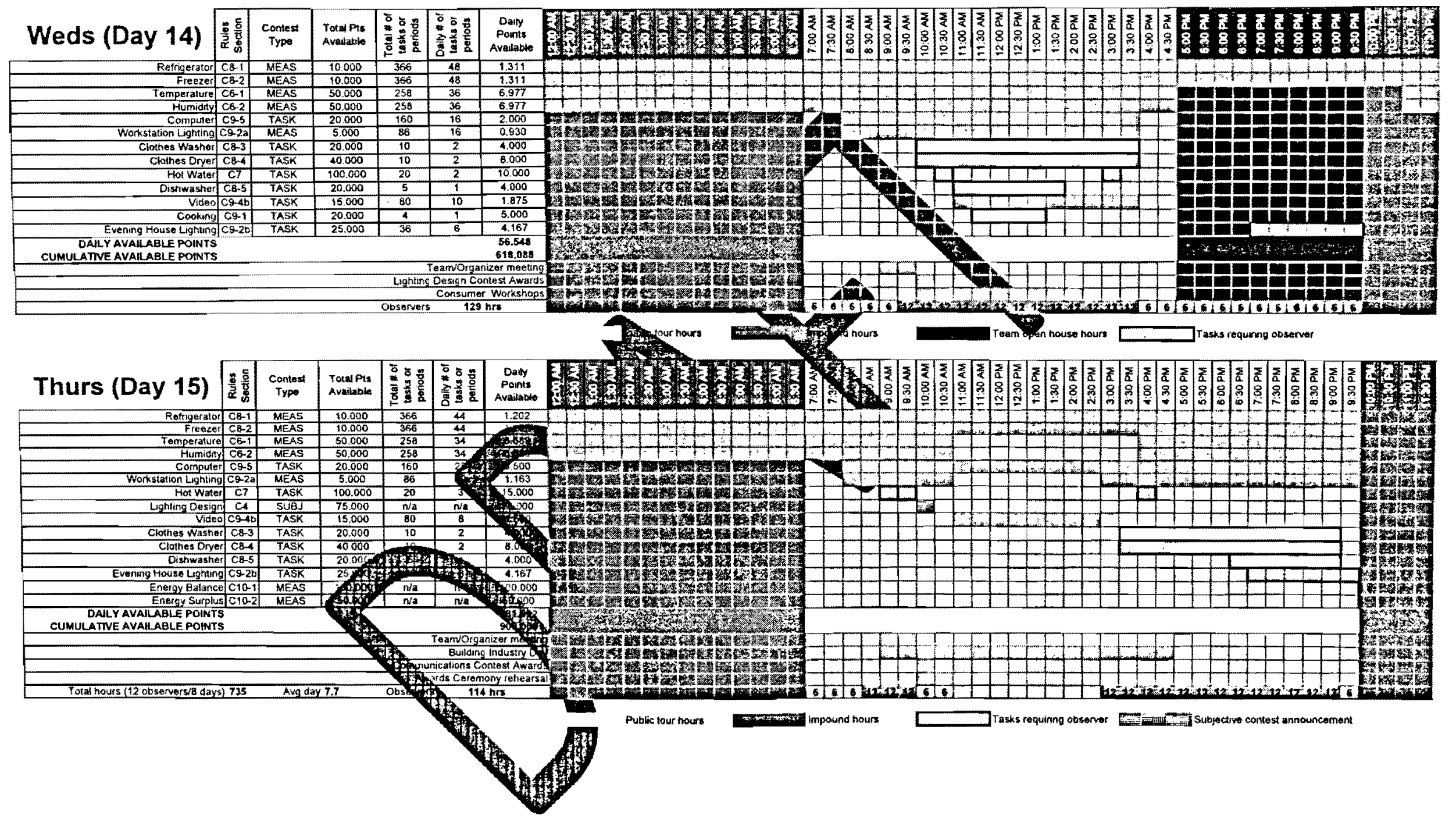




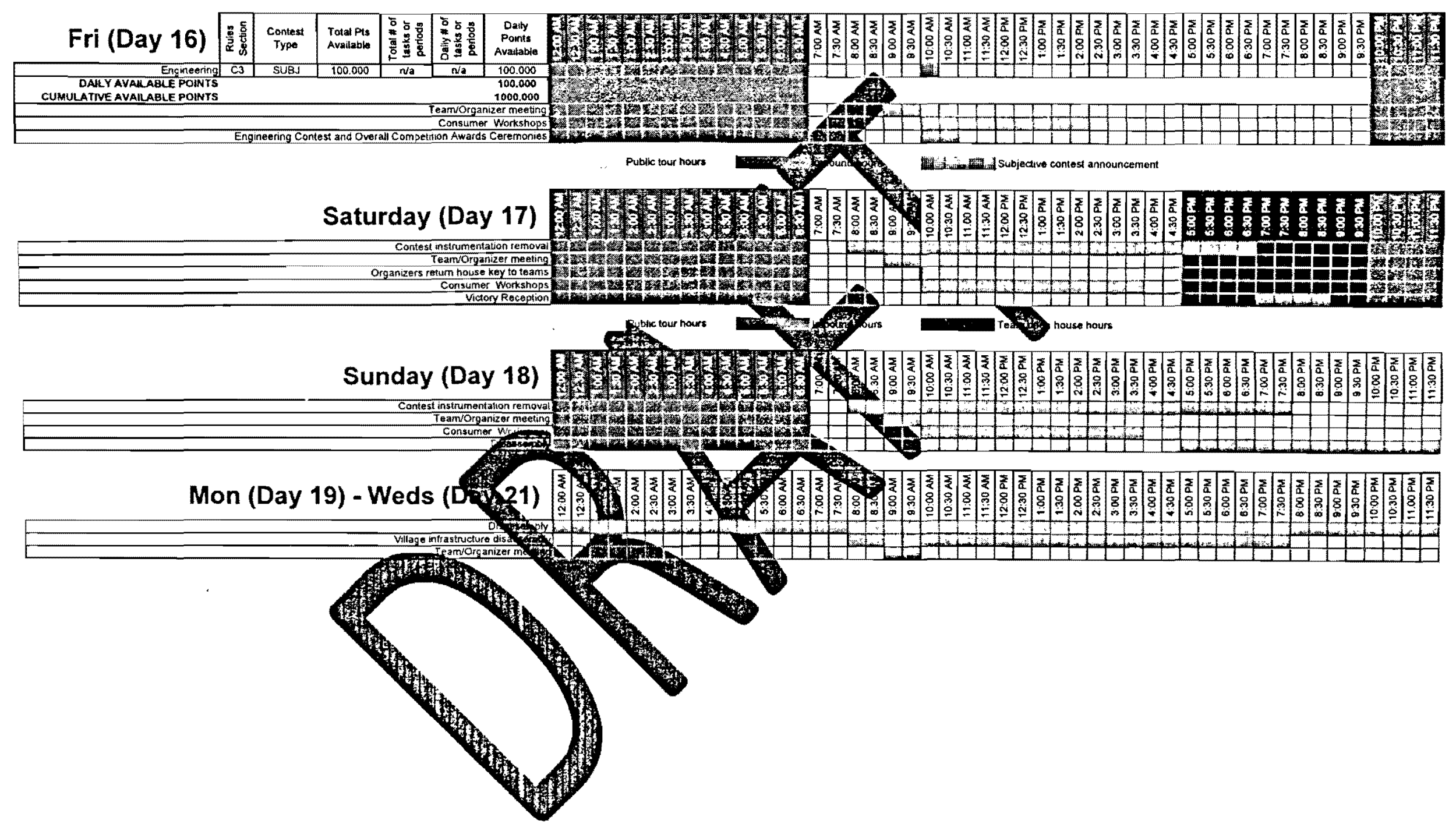




\section{Appendix B Subjective Sub-Contest Guidelines}

\section{B-1. Juror Guidelines}

A juror's evaluation of each team's project consists of the following 3 phases:

1. Deliverables review

2. Scheduled jury tours

3. Deliberation

Table 5 indicates the time commitments jurors are expected to make per team for each of the first two phases of the evaluation. Teams will be asked to consider these respective juror time commitments as they determine how much information to present to the juries in the narrative portions their Project Manuals and during the scheduled jury tours.

Table 5: Juror time commitments for deliverable 40 tw and scheduled jury tour

\begin{tabular}{|c|c|c|c|}
\hline Jury & $\begin{array}{c}\text { Time Commitment for } \\
\begin{array}{c}\text { Deliverables Review } \\
\text { (per team) }\end{array} \\
\end{array}$ & $\begin{array}{l}\text { Relevant Delive } \\
\text { (see Appenthe for Construt } \\
\text { Documend }\end{array}$ & $\begin{array}{l}\text { Time Commitment for } \\
\text { Scheduled Jury Tour } \\
\text { (per team) }\end{array}$ \\
\hline Architecture & 10 to 20 minutes & & 30 minutes \\
\hline Market Viability & & & 30 minutes \\
\hline Engineerin & & & 30 minutes \\
\hline Lighting Des & & $\begin{array}{l}\text { Construction drawings } \\
\text { Project Manual } \\
\text { - Construction specifications } \\
\text { Lighting design narrative }\end{array}$ & $\begin{array}{c}30 \text { minutes (day) } \\
10 \text { minutes (night) }\end{array}$ \\
\hline Communications & 1102 & $\begin{array}{l}\text { 1. Web site } \\
\text { 2. Final Communications Plan } \\
\text { 3. Construction drawings } \\
\text { (see Appendix D for Communications } \\
\text { deliverable requirements) }\end{array}$ & 30 minutes \\
\hline
\end{tabular}

\section{Phase 1: Deliverables Review}

The deliverables review offers the jurors an opportunity to explore the relevant details of each team's project via the deliverables outlined in Table 5 . If questions arise during the deliverables review phase, jurors may address those questions to the appropriate Contest Official before or during the event.

\section{Phase 2: Scheduled Jury Tours}

The scheduled jury tours take place on the competition site and offer the jurors an opportunity to make visual verifications of information presented in the deliverables and to ask the Decathletes for clarification of questions 
that may have arisen during the deliverables review. The logistical details of the scheduled jury tours will be provided to each juror by the Contest Official prior to the juror's arrival on the competition site.

\section{Phase 3: Deliberation}

\section{STEP \#1}

During the deliberation phase, which takes place after the completion of scheduled jury tours, each juror is encouraged to place each team into one of 4 classes based on each team's performance relative to the contest criteria. Contest criteria are included in each contest description. The 4 classes are:

\section{Class \#1: ECLIPSES Contest criteria $91-100 \%$ of available points \\ Class \#2: EXCEEDS Contest criteria $81-90 \%$ of available points \\ Class \#3: EQUALS Contest criteria $61-80 \%$ of available points \\ Class \#4: APPROACHES Contest criteria $0-60 \%$ available points}

Jurors are not required to place a uniform number of teams in all cla class. For example, if a jury determines that no teams are worthy 4 , there would be no teams with scores greater than $90 \%$. Note that the placing of teams into classes (a 4 st st 4 ward assigning an eventual percentage integer) is encouraged to ease the process of evagrong so many ys at one time.

If it is possible to further separate teams within a particy ass, assigning dithert percentage integers within the allowed range of the particular class is encouraged assigned percentage ho may fall anywhere within the range associated with the class. If it is not possible to ther separate teams with tho particular class, it may be appropriate to assign each team in a particular class the salifercentafyteger.

\section{STEP \#2}

After assigning each team a percentage integ to to to Contest Official. The Contest Official will then

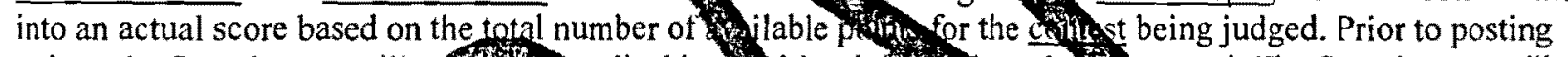

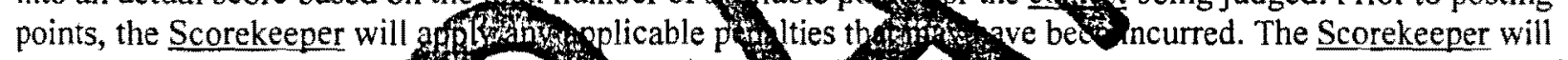
round off any non-integer spreadsheet.

\section{STEP \#3}

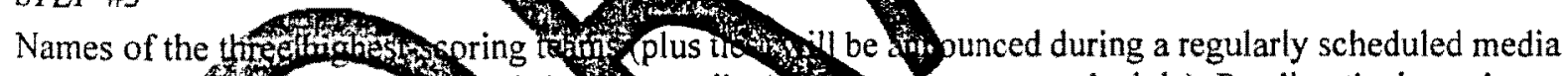

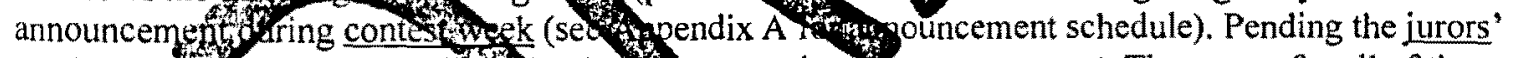
availability, posted immediste following the nounchonts.

STEP \#4

The jury shall submit a summary of the jury's justifications pro evaluated the team as it did.

\section{B-2. Team Guidelines}

a. It is ultimately the team's responsibility to ensure the house is cleared of visitors, and the team is ready for the arrival of a jury at the time indicated in the schedule (see Appendix A). A Solar Decathlon organizer or staff person called a "runner" will deliver a warning 30 to 60 minutes prior to the arrival of the jury and will help the team clear the house of visitors and manage the line of people waiting to tour the house. A team shall not start clearing its house prior to the runner's warning in anticipation of the arrival of a jury, because public tour times must also be maximized.

b. Show the Architecture and Market Viability, and, if appropriate, the Engineering, Lighting Design, and Communications juries all possible configurations of the house during the respective tours. House configurations that could affect the outcome of contests and that were not seen by the jury during their tours are prohibited during contest week. Some examples of reconfigurable features follow: 
- A significant moveable component, such as a room, wall, or bed (safety plan must also be in place)

- Significant shading devices, such as retractable awnings or operable shutters

- Towel-drying locations

- Window coverings that may obstruct views or reduce light levels.

If you do not have time to do a live reconfiguration during the jury tours, you must use some other method, such as photographs or video, to show all reconfigurable features in their various configurations. If you are not planning to actually reconfigure qualifying features at any time during contest week, you do not have to show the reconfiguration to the juries.

All plug-in or portable appliances that may be used during contest week must be in their fully deployed locations and configurations during all jury tours. Also be aware that juries may request plug-in, portable, or hard-wired appliances to be turned on so they can evaluate noise levels or other characteristics of the appliances that may not be apparent when the appliance is off.

c. Up to six (6) Decathletes may give tours to the juries. Team $\mathrm{Cr}$ aly not give tours to the juries. A faculty member may be a silent observer during the tours.

d. The jury visits will be held to a very strict schedule for eacthe the importance of following this schedule is twofold. First, to ensure each team receiveryal visitation by the juries to maintain a sense of fairness among all the teams. And second, any doforto on from the schell have an immediate effect on other events planned during the days the jurie 7 be evaluating houses. $y$ mall deviation in the schedule set for the juries could result in a very difortution situation resolve in component of the

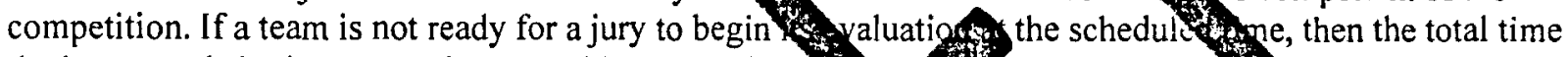

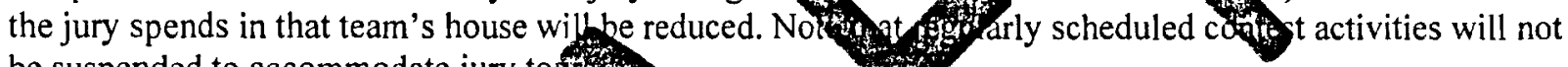
be suspended to accommodate jury totify

e. The juries will have 30 minutes to visit

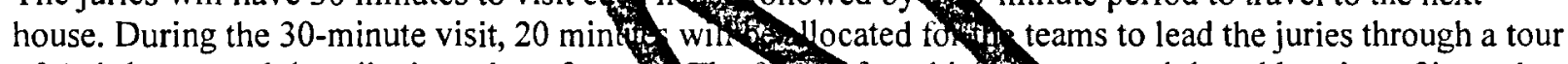
of their house and describe its unique featurat The forstor which our and the addressing of jurors'

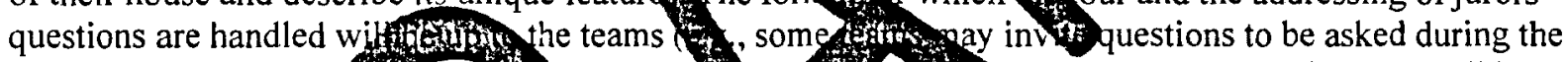

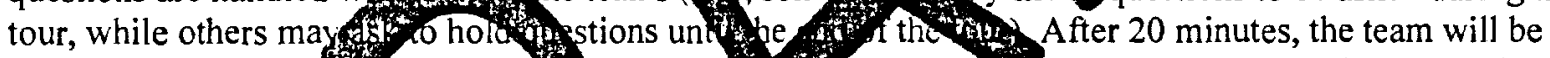
asked to leave its hou that the s can hold $\mathrm{s}$ she they have just seen.

f. The Lighting Desion jury wh sit a the nighttime

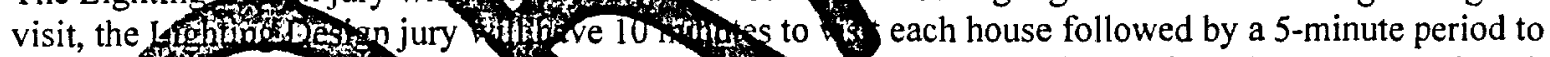
travel to din highlis visit. The period.

g. A Solar Decathithrganizer will tord appropriate comments to be passed on as feedback to the teams. This information provided feedback to each team so it might better understand why the jury evaluated the team as

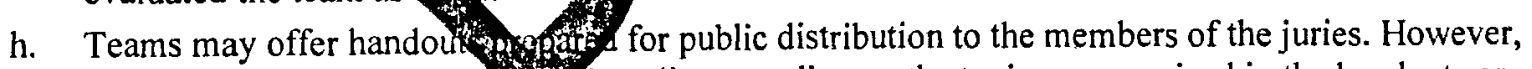
presentation boards or other 4 al media expanding on the topics summarized in the handouts or construction documents are permitted to be on display during jury tours.

i. One of the six participating Decathletes may audiotape or videotape the jury tour as it is happening, but taping of the jury discussion period is prohibited.

j. Areas of the house not located on the accessible route may be accessed by the juries and considered in their evaluations.

k. The organizers will provide all juries with summaries of important rule and code violations for each team so that juries are aware of violations before giving credit for aspects of the project that are not in compliance. 


\section{Appendix C Objective Sub-Contest Guidelines}

\section{C-1. Measured Performance Sub-Contests}

The "measured performance" sub-contests listed in Table 6 are classified as such because points are automatically awarded in the scoring spreadsheet based on measurements collected by each home's datalogger.

Table 6: Sensors used in "measured performance" sub-contests

\begin{tabular}{|c|c|c|c|c|}
\hline Sub-contest(s) & Sensor Type & Vendor & Item Number & $\begin{array}{c}\text { Approx. } \\
\text { Price }\end{array}$ \\
\hline $\begin{array}{l}\text { 6-1. Temperature } \\
6-2 . \text { Humidity }\end{array}$ & $\begin{array}{l}\text { Temp and humidity probe w/ } \\
\text { custom radiation shield }\end{array}$ & $\begin{array}{l}\text { Campbell } \\
\text { Scientific }\end{array}$ & HMP5 & $\$ 425$ \\
\hline 8-1. Refrigerator & $\begin{array}{l}\text { Thermocouple inserted in } \\
\text { rubber "Super Ball" for mass }\end{array}$ & Omega & & $\$ 75$ \\
\hline 8-2. Freezer & $\begin{array}{l}\text { Thermocouple inserted in } \\
\text { rubber "Super Ball" for mass }\end{array}$ & & & $\$ 75$ \\
\hline $\begin{array}{l}\text { 9-2a. Workstation } \\
\text { Lighting }\end{array}$ & Photometer mounted on base & & & $\$ 450$ \\
\hline 9-4. Public Exhibit & $\begin{array}{l}\text { AC Watt-hour meter and } \\
\text { current transformer (CT) }\end{array}$ & & $\frac{208-P 3-0508}{6}$ ill used in SD) & $\$ 225$ \\
\hline $\begin{array}{l}\text { 10-1. Energy Balance } \\
\text { 10-2. Energy Surplus }\end{array}$ & $\begin{array}{l}\text { AC Watt-hour meter and } \\
\text { current transformer }(C T)\end{array}$ & & $\begin{array}{l}-\mathrm{P}-050 \mathrm{~Hz} \text { (discontinued } \\
\text { used in SD) } \\
50\end{array}$ & $\$ 250$ \\
\hline & & & TOTAL & $\$ 1500$ \\
\hline
\end{tabular}

The central data acquisition equent list the scoring spreadsheet

\begin{tabular}{|c|c|c|c|}
\hline Equipment De & & Item Number & $\begin{array}{l}\text { Approx. } \\
\text { Price }\end{array}$ \\
\hline Datalogger enclosure & entific & ENC14/16-DC-NM & $\$ 275$ \\
\hline Datalogger & & $\begin{array}{l}\text { CR1000-ST-SW-NC (discontinued CR10X is still used in } \\
\text { SD) }\end{array}$ & $\$ 1400$ \\
\hline Power supply & Catoll Scientific & PS100.SW & $\$ 225$ \\
\hline Transformer & Campbell Scientific & 9591 & $\$ 50$ \\
\hline Solid-state multiplexer & Campbell Scientific & AM25T-ST-SW & $\$ 950$ \\
\hline Switch-closure module & Campbell Scientific & SDM-SWBA-SW & $\$ 275$ \\
\hline RF radio and antenna & Campbell Scientific & $\begin{array}{l}\text { Radio: } \mathrm{RF} 401-\mathrm{ST} \text { (discontinued RF } 400 \text { is still used in SD) } \\
\text { Antenna: } 14204\end{array}$ & $\$ 475$ \\
\hline $\begin{array}{l}\text { Sensor wire and miscellaneous } \\
\text { parts }\end{array}$ & Various & Various & $\$ 350$ \\
\hline & & TOTAL & $\$ 4000$ \\
\hline
\end{tabular}


One or more drawings containing the following information shall be included in the construction drawings to facilitate the planning and installation of the competition monitoring system:

- Proposed locations for the datalogger and Watt-hour meter enclosures

- Proposed location(s) for the temperature and humidity probe(s)

- Refrigerator/freezer location

- Workstation location

- AC load panel location and circuit schedule

- Proposed wire routing paths:

- Temp/humidity probe(s) to datalogger enclosure

- Refrigerator/freezer thermocouples to datalogger enclosure

- Photometer to datalogger enclosure

- AC load panel to Watt-hour meter enclosure

- Watt-hour meter enclosure to datalogger enclosur

Teams shall be mindful of the following considerations when deghe required instrumentation drawing(s):

\section{General Comments}

Measurements of temperature, humidity, electric power 1 fuminance dete a significant portion of the

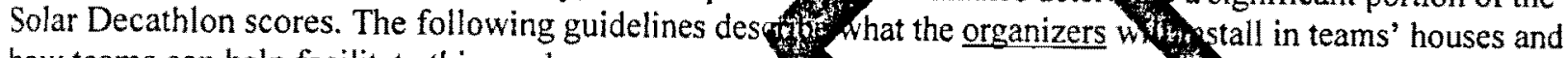
how teams can help facilitate this work.

The location of sensors is determined via a negotiation betwe each to and the orgatys. The organizers

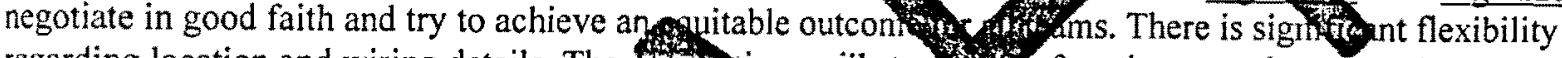
regarding location and wiring details. The

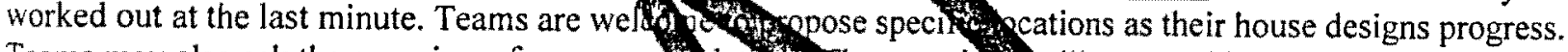

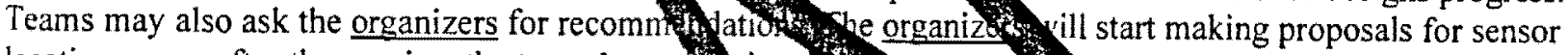

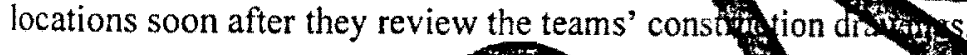

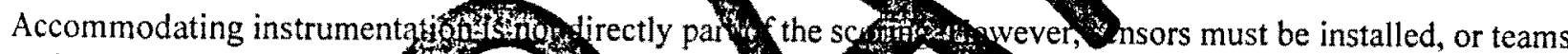

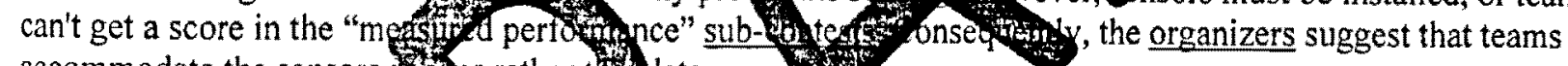
accommodate the sensors stopr rather th later.

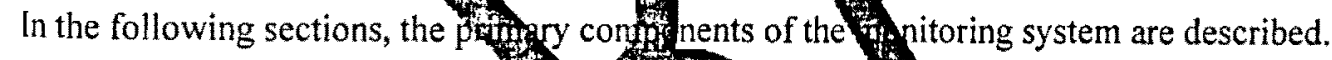

\section{Datalogger}

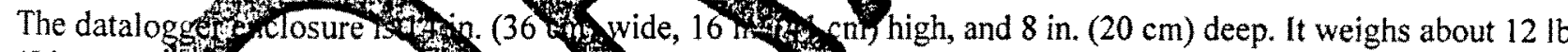

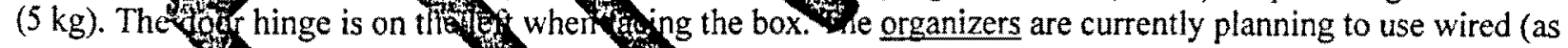
opposed to whess) sensors, so wete must provided for running sensor wires from each sensor location to the datalogger. datalogger box. The ures are usual of instahed in conduit. The datalogger box is usually mounted in a

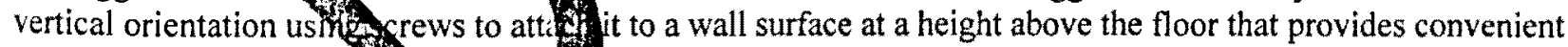
working access. The typutation folt e datalogger box is in a utility room or closet. The box can be mounted horizontally or upside downe not orientation is not available. The datalogger requires a small amount of electric power (approximately rom the house's electric system, with the burden on each house being about the same. A standard 120 receptacle is usually used to supply this power. The organizers communicate with the datalogger via a wireless modem located inside or adjacent to the datalogger box. An external antenna may be required for successful wireless modem communication. However, in the past, no external antennas were required.

\section{Temperature and Relative Humidity Probe(s)}

All of the scoring in Contest 6: Comfort Zone is derived from the measured dry bulb temperature and relative humidity inside the house. The organizers plan to use a temperature and relative humidity sensor mounted inside a radiation shield to make this measurement. The sensor will be placed in a location that is representative of the temperature and humidity conditions through the entire house. This location will usually be between 4 and $5 \mathrm{ft}$ ( 1 and $2 \mathrm{~m}$ ) above the floot in the largest open room of the house. A location adjacent to a standard house thermostat is typical. In a closed bedroom, on an exterior wall, near the floor or ceiling, or near a window are all highly undesirable locations. If there is clearly more than one zone in the house, the organizers will install more than one 
sensor. The objective of Contest 6 is to heat and cool the house (not to heat and cool the temperature sensor) and
to maintain comfort conditions throughout the entire space.

\section{Thermocouples}

The temperatures inside the refrigerator and freezer will be measured with thermocouples. These measurements typically require the placement of a small wire through the refrigerator or freezer door so that the gasket closes around the wire. This approach was used in the past with satisfactory results. The organizers will identify a route for the thermocouple wires to be run from the datalogger to the refrigerator and freezer. If a team is concerned that jamming wires in the door will significantly impair the thermal performance, note that all teams are subject to the same installation approach. If a team is going to use a nonstandard door gasket, the organizers need to be made aware of it.

\section{Light Sensor}

Sub-contest 9-2a requires that a minimum average illuminance be maintaty on the workstation desk surface during certain hours. The organizers will install a photometer on the d 8 continuously measure the illuminance on the horizontal work surface. The photometer with its base is aheffor $(8 \mathrm{~cm})$ in diameter and about 1 in. $(3$ $\mathrm{cm})$ high and requires a wire to connect it to the datalogger. Tha 10 will negotiate with each team to determine a specific location that is representative of the tas jong and on the desk.

\section{AC Watt-hour Meters}

The net AC energy of the public exhibit circuit(s) and A pains must be measured torn a score in Sub-contest 9-4 (Public Exhibit) and Contest 10 (Net Metering). The A ytt-hory ters are moutsy in a standard electric

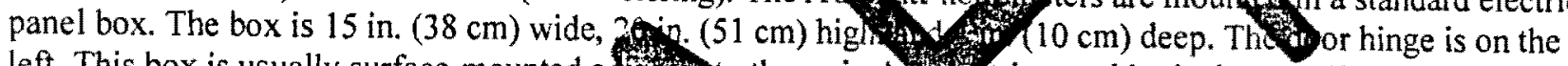
left. This box is usually surface-mounted adfore the main A taps and current transformers will be installed the meter boyed the circuits inside the main AC panel.

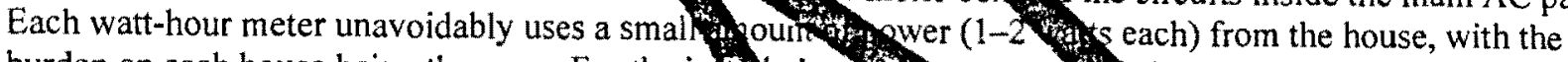
burden on each house being the same. For the ins yation 3 ate meters, helpful to have extra room for the current transformers and extrportakefor the volk taps.

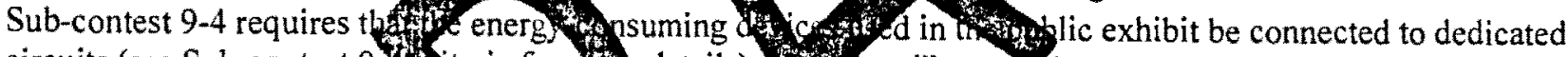

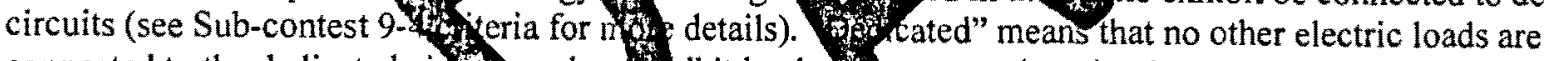
connected to the dedicated cir and no hibit loads 3 . connected to circuits other than the dedicated exhibit circuits. The organizers will insta 4 rof

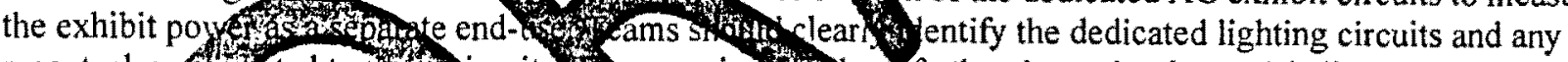

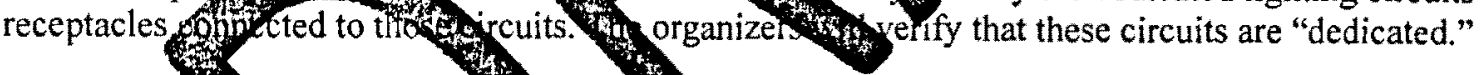

\section{C-2. Task Completion Sub-Contests}

The "task completion sub-contests lof in Table are classified as such because points are earned by successfully complettig task that is of rved by, and the results of which are recorded by, an observer:

The 8: Equfich nent used in "task completion" sub-contests

\begin{tabular}{|c|c|c|c|c|}
\hline Sub-contest(s) & Instrumenxy gost & Vendor & Item Number & Price \\
\hline Contest 7. Hot Water & $\begin{array}{l}\text { Flowmeter / 1 } \\
\text { thermometer }\end{array}$ & Omega / Fluke & $\begin{array}{l}\text { ETB-4105A-P / } 52 \text { II (Fluke } \\
\text { Model \#) }\end{array}$ & $\begin{array}{l}\$ 175 / \\
\$ 250 \\
\end{array}$ \\
\hline 8-3. Clothes Washer & Non-reversible temperature label & Omega & IL-5-105-10 & $\$ 10$ \\
\hline 8-4. Clothes Dryer & Scale & Acculab & & \\
\hline 8-5. Dishwasher & Non-reversible temperature label & Omega & TL-5-105-10 & $\$ 10$ \\
\hline 9-1. Cooking & Kitchen scale & Salton & 1008 & $\$ 50$ \\
\hline 9-2b. House Lighting & Visual inspection & $\mathrm{n} / \mathrm{a}$ & na & $\mathrm{n} / \mathrm{a}$ \\
\hline
\end{tabular}


Teams are encouraged to download the video and accompanying PDF file posted at $\mathrm{ftp} / / \mathrm{ftp} 2 . \mathrm{nrel}$.gov/pub/solar decathlonDayInTheLife/ to learn more about the tasks to be completed during a typical day during contest week.

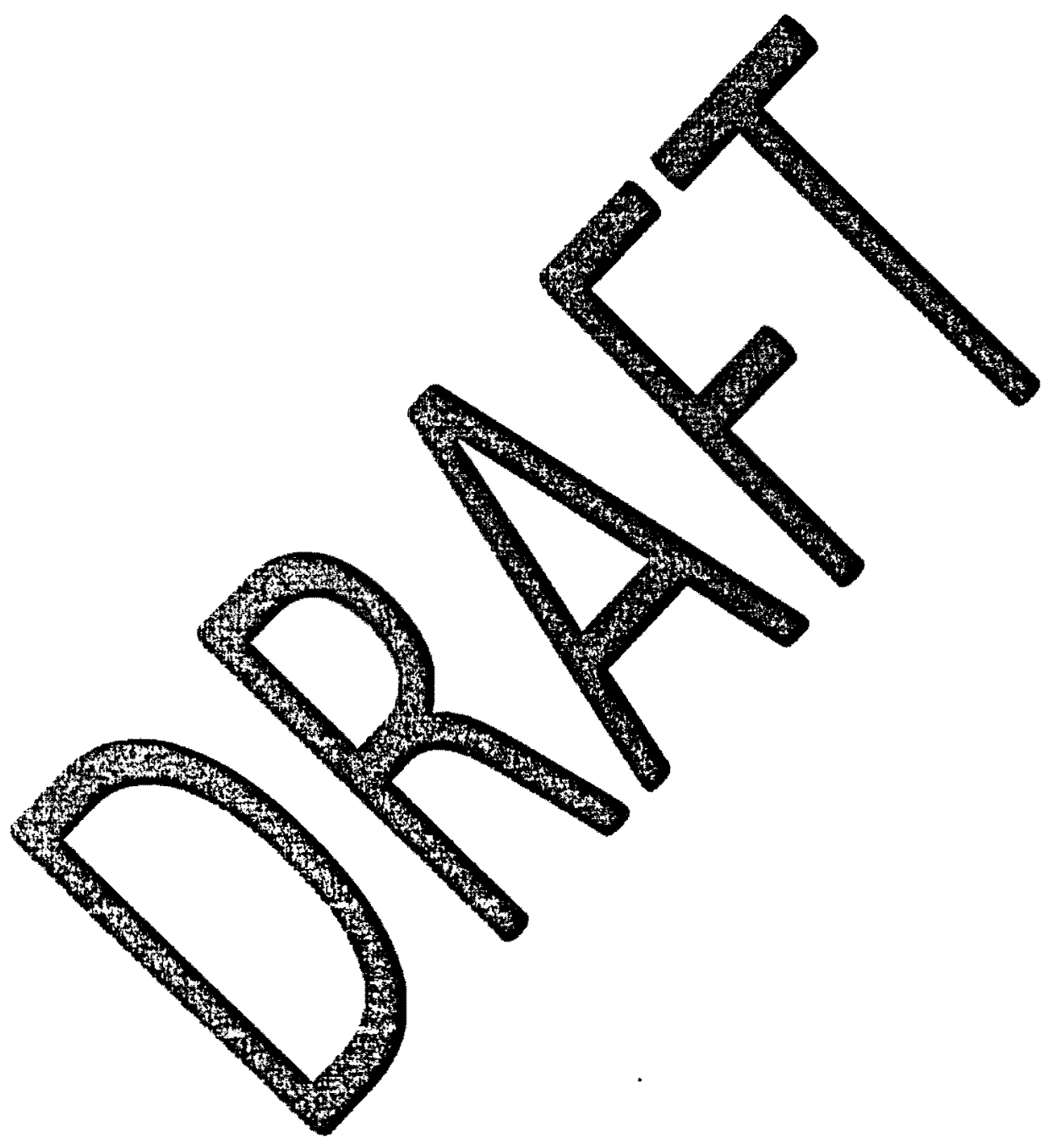




\section{Appendix D Construction Documents}

The Construction Documents consist of the drawings and project manual and serve the following important functions:

- The Construction Documents shall demonstrate compliance with the Solar Decathlon Building Codeand the Solar Decathlon Rules so that the inspectors will be able to grant final on-site approval by simply verifying that the constructed project on the competition site was accurately represented by the Construction Documents.

- The Construction Documents shall clearly describe a team's proposed assembly and disassembly procedures. The Site Operations Manager will review the teams' procedures to identify and address potential conflicts among the teams. Each team is encouraged to consult with the Site Operations Manager as the relevant sections of the Construction Documenteys being developed.

- The Construction Documents shall provide a residential cond

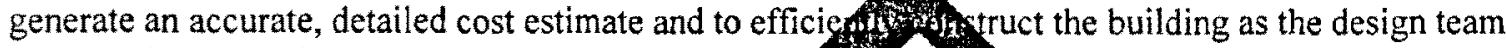
intended it to be built. The Construction Documents me colve because the design team shall assume that the contractor has had no prior cofinunication wro design team, has no prior knowledge of the design, and has little or no exp fftere building high dexprmance residences.

- Since the juries have a very limited opportunite evaluate the constructedypects on the competition

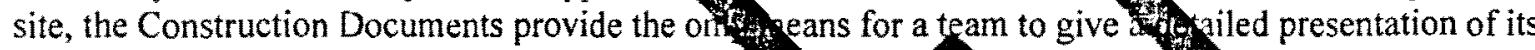
project to the juries. In the weeks leading up to conksw week ats juror shall spend a total of

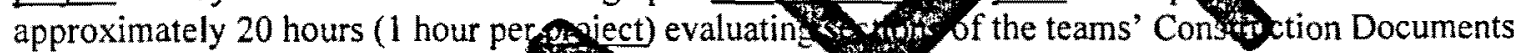

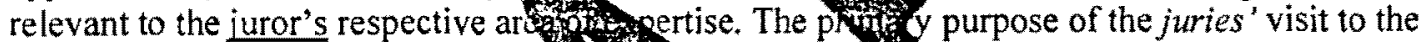
competition site is twofold: 1) verify (A.

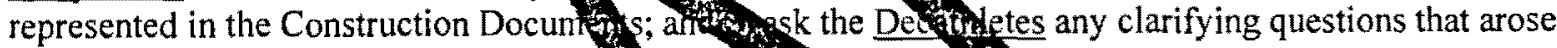

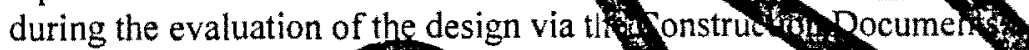
Axting (t)

\section{D-1. Formatting Requirements}

Drawings

$\square$ ANSI "B" (11 in. X 17 in.) 5 so "

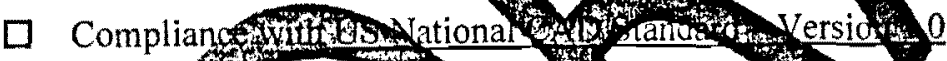

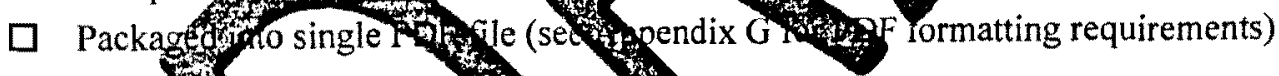

\section{Project Mantio}

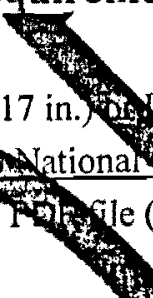

ANSI "A"

$\square$ Organization andrating of $c$ truction specifications in compliance with MasterFormat 2004 Edition

$\square$ Packaged into sing 4 for file (se pendix G for PDF formatting requirements)

\section{D-2. Project Manual Content}

Complete set of construction specifications (including links to manufacturers' data sheets)

Summary of changes since last Construction Documents submission

Content (other than drawings) required to demonstrate compliance with the Solar Decathlon Rules (see

Appendix D-3) and the Solar Decathlon Building Code

$\square$ Structural calculations

$\square$ Detailed water budget

$\square$ Summary of unlisted electrical components

$\square$ Interconnection Application

$\square$ Energy analysis results and discussion

$\square \quad$ Architecture design narrative 


\begin{tabular}{|c|c|c|c|}
\hline$\square$ & $8-1$ & $\begin{array}{l}\text { PV Technology } \\
\text { Limitations }\end{array}$ & Retail price quote for photovoltaic components \\
\hline$\square$ & $8-3$ & Thermal Energy Storage & Drawing(s) showing the location of thermal energy storage components \\
\hline 口 & $8-3$ & Thermal Energy Storage & $\begin{array}{l}\text { Data sheet(s) and/or specifications for thermal energy storage } \\
\text { components }\end{array}$ \\
\hline$\square$ & $8-3$ & Thermal Energy Storage & $\begin{array}{l}\text { Shading calculations and/or diagrams for thermal energy storage } \\
\text { components (if necessary) }\end{array}$ \\
\hline$\square$ & $8-4$ & Batteries & $\begin{array}{l}\text { Drawing(s) showing the location(s) and quantity of stand-alone, PV- } \\
\text { powered devices }\end{array}$ \\
\hline$\square$ & $8-4$ & Batteries & $\begin{array}{l}\text { Data sheet(s) and/or specifications for all stand-alone, PV-powered } \\
\text { devices }\end{array}$ \\
\hline$\square$ & $8-5$ & Desiccant Systems & Drawing(s) describing the operatto of the desiccant system \\
\hline$\square$ & $8-5$ & Desiccant Systems & Data sheet(s) and/or specifieds 1 is for desiccant system components \\
\hline$\square$ & $8-6$ & Village Grid & Completed Interco \\
\hline$\square$ & $8-6$ & Village Grid & 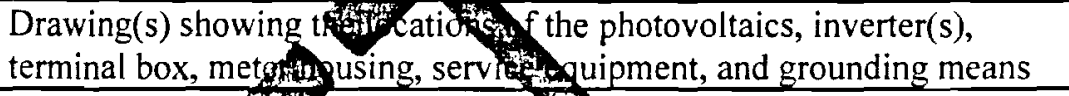 \\
\hline$\square$ & $8-6$ & Village Grid & 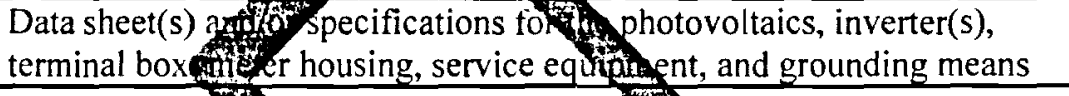 \\
\hline$\square$ & $8-6$ & Village Grid & One-line electros \\
\hline 口 & $8-6$ & Village Grid & eedercie computed lod per NEC 220 \\
\hline 口 & $8-6$ & Village Grid & 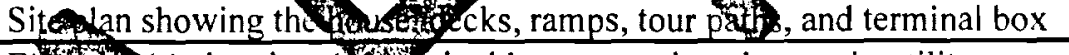 \\
\hline$\square$ & $8-6$ & Village Grid & $\begin{array}{l}\text { meter housing, main utility } \\
\text { it }\end{array}$ \\
\hline$\square$ & $9-4$ & Rainwater $\mathrm{C}$ & ration of rainwater collection \\
\hline$\square$ & $9-6$ & Thermal & ater-based thermal mass systems \\
\hline$\square$ & $9-6$ & Therr & \\
\hline & $10-2$ & $\begin{array}{l}\text { Ever } \\
\text { Recr }\end{array}$ & , including signage \\
\hline & $10-3$ & Rec & $\begin{array}{l}\text { ons, materials, artwork, and content of } \\
\text { cluding signage }\end{array}$ \\
\hline & $11-4$ & Puibic & entire accessible tour route \\
\hline & $11-4$ & & \\
\hline$\square$ & $11-4$ & 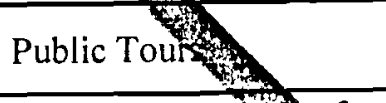 & $\begin{array}{l}\text { (s) showing the dimensions, materials, artwork, and content of } \\
\text { uniform }\end{array}$ \\
\hline$\square$ & $11-7$ & $\begin{array}{l}\text { House Config } \\
\text { Jury Tours }\end{array}$ & fist \\
\hline
\end{tabular}




\section{Appendix E Communications Deliverables}

\section{E-1. Preliminary Communications Plan and Web Site}

The Preliminary Communications Plan shall reflect the planning process for the team's fund-raising, mediaoutreach, and all other communications activities, including those required to participate in the Communications contest. The contents of the plan shall not consist of more than 20 pages.

A preliminary Web site URL to a site consisting of at least three pages shall be submitted with the Preliminary Communications Plan. The preliminary Web site shall be evaluated by communications professionals at the National Renewable Energy Laboratory (NREL) to ensure compliance with the Minimum Web site Coding and Accessibility Standards provided in this appendix. Each team shall be notified by 5 p.m., mountain time, on June $18^{\text {th }}$ regarding changes they are required to make to the site for compliance. This begins a "conversation" between NREL and each team resulting in the team's Web site being fully complian. As team's Web sites meet compliance, the sites are linked to from the main Solar Decathlon We 19, 2008, all teams' Web sites must be in compliance with standard 7 finked to from the main Solar Decathlon Web site. Any Web site not linked to by this deadline shall not by the Communications Jury. As significant changes (e.g., significant changes, new features, acow hete resign) are made to the teams' Web sites between August 19,2008, and the competition in 2009, NRES is available tuduct additional compliance reviews upon request.

\section{The Planning Process}

A plan is the result of a process. No two fund-raising, med communicatreach planning processes are the same.

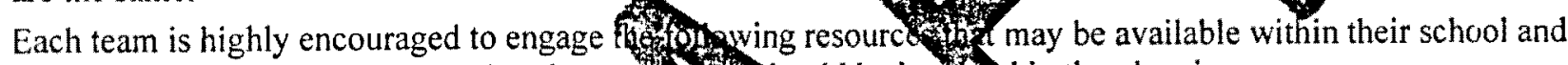

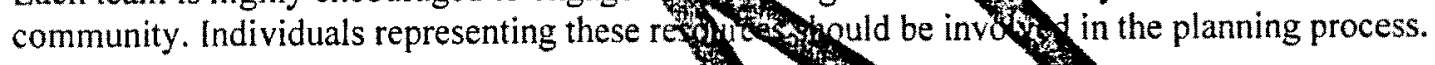

- Communications and marketing school onsuluto firms

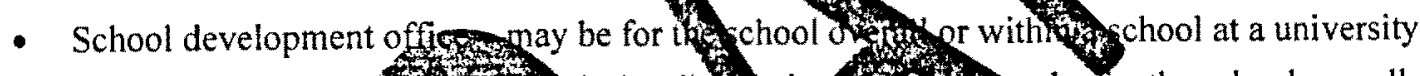

- School public relations school at a universtit

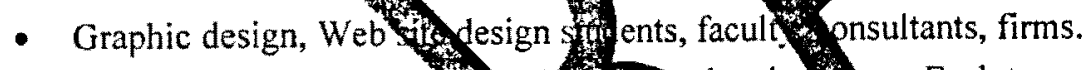

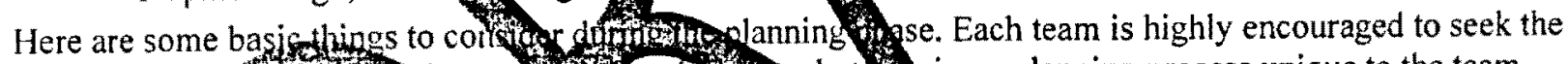

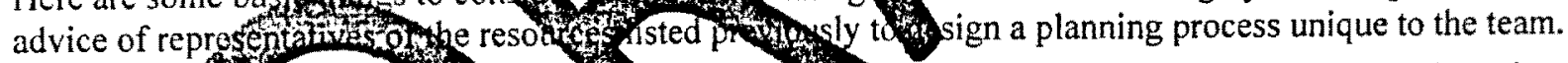

- Discus and describetheam's gronality. Hou believe in, want to accomplish, and care

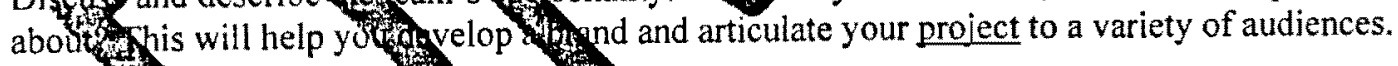

- Discuss, toribe, and quariog specitimals:

- Fuis ajsing: What is you need cash vs. in-

- Media Outreach: Deschity and quantify the media coverage you want to receive and by when.

- Communicat what do you want to result from your communications efforts? How will you achieve that resitury by when?

- Identify the baseline-what are you doing now, who's doing it, what's going well, and what needs to change and by when?

- Conduct audience analyses-all communications efforts are driven by the needs and requirements of the audience:

o Fund raising: Identify key donors (cash and in-kind); who are they?; what do they care about?; what motivates them?

- Media Outreach: Identify media outlets to contact; how can you shape your messages to interest their readers, users, and viewers?

- Communications: Who are the users of your Web site? What do they expect to find on your site? Who are the "off-site" spectators, and what do they want to know about your team? Who are the visitors to the solar village, and how can you best communicate with them? 
- Draft key messages - what is the best way to say what you want to say to specific audiences, based on what you know about those audiences?

- Messages are delivered through design and graphics as well as the written word.

- Establish a means and schedule for evaluating the effectiveness of your messages and changing them as needed.

- Identify and describe tactics-the means, tools, and specific products by which you will reach target audiences:

- Fund raising: What is the best way to reach donors; Web site, mailing, phone calls, special events?

- Media Outreach: What is the best way to reach media outlets; personal contacts, news releases, special media events?

- Communications: How will you use communications to 14 or effective management of your project? What is the best way to reach audiences bothon off the National Mall? How will you engage and educate visitors to the solar villag 4 during and outside of public hours? How will you incorporate your communication the overall design and presentation of your house?

- Identify, describe, and schedule a means of meagho the effectiveney your tactics. Test them on user

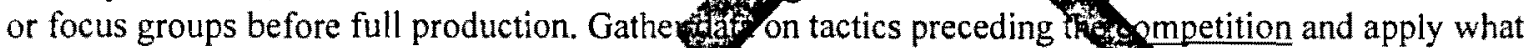
you have learned to your efforts at the competitin. Collect both quantitativat qualitative data about your efforts and be prepared to report that data.

- Develop a fund-raising/media outreas/communication

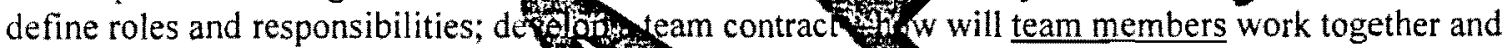
communicate to accomplish the plan

- Implement the plan

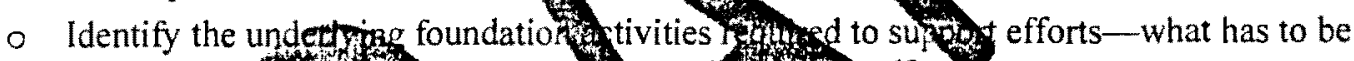

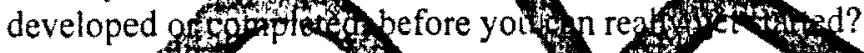

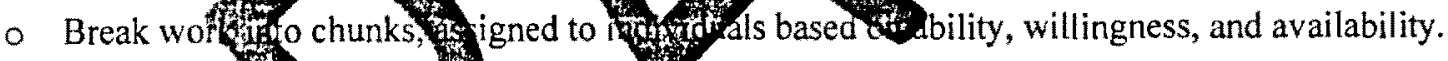

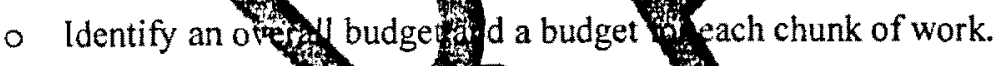

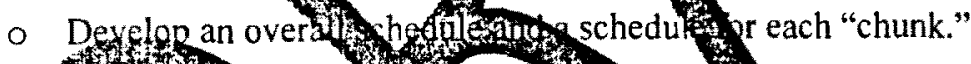

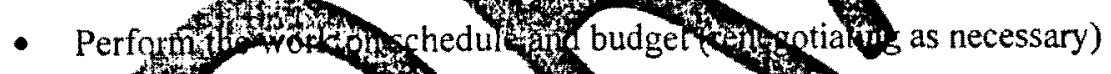

What's in thpen?

The Communtathons Plan will chach over it is a living document. Each team shall submit a preliminary plan, a Final Commications Plan, a Comnications Report. Plans and reports generally consist of the following - a plan reats what you infend to do at a given time, and a report describes what you did and the results of your actions

- Executive summary sumpiritzes the whole plan: $1-2$ pages.

- Background: This is ifforafifon needed to understand and contextualize the plan (may include references and links to more informbtor elsewhere), including your team's vision, mission, and overall goals and objectives for the project (not just the fund-raising, media-outreach, and communications efforts).

- Scope: Describe the limits or "boundaries" around your fund-raising, media-outreach, and communications efforts-roughly, what these efforts will and will not consider, accomplish, or include.

- Budget: What's the overall budget for everything in the plan? What's the budget for fund raising, media outreach, and communications, separately? What's the budget for chunks of work and/or individual projects?

- Description of targeted audiences

- Description of key messages

- Description of the team's brand-look, feel, key messages; may include graphical and content style guide 
- Description of project clients, contributors, and stakeholders and their needs: Whom do you have to answer to (make happy)? Whose contribution is important or essential to these efforts? Who else can be affected by your efforts that you must consider? Who are the reviewers for your efforts?

- Project Objectives:

- Fund Raising: how much money do you need to raise by when?

- Media Outreach: How many impressions and stories do you want to get?

- Communications: How many users and/or visitors do you want to reach? What impacts do want to have?

- Roles and Responsibilities: Describe who's going to do which chunks of work or specific projects, and identify (as much as possible) who else has to be involved. It's handy to repeat budgets for the chunks and individual projects in this section.

- Description of fund-raising, media outreach, and communicatignstics. Please note that it is especially important to include a robust description of the Web site and 0 plans for on-site exhibition, as these will be two key tactics evaluated by the Communications 0

\section{Minimum Web site Coding and Accessibility Standards}

- All team Web sites shall comply with Rule 10-2:

- The minimum coding standards were selected 40 standards that apply tou Web sites developed for the U.S. Department of Energy's Office of Energy fiency and Renewable Eletgy (EERE) as well as from Section 508 of the Americans with Disabilities Act DA). Whe applicable, to to relevant sections of the EERE Communications Standards Web site are prided the icon 1. Where applicable, thosestandards that are Section 508 have also been noted with the symbol 1.:. For more information 1 .

- Common Elements:

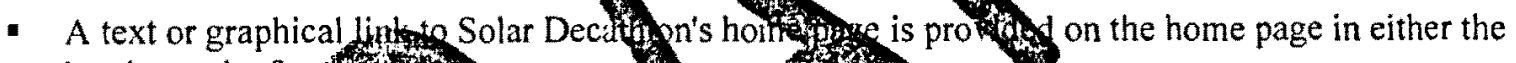
header or the fogterts

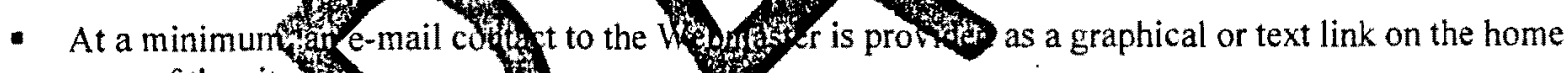
page of the site.

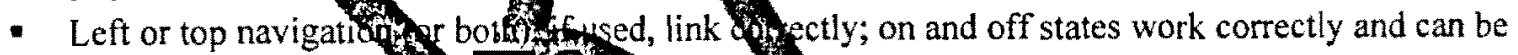
skippedothescen reads

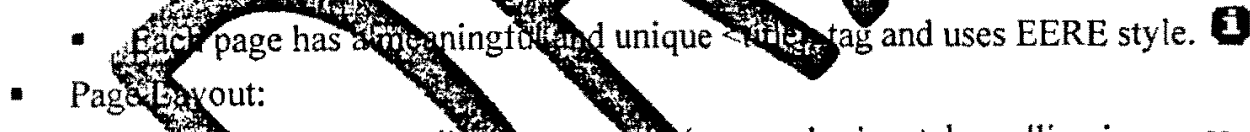

Pages must disha correcture, no horizontal scrolling is necessary to view the full width D. page) in $102 \times 768$ rotion. ( $800 \times 600$ resolution is also acceptable.)

- Pagenformation toyed with color is also available without color, and foreground and

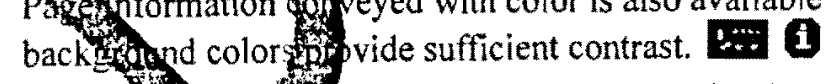

- Headers fogters are consistent throughout the site.

- Directories and Files:

- File names do not contain upper-case letters, spaces, or special characters (e.g., \& or \$).

- HTML Syntax:

- HTML syntax follows HTML 4.01 transitional standards or higher and has been validated by the W3C Validator. $\mathbf{1}$

- Row and column headings have been provided for all data tables. $\mathbf{A}$

- Links:

- All links work throughout the site.

- Hypertext links are used in content throughout the site are underlined to indicate they are links.

- Scripts/Applets/Dynamic Pages (CGI, JavaScript, Java, etc.): 
- Every script works correctly in the standard browser set. $\mathbf{1}$

- Content produced by scripting languages is accessible or has an accessible alternative.

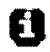

- Pages requiring applets or plug-ins must provide a link to an accessible page where they can be downloaded. $\mathbf{1}$

- If a timed response is required, the user can request more time to complete an operation. (1)

- Back button functionality is not impaired.

- Forms:

- Forms include text labels that correspond with form controls and markup to associate the two.

\section{B.:3 1}

- Graphics:

- All images are stored in a separate subdirecto

- Graphics have meaningful "alt" tags. (Use forty for spacer gifs and other unimportant graphics.) $\mathbf{1} \mathbf{1}$

- Multimedia:

- Alt descriptions are used with all cie

- All

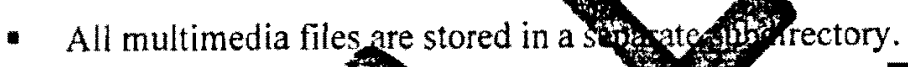

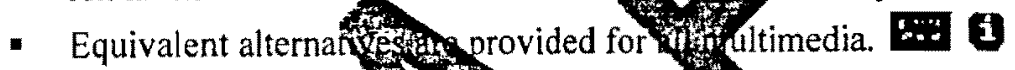

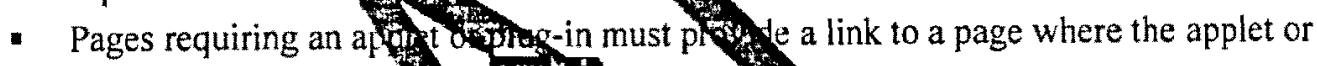
plug-in can be downlougd

QuickTimedita

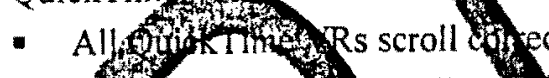

- AltuxickTime hapots link

- Flash

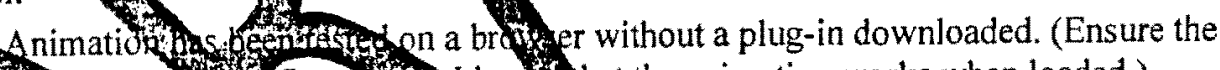

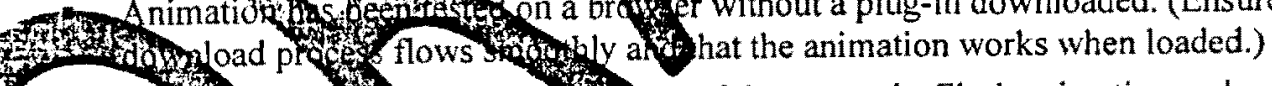

- Chectu links in Flash angon. If the user exits Flash animation early, ensure that she wilkgto an astoriate page.

Sound workgorrectly

7. If Flash is us ons antroluctory "splash" screen, there is an option provided to skip it.

-

- Documents for Dothading

- PDFs

- All PDFs stored in a subdirectory labeled "pdfs."

- References to PDFs within the HTML document use a consistent format and link scheme throughout the site (e.g., PDF 54 KB). 1

- Every page with a PDF link also includes a link to download Adobe Reader (http://www.adobe.com/products/acrobat/readstep2.html) with the text "Download Adobe Reader." : :... I

- Native file formats

- Native file format documents are placed in a separate subdirectory, such as a "docs" subdirectory.

- References to native files within the HTML document will use the following format and link scheme throughout the site: Title of Document (Software 54 KB). Examples: 
- The Value of Renewables (MS Word $54 \mathrm{~KB}$ )

- The Value of Renewables (Excel 54 KB)

- The Value of Renewables (PowerPoint $54 \mathrm{~KB}$ )

- Testing:

- For quality-control testing, test the site in the standard browser set:

- $\mathrm{PC}$

- Internet Explorer 6.0 and 7.0

- Firefox 2.0

- Mac

- Safari 2.0

\section{E-2. Final Communications Plan and Web Site}

The Final Communications Plan shall reflect changes and progrom's fund-raising, media-outreach, and communications efforts since the Preliminary Communicatto Plan submitted. The final plan shall not exceed 20 pages (excluding proofs) and shall include but 10 limited to:

- Progress of fund-raising activities-what is thookt nt quantity of conthktyons (cash and in-kind)? What is the current proiect budget and accounting? final fund-raising activitare planned?

- Progress on media-outreach activities-include ntrtys

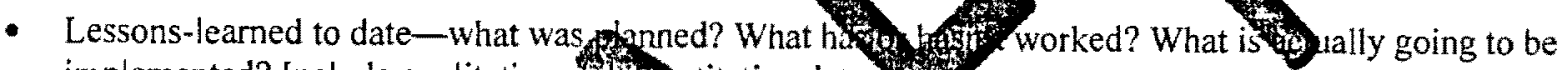
implemented? Include qualitative akd onditative data.

- Final plans for on-site exhibition actites,

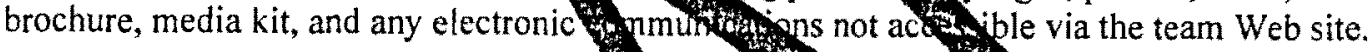

- The final URL for the tand

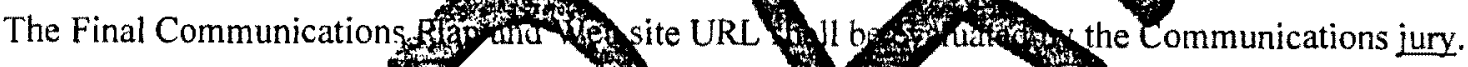

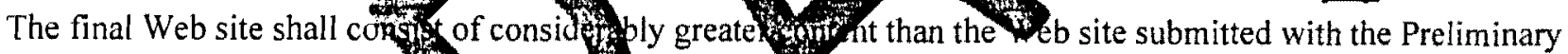
Communications Plan. The Chunicatigh jury shall bin evaluations of teams' Web sites at the same time that assembly begins on the Natiou Mal

$$
\text { mentionstions }
$$

\section{E-3. Communications Report}

The Communtertions Report shect sults of the team's fund-raising, media-outreach, and communicationseforts. The repor 20 pages (excluding artwork) and shall include but is not limited to:

- Results of fulk tising activitis and accounting;

- Results of media-oul hactiy es-include metrics

- Results of on-site exhibthongtivities-estimates of the number of visitors to the house (justify estimates); assessment of the visitors' experiences (include qualitative data); lessons learned-what went well, what didn't, what would you do differently?

- Evaluation of the team's Web site-number of hits, unique visits, and any other user statistics; lessons learned - what went well, what didn't, what would you do differently?

- Team perspective on the effectiveness of the organizers' communications on-site efforts-team members have more experience with individual visitors than anyone on site, and the organizers appreciate learning from that experience. 


\section{Appendix F Safety Plan}

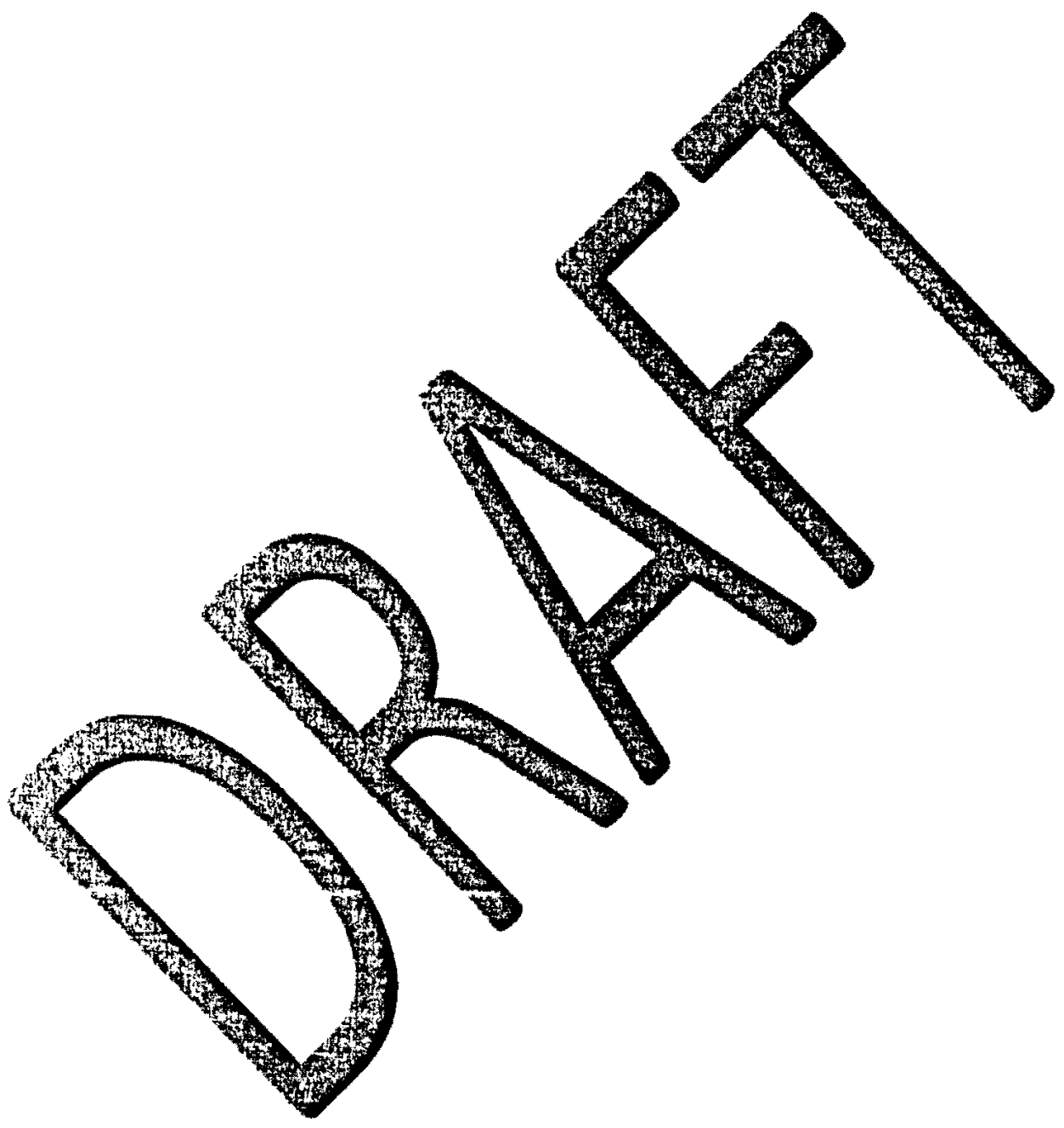




\section{Appendix G Deliverable Submission Instructions}

Deliverables are considered to be on-time if they are received by the Competition Manager by 5 p.m. mountain time on the respective due date. Refer to the "Event Lists" tab in the Yahoo Group calendar for deliverable due dates and required file formats for each of the respective deliverables.

\section{G-1. Hard Copies}

The structural drawings and calculations are the only required hard copy submissions. Please mail these deliverables to the Competition Manager at the following address:

Mike Wassmer

National Renewable Energy Lab

1617 Cole Blvd

Golden, CO 80401

Please do not submit hard copies of any other deliverables.

\section{G-2. Web Site URL.}

Web site URLs shall be Emailed to the Competition Mafrogr at sdrules@nrel.go

\section{G-3. Required PDF Specifications}

TO BE DETERMINED
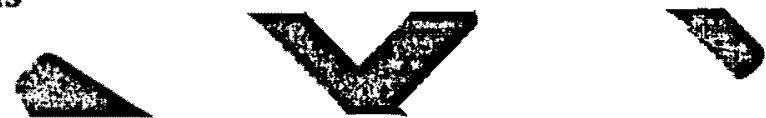

G-4. Required Graphics File Specifications

TOBEDETERMINED

\section{G-5. Electronic File Naming Instructions}

The required file naming consengon for all

[TEAM ABBREVIATION]_[DELIXERABC_ABBREVIA WON]_[SUBMISSION DATE (YYYY-MM-

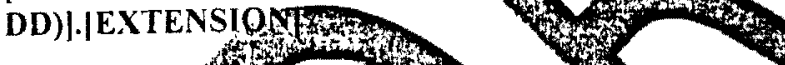

See the table

Example \#1: A sefof updated Constion Drangs submitted by Arizona to the organizers for follow-up review on April 5, 2009 would have thollowitg le name:

UAZ_CD_2009-04-05.pd

Example \#2: A set of 2 grat

Minnesota to the organizers on

UMN_GRAPHIC_1_2008-06-03.tit

UMN_GRAPHIC_2_2008-06-03.tif

UMN_GRAPHIC_3_2008-06-03.ai 


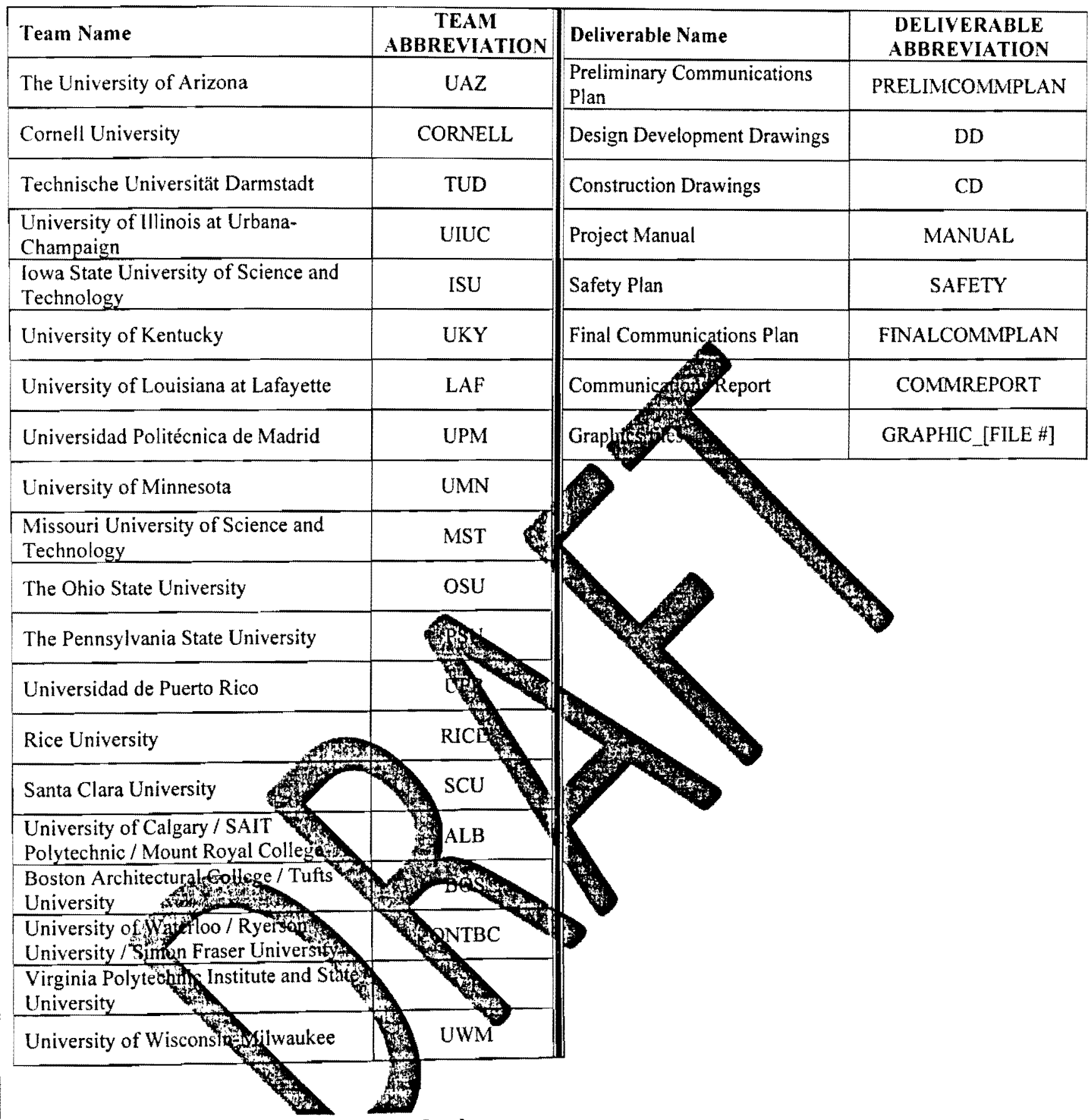

\section{G-6. Electronic File Submission Options}

Electronic files smaller than $5 \mathrm{MB}$ may be Emailed to the Competition Manager at sdrules@nrel.gov or uploaded to the Solar Decathlon Dropbox at http://dropbox.yousendit.com/SolarDecathlon. Electronic files larger than 5 MB shall be uploaded to the Dropbox. Teams wishing to reduce file upload times may archive electronic files in ZIP files. Please verify that files in ZIP archives can be extracted using WinZip. 


\section{Appendix H Construction Cost Estimate}

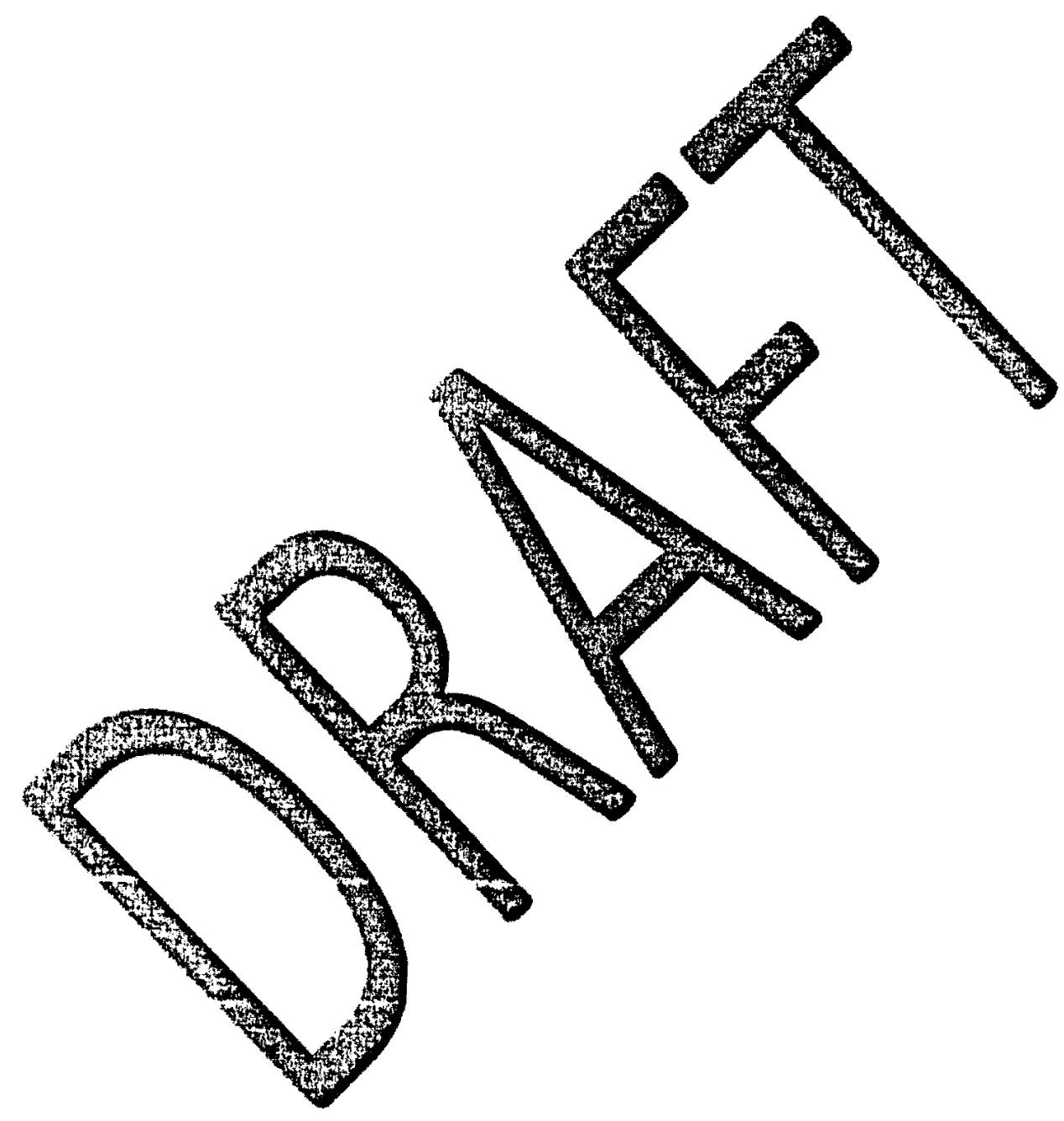

